\title{
Hypoxia, HIF and angiogenesis in atherosclerosis
}

Citation for published version (APA):

Sluimer, J. C. (2008). Hypoxia, HIF and angiogenesis in atherosclerosis. [Doctoral Thesis, Maastricht University]. Datawyse / Universitaire Pers Maastricht. https://doi.org/10.26481/dis.20080516js

Document status and date:

Published: 01/01/2008

DOI:

10.26481/dis.20080516js

Document Version:

Publisher's PDF, also known as Version of record

\section{Please check the document version of this publication:}

- A submitted manuscript is the version of the article upon submission and before peer-review. There can be important differences between the submitted version and the official published version of record.

People interested in the research are advised to contact the author for the final version of the publication, or visit the DOI to the publisher's website.

- The final author version and the galley proof are versions of the publication after peer review.

- The final published version features the final layout of the paper including the volume, issue and page numbers.

Link to publication

\footnotetext{
General rights rights.

- You may freely distribute the URL identifying the publication in the public portal. please follow below link for the End User Agreement:

www.umlib.nl/taverne-license

Take down policy

If you believe that this document breaches copyright please contact us at:

repository@maastrichtuniversity.nl

providing details and we will investigate your claim.
}

Copyright and moral rights for the publications made accessible in the public portal are retained by the authors and/or other copyright owners and it is a condition of accessing publications that users recognise and abide by the legal requirements associated with these

- Users may download and print one copy of any publication from the public portal for the purpose of private study or research.

- You may not further distribute the material or use it for any profit-making activity or commercial gain

If the publication is distributed under the terms of Article $25 \mathrm{fa}$ of the Dutch Copyright Act, indicated by the "Taverne" license above, 


\section{Hypoxia, HIF and angiogenesis in atherosclerosis}


(c) Copyright Judith Sluimer, Maastricht 2008

Cover illustration modified from "Airbubbles" () Copyright Kerry Skarbakka 2006 (www.skarbakka.com), Fifty-One Fine Art Photography, Antwerp, Belgium ISBN 978-90-5278-716-9

Press: Datawyse/Universitaire pers Maastricht 


\title{
Hypoxia, HIF and angiogenesis in atherosclerosis
}

\author{
PROEFSCHRIFT
}

ter verkrijging van de graad van doctor aan de

Universiteit Maastricht,

op gezag van de Rector Magnificus,

Prof. Mr. G.P.M.F. Mols

volgens het besluit van het College van Decanen,

in het openbaar te verdedigen

op vrijdag 16 mei 2008 om 12.00 uur

door

Judith Christina Sluimer

geboren op 22 maart 1977 te Rotterdam

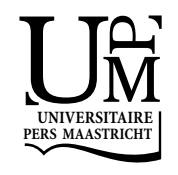




\section{Promotor}

Prof. dr. M.J.A.P. Daemen

\section{Copromotor}

Dr. A.P.J.J. Bijnens

\section{Beoordelingscommissie}

Prof. dr. M.J. Post (voorzitter)

Prof. dr. P. Lambin

Prof. dr. G. Molema (UMC Groningen)

Prof. dr. G. Pasterkamp (UMC Utrecht)

Prof. dr. J. Waltenberger

Financial support by the Netherlands Heart Foundation and the J.E. Jurriaanse stichting for the publication of this thesis is gratefully acknowledged.

Astellas, Menarini, Organon and Greiner Bio-One are also gratefully acknowledged for their contribution. 


\section{Contents}

Chapter 1 General introduction

Chapter 2 Dead or Alive: Gene expression profiles of advanced atherosclerotic plaques from autopsy and surgery

Chapter 3 Hypoxia, HIF and macrophages in human atherosclerotic plaques are correlated with intraplaque angiogenesis

Chapter 4 Hypoxia in murine plaque macrophages overrides the effect of HIF1 $\alpha$ and PHD1 deficiency on HIF protein expression and murine atherosclerosis

Chapter 5 Infrequent pericyte coverage and structural abnormalities of microvessels in human coronary atherosclerotic plaques

Chapter 6 General discussion

Summary

Samenvatting

Full color figures

Dankwoord

Curriculum Vitae

List of publications 


\section{List of abbreviations}

\begin{tabular}{|c|c|}
\hline $\mathrm{ACE}$ & angiotensin converting enzyme \\
\hline AHA & American heart association \\
\hline AKT & v-akt murine thymoma viral oncogene homolog 1 \\
\hline ALK & anaplastic lymphoma kinase \\
\hline ANGII & angiotensin II \\
\hline ANG & angiopoietin \\
\hline $\mathrm{AP}$ & alkaline phosphatase \\
\hline Apo & apolipoprotein \\
\hline $\mathrm{ApoE}^{-/}$ & apolipoprotein E knockout \\
\hline$\alpha \mathrm{SMA}$ & alpha smooth muscle actin \\
\hline bFGF & basic fibroblast growth factor \\
\hline BMT & bone marrow transplantation \\
\hline BSA & bovine serum albumin \\
\hline CA IX & carbonic anhydrase IX \\
\hline cDNA & complimentary DNA \\
\hline $\mathrm{C} / \mathrm{EBP}$ & CCAAT/enhancer-binding protein \\
\hline c-kit & v-kit Hardy-Zuckerman 5 feline sarcoma viral oncogene homolog \\
\hline CVD & cardiovascular disease \\
\hline $\mathrm{DAB}$ & diaminobenzidine \\
\hline DAG-PKC & diaglycerol-sensitive protein kinase C \\
\hline DNA & deoxyribonucleic acid \\
\hline EC & endothelial cell \\
\hline E-FA & early fibroatheroma \\
\hline EPC & endothelial progenitor cell \\
\hline EM & electron microscopy \\
\hline ER & endoplasmic reticulum \\
\hline FA & fibroatheroma \\
\hline FABP4 & fatty-acid-binding protein 4 \\
\hline FACS & fluorescence-activated cell sorting \\
\hline FCS & fetal calf serum \\
\hline FIH & factor inhibiting HIF \\
\hline FOXP3 & forkhead box P3 \\
\hline GLUT & glucose transporter \\
\hline $\mathrm{GO}$ & gene annotation \\
\hline GSEA & gene set enrichment analysis \\
\hline HDL & high density lipoprotein \\
\hline $\mathrm{HE}$ & hematoxylin and eosin \\
\hline HGF & hepatic growth factor \\
\hline
\end{tabular}


hypoxia inducible factor

HK hexokinase

HRE hypoxia response element

IEL internal elastic lamina

IFN interferon

IL interleukin

IM intima-media

IPH intraplaque hemorrhage

IRES internal ribosome entry site

IT intimal thickening

KiEC Ki-67 positive endothelial cells

LDL low density lipoprotein

LDLR $^{-1} \quad$ low density lipoprotein receptor knockout

L-FA late fibroatheroma

LPS lipopolysacharide

M1 classically activated macrophage subset

M2 alternatively activated macrophage subset

MAPK mitogen-associated protein kinase

MCP monocyte chemoattractant protein

MI myocardial infarction

MMP matrix metalloproteinase

MP microparticles

MRI magnetic resonance imaging

mTOR mammalian target of rapamycin

MVD microvessel density

$\mathrm{N}$-cadherin neural cadherin

NFkB nuclear factor kappa B

NK natural killer

NO nitric oxide

oxLDL oxidized low density lipoprotein

PBS phosphate-buffered saline

PCR polymerase chain reaction

PDGF platelet derived growth factor

PDGFR platelet derived growth factor receptor

PHD prolyl hydroxylase

PI3K phosphoinositide 3-kinase

PIT pathological intimal thickening

PIGF placental growth factor

PPAR peroxisome proliferator-activated receptors

PR-39 proline-rich 39 
qRT-PCR quantitative reverse transcriptase polymerase chain reaction RNA ribonucleic acid

ROS reactive oxygen species

siRNA small interfering RNA

SMC smooth muscle cell

SP1 promoter selective transcription factor 1

TBS tris-buffered saline

TCFA thin cap fibroatheroma

TGF transforming growth factor

Thelper T-cell

Tie tyrosine kinase with immunoglobulin and EGF-like domains

TNF tumor necrosis factor

TRAIL tumor necrosis factor-related apoptosis-inducing ligand

Treg regulatory T-cell

UPR unfolded protein response

VE-cadherin vascular endothelial cadherin

VEGF vascular endothelial growth factor

VEGFR vascular endothelial growth factor receptor

VHL von Hippel-Lindau

vWF von Willebrandt factor 


\section{General introduction}


10 Chapter 1 


\section{Atherosclerosis}

Atherosclerosis, a chronic inflammatory disease of the arteries, places a huge burden on modern-day society. The resulting cardiovascular complications, including myocardial infarction and stroke, accounted in 2006 for about one third of all deaths in the Netherlands (www.cbs.nl). Cardiovascular disease (CVD) remains the number one cause of death in the Netherlands, despite a slight decrease of 3\% (CVD/total mortality) over the last five years. Although much progress has been made over the years, the intricate interplay between genetic and lifestyle (risk) factors leading to the initiation of atherosclerosis has not been completely unraveled. Likewise, the underlying molecular mechanisms responsible for disease progression and clinical complications are far from clear. Angiogenesis in the atherosclerotic plaque is one of the key morphological features that has been linked to plaque growth and -instability, and is the focus of this thesis.

\section{Pathogenesis of atherosclerosis}

Close study of atherosclerotic pathology and morphology, together with the use of genetically altered animals and controlled cell culture experiments, have led to the following insights on the development of atherosclerosis.

Atherosclerotic lesions will only be initiated at certain arterial sites, predisposed due their anatomy (branch points, curvature) and flow patterns. Flow turbulence and/or low shear stress influence the shape, orientation, and gene expression of endothelial cells. Endothelial permeability and adhesiveness will increase due to cardiovascular risk factors (i.e. hypertension, hypercholesterolemia), rendering the arterial wall susceptible to lipoprotein influx and monocyte adhesion respectively. The development of atherosclerosis can roughly be divided into three stages, initiation, progression, and rupture (Figure 1.1), which all manifest inflammation and dyslipidemia. Both animal and human studies have shown that hyperlipidemia results in endothelial activation, which enables infiltration and retention of low-density lipoprotein (LDL) in the arterial intima. An inflammatory response is initiated, increasing expression of adhesion molecules on the activated endothelium to attract leukocytes. Monocytes migrate into the vessel wall, and differentiate into macrophages that take up modified LDL. ${ }^{1-3}$ Morphologically, an initial lesion with (pathological) intimal thickening shows mild thickening of the intima due to extracellular lipid and macrophage accumulation. ${ }^{4}$ 


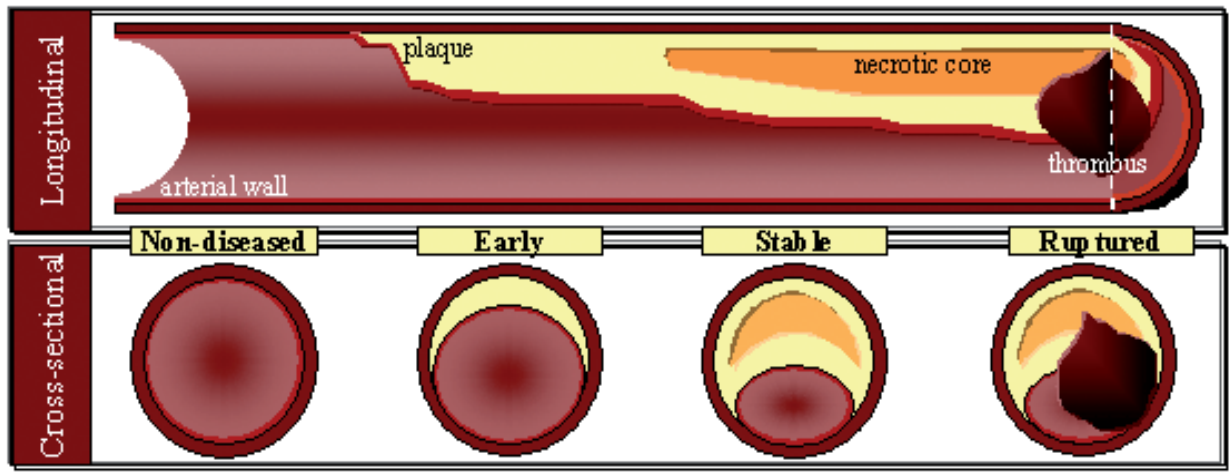

Figure 1.1 Schematic illustration of atherogenesis in a longitudinal and cross-sectional representation

The lesions progress into advanced atheromas with a fibrous cap overlying a necrotic/lipid core as a consequence of macrophage foam cell formation, production of reactive oxygen species (ROS), apoptosis/necrosis, smooth muscle cell migration, and matrix deposition. ${ }^{4}$ The activated macrophage foam cells initiate a surge of cytokine secretion, attracting more inflammatory cells, including T-cells. Activated T-cells will secrete pro- and anti-inflammatory cytokines, thus controlling inflammatory reactions in the atherosclerotic plaque. ${ }^{5,6}$

These advanced atheromas are regarded as stable lesions, but the ongoing inflammatory response, matrix degradation, and cell death eventually weaken the fibrous cap, leading to intraplaque hemorrhage, plaque instability, and rupture. Exposure of the thrombogenic plaque content to the blood will lead to thrombus formation, which may cause clinical symptoms such as acute coronary symptoms and stroke. A (clinically silent) non-occluding thrombus may be reendothelialized and re-organized by inflammatory cells, leading to plaque growth. ${ }^{1,3}$

\section{Novel concepts in atherogenesis}

Several new concepts on atherogenesis have been introduced or significantly substantiated in the last 5-10 years adding to the enormous complexity of this disease. These novel concepts include, but are not limited to, the role of specific cell (sub)types or cellular components, such as regulatory T-cells, mast cells, platelets, monocyte/macrophage subtypes, microparticles, and endothelial progenitor cells (EPC), and mechanisms of atherogenesis, such as apoptosis, phagocytosis, and angiogenesis. In addition, cardiovascular research has evolved from a single factor, single model approach to a more integral, multifactorial approach involving state-of-the-art techniques. This is clearly revealed by the increasing attention for inflammation and metabolism, and 
specifically for their cross talk. Recently, adipocyte fatty-acid-binding protein (FABP4), expressed in adipocytes and macrophages, was shown to integrate inflammatory and metabolic responses. An oral inhibitor of FABP4 reduced lesion size, progression, and lipid accumulation in the apolipoprotein E knockout $\left(\mathrm{ApoE}^{-/}\right)$model of atherosclerosis, while in the leptin-deficient $\left(\right.$Lep $\left.^{\mathrm{ob/b}}\right)$ model of obesity and diabetes, adipose tissue showed increased insulin sensitivity with reduced macrophages and cytokine production. ${ }^{8}$ Defective insulin signaling in the atherosclerotic LDL receptor knockout $\left(\mathrm{LDLR}^{-1}\right)$ mouse model resulted in more advanced lesions with larger cores and more apoptosis. ${ }^{9}$ Another group developed a mouse model to study the effect of type 2 diabetes and atherosclerosis independent of plasma lipid levels: the IGF-II/LDLR ${ }^{-1}$ ApoB ${ }^{100 / 100}$ mouse. ${ }^{10}$ Pancreatic cells of LDLR $^{-1} \mathrm{ApoB}^{100 / 100}$ overexpressed insulinlike growth factor-II and showed insulin resistance, hyperglycemia, and hypercholesterolemia. IGF-II/LDLR ${ }^{-1} \mathrm{ApoB}^{100 / 100}$ mice demonstrated similar lesion size, but increased lesion calcification compared to $\mathrm{LDLR}^{-} \mathrm{ApoB}^{100 / 100}$ mice. ${ }^{10}$ These studies exemplify the novel approach to cardiovascular research where targets/effect are not only studied in an in vivo model of a single disease (for instance atherosclerosis), but also in a model for diabetes, obesity or even a combination thereof. ${ }^{11}$ In combination with the myriad of genomics ${ }^{12-15}$ and proteomics ${ }^{16-18}$ data collected in the last few years, an integrative approach to (patho-) physiology of atherosclerosis, diabetes, and obesity is most likely to resolve important questions of cardiovascular disease mechanisms, and yield new therapeutic targets.

The concept that atherosclerosis is an inflammatory disease is well-accepted, and both innate and adaptive immunity greatly affect atherogenesis. In recent years much progress has been made in further characterizing adaptive immunity, specifically the diverse T-cell subtypes and their effects., ${ }^{5,6}$ The Thelper (Th) or $\mathrm{CD}_{4}^{+}$cell is the dominant T-cell found in atherosclerotic lesions compared to the T-cytotoxic or CD8 $8^{+}$cell. Initially, two subsets of Th cells were identified. Th1 cells are regarded as pro-atherogenic, and secrete interferon $\gamma$ (IFN $\gamma$ ), tumor necrosis factor $\alpha$ (TNF $\alpha$ ), and interleukin (IL)-2, whereas Th2 cells produce IL-4, IL-5, IL-10, and IL-13. Initially, a balance was proposed between the pro-atherogenic Th1 subset and the Th2 subset, however Th2 cells may have both pro- and anti-atherogenic effects depending on site and stage of lesion development. An additional subtype, T regulatory (Treg) cells, has more recently been implicated in atherogenesis., ${ }^{5,}$ Treg cells dampen the immune activity to ensure a balance between effective inflammation and self-recognition, thus preventing an auto-immune reaction. Natural Treg cells show marker expression of CD25 and the transcription factor FoxP3, recognize thymus-derived auto- 
antigens, and control self-tolerance and auto-immunity. On the other hand, adaptive Treg cells are stimulated by "tolerogenic" antigen presenting cells at inflammatory sites independent of the thymus. The production of antiinflammatory cytokines (transforming growth factor $\beta$ (TGF $\beta$ ) and IL-10) by both Treg cell types suppresses the function of Th cells. Recently, proof of concept was given for the therapeutic use of adaptive Treg cells in atherosclerosis. Transplantation of ovalbumin-specific Treg cells reduced atherosclerosis in ApoE ${ }^{-/-}$mice presumably through increased IL-10 production. ${ }^{19}$ Future studies will show if it is possible to use Treg that are specific for plaque antigen(s) as anti-atherogenic therapy., 6

Mast cells were recently shown to be functionally important in atherogenesis by two independent groups. Evidence until then was mainly descriptive and/or based on in vitro studies. ${ }^{20,21}$ The functional impact of mast cells was studied by a chemical alteration of mast cells recruitment ${ }^{22}$ and a transgenic mouse without mast cells. ${ }^{23}$ Both studies showed a pro-atherogenic effect of mast cells, and in particular an important role for mast cell-derived IL-6 and TNF $\alpha$. Also, mast cells increased intraplaque hemorrhage, a feature of plaque instability.

Macrophage heterogeneity and plasticity have long been recognized, and are currently refined as classically (M1) or alternatively (M2) activated subsets. ${ }^{24-26}$ M1 macrophages are activated by Th1 cytokines (IFN $\gamma, \mathrm{TNF} \alpha$ ), lipoproteins, and microbial stimuli (lipopolysacharide, LPS). M1 cells are regarded as proinflammatory and anti-proliferative due to the production of reactive nitrogenand oxygen species, and cytokines (TNF, IL-1, IL-6). The anti-inflammatory M2 subset responds to Th2 cytokines (IL-4, IL-13), or to deactivating cytokines (IL10, TGF $\beta$ ), hormones (glucocorticoid and vitamin D3), and apoptotic cells. Their response include the production of anti-inflammatory cytokines (IL-10, TGF- $\beta$ ), upregulation of lectin-like receptors and arginase, and induction of genes associated with lipid metabolism (PPAR $\gamma$, stabilin1) ${ }^{24-26}$ Recent in vivo reports of M2-M1 phenotype switching of adipose tissue macrophages in murine obesity ${ }^{27}$ and selective monocyte subset recruitment to the murine atherosclerotic vessel, ${ }^{28}$ aid in defining a function of monocyte/macrophage heterogeneity in these chronic inflammatory diseases. Likely, the definition of the M1/M2 subsets is oversimplified, perhaps even arbitrary, but nevertheless may be a useful starting tool to study macrophage heterogeneity in vivo.

Platelets are traditionally viewed to be involved in thrombosis after their activation by the exposure to collagen and tissue factor in the presence of damaged endothelium. However, platelets are now also regarded as an important bridge between inflammation and atherosclerosis. In vivo injection of activated platelets increased adhesion of platelet-monocyte aggregates to the 
endothelium of $\mathrm{ApoE}^{-1-}$ mice, and accelerated the formation of atherosclerosis. ${ }^{29}$ Platelets recruit leukocytes and enhance inflammation through their cell surface interaction and the secretion of recruitment signals (chemokines, leukotrienes). Platelets are thus not only thought to be involved in hemostasis, but also in progression of atherosclerosis. ${ }^{30-32}$

Microparticles (MP) are pro-coagulant fragments derived from the plasma membranes of activated and/or apoptotic cells, such as platelets, leukocytes, and endothelial cells. MP are found in the atherosclerotic plaque and in the circulation, where increased levels are associated with cardiovascular events. At present their exact origin, composition, and contribution to atherosclerotic initiation or progression in vivo have yet to be determined. When MP are convincingly proven to be more than an epiphenomenon of cell activation/death, they might be useful diagnostic tools. ${ }^{33,34}$

Another novel (prognostic) marker of cardiovascular disease may be provided by the number of circulating endothelial progenitor cells (EPC), which are reduced in disease. ${ }^{35}$ In addition, the therapeutic potential of EPC is investigated in cardiac disease. Injection or mobilization of bone marrowderived stem cells/EPC should induce tissue regeneration and/or alleviate endothelial dysfunction by restoring EPC counts. ${ }^{36}$ This new field of research has encountered several problems, such as the use of unambiguous subtype markers, isolation procedure, donor age, and timing of administration, which obscure current results. Although stem cell injection, containing $<1 \% \mathrm{EPC}$, has been shown to increase functional and hemodynamic outcome after MI in humans, groups were not randomized or a control group was lacking. ${ }^{37,38}$ These initial and short-term studies should thus be interpreted with care, especially since a randomized, double-blined clinical trial only showed swifter recovery, but no difference in final outcome at one-year follow-up. ${ }^{39}$ Nonetheless, clinical endpoints (death, recurrent MI, and rehospitalization) were reduced in the bone marrow-treated group. Larger, controlled studies are currently being undertaken, allowing a proper evaluation of this novel therapy in MI. Aside from the selection of the most effective cell population, questions regarding the mechanism of EPC therapy, timing of EPC administration, and the patient groups benefiting most form therapy, should be resolved to assess the maximal benefits of EPC therapy ${ }^{36}$

In the atherosclerosis field, a study of EPC injection/mobilization in $\mathrm{ApoE}^{-1-}$ mice resulted in reduction of plaque progression, without affecting plaque initiation.$^{40}$ However, the latter study was limited due to its use of a mixed population of stromal and hematopoetic cells. Also, the mechanism was not precisely defined, nor was it clear if EPC were acting locally. Another critical 
issue in EPC research is the variation in markers to detect EPC between studies, although the combination of $\mathrm{CD}^{+} 4^{+} / \mathrm{VEGFR}^{+}$, and optionally CD133, is now accepted as the gold standard. Actually, few studies have detected primary EPC in human atherosclerosis. No $\mathrm{cKit}^{+}$(progenitor) cells were detected in atherosclerotic plaques, albeit these plaque hardly contained any EC and macrophages $\left(\mathrm{CD} 31^{+}\right.$and $\mathrm{CD} 68^{+}$cells respectively). ${ }^{41}$ Another study showed that

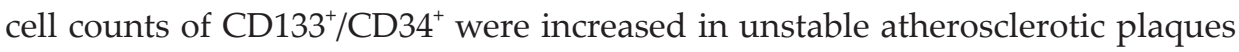
of human coronaries. ${ }^{42}$ Although EPC may be a promising therapeutic intervention, the definite effect of EPC on atherogenesis will only be established if aforementioned obstacles are overcome.

The insight into the process of macrophage death in atherosclerosis has considerably advanced over the years. Macrophage apoptosis has been attributed to several stimuli such as oxLDL, nitric oxide, and intracellular accumulation of unesterified cholesterol. The latter stimulus has received considerable attention, and is mediated by endoplasmatic reticulum (ER) stress and subsequent induction of apoptosis by the unfolded protein response (UPR). ${ }^{43}$ Another pathway mediating pro-apoptotic stimuli involves cell surface "death receptors", such as Fas and TNF related apoptosis-inducing ligand (TRAIL). Both pathways converge to activate caspases, which finally execute cell death. The effect of cell death may depend on lesion stage as evidenced by differential effects of selective monocyte/macrophage depletion in CD11b-diphtheria toxin receptor transgenic mice. ${ }^{44}$ A 50\% monocyte/macrophage suppression reduced plaque size in early lesions, but was ineffective in established lesions. Apoptosis is currently regarded to enhance plaque stability as long as apoptotic cells are cleared by phagocytosis, as seems to occur in early lesion. However in advanced lesions, defective phagocytosis may cause post-apoptotic necrosis, and enhancement of the necrotic core and inflammation. On the other hand, phagocytosis of platelets, lipoproteins, and erythrocytes seems to be proatherogenic, independent of lesion stage. ${ }^{43}, 45$ This theory possibly explains the contradictory effects of general apoptosis on atherosclerotic core size and necrosis that have been reported thus far. ${ }^{46,47}$

Angiogenesis of the atherosclerotic plaque is an influential aspect of atherosclerotic plaque growth and specifically instability, which has been the focus of extensive research over the last years. This process will be discussed in more detail below, since it is the main subject of this thesis. 
Angiogenesis in atherosclerosis

\section{Physiological angiogenesis}

Angiogenesis, the process in which new blood vessels sprout from pre-existing ones, is essential for normal embryogenesis and physiology, i.e. in wound healing. Physiological angiogenesis involves four major processes: 1 . formation; 2. maturation; 3. branching, remodeling, and pruning; and 4. specialization. Figure 1.2 illustrates the angiogenic cascade and relevant molecular regulators. The formation of a new blood vessel is initiated upon a change in environment, such as low oxygen (hypoxia), low $\mathrm{pH}$, hypoglycemia, or inflammatory infiltration. The "angiogenic switch", a balance between pro- and anti-angiogenic factors, is activated, and expression/production of vascular endothelial growth factor (VEGF) and nitric oxide (NO) will induce dilation and permeability of existing vessels. Matrix degradation by proteases (matrix metalloproteinases-2 (MMP2), MMP3, and MMP9) mechanically allows migration of endothelial cells, and also releases additional pro-angiogenic factors i.e., VEGF, basic fibroblast growth factor (bFGF), hepatic growth factor (HGF), and placental growth factor (PlGF). Migrated endothelial cells align to form a new sprout. ${ }^{4850}$

Maturation of new sprouts, highly permeable endothelial lined tubes, is achieved by basement membrane generation, and recruitment of mural cells, pericytes. Sprouting is halted, and immature vessels are stabilized by several molecular pathways. Platelet-derived growth factor beta (PDGF $\beta$ ) and its receptor PDGFR- $\beta$, expressed on endothelial cells and pericytes respectively, recruit pericytes to nascent vessels. Also, the Tie-2 receptor and the ratio of its ligands angiopoietin-1 (ANG1) and ANG2 affects vessel maturation: ANG1 will stabilize vessels by facilitating EC-pericyte communication and suppressing apoptosis, whereas ANG2 antagonizes these actions. However, ANG2 facilitates sprouting if VEGF is present. Additionally, TGF $\beta 1$ signaling through anaplastic lymphoma kinase-5 (ALK5) will promote vessel maturation by stimulating matrix production and differentiation of mural progenitors to pericytes. In contrast, TGF $\beta 1$-endoglin-ALK1 signaling will inhibit maturation by continuous stimulation of EC migration and proliferation. Finally, AKT1 regulates pericyte coverage and basement membrane assembly through reduced expression of thrombospondin-1 and $-2 .{ }^{51}$ Ongoing research continues to reveal novel pathways and molecules involved in pericyte recruitment, such as spingosine-1phospate, N-cadherin, and the Notch ligand Delta4..$^{50,52,53}$ 
1. Initiation Pericyte $\rightleftharpoons$; Basal lamina mmmmm; Endothelial cell $\rightleftharpoons$ $\underset{\mathrm{VEGF}, \mathrm{FGF}}{\mathrm{PlGF} ; \mathrm{HGF} \text { NO }}$ Dilation

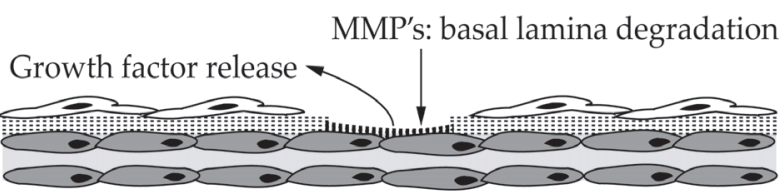

2. Migration+proliferation

VEGFR2 $\longrightarrow$ Proliferation

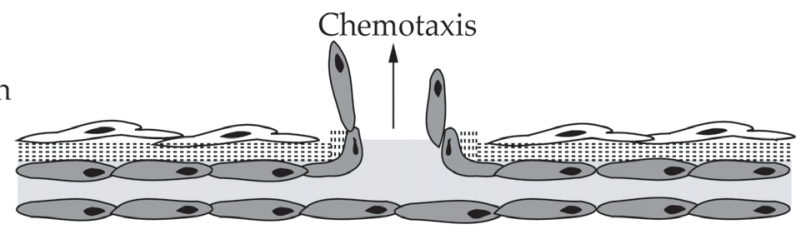

3. Immature tube formation VEGFR1 $\longrightarrow$ Tube formation TGF $\beta 1 ;$ AKT $\longrightarrow$ Matrix assembly

\section{Maturation}

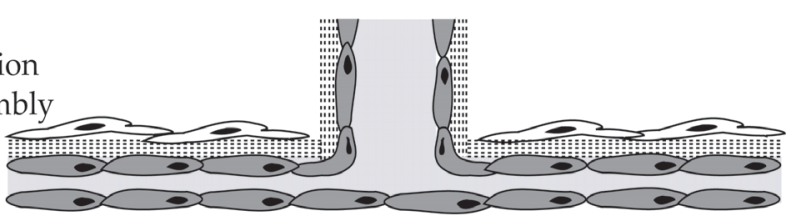

TGF $\beta 1$; AKT

ANG1, -2 $\rightarrow$ Tie-2

PDGF $\beta \rightarrow$ PDGFR $\beta$

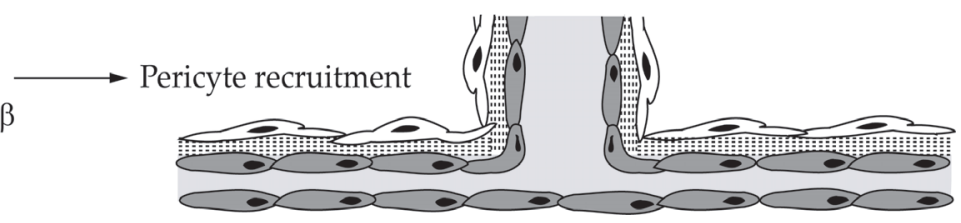

Figure 1.2 Physiological angiogenesis cascade

Physiological angiogenesis involves four major processes: formation; maturation; branching, remodeling and pruning; and specialization. The formation and maturation of a new blood vessel are depicted here in more detail. 1. A stimulus initiates angiogenesis by several growth factors and nitric oxide, inducing dilation and permeability of an existing vessel. The basal lamina is degraded by matrix metalloproteinases, releasing additional growth factors. 2. Endothelial cells proliferate, and migrate towards a chemotactic growth factor gradient. 3. Endothelial cells align to form an immature tube, and matrix is assembled to construct the basal lamina. 4. Pericytes are recruited to cover the immature tube, resulting in a mature, novel blood vessel. The abbreviations are indicated in the main text. ${ }^{48.50}$

Remodeling of the mature vasculature results in an organized vascular network without excessive vessels. The balance between expansion and regression is achieved by survival vs. apoptosis of EC and pericytes. Survival depends on cell-matrix adhesion, matrix proteases, and -inhibitors. Matrix degradation releases various pro-angiogenic (VEGF, bFGF) and anti-angiogenic molecules (angiostatin, endostatin, thrombospondins, integrins). Ultimately, the interaction of these factors determines whether cells survive or die, thereby regulating angiogenesis. ${ }^{50,54}$ 
Vessel specialization involves arterio-venous differentiation, regulated by notch and ephrin signaling, and/or adaptation of inter/intracellular junctions to facilitate cellular communication and permeability. Several molecules govern cell-cell interactions and junctions, such as VE-cadherin, N-cadherin, connexins, occludins (zona occludens-1 (ZO1), and claudins. Vessel specialization realizes adaptation to local demands in different organs. ${ }^{50}$

\section{Pathological angiogenesis}

In pathological angiogenesis a pro-angiogenic switch results in a highly disorganized vasculature with excessive (branching of) vessels, and enlarged and irregular vessel diameters. Excessive angiogenesis has been described in an ever growing number of pathological disorders, such as tumorigenesis, diabetic retinopathy, multiple sclerosis, endometriosis, macular degeneration, asthma, and of course atherosclerosis. Ultra structurally, tumor endothelial cells are abnormal showing large numbers of fenestrations, vesicles, blebbing, wide or missing junctions, and membrane detachment. In addition, tumor angiogenesis shows reduced pericyte coverage, indicative of abnormal microvessel maturation. These features explain the increased permeability of tumor vessels, which most likely results from a distortion in the balance of angiogenic and maturation signals..$^{4850}$

Table 1.1 Dimensions of intraplaque microvessels

\begin{tabular}{lcccc}
\hline & N & Mean (SD) & Minimum & Maximum \\
\hline Diameter minor axis $(\mu \mathrm{m})$ & 63 & $36.4(46.1)$ & 1.6 & 197.1 \\
Diameter major axis $(\mu \mathrm{m})$ & 47 & $52.7(49.2)$ & 5.1 & 199.7 \\
Area $\left(\mu \mathrm{m}^{2}\right)$ & 167 & $1,579.3(497.5)$ & 18.6 & $20,489.8$ \\
\hline
\end{tabular}

Measurements in atherosclerotic carotid plaques of 5 symptomatic patients using computerassisted image analysis (Leica Qwin V3)

\section{Angiogenesis in human atherosclerosis}

Non-diseased blood vessels are nourished from the vessel lumen, and from microvessels in the adventitia, the vasa vasorum. The presence of microvessels in the atherosclerotic plaque and their absence in the normal intima was already described in $1936 .{ }^{55} \mathrm{~A}$ mechanistic explanation of its association to atherosclerotic disease progression was unknown at the time. In the early ' $80 \mathrm{~s}^{56,57}$ research refocused on microvessels, and the percentage of papers studying angiogenesis in 
the human atherosclerosis field has more than quadrupled since then (Figure 1.3).

The morphology of adventitial microvessels appears physiological in normal arteries. However, adventitial angiogenesis, occurring with the onset of disease, results in a fairly disorganized vascular network with increased inflammatory infiltration. ${ }^{58-60}$ The majority $(>96 \%)$ of intraplaque angiogenesis is shown to extend from the adventitia through the media into the neointima. The remaining intraplaque microvessels originate from the main artery lumen, and are often associated with intraplaque hemorrhage. ${ }^{55,61,62}$ Recently, EPC have been suggested to be recruited and incorporated into active angiogenic sprouts in tumor angiogenesis, but generally their contribution is considered very low. ${ }^{63}$ Although EPC have not yet been described in human intraplaque microvessels, microvessel endothelium in a Tie-LacZ allograft mouse model of atherosclerosis was derived from endothelial bone marrow progenitors. ${ }^{64}$ Therefore, the EPC origin of human microvessel endothelium needs to be studied further. The use of EPC injection or recruitment in myocardial infarction to alleviate EC dysfunction, may pose a pro-angiogenic threat to atherosclerotic plaque stabilization. Thus, despite positive results of bone marrow-derived progenitors (not EPC-enriched) in myocardial infarction, ${ }^{37,39}$ this new strategy must be applied with caution.

In the atherosclerotic plaque, microvessels are mainly found in its shoulder regions, ${ }^{4,62,65,66}$ presumably favoring the upstream compared to the downstream

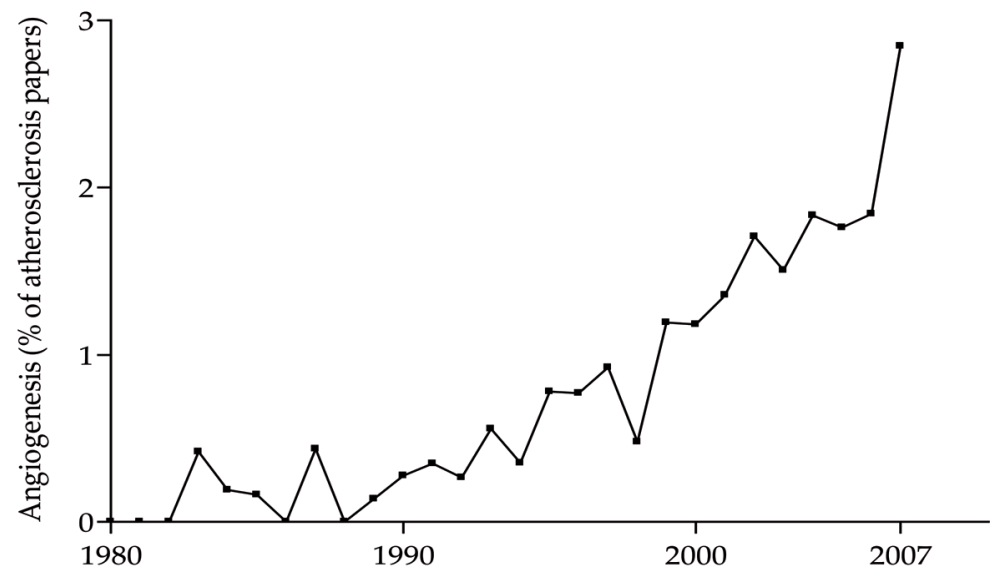

Figure 1.3 Percentage of papers on angiogenesis in atherosclerosis over time

Published original research manuscripts and reviews were identified using the NIH database PubMed (www.pubmed.gov; search terms "(angiogenesis OR neovascularization) AND atherosclerosis"; search limits "human, English, publication date"). The number of papers was divided by the total number of papers on "atherosclerosis" alone in each year. 
shoulder. ${ }^{67,68}$ Microvessels are also found at the plaque base (the intima-media border) or in the fibrous cap, and are generally surrounded by macrophage (foam) cells, ${ }^{67,69-74}$ mast cells, ${ }^{75,76}$ T-cells, ${ }^{65,70,77}$ red blood cells, ${ }^{65,67,78,79}$ albumin, ${ }^{66}$ and/or lipoproteins., ${ }^{4,65}$ Microvessels are generally oval or multi-lobular. Microvessel dimensions (measured in 5 atherosclerotic carotid plaques from symptomatic patients) vary between 2 and $200 \mu \mathrm{m}$ in diameter with a surface area ranging from $20-20,000 \mu \mathrm{m}^{2}$ (Table 1.1).

\section{Angiogenesis in progression of disease}

An extensive literature survey was done to systematically review quantitative (immuno-) histological studies reporting the association of angiogenesis to the progression of human atherosclerosis. Published data were identified using the NIH database PubMed (www.pubmed.gov; search terms "(angiogenesis OR neovascularization OR microvessel density) AND atherosclerosis"; search limits "human, English"). References of the resulting papers and recent reviews on this topic ${ }^{58,59,80-83}$ were cross-checked, adding to the survey results.

The literature survey resulted in 30 studies published between January 1987 to November 2007, which used 21-525 lesions (10-272 patients) per study (Table 1.2 and Figure 1.4). Most papers described coronary arteries (11 autopsy-, 3 surgical collections), carotid arteries (10 surgical-, 1 autopsy collection), and some used the aorta ( 3 autopsy collections). Some only used histology $(n=5)$ to distinguish microvessels, but the majority used endothelial-specific immunohistochemical markers, either single: CD31 $(n=2)$, CD34 $(n=8)$, or von Willebrandt factor (Factor VIII; $\mathrm{n}=8$ ), or a double/triple (cocktail) combination thereof $(n=6)$. Authors used different read-out parameters to quantify microvessels: the sum of microvessels (absolute sum or sum/microscopic field; $\mathrm{n}=13$ ), the frequency of positive samples $(\mathrm{n}=11)$, surface area (EC or microvessel lumen, $\mathrm{n}=3$ ) or a semiquantative score (scale $0-3, \mathrm{n}=2$ ). Classification of atherosclerotic lesions was mainly conform the AHA consensus ${ }^{84}$ described by Virmani et $\mathrm{al}^{4}$ or a similar scheme $(\mathrm{n}=20){ }^{85,86}$ It proved impossible to perform a systematic meta-review as quantitative data were generally not presented per lesion stage. If presented per lesion stage, combinations of lesion stages were frequently used. As the combinations of stages were inconsistent across studies, data could not be compared directly. Also, quantitative data of different arteries were summarized, not taking differences between vascular beds into account. Finally, a variety of different read-out parameters were used (microvessel sum, microvessel $^{+}$plaque frequency, EC surface area, and semiquantative scores), also precluding a direct comparison. Therefore, the results will merely be summarized (Figure 1.4, Table 1.2). 
Table 1.2 Results of literature survey on the (quantitative) description of intraplaque microvessels in human atherosclerosis

\begin{tabular}{|c|c|c|c|c|c|c|c|c|c|c|}
\hline Ref & $\begin{array}{l}\text { Sections } \\
\text { (n) }\end{array}$ & $\begin{array}{l}\text { Donors } \\
\text { (n) }\end{array}$ & $\begin{array}{l}\text { Male } \\
\text { (\%) }\end{array}$ & Site & $\begin{array}{l}\text { Age } \\
\text { range } \\
\left(\text { mean }^{+} S D\right)\end{array}$ & $\begin{array}{l}\text { Source } \\
A u / S u\end{array}$ & Classification & Marker & Read-out & $\begin{array}{l}\text { Association } \\
\text { with } \\
\text { atherogenesis }\end{array}$ \\
\hline 74 & 42 & 36 & $82 \%$ & CA & $\begin{array}{l}\text { unk } \\
(61 \pm 15)\end{array}$ & $\mathrm{Su}$ & AHA & CD34 & $\begin{array}{l}\text { Count/ } \\
\text { 200x field }\end{array}$ & + \\
\hline 72 & 28 & 28 & $75 \%$ & CA & $\begin{array}{l}\text { 49-81 } \\
\text { (unk) }\end{array}$ & $\mathrm{Su}$ & other & CD31 & $\begin{array}{l}\text { MVD, } \\
\text { count }\end{array}$ & + \\
\hline 70 & 165 & 162 & $76 \%$ & CA & $\begin{array}{l}40-83 \\
(8 \pm 8)\end{array}$ & $\mathrm{Su}$ & other & $\begin{array}{l}\text { CD31 } \\
\text { CD34 } \\
\text { vWF }\end{array}$ & Freq & + \\
\hline 225 & 281 & 272 & $78 \%$ & CA & $\begin{array}{l}40-84 \\
(68 \uparrow /-8)\end{array}$ & $\mathrm{Su}$ & other & $\begin{array}{l}\text { CD31 } \\
\text { CD34 } \\
\text { vWF }\end{array}$ & Freq & + \\
\hline 89 & 239 & 73 & $58 \%$ & CA & $\begin{array}{l}50-87 \\
\text { (unk) }\end{array}$ & $\mathrm{Su}$ & AHA & CD34 & $\begin{array}{l}\text { MVD } \\
\text { median }\end{array}$ & + \\
\hline 226 & 294 & 49 & $49 \%$ & $\begin{array}{c}\mathrm{CA} \\
\mathrm{IL} \\
\mathrm{RE}\end{array}$ & unk & $\mathrm{Au}$ & AHA & vWF & Freq & nd \\
\hline 77 & 25 & 25 & $60 \%$ & $\begin{array}{l}\mathrm{CA} \\
\mathrm{FE} \\
\mathrm{AO}\end{array}$ & $\begin{array}{l}\text { unk } \\
(65 \pm 10)\end{array}$ & $\mathrm{Su}$ & other $^{86}$ & $\begin{array}{l}\text { vWF } \\
\text { /Ulex }\end{array}$ & $\begin{array}{l}\text { MVD, } \\
\text { Freq }\end{array}$ & + \\
\hline 65 & 191 & 191 & unk & CA & unk & $\mathrm{Su}$ & AHA & $\begin{array}{l}\text { CD31 } \\
\text { CD34 } \\
\text { vWF }\end{array}$ & Freq & + \\
\hline 227 & 319 & 26 & $50 \%$ & $\mathrm{CA}$ & $\begin{array}{l}43-84 \\
(68 \pm 9)\end{array}$ & $\mathrm{Su}$ & AHA & $\mathrm{vWF}$ & Freq & nd \\
\hline 68 & 54 & 54 & $56 \%$ & CA & $\begin{array}{l}\text { unk (unk) } \\
\text { median } 71\end{array}$ & $\mathrm{Su}$ & AHA & CD34 & Freq & nd \\
\hline 78 & unk & 15 & $79 \%$ & $\mathrm{CA}$ & $\begin{array}{l}54-79 \\
\text { (66 } \pm \text { unk) }\end{array}$ & $\mathrm{Su}$ & AHA & $\mathrm{vWF}$ & MVD & + \\
\hline & 91 & 91 & unk & CA & unk & $\mathrm{Su}$ & none & $\mathrm{HE}$ & Freq & nd \\
\hline 228 & 43 & 43 & unk & CA & $\begin{array}{l}57-82 \\
\text { (unk) }\end{array}$ & $\mathrm{Su}$ & none & CD34 & count & nd \\
\hline 229 & 47 & 47 & $87 \%$ & $\mathrm{CA}$ & $\begin{array}{l}\text { unk } \\
(69 \pm 9)\end{array}$ & $\mathrm{Su}$ & other & CD34 & Score $0-3$ & nd \\
\hline 211 & 21 & 21 & $71 \%$ & $\mathrm{CO}$ & $\begin{array}{l}41-82 \\
\text { (unk) }\end{array}$ & $\mathrm{Su}$ & none & CD31 & $\begin{array}{l}\text { Count/ } \\
\text { 400x field }\end{array}$ & nd \\
\hline 162 & 169 & 23 & $61 \%$ & $\mathrm{CO}$ & $\begin{array}{l}57-93 \\
(76 \pm 11)\end{array}$ & $\mathrm{Au}$ & AHA & CD34 & $\begin{array}{l}\text { Count, } \\
\text { Freq }\end{array}$ & + \\
\hline 62 & 251 & 251 & unk & $\mathrm{CO}$ & unk & $\mathrm{Au}$ & Virmani & Movat & count & + \\
\hline
\end{tabular}




\begin{tabular}{|c|c|c|c|c|c|c|c|c|c|c|}
\hline Ref & $\begin{array}{l}\text { Sections } \\
\text { (n) }\end{array}$ & $\begin{array}{l}\text { Donors } \\
\text { (n) }\end{array}$ & $\begin{array}{l}\text { Male } \\
(\%)\end{array}$ & Site & $\begin{array}{l}\text { Age } \\
\text { range } \\
\left(\text { mean }^{+} S D\right)\end{array}$ & $\begin{array}{l}\text { Source } \\
A u / S u\end{array}$ & Classification & Marker & Read-out & $\begin{array}{l}\text { Association } \\
\text { with } \\
\text { atherogenesis }\end{array}$ \\
\hline 129 & 33 & 33 & unk & $\mathrm{CO}$ & unk & $\mathrm{Su}$ & none & $\begin{array}{l}\text { CD31 } \\
\text { CD34 }\end{array}$ & count & nd \\
\hline 87 & 43 & 22 & $73 \%$ & $\mathrm{CO}$ & $\begin{array}{l}25-85 \\
\text { (unk) }\end{array}$ & $\mathrm{Au}$ & none & Giemsa & count & nd \\
\hline 218 & 80 & 40 & $60 \%$ & $\mathrm{CO}$ & $\begin{array}{l}25-85 \\
\text { (unk) }\end{array}$ & $\mathrm{Au}$ & AHA & CD34 & count & nd \\
\hline 75 & 37 & 37 & unk & $\mathrm{CO}$ & $\begin{array}{l}24-84 \\
\text { (unk) }\end{array}$ & $\mathrm{Au}$ & none & vWF & count & nd \\
\hline 130 & 31 & 31 & $94 \%$ & $\mathrm{CO}$ & $\begin{array}{l}41-74 \\
(58 \pm 9)\end{array}$ & $\mathrm{Su}$ & AHA & vWF & MVD & nd \\
\hline 76 & 30 & 30 & $80 \%$ & $\mathrm{CO}$ & $\begin{array}{l}\text { 34-78 } \\
\text { unk) }\end{array}$ & $\mathrm{Au}$ & AHA & $\begin{array}{l}\text { CD31 } \\
\text { CD34 }\end{array}$ & $\begin{array}{l}\text { MVD, } \\
\text { Freq }\end{array}$ & + \\
\hline 61 & 250 & 31 & $58 \%$ & $\mathrm{CO}$ & $\begin{array}{l}\text { 35-89 } \\
\text { (unk) }\end{array}$ & $\mathrm{Au}$ & Other ${ }^{85}$ & $\mathrm{HE}$ & MVD & + \\
\hline 128 & 525 & 48 & $56 \%$ & $\mathrm{CO}$ & $\begin{array}{l}20-93 \\
(71 \pm 15)\end{array}$ & $\mathrm{Au}$ & AHA & CD34 & Freq & + \\
\hline 109 & 89 & 20 & unk & $\mathrm{CO}$ & unk & $\mathrm{Au}$ & AHA & $\begin{array}{l}\text { CD31 } \\
\text { CD34 } \\
\text { vWF }\end{array}$ & Freq & nd \\
\hline 131 & 38 & 15 & unk & $\mathrm{CO}$ & $\begin{array}{l}21-72 \\
\text { (unk) }\end{array}$ & $\mathrm{Au}$ & $\sim \mathrm{AHA}$ & $\mathrm{vWF}$ & $\begin{array}{l}\text { Surface } \\
\text { area EC }\end{array}$ & nd \\
\hline 66 & 299 & 68 & unk & $\mathrm{CO}$ & unk & $\mathrm{Au}$ & none & vWF & score $0-3$ & nd \\
\hline 69 & 40 & 10 & $60 \%$ & $\mathrm{CO}$ & $\begin{array}{l}37-84 \\
(60 \pm 16)\end{array}$ & $\mathrm{Au}$ & none & $\mathrm{HE}$ & count & nd \\
\hline 69 & 25 & 25 & $88 \%$ & $\mathrm{CO}$ & $\begin{array}{l}35-75 \\
(63 \pm 13)\end{array}$ & $\mathrm{Su}$ & none & $\mathrm{HE}$ & count & nd \\
\hline 230 & 28 & 28 & $79 \%$ & $\mathrm{CO}$ & $\begin{array}{l}\text { unk } \\
(58 \pm 1)\end{array}$ & $\mathrm{Su}$ & none & $\begin{array}{l}\text { CD31 } \\
\text { CD34 } \\
\text { vWF }\end{array}$ & count & nd \\
\hline 218 & 40 & 20 & $70 \%$ & $\mathrm{AO}$ & $\begin{array}{l}\text { 33-96 } \\
\text { (unk) }\end{array}$ & $\mathrm{Au}$ & AHA & CD34 & nd & nd \\
\hline 88 & 269 & 24 & $100 \%$ & $\mathrm{AO}$ & $\begin{array}{l}29-89 \\
(61 \pm 16)\end{array}$ & $\mathrm{Au}$ & AHA & CD34 & MVD & + \\
\hline
\end{tabular}

Abbreviations: $\mathrm{CA}$, Carotid artery; $\mathrm{CO}$, coronary artery; $\mathrm{AO}$, aortic artery; $\mathrm{IL}$, iliac artery; $\mathrm{RE}$, renal artery; Fe, femoral artery; unk, unknown; Au, autopsy; Su, Surgery; AHA, American Heart Association; vWF, Von Willebrandt factor; Ulex, Ulex aeropeus; MVD, microvessel density; Freq, frequency of microvessel positive plaques; nd, association with atherogenesis not determined or data not presented. 
Adventitial microvessels were only studied by three groups, one of which presented the data per lesion stage, and showed significantly more microvessels in advanced vs. early lesions. ${ }^{76}$ Adventitial and intimal microvessels were significantly associated. ${ }^{87}$ An increase in intimal microvessels was generally associated with progression of atherosclerosis, although the exact relation with each disease stage was not always studied or statistically tested. Numerous studies showed significant increases in total microvessels between non-diseased and early lesions $(n=2)$, early and advanced lesions $(n=5 / 6)$, fibrocalcified lesions and atheromas $(n=2 / 3)$, advanced lesions and lesions with intraplaque hemorrhage $(n=5 / 6)$, and early $(n=4 / 4)$ or advanced $(n=7 / 9)$ with ruptured lesions. Intimal microvessels in lesions with intraplaque hemorrhage and ruptured lesions were similar, but compared only once. ${ }^{72}$ Thus, intimal microvessels gradually incline with lesion progression independent of the used read-out parameter, which can be appreciated from all 4 panels of figure 1.4.
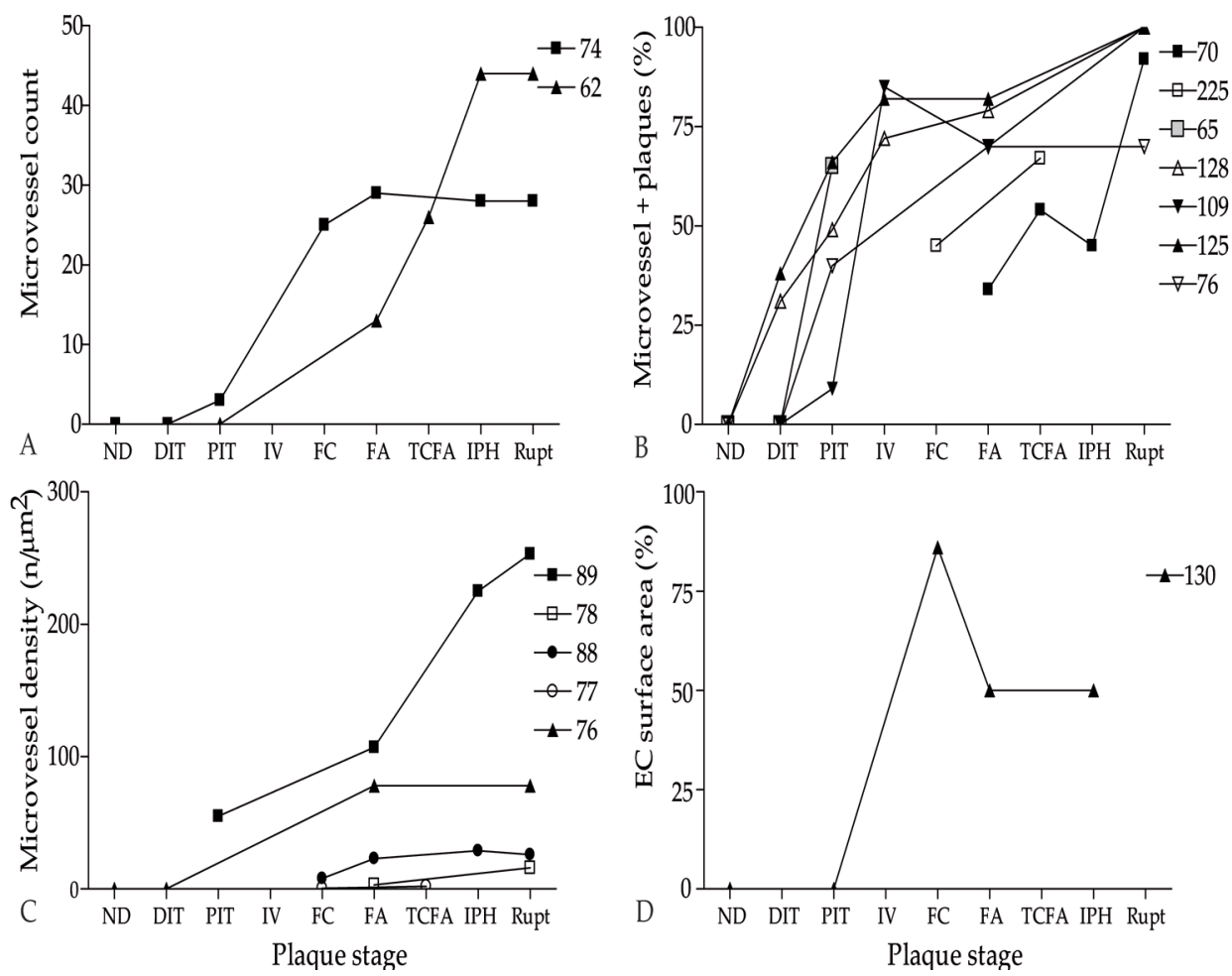

Figure 1.4 Microvessel quantifications per atherosclerotic plaque stage

A. The sum of microvessels, B. frequency of microvessel positive plaques, C. microvessel density,

D. endothelial surface area per atherosclerotic plaque stage. $\square$; carotid arteries, $\triangle$; coronary arteries;

$\mathrm{O}$; aortic/femoral arteries, Legend numbers correspond to reference number. ND, non-diseased; DIT, diffuse intimal thickening; PIT, pathological thickening; IV, AHA stage IV; FC, fibrocalcified; FA, fibroatheroma; TCFA, thin cap fibroatheroma, IPH, intraplaque hemorrhage; Rupt, ruptured 
There was some divergence in the intraplaque location of microvessels that was associated to rupture and/or hemorrhage, when such discrimination was made. Moreno et $\mathrm{al}^{88}$ found that microvessels in the plaque base (intima-media border) were important for plaque hemorrhage or rupture, whereas Mofidi et al ${ }^{89}$ found a significant association with total microvessels and microvessels in the cap/shoulders.

Nevertheless, the link between intraplaque microvessels and plaque instability is further substantiated by its significant association with inflammatory infiltration $(n=10 / 10)$, stenosis $(n=3 / 3)$, and symptomatic patients $(n=8 / 9)$. In summary, human descriptive, and therefore cross-sectional studies, suggest a clear association between angiogenesis and several phases of atherosclerotic development, specifically progression and instability.

\section{Angiogenesis in animal models}

Despite the overwhelming evidence from human (immuno-)histological observations of the involvement of intraplaque angiogenesis in atherosclerosis, this does not prove causality or consequence, as was pointed out recently. ${ }^{82}$ Human atherosclerotic lesions do have an angiogenic potential, as plaque lysates were pro-angiogenic in a corneal angiogenesis model. ${ }^{90}$ In murine atherosclerosis, pro-angiogenic ${ }^{91-94}$ and anti-angiogenic $c^{94-98}$ approaches have been used to establish a functional effect of angiogenesis on atherogenesis. Without an exception, these studies found that pro-angiogenic therapy enhanced atherosclerosis, while anti-angiogenic therapy reduced plaque burden. Some studies reported altered intraplaque ${ }^{91,97,98}$ or adventitia ${ }^{95}$ angiogenesis, but especially the effect on intraplaque angiogenesis has thus far been difficult to reproduce. Notably, in the majority of studies the effect was angiogenesisindependent, presumably because of the scarce presence of intraplaque microvessels. Indeed, evidence from in vivo studies in atherosclerotic animal models is hampered by the ambiguous detection of intraplaque microvessels, and are thus mainly based on adventitial microvessels. The actual existence of the former is, especially in mice under heavy debate, however as elegantly put by Schwartz et al: "absence of evidence is not evidence of absence". ${ }^{99}$ Even though microvessels may not be as numerous in mice as in larger species, their detection is hugely hindered by the lack of adequate (immunohistochemical) markers. Indeed, an innovative imaging tool, micro-computed tomography did prove their existence and adventitial origin. ${ }^{100}$ Unfortunately quantitative information was not shown, and as of yet this observation is not reproduced. The majority of available immunohistochemical markers only works on cryo-sections, in which the positive identification of minuscule microvessels is challenging. In our 
hands, the few markers suitable for paraffin sections fail to stain all microvessels, including the ones morphologically distinguishable using histology. Another critical issue is that the expression of the frequently used EC marker CD31, seems to be lost with inflammation. Indeed, EC of human intraplaque microvessels do not always express CD31, ${ }^{67}$ although a quantitative association of CD31 expression with atherosclerotic progression is lacking. Novel EC imaging tools or a cocktail of immunohistochemical markers will hopefully resolve the detection issue, and at least establish the presence or absence of intraplaque microvessels in mice.

In larger experimental models of atherosclerosis, such as hypercholesterolemic pigs, and balloon-injured or grafted dogs, intraplaque microvessels are more frequently, but not inevitably encountered. ${ }^{82}$ Thus far, intraplaque microvessels were not convincingly demonstrated in rabbit models (Table 1.3). However, adventitial microvessels can be detected in all animal models from mice through primate, and available data argues in favor of a relation with atherosclerosis. First, the anatomical sites predisposed for atherosclerosis show an increased density of adventitial microvessels in mice ${ }^{100}$ and pigs. ${ }^{101}$ In addition, adventitial and intimal blood flow measured by micro spheres was substantially increased in atherosclerotic primates. ${ }^{102}$ Secondly, experimental studies support a role for adventitial microvessels in the initiation and/or progression of atherosclerosis, although there are few reports available. Even before the plaque initiation phase, adventitial microvessels density was reported to increase in hypercholesterolemic pigs. ${ }^{103,104}$ In contrast, a recent study suggested that adventitial microvessels only stimulate, not initiate intimal thickening. ${ }^{105}$ However, the model used, smooth muscle cell-dependent hyperplasia, does not reveal accumulation of macrophages and lipid in the plaque, crucial events in the initiation of human atherosclerosis. In summary, although adventitial microvessels seem to be related to atherosclerotic disease, their functional relationship to specific stages of disease remains to demonstrated.

\section{Angiogenesis as a cause for atherosclerotic plaque instability}

Although both adventitial and intraplaque angiogenesis have been associated with atherosclerosis, plaque instability has mostly been ascribed to intraplaque microvessels. Based on the aforementioned cross-sectional observations, an important theory has been postulated stating that intraplaque microvessels are inherently leaky, providing an entry point for cellular and soluble components such as red blood cells, inflammatory cells, and lipid/lipoproteins. ${ }^{62,78,79}$ Aside from observations of red blood cells in the atherosclerotic plaque surrounding 
intraplaque microvessels, a specific red blood cell membrane component (glycophorin A) has been detected in the core of vulnerable plaques. ${ }^{79}$ In vivo injection of RBC in plaques of hypercholesterolemic rabbits resulted in a marked increase in cholesterol crystals, lipid content, foam cells, and iron deposits. ${ }^{79}$ The increased lipid content can be ascribed to the high cholesterol content of red blood cells. Interestingly, total cholesterol content of erythrocyte membranes was markedly increased in patients with acute coronary disease. ${ }^{106}$ Extravasated red blood cells and platelets will be phagocytosed by macrophages leading to heme and iron accumulation, and lipid peroxidation, which recruit and activate macrophage foam cell formation as demonstrated in vitro. ${ }^{78}$ Repeated erythrophagocytosis could lead to macrophage free cholesterol-loaded apoptosis. In concert with the suggested defective clearance of apoptotic cells in atherosclerosis, ${ }^{43}, 45$ this may lead to necrotic core expansion. Necrotic core expansion and intraplaque hemorrhage were identified as independent predictors of plaque growth and clinical symptoms in a prospective MRI study. ${ }^{107}$ The release of foam cell content will exacerbate inflammatory cell recruitment through intraplaque microvessels. Functional evidence for the entry of leucocytes through intraplaque microvessels has been provided by manipulation of microvessel density via VEGF administration ${ }^{91}$ or angiogenesis inhibitors $^{97,98}$ in atherosclerotic mice. These studies respectively showed an increased and reduced macrophage content in the plaques with a concomitant change in intraplaque microvessels density. However, it was unclear whether the augmented macrophage content was solely due to angiogenesis-dependent effects of the interventions.

\section{Microvessel phenotype and intraplaque hemorrhage}

The relation between intraplaque microvessels and intraplaque hemorrhage may not only be ascribed to their increased number in ruptured plaques, but may also be explained by phenotypic and/or functional changes related to extravasation of leucocytes and blood components. These changes may include leukocyteendothelial cell interactions, microvessel maturation, and endothelial integrity. Leukocyte-endothelial cell interactions are important in inflammation, and are regulated by cell adhesion molecules. Indeed, expression of adhesion molecules E-selectin, intercellular adhesion molecule-1, and vascular adhesion molecule-1 was more prevalent on EC of intraplaque microvessels compared to EC of the main artery lumen. ${ }^{108,109}$

Microvessel leakage is determined by microvessel maturation and endothelial integrity. Microvessel maturation, achieved by basement membraneand pericyte coverage, is thought to render EC quiescent, thus inhibiting further 
sprouting and matrix degradation. In addition, mature microvessels are structurally stable and resistant to collapse due to interstitial stress. In fact, several qualitative observations described "thin-walled microvessels" or absence of microvessel pericytes in the atherosclerotic plaque. ${ }^{71,109-111}$ However, the characteristics of microvessel maturation in relation to different plaque stages has not been thoroughly quantified, nor is the incidence of (im)mature adventitial microvessels known.

Microvascular leakage is also characterized by a disruption of endothelial integrity, normally maintained by intact inter-cellular junctions, such as tight, gap, and adherens junctions. ${ }^{112}$ Microvessels with aberrant or missing endothelial junctions indeed demonstrated a leaky phenotype. ${ }^{113}$ Formation and/or widening of endothelial gaps is mediated by inflammatory mediators and cytokines, lipoproteins, and release of growth factors and proteases from degraded matrix, signaling via VEGF, and/or ANG1/ANG2. These widened gaps are the sites for increased plasma leakage in tumours, ${ }^{114-116}$ and might be responsible for intraplaque hemorrhage in atherosclerosis.

The lack of structural integrity and incomplete maturation of intraplaque microvessels in human atherosclerosis might explain the leucocyte and red blood cell extravasation. Ultimately the interaction between angiogenesis and inflammation may not only result in leaky and fragile intraplaque microvessels prone to collapse, but also in mechanical destabilization of the plaque due to increased matrix degradation and reduced tissue coherence. Nevertheless, functional evidence of increased microvessel permeability and its causal relation to intraplaque hemorrhage is not available.

\section{Anti-atherogenic properties of angiogenesis?}

Angiogenesis is generally assumed to be pro-atherogenic, however some suggest that it may also execute athero-protective effects. ${ }^{59,109}$ The increased microvessel density associated with progression of atherosclerosis may represent a physiological reaction to an increased consumption of energy-substrates and/or oxygen in the atherosclerotic arterial wall. In addition, microvessels may not only transport solutes into, but also away from the arterial wall. Increased angiogenesis may be aimed at removal of entrapped lipid or other metabolites associated with plaque growth and metabolism. This hypothesis is supported by the pro-atherosclertoic effects of the obstruction or removal of adventitial microvessels in dogs, ${ }^{117,}{ }^{118}$ hypercholesterolemic rabbits, ${ }^{119}$ and -pigs. ${ }^{120}$ Microvessels are also assumed to allow HDL-mediated reversed lipid transport, substantiated by a porcine study in which statin-therapy was followed by increased HDL and microvessel regression. However, simvastatin did not induce 
LDL-lowering or a decreased plaque size..$^{103}$ Therefore, these studies do not allow a conclusion about regression of angiogenesis as a cause or consequence of plaque regression.

In normal tissue, the lymphatics are involved in the drainage of interstitial fluid, macromolecules, and leukocytes, and proliferate in response to inflammation. Theoretically, properly functioning lymphatic microvessels could be anti-atherogenic by transporting plasma and inflammatory cells out of the plaque. Inadequate or absent lymph angiogenesis may enhance the effects of leaky microvessels in atherosclerosis. ${ }^{121}{ }^{122}$ Lymphatic EC may be recognized by expression of the lymphatic markers podoplanin, prox-1, VEGFR3 or LYVE-1. Neither the expression of podoplanin nor Prox-1 expression has been studied in human atherosclerosis. VEGFR3 was not detected in atherosclerosis of the aorta, coronary or iliac artery, ${ }^{123}$ neither did an electron microscopy study identify lymphatic vessels in the plaque. ${ }^{124}$ LYVE- $1^{+}$vessels represented $0.3 \%$ of intraplaque microvessels and $5 \%$ of adventitial microvessels in the coronary artery. ${ }^{125}$ However, since then studies have shown that this marker lacked lymphatic specificity. ${ }^{126,}{ }^{127}$ Thus, lymphatics may be rare or absent in atherosclerotic lesions, and (dys)functionality has not been demonstrated yet.

Stimuli for angiogenesis in atherosclerosis

The molecular mechanisms generally regulating angiogenesis are becoming increasingly clear, especially from tumor research, and may involve oxygendependent and -independent stimuli and signaling cascades. The expression of pro-angiogenic growth factors (i.e. VEGF, FGF, PlGF) has been shown in several cell types involved in atherogenesis, such as monocyte/macrophages, mast cells, smooth muscle cells, T-cells, and platelets by cell culture and immunohistological studies. ${ }^{76,125,128-133}$ Despite the expression of these growth factors and the association with angiogenesis and plaque progression, the molecular pathways stimulating expression of these pro-angiogenic factors in atherosclerotic lesions have not been revealed.

\section{Hypoxia}

Hypoxia is regarded as an important stimulus of (patho)physiological angiogenesis. Normal oxygen tension in tissue ranges from $20-100 \mathrm{mmHg}$ to below $10 \mathrm{mmHg}$ in normal liver and kidney. ${ }^{134,135}$ In vitro effects of physiological low oxygen levels, hypoxia, are usually observed between $10 \mathrm{mmHg}(1 \%$ or 14 $\left.\mu \mathrm{M} \mathrm{O}_{2}\right)$ and $1.6 \mathrm{mmHg}\left(0.2 \% \mathrm{O}_{2}\right){ }^{136}$ as opposed to non- physiological anoxia $(0 \%$ $\mathrm{O}_{2}$ ). Hypoxia occurs when oxygen supply is decreased and/or demand is 
increased. ${ }^{136-139}$ In the atherosclerotic lesion hypoxia could be due to intimal thickening and/or an increased metabolic demand of inflammatory cells. Hypoxia of the vessel wall could be expected to arise when the intimal thickness exceeds the maximal oxygen diffusion distance of $\sim 100-250 \mu \mathrm{m} .{ }^{140}$ Hypoxia may also develop from the high oxygen demand of metabolically active inflammatory cells, ${ }^{141}$ such as macrophage foam cells.

The first observation providing indirect evidence for the presence of hypoxia in human atherosclerosis is based on the association of arterial wall thickness and occurrence of adventitial microvessels. Adventitial microvessels nourish the arterial wall, but are only present when the media exceeds a thickness of $0.5 \mathrm{~mm}$ or consists of more than 28 (fibromuscular) lamellae. ${ }^{142}$ Accordingly, the presence of intraplaque microvessels was only observed beyond a critical intimal thickness of 350-500 $\mu \mathrm{m}$, depending on the artery. ${ }^{142}$ Obstruction of adventitial microvessels caused a SMC-rich neointima, which was associated with medial hypoxia. ${ }^{120}$ Mild hypoxia has been shown to promote SMC proliferation and migration in vitro directly, ${ }^{143,}{ }^{144}$ although contradicting results are also reported. ${ }^{145}$

A second indirect indication of hypoxia results from the observed switch from aerobic to anaerobic glucose metabolism (glucose- and ATP depletion, and lactate accumulation) in more severe, thick $(>500 \mu \mathrm{m})$ rabbit $^{146,147}$ and human plaques. ${ }^{148}$ Yet, not all studies could demonstrate this switch. ${ }^{149,150}$

Additionally, inflamed tissue, exactly matching the phenotype of an atherosclerotic plaque, is virtually always chronically hypoxic, because of its high metabolic demand. ${ }^{151}$ Moreover, several processes and proteins involved in atherosclerosis may also result from hypoxia. The in vitro effects of hypoxia on cellular function are not only pro-angiogenic, but also pro-inflammatory, and anti-fibrotic, and could thus be pro-atherogenic. Specifically, hypoxia in macrophages increased cytokine production, ${ }^{141,151}$ low density lipoprotein (LDL) oxidation, ${ }^{152}$ lipid loading, ${ }^{153,154}$ reactive oxygen species formation, ${ }^{155}$ and MMP secretion. ${ }^{156}$ Also, hypoxia reduced macrophage migration in vitro, ${ }^{157}$ potentially stimulating macrophage accumulation in and preventing macrophage egression from the plaque. All these potential effects of hypoxia on atherosclerosis would promote the development of macrophage foam cells, a lipid and/or necrotic core, matrix degradation, and hence atherosclerotic progression. ${ }^{62}$

As of yet, arterial wall oxygen levels have only been measured directly in animal models, i.e. in the normal femoral artery of dogs, ${ }^{158}$ and in hypercholesterolemic ${ }^{159}$ or balloon-injured rabbit models. ${ }^{149}$ Hypoxia was demonstrated using oxygen micro-electrodes or a fluorescently-labeled hypoxia marker. Micro-electrodes showed a minimal $\mathrm{pO}_{2}$ of $50 \mathrm{mmHg}$ in normal aortic arteries, while hypoxia (min. $\mathrm{pO}_{2}=0-15 \mathrm{mmHg}$ ) was shown in the mid-regions of 
the atherosclerotic aortic arch and femoral artery, at 300 and $150 \mu \mathrm{m}$ from the lumen respectively. ${ }^{149,159}$ Oxygen levels raised to normal $\mathrm{pO}_{2}(50 \mathrm{mmHg})$ at $300 \mu \mathrm{m}$ from the aortic adventitia and $100 \mu \mathrm{m}$ from the aortic lumen ${ }^{159}$ Oxygen levels were lower in thicker, more advanced aortic lesions, despite a similar oxygen uptake. ${ }^{159}$ Disadvantages of the oxygen micro-electrode approach are the (micro-)disruption of the plaque and/or adventitial microvessels by cathode insertion or handling, and exogenous exposure to a buffer with nonphysiological oxygen levels. This may lead to inaccurate measurement of true, in vivo arterial hypoxia levels. A more recent, state-of-the-art approach by Bjornheden et al, used the in vivo injection of the hypoxia marker 7-(4'-(2nitroimidazol-1-yl)-butyl)-theophylline, and subsequent immunofluorescence visualization in cryo-sections of the rabbit aorta. This approach also detected hypoxia in 200-300 $\mu \mathrm{m}$ deep regions of the rabbit plaque, specifically in macrophage-rich areas. ${ }^{160}$ The depth at which hypoxia is detected in rabbits is in line with accepted values for the maximal oxygen diffusion distance of $~ 100-250$ $\mu \mathrm{m}$. Until now, arterial wall hypoxia has not been demonstrated in mice. However, mouse hypoxia might only be present in a minority of plaques considering the maximal intima-media thickness of normal and severely atherosclerotic mouse arteries, i.e. between 60 and $500 \mu \mathrm{m}$ in the collared carotid artery, 100 and $600 \mu \mathrm{m}$ in the aortic arch, and 70 and $400 \mu \mathrm{m}$ in the aortic root respectively (Table 1.3), and the scarce presence of microvessels. Thus, species size and consequently arterial and plaque size may be an important factor determining the presence of hypoxia and/or angiogenesis (Table 1.3).

The functional effect of hypoxia on atherosclerosis has been studied in animals in vivo by modulating exogenous oxygen concentrations in research focused on the relation between atherosclerosis and sleep apnea or high-altitude. An hypoxic milieu aggravated atherosclerosis compared to normoxic exposure of balloon-injured rabbits, ${ }_{16}^{161} \mathrm{C} 57 / \mathrm{Bl}-\mathrm{ApoE}^{-1},{ }^{162}$ and even in atherosclerosisresistant $\mathrm{C} 57 / \mathrm{Bl}^{163}$ mice all subjected to a high fat/cholesterol diet. Results were similar in all models, despite the variability in duration $(3,6$, or 12 weeks) and oxygen exposure (chronic or intermittent; $5 \%$ or $10 \%$ ). A change in arterial wall or plaque oxygen is likely (but not demonstrated) as arterial blood oxygen pressure was decreased. Hypoxic exposure was associated with increased dyslipidemia. Experiments in mice, but not in the rabbit, were also associated with increased lipid peroxidation or ROS formation. It is likely that effects of exogenous hypoxia were also influenced by other systemic changes, such as right ventricular hypertrophy, pulmonary hypertension, ${ }^{164,165}$ increased permeability of the blood-brain barrier, ${ }^{166}$ and increased activation of the sympathetic nervous system. ${ }^{167,168}$ These studies have shown a pro-atherogenic 


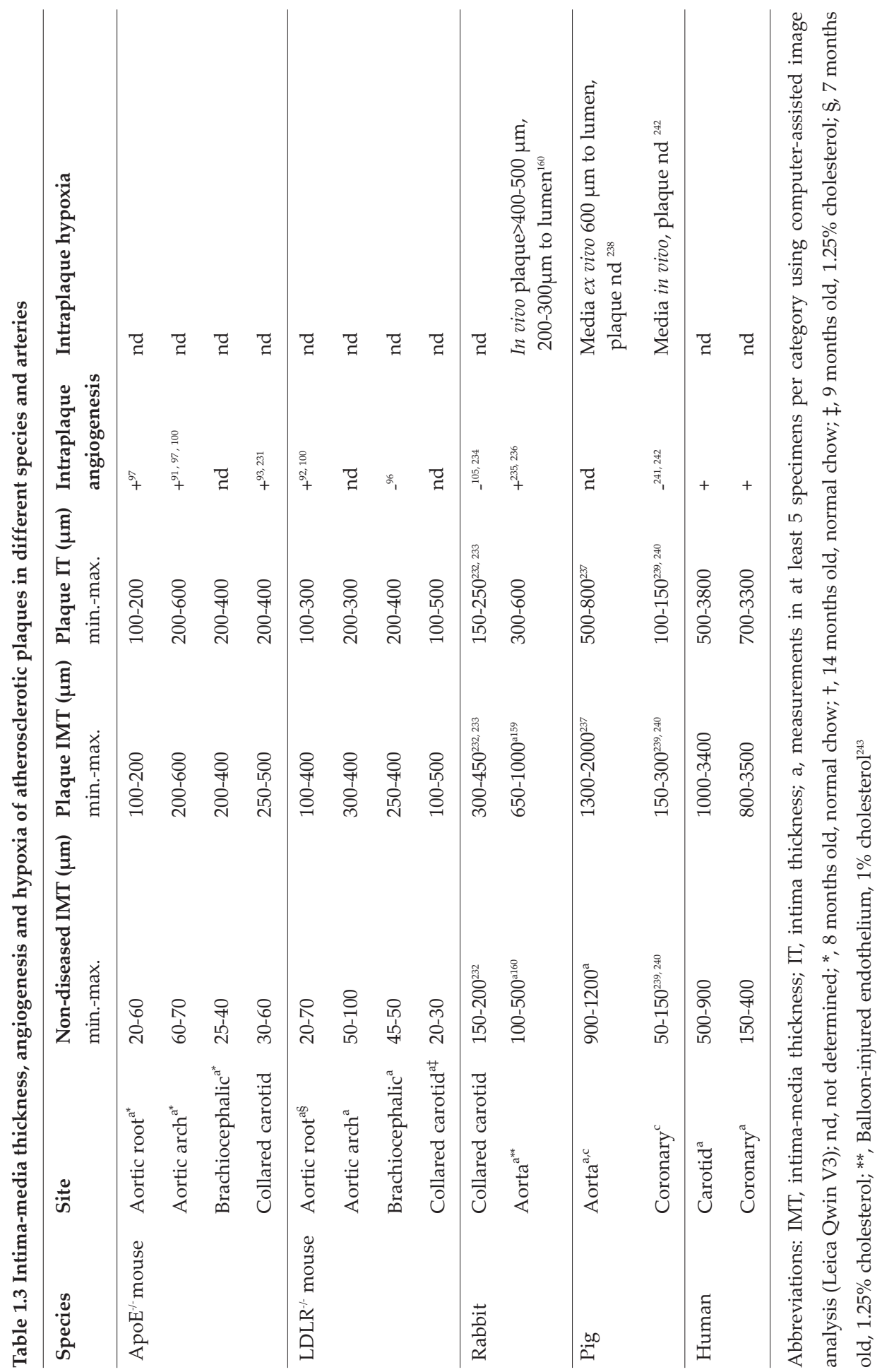


effect of hypoxia on the initiation of atherosclerosis, while it remains unclear whether the effect is mediated by decreased plaque oxygen, and whether hypoxia would also aggravate existing lesions.

In human atherosclerosis, hypoxia has not yet been demonstrated, although a mathematical model did predict arterial wall hypoxia in regions with low wall shear stress. ${ }^{169}$ As rodent atherosclerotic plaque morphology does not equal that in humans, ${ }^{99,170,171}$ the results from rabbit hypoxia can not simply be extrapolated to humans. Therefore, a clinical study elucidating the presence of hypoxia in human atherosclerosis is warranted.

\section{Hypoxic regulation of HIF expression}

Cell survival in hypoxic circumstances involves a general shut-down of energyconsuming transcription and translation, with one major exception: the hypoxiainducible transcription factor (HIF) pathway. HIF is widely recognized as the key mediator of the hypoxic response to promote cell survival. ${ }^{136-139,172}$ Hypoxia-driven transcription is regulated by an $\alpha \beta$ heterodimer protein consisting of two subunits: a HIF1 $\beta$ subunit, which is constitutively expressed, and a HIF $1 \alpha$ or $2 \alpha$ subunit, whose protein levels are highly regulated by the oxygen concentration. HIF $3 \alpha$ is a third $\alpha$-subunit, appearing to provide a negative feedback signal. In the presence of oxygen, HIF $1 \alpha$ and $2 \alpha$ proteins are generated, but immediately degraded by the ubiquitin/proteasome pathway (Figure 1.5). In hypoxia, HIF $\alpha$ subunit degradation is inhibited, the protein translocates to the nucleus, and dimerizes with HIF1 $\beta$. HIF then binds to a hypoxia responsive element (HRE) in the promoter or enhancer regions of hypoxia responsive genes ${ }^{137}$ involved in angiogenesis, glucose metabolism, and cell proliferation/survival, and include VEGF, glucose transporters (GLUT) 1 and 3, hexokinases (HK) 1 and 2, and carbonic anhydrase (CA) IX..$^{136-139}$

Molecular regulation of $\mathrm{HIF} \alpha$ subunits is achieved by controlling mRNA expression, protein stability, and HIF transcriptional activity. The HIF $\alpha$ gene is constitutively expressed mainly through the SP1 transcription factor, and translation is maintained in hypoxia by the presence of an internal ribosome entry site (IRES) in the 5' untranslated region. In normoxia, HIF protein degradation is regulated by three prolyl hydroxylase (PHD) enzymes, which hydroxylate HIF on proline residues (pro402 and pro564) only in the presence of oxygen, iron, ascorbate, and 2-oxoglutarate. Each of the hydroxylated sites may interact with the von Hippel-Lindau (VHL)-E3 ubiquitin ligase complex resulting in ultra rapid proteasomal degradation (Figure 1.5)..$^{136-139}$

Additional regulation of HIF protein stabilization is achieved by lysine acetylation, and HIF activity is influenced by another oxygen-dependent 


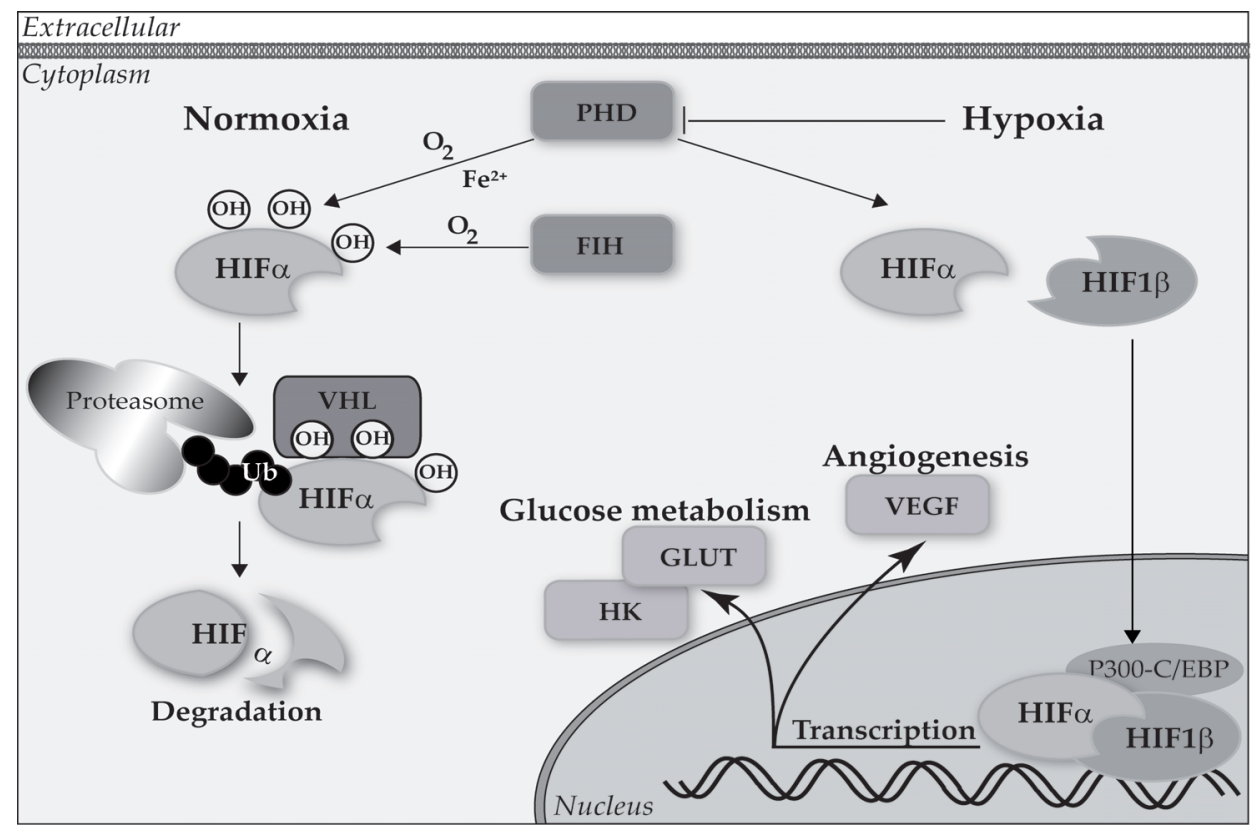

Figure 1.5 Hypoxic regulation of HIF

$\mathrm{HIF} \alpha$ protein is hydroxylated by PHD enzymes when oxygen is present, targeting HIF $\alpha$ for ubiquitinproteasomal degradation. Hydroxylation is inhibited in the absence of oxygen. HIF $\alpha$ protein is not degraded, but dimerizes with HIF1 $\beta$, translocates to the nucleus, and induces transcription of HIFtarget genes, such as VEGF, GLUT, and HK. Abbreviations are indicated in the main text.

hydroxylation on asparagine residue Asn803 by factor inhibiting HIF (FIH). The latter inhibits binding of HIF to its transcriptional co-activators p300-C/EBP. HIFinduced transcriptional activity is also reliant on phosphorylation by the $\mathrm{p} 42 / \mathrm{p} 44$ mitogen activated protein kinase (MAPK)-pathway, which stimulates HIF nuclear accumulation. This process is indirectly dictated by oxygen, as it depends on HIF protein availability (Figure 1.5). ${ }^{138,173}$

\section{PHD enzymes, the true oxygen sensors}

The PHD enzymes are currently regarded as the true oxygen sensors because their enzymatic activity critically depends on the presence of oxygen. The three isoforms, PHD1, PHD2, and PHD3 vary in their tissue distribution, activity, substrate specificity, and regulation, but nonetheless seem to exert nonredundant functions. PHD2 protein is most ubiquitously expressed, and is the major HIF repressor in normoxia, although PHD1 mRNA is more ubiquitous than PHD2 mRNA. ${ }^{174}$ Reports vary in the relative abundance of PHD1 and PHD3. ${ }^{175,}{ }^{176}$ The PHD isoforms also show different specificity for the proline 
residues and HIF $\alpha$ subunits. The two proline substrates are differentially hydroxylated: all PHDs can hydroxylate HIF1 $\alpha$ pro564, but only PHD1 and PHD2 also hydroxylate pro402. In addition, PHD2 is the main HIF1 $\alpha$ hydroxylase, whereas PHD3 provides negative feedback in hypoxia, preferentially on HIF2 $\alpha .{ }^{176}$ PHD1 has been shown to repress HIF $2 \alpha$ both in normoxic and hypoxic skeletal muscle, while hardly affecting HIF1 $\alpha .{ }^{177}$

In hypoxia, PHD enzymes are regulated by HIF-dependent and independent signals (ROS, estrogens). ${ }^{176}$ Hypoxia in vitro induced strong expression of PHD3, moderate expression of PHD2, but PHD1 protein levels were unchanged. ${ }^{174}$ PHD2 exerts a dominant role in vascular development, which is confirmed by the lethality of the PHD2 ${ }^{--}$mouse and viability of PHD1 ${ }^{-1}$ and $\mathrm{PHD}^{-}$mice. ${ }^{177,178}$ Also, only PHD2 conditional knockout mice showed hyperactive angiogenesis associated with HIF1 $\alpha$ expression. ${ }^{179}$ In contrast, PHD1 is of major functional importance in the oxidative metabolism of normal skeletal muscle. ${ }^{177}$ Although functional performance of normal PHD1 ${ }^{-1}$ skeletal muscle was impaired, PHD1- induced tolerance of skeletal muscle to hypoxia. Notably, the protective effect $\mathrm{PHD}^{-}$was angiogenesis-independent. $\mathrm{PHD}^{-}$skeletal muscle was more efficient in generating energy and preventing ROS formation in hypoxia, which was mediated by increased HIF2 $\alpha$ expression. ${ }^{177}$ In normoxia, the biological importance of PHD1 is also exemplified by HIF-independent repression of nuclear factor (NF)- $\mathrm{kB}$ activity by PHD1. ${ }^{180}$ In summary, the activity of the different PHDs seems to be non-redundant, and depends on the specific (cellular) micro-environment. ${ }^{174}$

\section{Hypoxia-independent regulation of HIF expression}

Although it is widely accepted that HIF $\alpha$ expression is mainly regulated by hypoxia at the protein level, transcriptional, and translational regulation of HIF has also been suggested upon non-hypoxic stimuli such as such as inflammation, ${ }^{181}$ vasoactive ${ }^{182}$ and thrombotic factors, ${ }^{183}$ and ROS. ${ }^{184}$

Presently, (at least) 5 intracellular signaling pathways are involved in the normoxic regulation of HIF-driven transcription, generally without a change in protein degradation (Figure 1.6). Nevertheless, changes in HIF transcription, translation, and activity appear sufficient to enhance its transcriptional effects. Two pathways increase HIF transcription, diaglycerol-sensitive protein kinase $C$ (DAG-PKC) and $\mathrm{NF \kappa B}$, through activation of their respective functional sites in the HIF promoter (SP1 and NFkB respectively). ${ }^{182,185} \mathrm{HIF}$ in turn may upregulate NFkB expression. ${ }^{186}$ HIF translation is increased by activation of the phospatidylinositol-3-kinase (PI3K)/AKT pathway, converging with mammalian target of rapamycin (mTOR). ${ }^{173,182}$ As mentioned earlier, stimulation of $\mathrm{p} 42 / \mathrm{p} 44$ 
MAPK pathway will increase HIF activity. A cell type specific decrease in HIF degradation is achieved by a ROS-induced change in available $\mathrm{Fe}^{2+}$, reducing PHD enzymatic activity. ${ }^{184}$ ROS will also result in increased HIF expression via stimulation of (PI3K)-AKT-mTOR and NFkB after numerous oxidative stress initiating stimuli, such as angiotensin II (ANGII), ${ }^{182,187}$ lipopolysacharide (LPS), ${ }^{181}$ OxLDL, ${ }^{188}$ and thrombin. ${ }^{183}$ Most of these initiators signal through toll-like receptors (TLR), and affect more than one signaling cascade to increase HIFdriven transcription, illustrating the complexity of hypoxia-independent signaling.

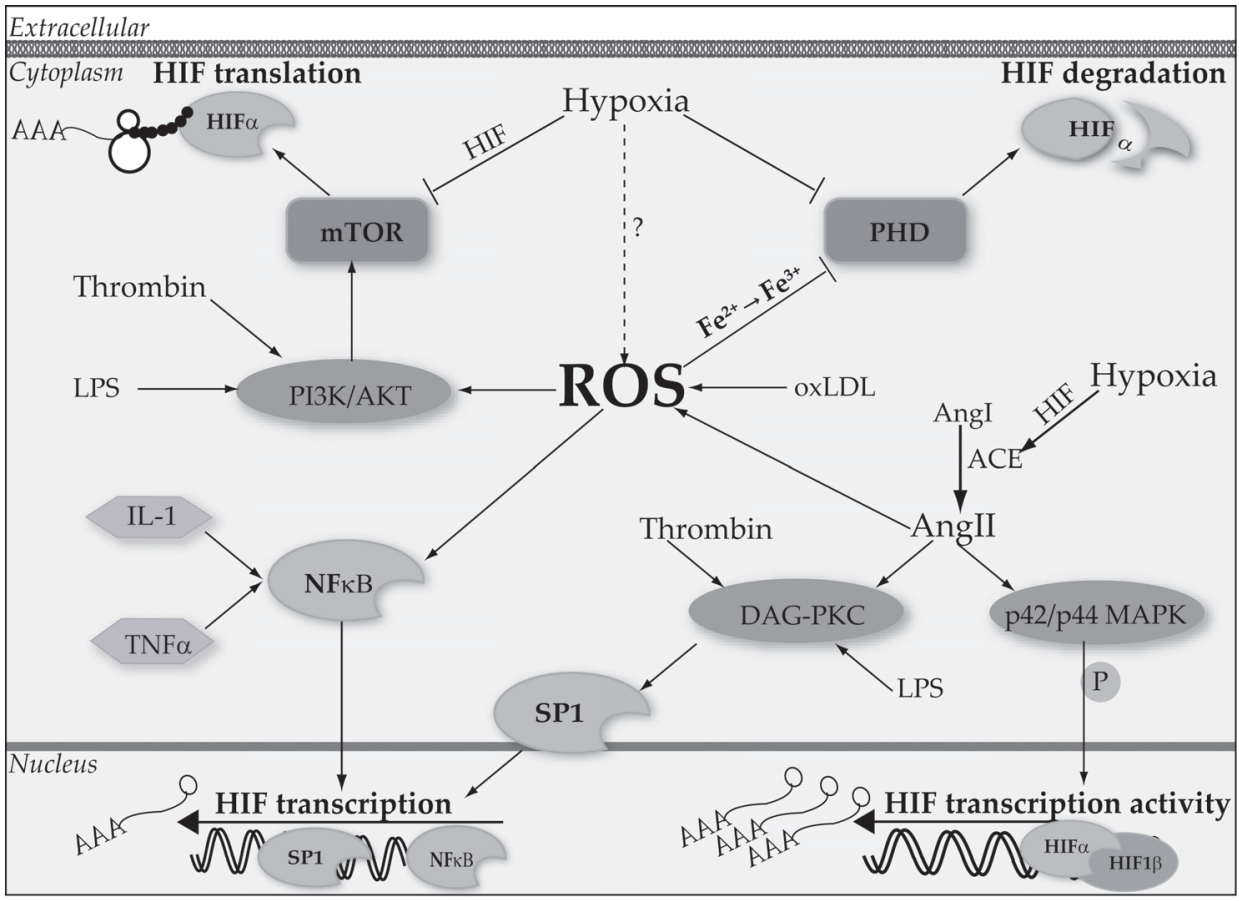

Figure 1.6 Molecular pathways regulating HIF expression

Oxygen-independent HIF $\alpha$ expression is regulated at four levels: transcription, mRNA translation, protein degradation, and transcriptional activity, whereas oxygen-dependent HIF $\alpha$ expression is mainly regulated by protein degradation. Hypoxia plus an oxygen-independent stimulus exerts both positive and negative feedback on HIF $\alpha$ translation and activity respectively. The common oxygenindependent stimulus is ROS, but also include thrombin, LPS, oxLDL, AngII, IL-1, and TNF $\alpha$. Five major signal transduction pathways execute HIF $\alpha$ regulation: NFKB, PI3/AKT-mTOR, DAG-PKC, and p42/p44 MAPK. Abbreviations are indicated in the main text. 
An elegant study showed the important functional effect of ROS on angiogenesis in a ligation model of atherosclerosis using SMC-targeted overexpression of p22phox. This component of $\mathrm{NAD}(\mathrm{P}) \mathrm{H}$ oxidase lead to increased levels of $\mathrm{H}_{2} \mathrm{O}_{2}$, VEGF, and HIF, and increased atherosclerotic plaque size and neointimal angiogenesis. Antioxidant treatment reversed atherosclerosis and associated angiogenesis. ${ }^{189}$ Although the ligation model does not closely resemble human atherosclerosis, it supports a role for SMC-derived ROS in expression of HIF, VEGF, and angiogenesis in vivo.

Inflammatory agents such as lipopolysacharide (LPS) and antimicrobial agents also stimulate angiogenesis. Although endogenous antimicrobial agents have not been implicated in angiogenesis in human atherosclerosis, an exogenous porcine agent, proline-rich (PR)-39 resulted in accelerated angiogenesis in vitro and in vivo. ${ }^{190}$ PR-39 inhibits the ubiquitin-proteasomedependent degradation of HIF1 $\alpha$ protein.

Hypoxia-independent stimuli may also be present in a low oxygen environment, and hypoxia-induced HIF may then provide both positive and negative feedback to the hypoxia-independent stimuli. Hypoxia was shown to increase HIF-mediated expression of angiotensin converting enzyme (ACE)-1, resulting in increased ANGII levels, and thus HIF levels via the aforementioned cascades. ${ }^{187}$ In another study, hypoxia directly reduced mTOR activity, and thus HIF levels. ${ }^{136}$ In addition, several reports describe increased (mitochondrial) ROS production in hypoxic cells, which can act synergistically via the described pathways to increase HIF-driven transcription. ${ }^{19-194}$ However, this remains a controversial subject as most results of mitochondria-rich contractile cells are contrasted by other cell types showing similar or decreased mitochondrial ROS. In addition, ROS measurements are often imprecise, and results may vary with different oxygen levels..$^{195}$

These non-hypoxic stimuli and their downstream signaling cascades, as well as their complex interaction with hypoxia, show that regulation of HIF expression is achieved at several levels of control. HIF expression seems to be dependent on cell type as well as micro-environment, but ultimately leads to HIF-driven transcription maximizing the cellular capacity to cope with metabolic stress.

\section{Biological effects of HIF}

Since its original discovery as the transcription factor for erythropoietin, HIF has been held accountable for the expression of at least 60 genes. HIF-responsive genes are not only involved in restoring tissue oxygen by angiogenesis or enhancing oxygen transport capacity, but also in anaerobic glucose metabolism, 
apoptosis, lipid metabolism, and immune responses..$^{137,151,172,196,197}$

In addition to the presence of angiogenic regions in atherosclerosis, evidence for a biologic effect of HIF on atherosclerosis is derived from the expression of several of its down-stream genes, i.e. VEGF, ${ }^{11,} 198$ endothelin-1,196, 199 matrixmetalloproteinase-2, ${ }^{200,201}$ and plasminogen-activator inhibitor- $1^{202,}{ }^{203}$ in atherosclerotic lesions, and their association with progression. Also, an overwhelming number of studies show a vital role for HIF in immune responses, suggesting in vivo relevance for inflammation in atherosclerosis. HIF1 $\alpha$ appeared essential for several aspects of myeloid cell-mediated innate immune responses, i.e., invasion, motility, and phagocytosis, which all rely heavily on HIFdependent glycolytic energy production. ${ }^{151,204}$ HIF1 $\alpha$ also mediated monocyte adhesion through integrin gene expression. ${ }^{205}$ In addition, HIF is involved in adaptive immunity as shown by its regulation of T-cell receptor signal transduction. ${ }^{206}$ Recently, HIF1 $\alpha$ has also been found involved in recruitment and differentiation of progenitor cells, responsible for angiogenesis in murine hindlimb ischemia ${ }^{207}$ and a rat myocardial infarction model. ${ }^{208}$ Moreover, hypoxia and HIF1 $\alpha$ are involved in dendritic cell maturation and subsequent lymphocyte proliferation. ${ }^{209}$ These findings could be of considerable interest for atherosclerosis, wherein both progenitor cells and dendritic cells are currently investigated.

Finally, two recent animal studies showed HIF1 $\alpha$ expression in the medial layers of the arterial wall of hypertensive rats ${ }^{210}$ and hypercholesterolemic pigs. ${ }^{104}$ The increase in adventitial microvessels by either experimental stimuli, hypertension, and hypercholesterolemia, was associated with a parallel increase in HIF1 $\alpha$ and VEGF expression. Two recent studies reported the expression of $\mathrm{HIF} \alpha$ in human coronary and carotid atherosclerosis. ${ }^{211,212} \mathrm{HIF} \alpha$ was expressed in macrophages and smooth muscle cells in carotid atherosclerosis, bordering the necrotic core. Expression co-localized with VEGF immunoreactivity, CD68 ${ }^{+}$ macrophages, and was associated with inflammation and angiogenesis. ${ }^{212} \mathrm{HIF} \alpha$ expression in coronary atherosclerosis was similar between symptomatic and asymptomatic patients, possibly because the lesions showed a similar plaque morphology. ${ }^{211}$ Although results from animal and human atherosclerosis support a pro-atherogenic role for HIF in atherosclerosis, a potential association with plaque hypoxia and a functional role for HIF in the development of atherosclerosis have not been demonstrated experimentally.

\section{HIF-independent regulation of angiogenesis}

Although gene expression studies using $\mathrm{HIF}^{-/-}$cells indicate that the majority of hypoxia-induced expression is mediated via HIF, at least one important pro- 
angiogenic factor is HIF independent: interleukin-8 (IL-8). IL-8 expression is induced by hypoxia in human alveolar macrophages, ${ }^{213}$ and in HIF1 $\alpha^{-1-}$ colon cancer cells. ${ }^{214}$ Human coronary atherosclerosis expressed IL-8 mRNA and protein. The angiogenic potential of IL-8 in atherosclerosis was demonstrated by implantation of protein lysates of these plaques in the rat cornea, a model for angiogenesis. Plaque lysates induced corneal angiogenesis, which was reversed by IL-8 inhibition. ${ }^{215}$ Also, the IL-8 receptor CXCR2 is functionally involved in atherosclerosis. Leukocyte specific CXCR2 knock-out attenuated atherosclerosis in LDLR $^{-r}$ mice. ${ }^{216}$ Growth-related oncogene (GRO)-alpha is another ligand of this receptor implicated in atherosclerosis ${ }^{216,217}$ but no proof is available verifying HIF-(in)dependence. Similarly, the relative contribution of hypoxia and/or HIF to several other angiogenic growth-factors expressed in human atherosclerosis, such as thymidine phosphorylase, ${ }^{109} \mathrm{bFGF}^{76}$ and pigment epithelium-derived factor, ${ }^{218}$ remains unclear.

Another important example of HIF-independent, but hypoxia-dependent signaling is derived from VEGF regulation. VEGF-mediated angiogenesis in hypoxia is not only induced via HIF-driven transcription, but also via RNAbinding proteins that increase VEGF mRNA stability. ${ }^{133,138}$ Also, VEGF mRNA translation is preserved in hypoxia by an internal ribosome entry site (IRES) site. ${ }^{138,219}$ Additionally, hypoxia increased expression of VEGF receptors to augment VEGF signaling..$^{138}$

Hypoxia- ánd HIF-independent regulation of angiogenesis may be regulated by protease-induced matrix release of pro- and anti-angiogenic growth factors, glucose deprivation, and the anti-angiogenic effects of p53, ${ }^{220,221}$ but angiogenic regulation is mostly mediated by ROS and inflammation. The angiogenic effect of ROS is achieved by signaling through the earlier mentioned pathways, PI3KAKT-mTOR and NFkB. Cellular sources of oxidative stress in atherosclerosis include for instance dysfunctional endothelial cells due to hypertension and dyslipidemia, and activated macrophages or smooth muscle cells resulting from scavenged oxLDL. ${ }^{222,223}$ The regulation of angiogenesis by inflammation involves several cytokines, and a central role is played by Toll-like receptors and NFkB signalling. ${ }^{20,}{ }^{221}$ Reports link IL-6, IL-1beta, and TNF $\alpha$ to increased VEGF expression, via ERK/MAPK, JAK/STAT3, and/or NFkB signaling cascades. NFkB is thought to be both pro- and anti-atherogenic and is not only involved in inflammation, but also in cell survival and proliferation. ${ }^{224}$ Although its is very likely that NFkB signaling is involved in angiogenesis of atherosclerotic plaques, functional evidence is unavailable. 


\section{Hypothesis and outline thesis}

Angiogenesis is a key feature of atherosclerotic lesions, and is associated with plaque growth- and instability. However, insight into the mechanisms regulating the formation of intraplaque microvessels in atherosclerotic disease is lacking, as well as knowledge of the (ultra) structural microvessel morphology possibly explaining microvascular leakage. The main hypothesis of this thesis was that hypoxia-induced, HIF-driven transcription stimulates the progression and angiogenic infestation of atherosclerosis. In addition, we hypothesized that the (ultra) structural abnormal morphology of intraplaque microvessels is associated with plaque progression.

Microarray analysis was an intended part of this thesis to determine differential gene expression between different stages of atherosclerosis. Inclusion of atherosclerotic tissues from more than one source (autopsy and surgery) is often indispensable to study the full atherogenic spectrum. However, post-mortem changes are undeniably associated with cellular ischemia/hypoxia, pointing towards the hypothesis of a differential regulation of hypoxia-driven pathways between autopsy and surgery. Thus, as part of an ongoing project to dissect aspects influencing gene expression in human atherosclerosis research, in chapter 2 the gene expression profiles of advanced atherosclerotic plaques from autopsy and surgery were compared. Microarray and bioinformatics results were validated on mRNA and protein expression levels using quantitative realtime PCR (qRT-PCR) and immunohistochemistry.

In chapter 3, the hypothesis that hypoxia and HIF are present in human carotid atherosclerosis, and associated with progression and/or angiogenesis of human atherosclerosis was investigated. To demonstrate hypoxia, the in vivo hypoxia marker pimonidazole was administered to symptomatic carotid endarterectomy patients, and subsequent immunohistochemistry was used to detect pimonidazole. Also, mRNA and protein expression of HIF1 $\alpha$, HIF2 $\alpha$, HIFresponsive genes (VEGF, GLUT1, GLUT3, HK1, and HK2), and microvessel density were determined in non-diseased and atherosclerotic carotid arteries using microarray, qRT-PCR, in situ hybridization, and immunohistochemistry.

In chapter 4 the functional importance of hypoxia and HIF-driven transcription in murine atherosclerosis was addressed. First, the detection of hypoxia in murine atherosclerosis using the hypoxia marker pimonidazole was described, while the effect of hypoxia on atherogenesis was investigated by exposing mice with advanced plaques four weeks to $10 \% \mathrm{O}_{2}$. The function of macrophage-specific HIF1 $\alpha$ and its regulator prolyl hydroxylase (PHD1) on the development of diet- and/or collar-induced atherosclerosis was studied using 
bone marrow transplantations into LDLR ${ }^{-}$mice. Also, the effect of hypoxia on mRNA and protein expression of HIF $1 \alpha, \mathrm{HIF} 2 \alpha$, and HIF-responsive genes was investigated in bone marrow-derived macrophages in vitro using western blot and qRT-PCR.

The second aim of this thesis was to phenotypically characterize the formed microvessels in human atherosclerosis, as there is very limited data on the structural integrity of microvessels in human atherosclerosis. We hypothesized that microvessels were immature, with (incomplete) basement membrane and/or pericyte coverage, and showed an ultra structurally abnormal endothelial integrity. The hypothesis was tested in chapter 5 using quantitative immunohistochemistry and electron microscopy in a large series of human coronary arteries with different stages of atherosclerosis.

Finally, in chapter 6 the experimental results, described in this thesis, and their possible implications are discussed, and future directions are given. 


\section{Chapter 1}

\section{References}

1. Hansson GK. Inflammation, atherosclerosis, and coronary artery disease. N Engl J Med. 2005;352:1685-1695.

2. Libby P, Geng YJ, Aikawa M, et al. Macrophages and atherosclerotic plaque stability. Curr Opin Lipidol. 1996;7:330-335.

3. Lusis AJ. Atherosclerosis. Nature. 2000;407:233-241.

4. Virmani R, Kolodgie FD, Burke AP, et al. Lessons from sudden coronary death: A comprehensive morphological classification scheme for atherosclerotic lesions. Arterioscler Thromb Vasc Biol. 2000;20:1262-1275.

5. Robertson AK, Hansson GK. T cells in atherogenesis: For better or for worse? Arterioscler Thromb Vasc Biol. 2006;26:2421-2432.

6. Mallat Z, Ait-Oufella H, Tedgui A. Regulatory t-cell immunity in atherosclerosis. Trends Cardiovasc Med. 2007;17:113-118.

7. Virmani R, Burke AP, Farb A, et al. Pathology of the unstable plaque. Prog Cardiovasc Dis. 2002;44:349-356.

8. Furuhashi M, Tuncman G, Gorgun CZ, et al. Treatment of diabetes and atherosclerosis by inhibiting fatty-acid-binding protein ap2. Nature. 2007;447:959-965.

9. Han S, Liang CP, DeVries-Seimon T, et al. Macrophage insulin receptor deficiency increases er stress-induced apoptosis and necrotic core formation in advanced atherosclerotic lesions. Cell Metab. 2006;3:257-266.

10. Heinonen SE, Leppanen $\mathrm{P}$, Kholova I, et al. Increased atherosclerotic lesion calcification in a novel mouse model combining insulin resistance, hyperglycemia, and hypercholesterolemia. Circ Res. 2007;101:1058-1067.

11. Renard CB, Kramer F, Johansson F, et al. Diabetes and diabetes-associated lipid abnormalities have distinct effects on initiation and progression of atherosclerotic lesions. J Clin Invest. 2004;114:659-668.

12. Adams LD, Geary RL, Li J, et al. Expression profiling identifies smooth muscle cell diversity within human intima and plaque fibrous cap: Loss of rgs5 distinguishes the cap. Arterioscler Thromb Vasc Biol. 2006;26:319-325.

13. Faber BC, Cleutjens KB, Niessen RL, et al. Identification of genes potentially involved in rupture of human atherosclerotic plaques. Circ Res. 2001;89:547-554.

14. King JY, Ferrara R, Tabibiazar R, et al. Pathway analysis of coronary atherosclerosis. Physiol Genomics. 2005;23:103-118.

15. Seo D, Wang T, Dressman H, et al. Gene expression phenotypes of atherosclerosis. Arterioscler Thromb Vasc Biol. 2004;24:1922-1927.

16. Donners MM, Verluyten MJ, Bouwman FG, et al. Proteomic analysis of differential protein expression in human atherosclerotic plaque progression. J Pathol. 2005;206:39-45.

17. Martinet W, Schrijvers DM, De Meyer GR, et al. Western array analysis of human atherosclerotic 
plaques: Downregulation of apoptosis-linked gene 2. Cardiovasc Res. 2003;60:259-267.

18. Robert R, Jacobin-Valat MJ, Daret D, et al. Identification of human scfvs targeting atherosclerotic lesions: Selection by single round in vivo phage display. J Biol Chem. 2006;281:40135-40143.

19. Mallat Z, Gojova A, Brun V, et al. Induction of a regulatory t cell type 1 response reduces the development of atherosclerosis in apolipoprotein e-knockout mice. Circulation. 2003;108:12321237.

20. Libby P, Shi GP. Mast cells as mediators and modulators of atherogenesis. Circulation. 2007;115:2471-2473.

21. Kovanen PT. Mast cells: Multipotent local effector cells in atherothrombosis. Immunol Rev. 2007;217:105-122.

22. Bot I, de Jager SC, Zernecke A, et al. Perivascular mast cells promote atherogenesis and induce plaque destabilization in apolipoprotein e-deficient mice. Circulation. 2007;115:2516-2525.

23. Sun J, Sukhova GK, Wolters PJ, et al. Mast cells promote atherosclerosis by releasing proinflammatory cytokines. Nat Med. 2007;13:719-724.

24. Gordon S. Macrophage heterogeneity and tissue lipids. J Clin Invest. 2007;117:89-93.

25. Van Ginderachter JA, Movahedi K, Hassanzadeh Ghassabeh G, et al. Classical and alternative activation of mononuclear phagocytes: Picking the best of both worlds for tumor promotion. Immunobiology. 2006;211:487-501.

26. Mantovani A, Sica A, Locati M. Macrophage polarization comes of age. Immunity. 2005;23:344-346.

27. Lumeng $\mathrm{CN}$, Bodzin JL, Saltiel AR. Obesity induces a phenotypic switch in adipose tissue macrophage polarization. J Clin Invest. 2007;117:175-184.

28. Swirski FK, Libby P, Aikawa E, et al. Ly-6chi monocytes dominate hypercholesterolemiaassociated monocytosis and give rise to macrophages in atheromata. J Clin Invest. 2007;117:195-205.

29. Huo Y, Schober A, Forlow SB, et al. Circulating activated platelets exacerbate atherosclerosis in mice deficient in apolipoprotein e. Nat Med. 2003;9:61-67.

30. Croce K, Libby P. Intertwining of thrombosis and inflammation in atherosclerosis. Curr Opin Hematol. 2007;14:55-61.

31. May AE, Langer $H$, Seizer $P$, et al. Platelet-leukocyte interactions in inflammation and atherothrombosis. Semin Thromb Hemost. 2007;33:123-127.

32. von Hundelshausen P, Weber C. Platelets as immune cells: Bridging inflammation and cardiovascular disease. Circ Res. 2007;100:27-40.

33. Morel O, Toti F, Hugel B, et al. Procoagulant microparticles: Disrupting the vascular homeostasis equation? Arterioscler Thromb Vasc Biol. 2006;26:2594-2604.

34. Boulanger CM, Amabile N, Tedgui A. Circulating microparticles: A potential prognostic marker for atherosclerotic vascular disease. Hypertension. 2006;48:180-186.

35. Werner N, Nickenig G. Clinical and therapeutical implications of epc biology in atherosclerosis. J Cell Mol Med. 2006;10:318-332.

36. Dimmeler S, Burchfield J, Zeiher AM. Cell-based therapy of myocardial infarction. Arterioscler Thromb Vasc Biol. 2008;28:208-216. 
37. Assmus B, Schachinger V, Teupe C, et al. Transplantation of progenitor cells and regeneration enhancement in acute myocardial infarction (topcare-ami). Circulation. 2002;106:3009-3017.

38. Strauer BE, Brehm M, Zeus T, et al. Repair of infarcted myocardium by autologous intracoronary mononuclear bone marrow cell transplantation in humans. Circulation. 2002;106:1913-1918.

39. Meyer GP, Wollert KC, Lotz J, et al. Intracoronary bone marrow cell transfer after myocardial infarction: Eighteen months' follow-up data from the randomized, controlled boost (bone marrow transfer to enhance st-elevation infarct regeneration) trial. Circulation. 2006;113:1287-1294.

40. Rauscher FM, Goldschmidt-Clermont PJ, Davis BH, et al. Aging, progenitor cell exhaustion, and atherosclerosis. Circulation. 2003;108:457-463.

41. Hibbert B, Chen YX, O'Brien ER. C-kit-immunopositive vascular progenitor cells populate human coronary in-stent restenosis but not primary atherosclerotic lesions. Am J Physiol Heart Circ Physiol. 2004;287:H518-524.

42. Friedrich EB, Walenta K, Scharlau J, et al. Cd34-/cd133+/vegfr-2+ endothelial progenitor cell subpopulation with potent vasoregenerative capacities. Circ Res. 2006;98:e20-25.

43. Tabas I. Consequences and therapeutic implications of macrophage apoptosis in atherosclerosis: The importance of lesion stage and phagocytic efficiency. Arterioscler Thromb Vasc Biol. 2005;25:2255-2264.

44. Stoneman V, Braganza D, Figg N, et al. Monocyte/macrophage suppression in cd11b diphtheria toxin receptor transgenic mice differentially affects atherogenesis and established plaques. Circ Res. 2007;100:884-893.

45. Schrijvers DM, De Meyer GR, Herman AG, et al. Phagocytosis in atherosclerosis: Molecular mechanisms and implications for plaque progression and stability. Cardiovasc Res. 2007;73:470-480.

46. Liu J, Thewke DP, Su YR, et al. Reduced macrophage apoptosis is associated with accelerated atherosclerosis in low-density lipoprotein receptor-null mice. Arterioscler Thromb Vasc Biol. 2005;25:174-179.

47. von der Thusen JH, van Vlijmen BJ, Hoeben RC, et al. Induction of atherosclerotic plaque rupture in apolipoprotein e-/- mice after adenovirus-mediated transfer of p53. Circulation. 2002;105:2064-2070.

48. Carmeliet P. Angiogenesis in life, disease and medicine. Nature. 2005;438:932-936.

49. Carmeliet P, Jain RK. Angiogenesis in cancer and other diseases. Nature. 2000;407:249-257.

50. Jain RK. Molecular regulation of vessel maturation. Nat Med. 2003;9:685-693.

51. Chen J, Somanath PR, Razorenova O, et al. Akt1 regulates pathological angiogenesis, vascular maturation and permeability in vivo. Nat Med. 2005;11:1188-1196.

52. Gerhardt H, Betsholtz C. Endothelial-pericyte interactions in angiogenesis. Cell Tissue Res. 2003;314:15-23.

53. Armulik A, Abramsson A, Betsholtz C. Endothelial/pericyte interactions. Circ Res. 2005;97:512-523.

54. Stupack DG, Cheresh DA. Apoptotic cues from the extracellular matrix: Regulators of angiogenesis. Oncogene. 2003;22:9022-9029. 
55. Paterson JC. Vascularization and hemorrhage of the intima of arteriosclerotic coronary arteries. Arch path. 1936;22:313-324.

56. Schwartz SM. Cellular proliferation in atherosclerosis and hypertension. Proc Soc Exp Biol Med. 1983;173:1-13.

57. Grundy SM. Atherosclerosis: Pathology, pathogenesis, and role of risk factors. Dis Mon. 1983;29:1-58.

58. Langheinrich AC, Kampschulte M, Buch T, et al. Vasa vasorum and atherosclerosis - quid novi? Thromb Haemost. 2007;97:873-879.

59. Herrmann J, Lerman LO, Mukhopadhyay D, et al. Angiogenesis in atherogenesis. Arterioscler Thromb Vasc Biol. 2006;26:1948-1957.

60. Moos MP, John N, Grabner R, et al. The lamina adventitia is the major site of immune cell accumulation in standard chow-fed apolipoprotein e-deficient mice. Arterioscler Thromb Vasc Biol. 2005;25:2386-2391.

61. Kumamoto M, Nakashima $Y$, Sueishi K. Intimal neovascularization in human coronary atherosclerosis: Its origin and pathophysiological significance. Hum Pathol. 1995;26:450-456.

62. Virmani R, Kolodgie FD, Burke AP, et al. Atherosclerotic plaque progression and vulnerability to rupture angiogenesis as a source of intraplaque hemorrhage. Arterioscler Thromb Vasc Biol. 2005;25:2054-2061.

63. Ribatti D. The involvement of endothelial progenitor cells in tumor angiogenesis. J Cell Mol Med. 2004;8:294-300.

64. Hu Y, Davison F, Zhang Z, et al. Endothelial replacement and angiogenesis in arteriosclerotic lesions of allografts are contributed by circulating progenitor cells. Circulation. 2003;108:3122-3127.

65. Jeziorska M, Woolley DE. Neovascularization in early atherosclerotic lesions of human carotid arteries: Its potential contribution to plaque development. Hum Pathol. 1999;30:919-925.

66. Zhang Y, Cliff WJ, Schoefl GI, et al. Immunohistochemical study of intimal microvessels in coronary atherosclerosis. Am J Pathol. 1993;143:164-172.

67. Jeziorska M, Woolley DE. Local neovascularization and cellular composition within vulnerable regions of atherosclerotic plaques of human carotid arteries. J Pathol. 1999;188:189-196.

68. Yilmaz A, Lipfert B, Cicha I, et al. Accumulation of immune cells and high expression of chemokines/chemokine receptors in the upstream shoulder of atherosclerotic carotid plaques. Exp Mol Pathol. 2007;82:245-255.

69. Depre C, Havaux X, Wijns W. Neovascularization in human coronary atherosclerotic lesions. Cathet Cardiovasc Diagn. 1996;39:215-220.

70. Milei J, Parodi JC, Alonso GF, et al. Carotid rupture and intraplaque hemorrhage: Immunophenotype and role of cells involved. Am Heart J. 1998;136:1096-1105.

71. Fryer JA, Myers PC, Appleberg M. Carotid intraplaque hemorrhage: The significance of neovascularity. J Vasc Surg. 1987;6:341-349.

72. McCarthy MJ, Loftus IM, Thompson MM, et al. Angiogenesis and the atherosclerotic carotid plaque: An association between symptomatology and plaque morphology. J Vasc Surg. 
1999;30:261-268.

73. Moreno PR, Falk E, Palacios IF, et al. Macrophage infiltration in acute coronary syndromes. Implications for plaque rupture. Circulation. 1994;90:775-778.

74. Schmeisser A, Marquetant R, Illmer T, et al. The expression of macrophage migration inhibitory factor 1alpha (mif 1alpha) in human atherosclerotic plaques is induced by different proatherogenic stimuli and associated with plaque instability. Atherosclerosis. 2005;178:83-94.

75. Kaartinen M, Penttila A, Kovanen PT. Mast cells accompany microvessels in human coronary atheromas: Implications for intimal neovascularization and hemorrhage. Atherosclerosis. 1996;123:123-131.

76. Lappalainen $\mathrm{H}$, Laine $\mathrm{P}$, Pentikainen MO, et al. Mast cells in neovascularized human coronary plaques store and secrete basic fibroblast growth factor, a potent angiogenic mediator. Arterioscler Thromb Vasc Biol. 2004;24:1880-1885.

77. de Boer OJ, van der Wal AC, Teeling P, et al. Leucocyte recruitment in rupture prone regions of lipid-rich plaques: A prominent role for neovascularization? Cardiovasc Res. 1999;41:443-449.

78. Kockx MM, Cromheeke KM, Knaapen MW, et al. Phagocytosis and macrophage activation associated with hemorrhagic microvessels in human atherosclerosis. Arterioscler Thromb Vasc Biol. 2003;23:440-446.

79. Kolodgie FD, Gold HK, Burke AP, et al. Intraplaque hemorrhage and progression of coronary atheroma. N Engl J Med. 2003;349:2316-2325.

80. Doyle B, Caplice N. Plaque neovascularization and antiangiogenic therapy for atherosclerosis. J Am Coll Cardiol. 2007;49:2073-2080.

81. Kolodgie FD, Narula J, Yuan C, et al. Elimination of neoangiogenesis for plaque stabilization: Is there a role for local drug therapy? J Am Coll Cardiol. 2007;49:2093-2101.

82. Khurana R, Simons M, Martin JF, et al. Role of angiogenesis in cardiovascular disease: A critical appraisal. Circulation. 2005;112:1813-1824.

83. Moreno PR, Purushothaman KR, Sirol M, et al. Neovascularization in human atherosclerosis. Circulation. 2006;113:2245-2252.

84. Stary HC. Natural history and histological classification of atherosclerotic lesions: An update. Arterioscler Thromb Vasc Biol. 2000;20:1177-1178.

85. Cliff WJ, Heathcote CR, Moss NS, et al. The coronary arteries in cases of cardiac and noncardiac sudden death. Am J Pathol. 1988;132:319-329.

86. Davies MJ. A macro and micro view of coronary vascular insult in ischemic heart disease. Circulation. 1990;82:II38-46.

87. Kamat BR, Galli SJ, Barger AC, et al. Neovascularization and coronary atherosclerotic plaque: Cinematographic localization and quantitative histologic analysis. Hum Pathol. 1987;18:1036-1042.

88. Moreno PR, Purushothaman KR, Fuster V, et al. Plaque neovascularization is increased in ruptured atherosclerotic lesions of human aorta: Implications for plaque vulnerability. Circulation. 2004;110:2032-2038.

89. Mofidi R, Crotty TB, McCarthy P, et al. Association between plaque instability, angiogenesis and 
symptomatic carotid occlusive disease. Br J Surg. 2001;88:945-950.

90. Alpern-Elran H, Morog N, Robert F, et al. Angiogenic activity of the atherosclerotic carotid artery plaque. J Neurosurg. 1989;70:942-945.

91. Celletti FL, Waugh JM, Amabile PG, et al. Vascular endothelial growth factor enhances atherosclerotic plaque progression. Nat Med. 2001;7:425-429.

92. Leppanen P, Koota S, Kholova I, et al. Gene transfers of vascular endothelial growth factor-a, vascular endothelial growth factor-b, vascular endothelial growth factor-c, and vascular endothelial growth factor-d have no effects on atherosclerosis in hypercholesterolemic lowdensity lipoprotein-receptor/apolipoprotein b48-deficient mice. Circulation. 2005;112:1347-1352.

93. Lucerna M, Zernecke A, de Nooijer R, et al. Vascular endothelial growth factor-a induces plaque expansion in apoe knock-out mice by promoting de novo leukocyte recruitment. Blood. 2007;109:122-129.

94. Luttun A, Tjwa M, Carmeliet P. Placental growth factor (plgf) and its receptor flt-1 (vegfr-1): Novel therapeutic targets for angiogenic disorders. Ann N Y Acad Sci. 2002;979:80-93.

95. Petrovan RJ, Kaplan CD, Reisfeld RA, et al. DNA vaccination against vegf receptor 2 reduces atherosclerosis in ldl receptor-deficient mice. Arterioscler Thromb Vasc Biol. 2007;27:1095-1100.

96. Hauer AD, van Puijvelde GH, Peterse N, et al. Vaccination against vegfr2 attenuates initiation and progression of atherosclerosis. Arterioscler Thromb Vasc Biol. 2007;27:2050-2057.

97. Moulton KS, Heller E, Konerding MA, et al. Angiogenesis inhibitors endostatin or tnp-470 reduce intimal neovascularization and plaque growth in apolipoprotein e-deficient mice. Circulation. 1999;99:1726-1732.

98. Moulton KS, Vakili K, Zurakowski D, et al. Inhibition of plaque neovascularization reduces macrophage accumulation and progression of advanced atherosclerosis. Proc Natl Acad Sci U S A. 2003;100:4736-4741.

99. Schwartz SM, Galis ZS, Rosenfeld ME, et al. Plaque rupture in humans and mice. Arterioscler Thromb Vasc Biol. 2007;27:705-713.

100. Langheinrich AC, Michniewicz A, Sedding DG, et al. Correlation of vasa vasorum neovascularization and plaque progression in aortas of apolipoprotein $\mathrm{e}^{(-)}$)/low-density lipoprotein $(-)$ double knockout mice. Arterioscler Thromb Vasc Biol. 2006;26:347-352.

101. Galili O, Herrmann J, Woodrum J, et al. Adventitial vasa vasorum heterogeneity among different vascular beds. J Vasc Surg. 2004;40:529-535.

102. Heistad DD, Armstrong ML, Marcus ML. Hyperemia of the aortic wall in atherosclerotic monkeys. Circ Res. 1981;48:669-675.

103. Wilson SH, Herrmann J, Lerman LO, et al. Simvastatin preserves the structure of coronary adventitial vasa vasorum in experimental hypercholesterolemia independent of lipid lowering. Circulation. 2002;105:415-418.

104. Herrmann J, Lerman LO, Rodriguez-Porcel M, et al. Coronary vasa vasorum neovascularization precedes epicardial endothelial dysfunction in experimental hypercholesterolemia. Cardiovasc Res. 2001;51:762-766. 
105. Khurana R, Zhuang Z, Bhardwaj S, et al. Angiogenesis-dependent and independent phases of intimal hyperplasia. Circulation. 2004;110:2436-2443.

106. Tziakas DN, Kaski JC, Chalikias GK, et al. Total cholesterol content of erythrocyte membranes is increased in patients with acute coronary syndrome: A new marker of clinical instability? J Am Coll Cardiol. 2007;49:2081-2089.

107. Takaya N, Yuan C, Chu B, et al. Presence of intraplaque hemorrhage stimulates progression of carotid atherosclerotic plaques: A high-resolution magnetic resonance imaging study. Circulation. 2005;111:2768-2775.

108. O'Brien KD, McDonald TO, Chait A, et al. Neovascular expression of e-selectin, intercellular adhesion molecule-1, and vascular cell adhesion molecule-1 in human atherosclerosis and their relation to intimal leukocyte content. Circulation. 1996;93:672-682.

109. Boyle JJ, Wilson B, Bicknell R, et al. Expression of angiogenic factor thymidine phosphorylase and angiogenesis in human atherosclerosis. J Pathol. 2000;192:234-242.

110. Hoshiga M, Alpers CE, Smith LL, et al. Alpha-v beta-3 integrin expression in normal and atherosclerotic artery. Circ Res. 1995;77:1129-1135.

111. Virmani R, Narula J, Farb A. When neoangiogenesis ricochets. Am Heart J. 1998;136:937-939.

112. Dejana E. Endothelial cell-cell junctions: Happy together. Nat Rev Mol Cell Biol. 2004;5:261-270.

113. Hashizume H, Baluk P, Morikawa S, et al. Openings between defective endothelial cells explain tumor vessel leakiness. Am J Pathol. 2000;156:1363-1380.

114. McDonald DM, Thurston G, Baluk P. Endothelial gaps as sites for plasma leakage in inflammation. Microcirculation. 1999;6:7-22.

115. Baluk P, Hirata A, Thurston G, et al. Endothelial gaps: Time course of formation and closure in inflamed venules of rats. Am J Physiol. 1997;272:L155-170.

116. Ezaki T, Baluk P, Thurston G, et al. Time course of endothelial cell proliferation and microvascular remodeling in chronic inflammation. Am J Pathol. 2001;158:2043-2055.

117. Nakata Y, Kamiya K. An experimental study on the vascular lesions caused by obstruction of the vaso vasorum. Ii. Special consideration on the deposition of fat into vascular wall. Jpn Circ J. 1970;34:1029-1034.

118. Nakata Y, Shionoya S, Matsubara J, et al. An experimental study on the vascular lesions caused by disturbance of the vasa vasorum (ii). Jpn Circ J. 1972;36:945-951.

119. Booth RF, Martin JF, Honey AC, et al. Rapid development of atherosclerotic lesions in the rabbit carotid artery induced by perivascular manipulation. Atherosclerosis. 1989;76:257-268.

120. Barker SG, Talbert A, Cottam S, et al. Arterial intimal hyperplasia after occlusion of the adventitial vasa vasorum in the pig. Arterioscler Thromb. 1993;13:70-77.

121. Tammela T, Petrova TV, Alitalo K. Molecular lymphangiogenesis: New players. Trends Cell Biol. 2005;15:434-441.

122. Alitalo K, Tammela T, Petrova TV. Lymphangiogenesis in development and human disease. Nature. 2005;438:946-953.

123. Rutanen J, Leppanen P, Tuomisto TT, et al. Vascular endothelial growth factor-d expression in 
human atherosclerotic lesions. Cardiovasc Res. 2003;59:971-979.

124. Eliska O, Eliskova M, Miller AJ. The absence of lymphatics in normal and atherosclerotic coronary arteries in man: A morphologic study. Lymphology. 2006;39:76-83.

125. Nakano T, Nakashima Y, Yonemitsu $Y$, et al. Angiogenesis and lymphangiogenesis and expression of lymphangiogenic factors in the atherosclerotic intima of human coronary arteries. Hum Pathol. 2005;36:330-340.

126. Mouta Carreira C, Nasser SM, di Tomaso E, et al. Lyve-1 is not restricted to the lymph vessels: Expression in normal liver blood sinusoids and down-regulation in human liver cancer and cirrhosis. Cancer Res. 2001;61:8079-8084.

127. Schledzewski K, Falkowski M, Moldenhauer G, et al. Lymphatic endothelium-specific hyaluronan receptor lyve- 1 is expressed by stabilin- $1^{+}, \mathrm{f} 4 / 80^{+}, \mathrm{cd}_{11 \mathrm{~b}^{+}}$macrophages in malignant tumours and wound healing tissue in vivo and in bone marrow cultures in vitro: Implications for the assessment of lymphangiogenesis. J Pathol. 2006;209:67-77.

128. Chen YX, Nakashima Y, Tanaka K, et al. Immunohistochemical expression of vascular endothelial growth factor/vascular permeability factor in atherosclerotic intimas of human coronary arteries. Arterioscler Thromb Vasc Biol. 1999;19:131-139.

129. Couffinhal T, Kearney M, Witzenbichler B, et al. Vascular endothelial growth factor/vascular permeability factor (vegf/vpf) in normal and atherosclerotic human arteries. Am J Pathol. 1997;150:1673-1685.

130. Ignatescu MC, Gharehbaghi-Schnell E, Hassan A, et al. Expression of the angiogenic protein, platelet-derived endothelial cell growth factor, in coronary atherosclerotic plaques: In vivo correlation of lesional microvessel density and constrictive vascular remodeling. Arterioscler Thromb Vasc Biol. 1999;19:2340-2347.

131. Inoue M, Itoh $\mathrm{H}$, Ueda M, et al. Vascular endothelial growth factor (vegf) expression in human coronary atherosclerotic lesions: Possible pathophysiological significance of vegf in progression of atherosclerosis. Circulation. 1998;98:2108-2116.

132. Angelo LS, Kurzrock R. Vascular endothelial growth factor and its relationship to inflammatory mediators. Clin Cancer Res. 2007;13:2825-2830.

133. Salomonsson L, Pettersson S, Englund MC, et al. Post-transcriptional regulation of vegf expression by oxidised ldl in human macrophages. Eur J Clin Invest. 2002;32:767-774.

134. Koch CJ, Lord EM, Shapiro IM, et al. Imaging hypoxia and blood flow in normal tissues. Adv Exp Med Biol. 1997;428:585-593.

135. Adam MF, Gabalski EC, Bloch DA, et al. Tissue oxygen distribution in head and neck cancer patients. Head Neck. 1999;21:146-153.

136. Pouyssegur J, Dayan F, Mazure NM. Hypoxia signalling in cancer and approaches to enforce tumour regression. Nature. 2006;441:437-443.

137. Semenza GL. Targeting hif-1 for cancer therapy. Nat Rev Cancer. 2003;3:721-732.

138. Pugh CW, Ratcliffe PJ. Regulation of angiogenesis by hypoxia: Role of the hif system. Nat Med. 2003;9:677-684. 
139. Poellinger L, Johnson RS. Hif-1 and hypoxic response: The plot thickens. Curr Opin Genet Dev. 2004;14:81-85.

140. Torres Filho IP, Leunig M, Yuan F, et al. Noninvasive measurement of microvascular and interstitial oxygen profiles in a human tumor in scid mice. Proc Natl Acad Sci U S A. 1994;91:2081-2085.

141. Murdoch C, Muthana M, Lewis CE. Hypoxia regulates macrophage functions in inflammation. J Immunol. 2005;175:6257-6263.

142. Geiringer E. Intimal vascularization and atherosclerosis. J Pathol Bacteriol. 1951;63:201-211.

143. Basu Ray J, Arab S, Deng Y, et al. Oxygen regulation of arterial smooth muscle cell proliferation and survival. Am J Physiol Heart Circ Physiol. 2007.

144. Parenti A, Brogelli L, Filippi S, et al. Effect of hypoxia and endothelial loss on vascular smooth muscle cell responsiveness to vegf-a: Role of flt-1/vegf-receptor-1. Cardiovasc Res. 2002;55:201-212.

145. Morita T, Mitsialis SA, Koike H, et al. Carbon monoxide controls the proliferation of hypoxic vascular smooth muscle cells. J Biol Chem. 1997;272:32804-32809.

146. Leppanen O, Bjornheden T, Evaldsson M, et al. Atp depletion in macrophages in the core of advanced rabbit atherosclerotic plaques in vivo. Atherosclerosis. 2006.

147. Rudd JH, Warburton EA, Fryer TD, et al. Imaging atherosclerotic plaque inflammation with [18f]-fluorodeoxyglucose positron emission tomography. Circulation. 2002;105:2708-2711.

148. Cozzi PJ, Lyon RT, Davis HR, et al. Aortic wall metabolism in relation to susceptibility and resistance to experimental atherosclerosis. J Vasc Surg. 1988;7:706-714.

149. Zemplenyi T, Crawford DW, Cole MA. Adaptation to arterial wall hypoxia demonstrated in vivo with oxygen microcathodes. Atherosclerosis. 1989;76:173-179.

150. Zemplenyi T, Tidwell DF, Fronek K. Aortic enzymes and lactate in high altitude-raised and cholesterol-fed rabbits. Atherosclerosis. 1984;52:233-242.

151. Cramer T, Yamanishi Y, Clausen BE, et al. Hif-1alpha is essential for myeloid cell-mediated inflammation. Cell. 2003;112:645-657.

152. Rydberg EK, Krettek A, Ullstrom C, et al. Hypoxia increases ldl oxidation and expression of 15lipoxygenase-2 in human macrophages. Arterioscler Thromb Vasc Biol. 2004;24:2040-2045.

153. Lattimore JD, Wilcox I, Nakhla S, et al. Repetitive hypoxia increases lipid loading in human macrophages-a potentially atherogenic effect. Atherosclerosis. 2005;179:255-259.

154. Bostrom P, Magnusson B, Svensson PA, et al. Hypoxia converts human macrophages into triglyceride-loaded foam cells. Arterioscler Thromb Vasc Biol. 2006;26:1871-1876.

155. Lobanova EM, Tahanovich AD. Hydrogen peroxide metabolism in alveolar macrophages after exposure to hypoxia and heat. Physiol Res. 2006;55:569-575.

156. Burke B, Giannoudis A, Corke KP, et al. Hypoxia-induced gene expression in human macrophages: Implications for ischemic tissues and hypoxia-regulated gene therapy. Am J Pathol. 2003;163:1233-1243.

157. Negus RP, Turner L, Burke F, et al. Hypoxia down-regulates mcp-1 expression: Implications for macrophage distribution in tumors. J Leukoc Biol. 1998;63:758-765. 
158. Crawford DW, Blankenhorn DH. Arterial wall oxygenation, oxyradicals, and atherosclerosis. Atherosclerosis. 1991;89:97-108.

159. Jurrus ER, Weiss HS. In vitro tissue oxygen tensions in the rabbit aortic arch. Atherosclerosis. 1977;28:223-232.

160. Bjornheden T, Levin M, Evaldsson M, et al. Evidence of hypoxic areas within the arterial wall in vivo. Arterioscler Thromb Vasc Biol. 1999;19:870-876.

161. Lau AK, Chaufour X, McLachlan C, et al. Intimal thickening after arterial balloon injury is increased by intermittent repetitive hypoxia, but intermittent repetitive hyperoxia is not protective. Atherosclerosis. 2005.

162. Nakano D, Hayashi T, Tazawa N, et al. Chronic hypoxia accelerates the progression of atherosclerosis in apolipoprotein e-knockout mice. Hypertens Res. 2005;28:837-845.

163. Savransky V, Nanayakkara A, Li J, et al. Chronic intermittent hypoxia induces atherosclerosis. Am J Respir Crit Care Med. 2007;175:1290-1297.

164. van Suylen RJ, Aartsen WM, Smits JF, et al. Dissociation of pulmonary vascular remodeling and right ventricular pressure in tissue angiotensin-converting enzyme-deficient mice under conditions of chronic alveolar hypoxia. Am J Respir Crit Care Med. 2001;163:1241-1245.

165. van Suylen RJ, Smits JF, Daemen MJ. Pulmonary artery remodeling differs in hypoxia- and monocrotaline-induced pulmonary hypertension. Am J Respir Crit Care Med. 1998;157:1423-1428.

166. Synnestvedt K, Furuta GT, Comerford KM, et al. Ecto-5'-nucleotidase (cd73) regulation by hypoxia-inducible factor-1 mediates permeability changes in intestinal epithelia. J Clin Invest. 2002;110:993-1002.

167. Hansen J, Sander M. Sympathetic neural overactivity in healthy humans after prolonged exposure to hypobaric hypoxia. J Physiol. 2003;546:921-929.

168. Mazzeo RS, Bender PR, Brooks GA, et al. Arterial catecholamine responses during exercise with acute and chronic high-altitude exposure. Am J Physiol. 1991;261:E419-424.

169. Sun N, Wood NB, Hughes AD, et al. Fluid-wall modelling of mass transfer in an axisymmetric stenosis: Effects of shear-dependent transport properties. Ann Biomed Eng. 2006;34:1119-1128.

170. Cullen P, Baetta R, Bellosta S, et al. Rupture of the atherosclerotic plaque: Does a good animal model exist? Arterioscler Thromb Vasc Biol. 2003;23:535-542.

171. Westrick RJ, Winn ME, Eitzman DT. Murine models of vascular thrombosis. Arterioscler Thromb Vasc Biol. 2007.

172. Greijer AE, van der Groep P, Kemming D, et al. Up-regulation of gene expression by hypoxia is mediated predominantly by hypoxia-inducible factor 1 (hif-1). J Pathol. 2005;206:291-304.

173. Dery MA, Michaud MD, Richard DE. Hypoxia-inducible factor 1: Regulation by hypoxic and non-hypoxic activators. Int J Biochem Cell Biol. 2005;37:535-540.

174. Appelhoff RJ, Tian YM, Raval RR, et al. Differential function of the prolyl hydroxylases phd1, phd2, and phd3 in the regulation of hypoxia-inducible factor. J Biol Chem. 2004;279:38458-38465.

175. Soilleux EJ, Turley H, Tian YM, et al. Use of novel monoclonal antibodies to determine the expression and distribution of the hypoxia regulatory factors phd-1, phd-2, phd-3 and fih in 


\section{Chapter 1}

normal and neoplastic human tissues. Histopathology. 2005;47:602-610.

176. Berra E, Ginouves A, Pouyssegur J. The hypoxia-inducible-factor hydroxylases bring fresh air into hypoxia signalling. EMBO Rep. 2006;7:41-45.

177. Aragones J, Schneider M, Van Geyte K, et al. Deficiency or inhibition of oxygen sensor phd1 induces hypoxia tolerance by reprogramming basal metabolism. Nat Genet. 2008.

178. Takeda K, Ho VC, Takeda H, et al. Placental but not heart defects are associated with elevated hypoxia-inducible factor alpha levels in mice lacking prolyl hydroxylase domain protein 2 . Mol Cell Biol. 2006;26:8336-8346.

179. Takeda K, Cowan A, Fong GH. Essential role for prolyl hydroxylase domain protein 2 in oxygen homeostasis of the adult vascular system. Circulation. 2007.

180. Cummins EP, Berra E, Comerford KM, et al. Prolyl hydroxylase-1 negatively regulates ikappab kinase-beta, giving insight into hypoxia-induced nfkappab activity. Proc Natl Acad Sci U S A. 2006;103:18154-18159.

181. Blouin CC, Page EL, Soucy GM, et al. Hypoxic gene activation by lipopolysaccharide in macrophages: Implication of hypoxia-inducible factor 1alpha. Blood. 2004;103:1124-1130.

182. Page EL, Robitaille GA, Pouyssegur J, et al. Induction of hypoxia-inducible factor-1alpha by transcriptional and translational mechanisms. J Biol Chem. 2002;277:48403-48409.

183. Gorlach A, Diebold I, Schini-Kerth VB, et al. Thrombin activates the hypoxia-inducible factor-1 signaling pathway in vascular smooth muscle cells: Role of the p22(phox)-containing nadph oxidase. Circ Res. 2001;89:47-54.

184. Gerald D, Berra E, Frapart YM, et al. Jund reduces tumor angiogenesis by protecting cells from oxidative stress. Cell. 2004;118:781-794.

185. Bonello S, Zahringer C, BelAiba RS, et al. Reactive oxygen species activate the hif-1alpha promoter via a functional nfkappab site. Arterioscler Thromb Vasc Biol. 2007;27:755-761.

186. Jung YJ, Isaacs JS, Lee S, et al. Il-1beta-mediated up-regulation of hif-1alpha via an nfkappab/cox-2 pathway identifies hif-1 as a critical link between inflammation and oncogenesis. Faseb J. 2003;17:2115-2117.

187. Krick S, Hanze J, Eul B, et al. Hypoxia-driven proliferation of human pulmonary artery fibroblasts: Cross-talk between hif-1alpha and an autocrine angiotensin system. Faseb J. 2005;19:857-859.

188. Shatrov VA, Sumbayev VV, Zhou J, et al. Oxidized low-density lipoprotein (oxldl) triggers hypoxia-inducible factor-1alpha (hif-1alpha) accumulation via redox-dependent mechanisms. Blood. 2003;101:4847-4849.

189. Khatri JJ, Johnson C, Magid R, et al. Vascular oxidant stress enhances progression and angiogenesis of experimental atheroma. Circulation. 2004;109:520-525.

190. Li J, Post M, Volk R, et al. Pr39, a peptide regulator of angiogenesis. Nat Med. 2000;6:49-55.

191. Brunelle JK, Bell EL, Quesada NM, et al. Oxygen sensing requires mitochondrial ros but not oxidative phosphorylation. Cell Metab. 2005;1:409-414.

192. Guzy RD, Hoyos B, Robin E, et al. Mitochondrial complex iii is required for hypoxia-induced 
ros production and cellular oxygen sensing. Cell Metab. 2005;1:401-408.

193. Mansfield KD, Guzy RD, Pan Y, et al. Mitochondrial dysfunction resulting from loss of cytochrome c impairs cellular oxygen sensing and hypoxic hif-alpha activation. Cell Metab. 2005;1:393-399.

194. Sato H, Sato M, Kanai H, et al. Mitochondrial reactive oxygen species and c-src play a critical role in hypoxic response in vascular smooth muscle cells. Cardiovasc Res. 2005.

195. White CW. Commentary on "Hypoxia, hypoxic signaling, tissue damage, and detection of reactive oxygen species (ros)". Free Radic Biol Med. 2006;40:923-927.

196. Manalo DJ, Rowan A, Lavoie T, et al. Transcriptional regulation of vascular endothelial cell responses to hypoxia by hif-1. Blood. 2005;105:659-669.

197. Vengellur A, Woods BG, Ryan HE, et al. Gene expression profiling of the hypoxia signaling pathway in hypoxia-inducible factor 1alpha null mouse embryonic fibroblasts. Gene Expr. 2003;11:181-197.

198. Iyer NV, Kotch LE, Agani F, et al. Cellular and developmental control of o2 homeostasis by hypoxia-inducible factor 1 alpha. Genes Dev. 1998;12:149-162.

199. Ihling C, Szombathy T, Bohrmann B, et al. Coexpression of endothelin-converting enzyme-1 and endothelin-1 in different stages of human atherosclerosis. Circulation. 2001;104:864-869.

200. Pasterkamp G, Schoneveld AH, Hijnen DJ, et al. Atherosclerotic arterial remodeling and the localization of macrophages and matrix metalloproteases 1, 2 and 9 in the human coronary artery. Atherosclerosis. 2000;150:245-253.

201. Krishnamachary B, Berg-Dixon S, Kelly B, et al. Regulation of colon carcinoma cell invasion by hypoxia-inducible factor 1. Cancer Res. 2003;63:1138-1143.

202. Lijnen HR. Plasmin and matrix metalloproteinases in vascular remodeling. Thromb Haemost. 2001;86:324-333.

203. Fink T, Kazlauskas A, Poellinger L, et al. Identification of a tightly regulated hypoxia-response element in the promoter of human plasminogen activator inhibitor-1. Blood. 2002;99:2077-2083.

204. Anand RJ, Gribar SC, Li J, et al. Hypoxia causes an increase in phagocytosis by macrophages in a hif-1alpha-dependent manner. J Leukoc Biol. 2007;82:1257-1265.

205. Kong T, Eltzschig HK, Karhausen J, et al. Leukocyte adhesion during hypoxia is mediated by hif-1-dependent induction of beta2 integrin gene expression. Proc Natl Acad Sci U S A. 2004;101:10440-10445.

206. Neumann AK, Yang J, Biju MP, et al. Hypoxia inducible factor 1 alpha regulates $t$ cell receptor signal transduction. Proc Natl Acad Sci U S A. 2005;102:17071-17076.

207. Bosch-Marce M, Okuyama H, Wesley JB, et al. Effects of aging and hypoxia-inducible factor-1 activity on angiogenic cell mobilization and recovery of perfusion after limb ischemia. Circ Res. 2007;101:1310-1318.

208. Tillmanns J, Rota M, Hosoda T, et al. Formation of large coronary arteries by cardiac progenitor cells. Proc Natl Acad Sci U S A. 2008.

209. Rama I, Bruene B, Torras J, et al. Hypoxia stimulus: An adaptive immune response during 
dendritic cell maturation. Kidney Int. 2008.

210. Kuwahara F, Kai H, Tokuda K, et al. Hypoxia-inducible factor-1alpha/vascular endothelial growth factor pathway for adventitial vasa vasorum formation in hypertensive rat aorta. Hypertension. 2002;39:46-50.

211. Chen F, Eriksson P, Kimura T, et al. Apoptosis and angiogenesis are induced in the unstable coronary atherosclerotic plaque. Coron Artery Dis. 2005;16:191-197.

212. Vink A, Schoneveld AH, Lamers D, et al. Hif-1alpha expression is associated with an atheromatous inflammatory plaque phenotype and upregulated in activated macrophages. Atherosclerosis. 2007;195:e69-75.

213. Hirani N, Antonicelli F, Strieter RM, et al. The regulation of interleukin-8 by hypoxia in human macrophages--a potential role in the pathogenesis of the acute respiratory distress syndrome (ards). Mol Med. 2001;7:685-697.

214. Mizukami Y, Jo WS, Duerr EM, et al. Induction of interleukin-8 preserves the angiogenic response in hif-1alpha-deficient colon cancer cells. Nat Med. 2005;11:992-997.

215. Simonini A, Moscucci M, Muller DW, et al. Il-8 is an angiogenic factor in human coronary atherectomy tissue. Circulation. 2000;101:1519-1526.

216. Boisvert WA, Rose DM, Johnson KA, et al. Up-regulated expression of the cxcr2 ligand kc/groalpha in atherosclerotic lesions plays a central role in macrophage accumulation and lesion progression. Am J Pathol. 2006;168:1385-1395.

217. Boisvert WA, Santiago R, Curtiss LK, et al. A leukocyte homologue of the il-8 receptor cxcr-2 mediates the accumulation of macrophages in atherosclerotic lesions of ldl receptor-deficient mice. J Clin Invest. 1998;101:353-363.

218. Baba H, Yonemitsu Y, Nakano T, et al. Cytoplasmic expression and extracellular deposition of an antiangiogenic factor, pigment epithelium-derived factor, in human atherosclerotic plaques. Arterioscler Thromb Vasc Biol. 2005;25:1938-1944.

219. Du M, Roy KM, Zhong L, et al. Vegf gene expression is regulated post-transcriptionally in macrophages. Febs J. 2006;273:732-745.

220. North S, Moenner M, Bikfalvi A. Recent developments in the regulation of the angiogenic switch by cellular stress factors in tumors. Cancer Lett. 2005;218:1-14.

221. Frantz S, Vincent KA, Feron O, et al. Innate immunity and angiogenesis. Circ Res. 2005;96:15-26.

222. Griendling KK, Sorescu D, Lassegue B, et al. Modulation of protein kinase activity and gene expression by reactive oxygen species and their role in vascular physiology and pathophysiology. Arterioscler Thromb Vasc Biol. 2000;20:2175-2183.

223. Napoli C, de Nigris F, Palinski W. Multiple role of reactive oxygen species in the arterial wall. J Cell Biochem. 2001;82:674-682.

224. de Winther MP, Kanters E, Kraal G, et al. Nuclear factor kappab signaling in atherogenesis. Arterioscler Thromb Vasc Biol. 2005;25:904-914.

225. Milei J, Parodi JC, Ferreira M, et al. Atherosclerotic plaque rupture and intraplaque hemorrhage do not correlate with symptoms in carotid artery stenosis. J Vasc Surg. 2003;38:1241-1247. 
226. Fleiner M, Kummer M, Mirlacher M, et al. Arterial neovascularization and inflammation in vulnerable patients: Early and late signs of symptomatic atherosclerosis. Circulation. 2004;110:2843-2850.

227. Brandl R, Richter T, Haug K, et al. Topographic analysis of proliferative activity in carotid endarterectomy specimens by immunocytochemical detection of the cell cycle-related antigen ki-67. Circulation. 1997;96:3360-3368.

228. Dunmore BJ, McCarthy MJ, Naylor AR, et al. Carotid plaque instability and ischemic symptoms are linked to immaturity of microvessels within plaques. J Vasc Surg. 2007;45:155-159.

229. Mazzone A, Epistolato MC, Gianetti J, et al. Biological features (inflammation and neoangiogenesis) and atherosclerotic risk factors in carotid plaques and calcified aortic valve stenosis: Two different sites of the same disease? Am J Clin Pathol. 2006;126:494-502.

230. Tenaglia AN, Peters KG, Sketch MH, Jr., et al. Neovascularization in atherectomy specimens from patients with unstable angina: Implications for pathogenesis of unstable angina. Am Heart J. 1998;135:10-14.

231. de Nooijer R, Verkleij CJ, von der Thusen JH, et al. Lesional overexpression of matrix metalloproteinase-9 promotes intraplaque hemorrhage in advanced lesions but not at earlier stages of atherogenesis. Arterioscler Thromb Vasc Biol. 2006;26:340-346.

232. Matthys KE, Van Hove CE, Kockx MM, et al. Local application of ldl promotes intimal thickening in the collared carotid artery of the rabbit. Arterioscler Thromb Vasc Biol. 1997;17:2423-2429.

233. Soma MR, Natali M, Donetti E, et al. Effect of lercanidipine and its (r)-enantiomer on atherosclerotic lesions induced in hypercholesterolemic rabbits. Br J Pharmacol. 1998;125:14711476.

234. Bhardwaj S, Roy H, Heikura T, et al. Vegf-a, vegf-d and vegf-d(deltandeltac) induced intimal hyperplasia in carotid arteries. Eur J Clin Invest. 2005;35:669-676.

235. Tanaka H, Sukhova GK, Libby P. Interaction of the allogeneic state and hypercholesterolemia in arterial lesion formation in experimental cardiac allografts. Arterioscler Thromb. 1994;14:734-745.

236. Ganaha F, Kao EY, Wong H, et al. Stent-based controlled release of intravascular angiostatin to limit plaque progression and in-stent restenosis. J Vasc Interv Radiol. 2004;15:601-608.

237. Castaneda F, Ball SM, Wyffels PL, et al. Assessment of a polyester-covered nitinol stent in an atherosclerotic swine model. J Vasc Interv Radiol. 2000;11:483-491.

238. Bjornheden T, Evaldsson M, Wiklund O. A method for the assessment of hypoxia in the arterial wall, with potential application in vivo. Arterioscler Thromb Vasc Biol. 1996;16:178-185.

239. Kwon HM, Kang S, Hong BK, et al. Ultrastructural changes of the external elastic lamina in experimental hypercholesterolemic porcine coronary arteries. Yonsei Med J. 1999;40:273-282.

240. Egashira K, Tomoike H, Yamamoto Y, et al. Histamine-induced coronary spasm in regions of intimal thickening in miniature pigs: Roles of serum cholesterol and spontaneous or induced intimal thickening. Circulation. 1986;74:826-837.

241. Pels K, Deiner C, Coupland SE, et al. Effect of adventitial vegf(165) gene transfer on vascular 
thickening after coronary artery balloon injury. Cardiovasc Res. 2003;60:664-672.

242. Cheema AN, Hong T, Nili N, et al. Adventitial microvessel formation after coronary stenting and the effects of su11218, a tyrosine kinase inhibitor. J Am Coll Cardiol. 2006;47:1067-1075.

243. Lobbes MBI, Miserus RJJHM, Heeneman S, et al. Contrast-enhanced magnetic resonance vessel wall imaging in a rabbit model of atherosclerosis: Comparison of gadofosveset and gd-dtpa. Submitted. 2008. 
General introduction 57 


\section{Dead or Alive: Gene expression profiles of advanced atherosclerotic plaques from autopsy and surgery}

J.C. Sluimer*, N. Kisters*, K.B. Cleutjens, O.L. Volger, A.J. Horrevoets, L.H. van den Akker, A.P.J.J. Bijnens, M.J.A.P. Daemen

* Both authors have contributed equally

Physiol Genomics. 2007;30(3):335-41. 
$60 \quad$ Chapter 2

\section{Abstract}

Since inclusion of atherosclerotic tissues from different sources is often indispensable to study the full atherogenic spectrum, we investigated to what extent the expression profiles of advanced, stable atherosclerotic lesions obtained during autopsy and surgery are comparable. The gene expression profiles of human carotids with advanced atherosclerosis obtained at autopsy and at vascular surgery were studied using microarray analysis. Expression analysis was performed both at the single gene (Rosetta, Gene Ontology) and at the pathway level using Ingenuity and Gene Set Enrichment Analysis (GSEA). In addition, mRNA and protein expression levels were validated using qRT-PCR and immunohistochemistry on unrelated advanced carotid lesions from autopsy and surgery.

Microarray analysis indicated that the $97.2 \%$ of genes showed similar expression levels in advanced atherosclerotic lesions from autopsy and surgery. While the expression data revealed no differences in common atherosclerotic related pathways such as lipid metabolism and inflammation, the differentially expressed genes were mainly involved in basal cell metabolism and hypoxia driven pathways. QRT-PCR confirmed the differential expression of hypoxiadriven genes VEGFA (2.3 fold $\uparrow$ ), GLUT1 (2.5 fold $\uparrow)$, GLUT3 (8.3 fold $\uparrow)$, and HK1 (2.4 fold $\uparrow)$ in autopsy versus surgical specimens. Immunohistochemistry revealed that the transcriptional differences in these hypoxia-related genes were not reflected at the protein level. The gene expression profiles of advanced atherosclerotic lesions from autopsy and surgery are largely similar. However, over 500 genes, mostly involved in basal cell metabolism and hypoxia, were differentially expressed at the mRNA, but not at the protein level. 


\section{Introduction}

A myriad of expression profiling studies have been conducted over the past few years to unravel the molecular pathways involved in the initiation and progression of human atherosclerosis (reviewed in ${ }^{1}$ ). These studies compared complete atherosclerotic plaques ${ }^{2-4}$ or specific plaque regions $s^{5.7}$ to non-diseased arteries/regions. Transcript levels were analyzed to study either the early phases of atherosclerosis ${ }^{8,4,8,9}$ or the progression from stable to ruptured lesions. ${ }^{10,11}$ However, none of these studies have investigated the full spectrum of atherogenesis ranging from a non-diseased artery to early advanced stable, and advanced, ruptured lesions. In the optimal profiling study, tissue would be used that represents all these stages obtained from one type of artery and one source, i.e. autopsy or surgery, to ensure reliable and reproducible results. However, in practice there is a lack of available tissue from the same source. For instance, carotid arteries with early lesions are only available from autopsy, while ruptured carotid lesions are hardly available from this source. To overcome this obstacle, different sites ${ }^{7,11,12}$ and/or sources have been combined. ${ }^{7}$ Obviously, these approaches may introduce a high degree of variability, and may even obscure the expression profile of genes or pathways associated with atherogenesis.

Interestingly, there are no data available comparing the gene expression profiles of atherosclerotic tissue obtained at autopsy and surgery. The aim of this study was to compare gene expression profiles of atherosclerotic tissue with a stable advanced plaque phenotype from autopsy and surgery using microarray analysis. Expression analysis was performed both at single gene and pathway level to study biological functions and pathways associated with expression profiles of autopsy and surgery. In addition, results were validated on mRNA and protein expression levels using quantitative real-time PCR and immunohistochemistry.

\section{Material and methods}

\section{Tissue collection}

A total of 26 atherosclerotic carotid artery segments were obtained at autopsy ( $\mathrm{n}=11$ donors; Department of Pathology, University Hospital Maastricht) or from patients undergoing vascular surgery ( $\mathrm{n}=11$ donors; Department of Surgery, Maasland Hospital Sittard). The postmortem interval was $<24$ hours. The difference in mean age of the donors, $82 \pm 4$ years and $65 \pm 4$ years for autopsy and surgical donors respectively, was not significant $(p=0.06)$. The gender 
distribution was also not significantly different between autopsy $(72 \% \quad(n=8)$ male) and surgery $(64 \%(n=7)$ male; $p=0.65)$. Detailed patient characteristics are presented in Table 2.1. The tissue was obtained from the Maastricht Pathology Tissue Collection (MPTC), and collection, storage, and use of tissue and patient data were performed in agreement with the "Code for Proper Secondary Use of Human Tissue". Immediately after resection the atherosclerotic tissue was divided into parallel segments of $5 \mathrm{~mm}$. Snap frozen segments for RNA isolation were alternated by formalin-fixed segments for histology. The plaque stage was classified based on hematoxylin-eosin (HE) stained sections $(4 \mu \mathrm{m})$ according to Virmani et al. ${ }^{13}$ Snap frozen samples were only included when both adjacent HE stained sections were classified as stable, advanced atherosclerotic lesions.

Table 2.1 Patient characteristics

\begin{tabular}{|c|c|c|c|c|}
\hline Source & Sample & Gender & Age & Purpose \\
\hline \multirow{11}{*}{ Autopsy } & 1 & $\mathrm{M}$ & 74 & MA \\
\hline & 2 & $\mathrm{M}$ & 93 & MA \\
\hline & 3 & $\mathrm{~F}$ & 79 & MA \\
\hline & 4 & $\mathrm{~F}$ & 82 & MA \\
\hline & 5 & $\mathrm{M}$ & 71 & QRT-PCR \\
\hline & 6 & $\mathrm{M}$ & 73 & QRT-PCR \\
\hline & 7 & $\mathrm{M}$ & 76 & QRT-PCR +IHC \\
\hline & 8 & M & 83 & QRT-PCR +IHC \\
\hline & 9 & $\mathrm{M}$ & 65 & QRT-PCR +IHC \\
\hline & 10 & $\mathrm{M}$ & 76 & IHC \\
\hline & 11 & $\mathrm{~F}$ & 81 & $\mathrm{IHC}$ \\
\hline \multirow{11}{*}{ Surgery } & 12 & $\mathrm{M}$ & 57 & MA \\
\hline & 13 & $\mathrm{~F}$ & 70 & MA \\
\hline & 14 & $\mathrm{~F}$ & 68 & $\mathrm{MA}+\mathrm{IHC}$ \\
\hline & 15 & $\mathrm{~F}$ & 81 & QRT-PCR \\
\hline & 16 & $\mathrm{M}$ & 74 & QRT-PCR \\
\hline & 17 & $\mathrm{M}$ & 75 & QRT-PCR \\
\hline & 18 & $\mathrm{~F}$ & 68 & QRT-PCR \\
\hline & 19 & $\mathrm{M}$ & 49 & $\mathrm{IHC}$ \\
\hline & 20 & $\mathrm{M}$ & 57 & $\mathrm{IHC}$ \\
\hline & 21 & $\mathrm{M}$ & 35 & $\mathrm{IHC}$ \\
\hline & 22 & M & 62 & IHC \\
\hline
\end{tabular}

Abbreviations: M, male; F, Female; QRT-PCR, Quantitative real time PCR; MA, Microarray; IHC, Immunohistochemistry 


\section{RNA isolation}

Total RNA was isolated from advanced, stable carotid lesions collected at autopsy $(\mathrm{n}=4)$ or surgery $(\mathrm{n}=3)$ using the guanidine isothiocyanate/ $\mathrm{CsCl}$ method $^{14}$ followed by RNeasy extraction according to the manufacturer (Qiagen, Hilden, Germany). RNA quantity and quality were determined using a Nanodrop spectophotometer (Witec AG, Littau, Switzerland) and a 2100 Bioanalyzer (Agilent Technologies, Palo Alto, USA) respectively. All samples included had a RNA integrity number $\geq 5$.

\section{Microarray hybridization and data analysis}

Human oligonucleotide libraries (catalog no. HUMLIB384) were obtained from Sigma-Compugen Incorporated. Technical support was supplied by LabOnWeb (http://www.labonweb.com/cgi-bin/chips/full_loader.cgi). The libraries represent in total 18,600 LEADS ${ }^{\mathrm{TM}}$ clusters plus 231 controls. The oligonucleotide library was printed with a 2 x 12 pin Lucidea Array Spotter (GEHealthcare, Piscataway, USA) on commercial UltraGAPS slides (aminosilane-coated slides, Corning 40017), and processed according to the manufacturer's instructions. The slides contained 60-mer oligonucleotides, and the batch was checked for the quality of spotting by hybridizing with SpotCheck Cy3 labeled nonamers (Genetix, New Milton Hampshire, UK).

One $\mu \mathrm{g}$ of total RNA was amplified a single round using the Ambion MessageAmp kit (catalog no. 1750; Ambion, Huntingdon, UK), with 50\% of rUTP ribonucleotides replaced by aminoallyl-rUTP (catalog no. A5660; SigmaAldrich, Zwijndrecht, The Netherlands). Next, labeled cRNA probes were fragmented followed by purification using the RNeasy mini kit (Qiagen, Hilden, Germany). Aminoallyl-modified amplified RNA was labelled with either Cy3 (common reference sample) or Cy5 (samples) monoreactive dyes (GE Healthcare, Uppsala, Sweden). RNA concentration as well as dye incorporation was measured using the Nanodrop spectrophotometer (Witec). Equal amounts of labeled cRNAs (typically $1 \mu \mathrm{g}$ ) were applied in duplicate to oligonucleotide arrays, and were hybridized for $16 \mathrm{~h}$ at $40^{\circ} \mathrm{C} .{ }^{15}$ All samples were hybridized against a common reference sample composed of a pool of RNA isolated from human umbilical vein endothelial cells (HUVEC), the monocytic cell-line THP-1, and whole mount human carotid and aortic lesions to allow comparison between different hybridizations. The complete data set has been made available at http://www.ebi.ac.uk/arrayexpress (accession no. E-MEXP-1004).

Images were acquired using the Agilent II scanner (Agilent Technologies, Palo Alto, USA), and feature extraction was done using ArrayVision 8.0 software 
(GE Healthcare Europe, Diegem, Belgium). Background subtracted intensities were LOESS normalized (LIMMA package, Bioconductor software, http://www.bioconductor.org), and imported into Rosetta Resolver (Rosetta Biosoftware, Seattle, WA, USA). The Benjamini-Hochberg method to correct for multiple testing ${ }^{16}$ was used to identify genes significantly differentially expressed between advanced atherosclerotic lesions from autopsy and surgery. A p-value $<0.01$ was considered as statistically significant.

The differentially expressed genes were analyzed using gene ontology (GO) analysis (DAVID version 1, NIH). Ingenuity pathway analysis (Ingenuity Systems, Mountain View, CA, USA; https://analysis.ingenuity.com/pa) was performed on genes with an intensity level $>50$ (2.5x background) in either of the phenotypes, a fold change $>1.4$ or $<-1.4$, and a $p$-value $<0.01$. In addition, the expression data were analyzed using Gene Set Enrichment Analysis (GSEA) ${ }^{17}$. This method analyzes expression data at the level of pre-defined gene sets instead of individual genes to detect significant, concordant differences in biological processes between two phenotypes. We acknowledge the use of the GSEA 1.0 software, and Molecular Signature Database of genesets (MSigDB) C2.1 (http://www.broad.mit.edu/gsea/). All genes in the data set were ranked based on their correlation to the autopsy phenotype, and the rank positions of all members of a given gene set was used to calculate an enrichment score. Subsequently, 1000 permutations were used to determine which gene sets were significantly enriched in autopsy or surgery (false discovery rate (FDR) $<25 \%$ ).

\section{Quantitative real-time PCR ( $q$ RT-PCR)}

Total RNA from additional samples from autopsy $(n=5)$ and surgery $(n=4)$ was reverse transcribed, and qRT-PCR performed as described.18 Primers directed against HIF2 $\alpha^{19}, \mathrm{VEGFA}^{20}, \mathrm{VEGFB}^{20}$, and housekeeping gene $18 \mathrm{~S}^{21}$ were used in combination with SYBR® Green. FAM-TAMRA labeled primer-probe pairs were obtained for HIF1 $\alpha$, GLUT1, and GLUT3, HK1, and HK2, and housekeeping gene GAPDH (Applied Biosystems, Foster City, USA). Samples and runs were performed in duplicate. RNA copy numbers were calculated using a standard curve, and normalized to housekeeping gene mRNA expression. 


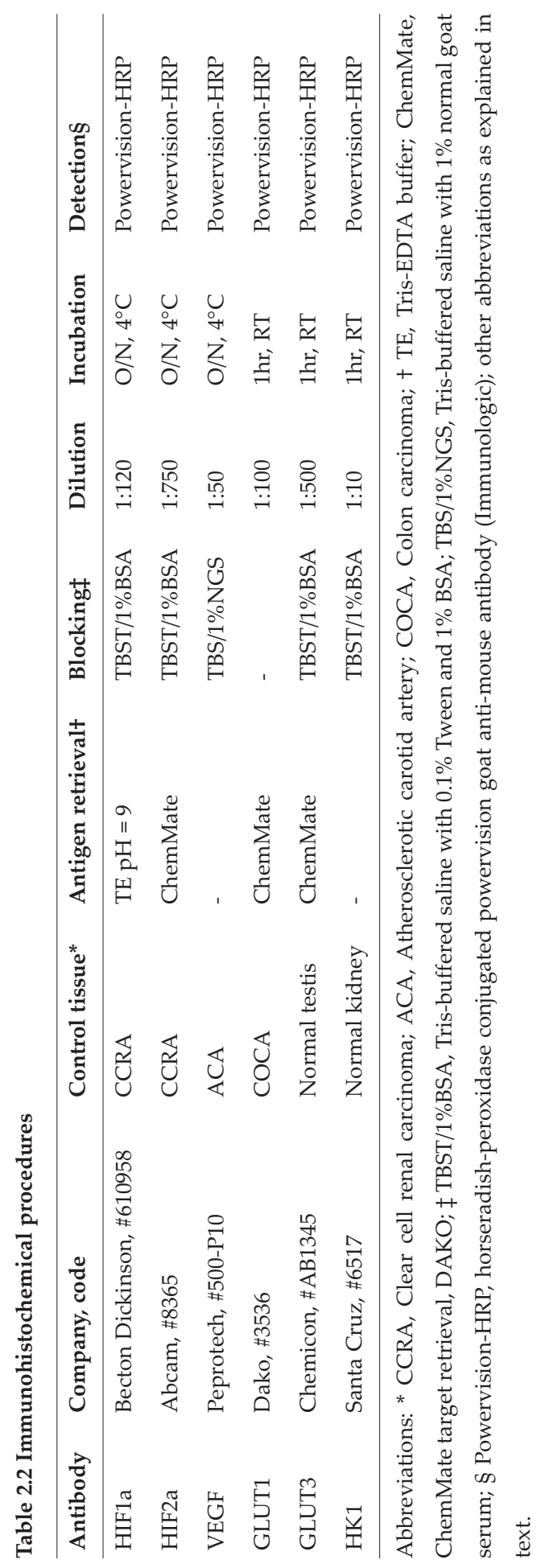


Quantitative immunohistochemistry ( $\mathrm{IIHC}$ )

Immunohistochemistry was performed on paraffin-embedded carotid arteries obtained at autopsy $(n=5)$ or surgery $(n=5)$. Expanded immunohistochemical methods can be found in Table 2.2. Sections were stained with primary antibodies against HIF1 $\alpha$, HIF2 $\alpha$, VEGF, GLUT1, GLUT3, and HK1 diluted in Tris-buffered saline (TBS) with $0.1 \%$ Tween and $1 \%$ bovine serum albumin (BSA). Sections were then incubated with appropriate secondary antibodies, and staining was visualized as a brown precipitate using 3,3'-diaminobenzidine tetrachloride (ChemMate Envision detection kit, DAKO, Glostrup Denmark). Sections incubated without the primary antibody served as a negative control. The sections were quantitatively assessed for a difference in immunoreactivity between autopsy and surgery by computer-assisted color image analysis (Leica QWin V3, Cambridge, UK). Immunoreactivity was quantified within 5 random fields at 100x magnification. The percentage of positive staining as a function of total tissue area was determined.

Statistical analysis of patient characteristics, qRT-PCR and qIHC

All qRT-PCR and qIHC results are presented as mean SEM. Groups were compared using a Mann-Whitney rank-sum test for continuous variables, and a Chi-square test for dichotomous variables (SPSS 11.0 Chicago, USA), and were considered statistically different when $\mathrm{p}<0.05$.

\section{Results}

\section{Expression profiles in autopsy and surgery}

Expression analysis using Rosetta Resolver, followed by Benjamini-Hochberg correction for multiple testing, showed that $97.2 \%$ of genes showed similar expression profiles in advanced, stable lesions from autopsy and surgery. Gene expression data were subjected to Gene Set Enrichment Analysis (GSEA), which showed no significant differences (FDR $>25 \%$ ) in expression level between autopsy and surgery samples for the predefined gene sets in the GSEA application.

However, expression analysis showed that 515 genes (2.8\%) were significantly differentially expressed between autopsy and surgery. These genes showed a fold change autopsy/surgery ranging from -8.5 to 7.6 , and the majority of differential genes $(n=343)$ was upregulated in autopsy samples. The full list of genes is available at http://physiolgenomics.physiology.org. 


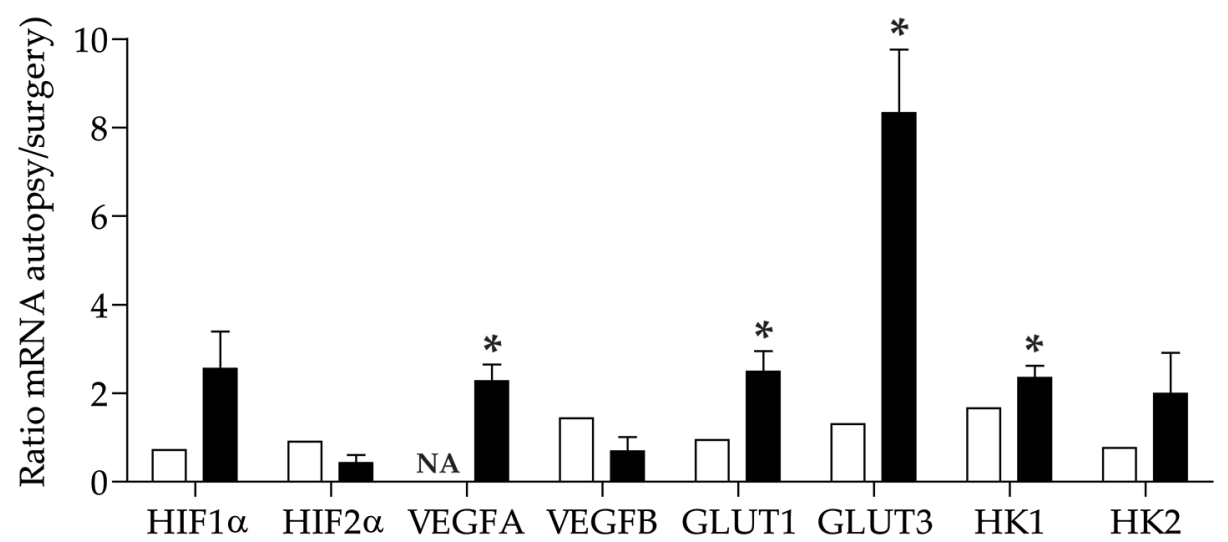

Figure 2.1 Expression ratio between advanced lesions from autopsy and surgery of genes involved in hypoxia and VEGF signaling

Ratio (autopsy/surgery) of mRNA expression level on microarray (white bars) and qRT-PCR (black bars) of genes involved in hypoxia and VEGF signaling. QRT-PCR of an independent set of samples showed the differential expression of VEGFA, GLUT1, GLUT3, and HK1 between advanced lesions from autopsy and surgery. The data are represented as a ratio of autopsy/surgery. * indicates $p<0.05$ for qRT-PCR; NA, indicates VEGFA probe not available on microarray

Differentially expressed genes are involved in hypoxia-driven pathways

The differentially expressed genes were further analyzed using Ingenuity pathway analysis to identify the involved biological functions and pathways, and revealed significant differential expression of only two canonical pathways: "Vascular endothelial growth factor (VEGF) signaling" ( $<<0.0001$ ), and "Hypoxia in cardiovascular disease" $(\mathrm{p}<0.01)$. Both pathways are associated with oxygen homeostasis.

Expression of mRNA as determined by microarray was validated with qRTPCR for several genes in these hypoxia-driven pathways on an independent set of atherosclerotic samples (Figure 2.1). QRT-PCR showed the significantly higher expression of GLUT1 (2.5 fold up), GLUT3 ( 8.3 fold up), and HK1 (2.4 fold up), in advanced lesions from autopsy compared to surgery samples. These differences in expression level were even higher than the differences determined in the microarray analysis. Expression of HIF1 $\alpha$, HIF2 $\alpha$, VEGFB, and HK2 was not differential when assessed by real time PCR. In addition, qRT-PCR showed that VEGFA, for which no probe was present on the microarray, was 2.4 fold higher expressed in autopsy samples. 

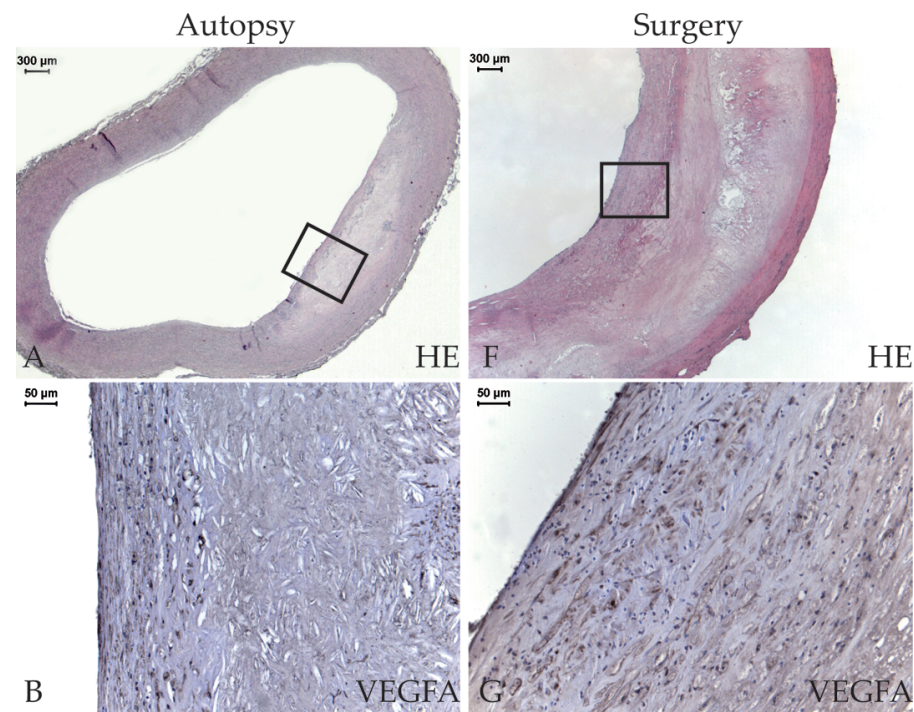

50
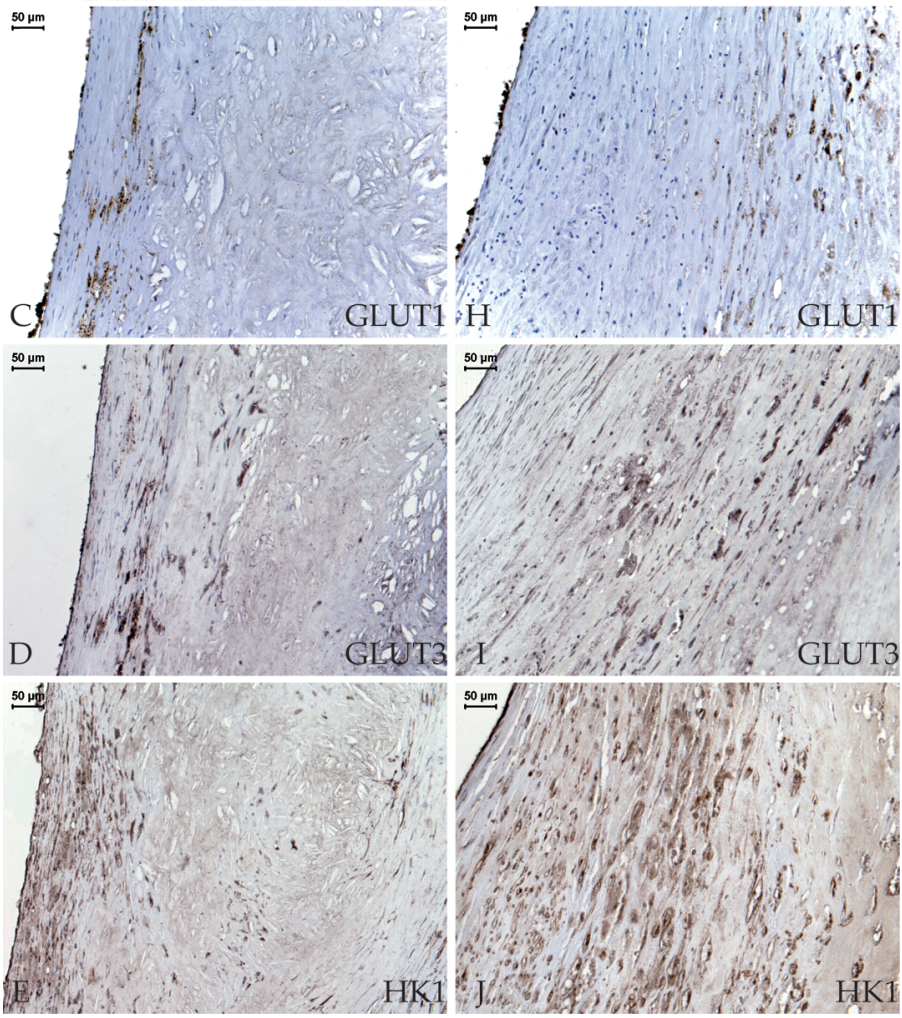

Figure 2.2 Immunohistochemical staining of proteins involved in hypoxia-driven pathways

Advanced lesions from autopsy (A-E) and surgery (F-J) were immunohistochemically stained and quantitative analysis showed similar immunoreactivity of VEGFA (B-G), GLUT1 (C-H), GLUT3 (DI), and HK1 (E, J) between autopsy and surgery. 
Quantitative immunohistochemical analysis of the hypoxia-driven genes, HIF1 $\alpha$, HIF2 $\alpha$, VEGFA, GLUT1, GLUT3, and HK1 showed that immunoreactivity and cellular distribution of these proteins were similar in advanced atherosclerotic lesions from autopsy and surgery (Figure 2.2 and 2.3). Macrophage foam cells of the atherosclerotic lesion were the most prominent cell type showing immunoreactivity of HIF1 $\alpha$ (data not shown), HIF2 $\alpha$ (data not shown), VEGFA (Figure 2.2B-G), GLUT1 (Figure 2.2C-H), GLUT3 (Figure 2.2D$\mathrm{J}$ ), and HK1 (Figure 2.2E-J). In addition, smooth muscle and endothelial cells in the atherosclerotic lesion showed less intense staining of HIF1 $\alpha, \mathrm{HIF} 2 \alpha$, and VEGFA compared to macrophages (Figure 2.2).

Table 2.3 Top 6 differential networks between advanced lesions from autopsy and surgery demonstrated by Ingenuity Pathway analysis

\begin{tabular}{|c|c|c|}
\hline & Genes in networks & Functions \\
\hline 1 & 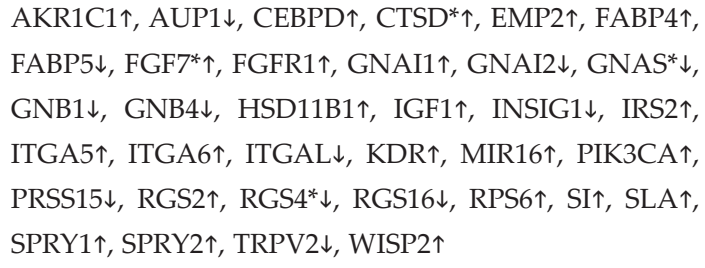 & $\begin{array}{l}\text { Signaling; } \\
\text { DNA replication, recombination, } \\
\text { repair; Nucleic acid metabolism }\end{array}$ \\
\hline 2 & 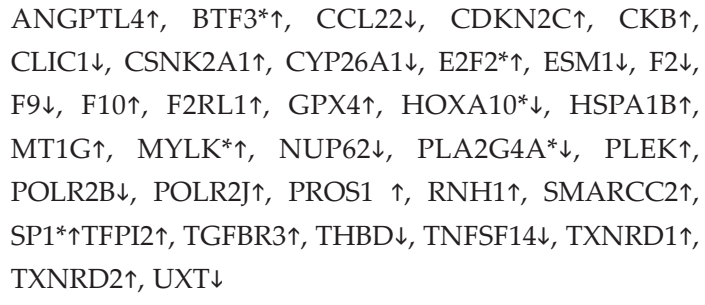 & $\begin{array}{l}\text { Hematological system } \\
\text { development and function; } \\
\text { Cardiovascular disease; } \\
\text { Hematological disease }\end{array}$ \\
\hline 3 & 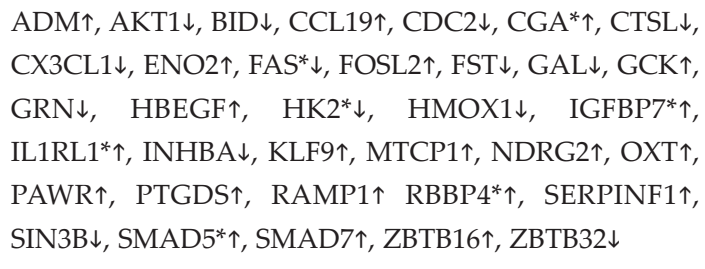 & $\begin{array}{l}\text { Cellular growth and proliferation; } \\
\text { Cell death; } \\
\text { Cancer }\end{array}$ \\
\hline 4 & 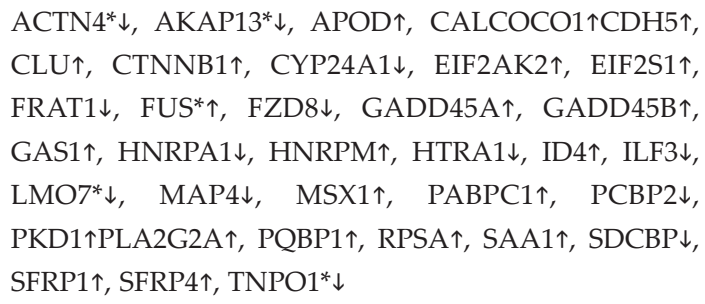 & $\begin{array}{l}\text { Cellular growth and proliferation; } \\
\text { Cell cycle; } \\
\text { Cellular function and maintenance }\end{array}$ \\
\hline
\end{tabular}




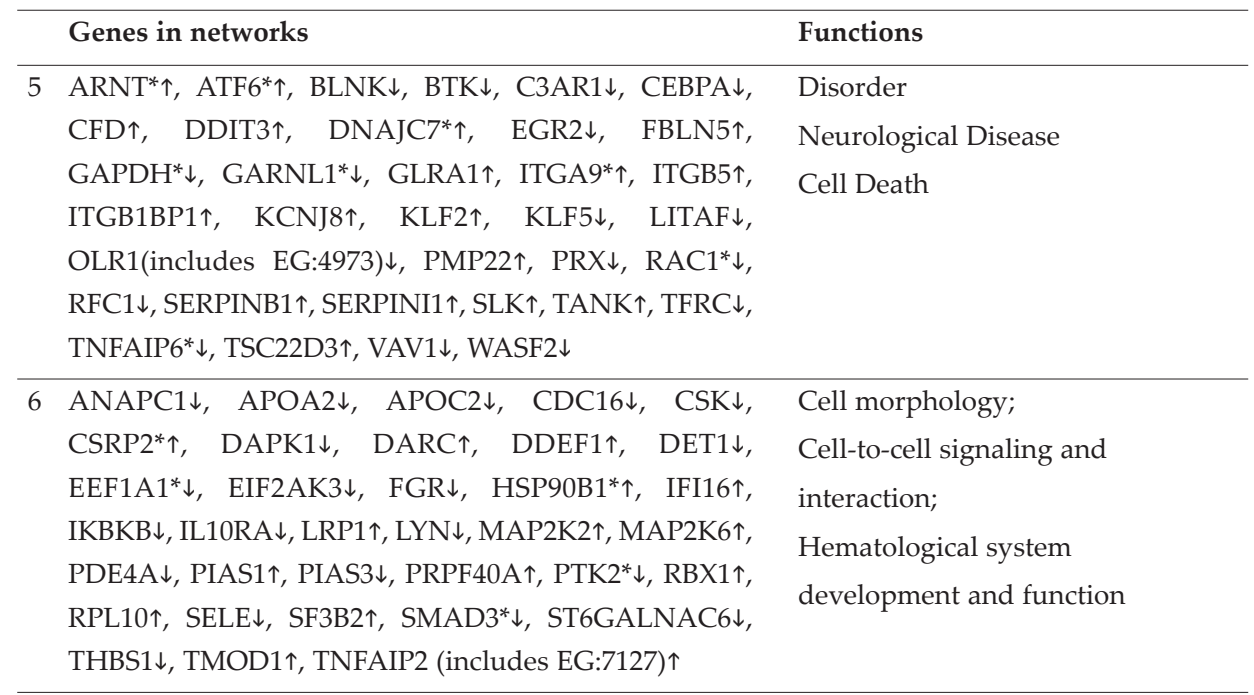

Ingenuity Pathway analysis revealed networks of genes involved in basal cell machinery, such as cell signaling, nucleic acid metabolism, cellular growth and proliferation, cell cycle and cell death. Upward-pointing arrows indicate increased expression in autopsy, downward-pointing arrows indicate increased expression in surgery. All genes depicted have an intensity level $>50(2.5 x$ background) in at least one of the phenotypes, a fold change $>1.4$ or $<-1.4$, and a p-value $<0.01$. All networks presented showed a $\mathrm{p}<1 \mathrm{E}-42$. Asterisks indicate scores of individual genes with $\mathrm{p}<1 \mathrm{E}-11$, which indicates the chance that the genes are in a network due to random chance.

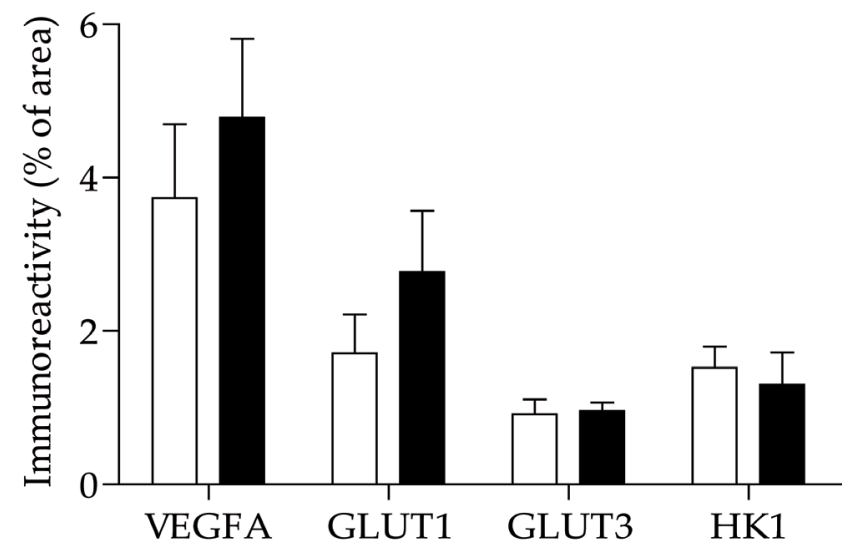

Figure 2.3 Quantitative immunohistochemical analysis of proteins involved in hypoxia-driven pathways

Quantitative immunohistochemical analysis showed a similar expression of VEGFA, GLUT1, GLUT3, and HK1 in advanced lesions from autopsy (white bars) and surgery (black bars). 
Table 2.4 Gene Ontology classification of differential genes after Benjamini-Hochberg correction

\begin{tabular}{|c|c|}
\hline GO term & Genes (N) \\
\hline Cell growth and/or maintenance & 79 \\
\hline Nucleobase, nucleoside, nucleotide and nucleic acid metabolism & 64 \\
\hline Signal transduction & 59 \\
\hline Protein metabolism & 54 \\
\hline Response to external stimulus & 29 \\
\hline Biosynthesis & 26 \\
\hline Organogenesis & 23 \\
\hline Catabolism & 21 \\
\hline Cell adhesion & 21 \\
\hline Response to stress & 17 \\
\hline Cell death & 15 \\
\hline Immune response & 15 \\
\hline Cell-cell signaling & 14 \\
\hline Neurophysiological process & 14 \\
\hline Phosphorus metabolism & 14 \\
\hline Lipid metabolism & 13 \\
\hline Organismal movement & 12 \\
\hline Electron transport & 10 \\
\hline Regulation of cell proliferation & 10 \\
\hline Organic acid metabolism & 8 \\
\hline Carbohydrate metabolism & 6 \\
\hline Cell motility & 6 \\
\hline Coenzyme and prosthetic group metabolism & 5 \\
\hline Energy pathways & 4 \\
\hline Extracellular matrix organization and biogenesis & 4 \\
\hline Regulation of body fluids & 4 \\
\hline Response to endogenous stimulus & 4 \\
\hline Alcohol metabolism & 3 \\
\hline Amine metabolism & 3 \\
\hline Blood coagulation & 3 \\
\hline Unclassified & 273 \\
\hline
\end{tabular}


Differentially expressed genes are involved in basal cell metabolism

In addition to changes related to hypoxia pathways, Ingenuity pathway analysis also listed highly significant networks involved in functions such as cell signaling, DNA replication, nucleic acid metabolism, cardiovascular disease, cellular growth and differentiation, cell cycle, and cell death (Table 2.3). Likewise, GO analysis showed that the differential genes were mainly involved in cell growth and -maintenance (99 genes; 19\%), signal transduction (79 genes; $15 \%$ ), nucleic acid metabolism (77 genes; 15\%), and protein metabolism (66 genes; $13 \%$ ) and to a smaller extent in cell death (15 genes; $3 \%$ ), and cell signaling (14 genes; 3\%) (Table 2.4).

\section{Differentially expressed genes are not related to atherosclerosis}

The gene expression data were also analyzed to establish whether the differences in expression were related to atherosclerosis. All 515 differentially expressed genes were manually compared to a recently published list of 92 genes related to processes involved in atherosclerotic disease, such as lipid metabolism, inflammation, and matrix degradation ${ }^{22}$. Probes representing these 92 genes were indeed present on our microarray, and the expression of 87 genes (95\%) was similar between autopsy and surgery. Only the expression levels of 5 genes were different after Benjamini-Hochberg correction for multiple testing (Table 2.5). Lamin A/C, Fas, thrombin, and fibrillin were downregulated 1.4, 1.5, 1.7, and 1.9 fold respectively in autopsy, whereas hydroxysteroid (11-beta) dehydrogenase 1 was upregulated 2.1 fold in samples obtained at autopsy. Thus, the expression of the majority of atherosclerosis-related genes was similar between autopsy and surgery, and consequently the combination of autopsy and surgery samples for transcriptional analysis might not obscure the atherosclerosis-specific expression profile. 
Table 2.5 Genes previously related to atherosclerosis and differentially expressed between atherosclerotic samples from autopsy and surgery

\begin{tabular}{lllll}
\hline Gene symbol & Gene name & Function & FC & p-value \\
\hline LMNA & Lamin A/C & $\begin{array}{l}\text { Nuclear lamina constituent } \\
\text { involved in Hutchinson- } \\
\text { Gilford progeria }\end{array}$ & -1.4 & $0.2 \mathrm{E}-03$ \\
TNFRSF6/Fas & $\begin{array}{l}\text { TNF receptor super } \\
\text { family, member 6 }\end{array}$ & Apoptosis & -1.5 & $2.9 \mathrm{E}-09$ \\
F2 & Thrombin & Blood coagulation & & \\
FBN1 & Fibrillin & Extracellular matrix & -1.7 & $1.5 \mathrm{E}-06$ \\
constituent, wall stiffness & -1.9 & $9.6 \mathrm{E}-12$ \\
HSD11B1 & $\begin{array}{l}\text { Hydroxysteroid(11- } \\
\text { beta)dehydrogenase1 }\end{array}$ & Glucocorticoid metabolism, & 2.1 & $1.6 \mathrm{E}-12$ \\
adipocyte function and & & \\
differentiation & &
\end{tabular}

Microarray expression levels of single, differentially expressed genes were linked to 92 genes involved in atherogenesis. ${ }^{22}$ The expression of all genes was comparable in advanced lesions from autopsy and surgery, apart from the four genes presented in this table. * Fold change autopsy/surgery; p-values corrected for multiple testing by Benjamini-Hochberg method

\section{Discussion}

Microarray analysis combined with GO analysis and extensive pathway profiling (Ingenuity and GSEA), qRT-PCR, and immunohistochemistry were used to study the expression profiles of advanced atherosclerotic lesions from autopsy and surgery. Our results clearly showed that more than $97 \%$ of genes, including several genes known to be involved in atherosclerosis, were unaffected by the source of the tissue, i.e. autopsy or surgery. However, 515 genes primarily involved in basal cell metabolism and hypoxia-driven pathways, were differentially expressed, and mainly associated with active postmortem transcription. Nevertheless, immunohistochemistry showed that the transcriptional differences in hypoxia-driven genes were not reflected at the protein level.

Sanoudou et al. compared the transcriptome of skeletal muscle from autopsy and surgery, and also showed the differential expression of only a minority of 
genes $(1.1 \%) .{ }^{23}$ Remarkably, also in human skeletal muscle, only genes involved in basal cell metabolism, i.e., cell growth/-maintenance, nucleic acid- and protein metabolism, and cell communication showed differential expression between autopsy and surgical samples. In their study, all differential transcripts showed increased expression in postmortem samples. It seems likely that these processes represent a cellular survival response triggered by the complex environmental changes associated with the cessation of life.

In addition to the cellular response of increased basal metabolism, hypoxiadriven pathways were also initiated. The hypoxic response is regulated by the protein stabilization of hypoxia-inducible transcription factors (HIF) 1 and 2 in hypoxic cells. These oxygen sensors orchestrate the transcription of several hypoxia responsive genes involved in angiogenesis, glucose metabolism, and cell proliferation/survival, and include VEGF, GLUT1, GLUT3, HK1, and HK2. ${ }^{24}$ It may be appreciated that cessation of life is undeniably associated with cellular ischemia/hypoxia, as our data clearly show. HIF1 $\alpha$ mRNA expression in postmortem kidney compared to surgery was significantly increased in postmortem human kidney, but surprisingly VEGF mRNA was decreased in the same samples. ${ }^{25,26}$ Postmortem skeletal muscle did not show a significant increase in HIF1 $\alpha$ and VEGF mRNA expression. ${ }^{23}$

The differences in gene expression we observed were not reflected at protein level. Our findings are corroborated by similar VEGF protein expression in tubuli and arteries of human kidney from deceased and living donors. However, in the same sections a slightly different expression was shown in glomeruli. It seems that differences in protein expression between postmortem and living tissue, if any, are smaller than the transcriptional differences. Theoretically, perishing cells might be able to start transcription and/or translation, but their evident death will prevent them from continuing any process. In addition, protein turnover is a more time-consuming process than mRNA turnover, and therefore less sensitive to detect changes. However, changes in post-translational modifications such as phosphorylation or glycosylation may occur within minutes, but are beyond the scope of this study.

A potential concern using autopsy samples to study gene expression would be the quality and integrity of mRNA derived from this source. However, mRNA from autopsy is fairly resistant to degradation in a wide variety of tissues. ${ }^{23,27,28}$ Total mRNA remained intact up to 48 hours postmortem, ${ }^{23,27}$ and microarray expression data were found to be reliable even when mRNA was partially degraded..$^{28}$ More specifically, others studied the transcript levels of HIF1 $\alpha$ and VEGF mRNA using qRT-PCR which were shown to be resistant to degradation up to 48 hours postmortem. ${ }^{29}$ Therefore, any degradation is unlikely to influence 
detection of gene expression using microarray and qRT-PCR. Aside from the source possibly influencing RNA integrity, another concern was raised by a recent report on the presence of RNA damage in human atherosclerosis. ${ }^{30}$ However, a mRNA quality control was applied ensuring similar mRNA integrity of samples from autopsy and surgery. Therefore, any differences in expression profile of autopsy and surgery are not expected to be caused by a difference in mRNA quality and integrity between these two sources.

In conclusion, the gene expression profiles of advanced atherosclerotic lesions from autopsy and surgery are largely similar. However, specific gene pathways, mostly involved in basal cell metabolism and hypoxia, were differentially expressed at the mRNA level. Despite the transcriptional differences in hypoxia-related genes, protein expression in advanced atherosclerotic lesions from autopsy and surgery was comparable. Nevertheless, human expression profiling studies using a combination of both sources should be analyzed with caution.

\section{Acknowledgements}

We gratefully acknowledge Moniek Faessen for excellent technical assistance and Jack Cleutjens for assistance with colorimetric analysis. The work described herein was performed in the framework of the European vascular genomics network (EVGN, grant LSHM-CT-2003-503254; KBC, A-PJJB, and MJAPD), and was supported in part by two grants of the Netherlands Organization of Scientific research; i.e. the Innovational research Veni program (grant 916.046.083 to A-PJJB), and the Genomics program (grant 050-10-014 to NK). 


\section{References}

1. Bijnens AP, Lutgens E, Ayoubi T, Kuiper J, et al. Genome-wide expression studies of atherosclerosis: critical issues in methodology, analysis, interpretation of transcriptomics data. Arterioscler Thromb Vasc Biol. 2006;26:1226-1235.

2. King JY, Ferrara R, Tabibiazar R, Spin JM, et al. Pathway analysis of coronary atherosclerosis. Physiol Genomics. 2005;23:103-118.

3. Ijas P, Nuotio K, Saksi J, Soinne L, et al. Microarray Analysis Reveals Overexpression of CD163 and HO-1 in Symptomatic Carotid Plaques. Arterioscler Thromb Vasc Biol. 2006.

4. Seo D, Wang T, Dressman H, Herderick EE, et al. Gene expression phenotypes of atherosclerosis. Arterioscler Thromb Vasc Biol. 2004;24:1922-1927.

5. Adams LD, Geary RL, Li J, Rossini A, et al. Expression profiling identifies smooth muscle cell diversity within human intima and plaque fibrous cap: loss of RGS5 distinguishes the cap. Arterioscler Thromb Vasc Biol. 2006;26:319-325.

6. Martinet W, Schrijvers DM, De Meyer GR, Thielemans J, et al. Gene expression profiling of apoptosis-related genes in human atherosclerosis: upregulation of death-associated protein kinase. Arterioscler Thromb Vasc Biol. 2002;22:2023-2029.

7. Tuomisto TT, Korkeela A, Rutanen J, Viita H, et al. Gene expression in macrophage-rich inflammatory cell infiltrates in human atherosclerotic lesions as studied by laser microdissection and DNA array: overexpression of HMG-CoA reductase, colony stimulating factor receptors, CD11A/CD18 integrins, and interleukin receptors. Arterioscler Thromb Vasc Biol. 2003;23:22352240.

8. Archacki SR, Angheloiu G, Tian XL, Tan FL, et al. Identification of new genes differentially expressed in coronary artery disease by expression profiling. Physiol Genomics. 2003;15:65-74.

9. Tabibiazar R, Wagner RA, Ashley EA, King JY, et al. Signature patterns of gene expression in mouse atherosclerosis and their correlation to human coronary disease. Physiol Genomics. 2005;22:213-226.

10. Papaspyridonos M, Smith A, Burnand KG, Taylor P, et al. Novel candidate genes in unstable areas of human atherosclerotic plaques. Arterioscler Thromb Vasc Biol. 2006;26:1837-1844.

11. Faber BC, Cleutjens KB, Niessen RL, Aarts PL, et al. Identification of genes potentially involved in rupture of human atherosclerotic plaques. Circ Res. 2001;89:547-554.

12. Hiltunen MO, Tuomisto TT, Niemi M, Brasen JH, et al. Changes in gene expression in atherosclerotic plaques analyzed using DNA array. Atherosclerosis. 2002;165:23-32.

13. Virmani R, Kolodgie FD, Burke AP, Farb A, et al. Lessons from sudden coronary death: a comprehensive morphological classification scheme for atherosclerotic lesions. Arterioscler Thromb Vasc Biol. 2000;20:1262-1275.

14. Chomczynski P, Sacchi N. Single-step method of RNA isolation by acid guanidinium thiocyanate-phenol-chloroform extraction. Anal Biochem. 1987;162:156-159.

15. Dekker RJ, Boon RA, Rondaij MG, Kragt A, et al. KLF2 provokes a gene expression pattern that 
establishes functional quiescent differentiation of the endothelium. Blood. 2006;107:4354-4363.

16. Baldi P, Long AD. A Bayesian framework for the analysis of microarray expression data: regularized $t$-test and statistical inferences of gene changes. Bioinformatics. 2001;17:509-519.

17. Subramanian A, Tamayo P, Mootha VK, Mukherjee S, et al. Gene set enrichment analysis: a knowledge-based approach for interpreting genome-wide expression profiles. Proc Natl Acad Sci U S A. 2005;102:15545-15550.

18. Demir AY, Groothuis PG, Nap AW, Punyadeera C, et al. Menstrual effluent induces epithelialmesenchymal transitions in mesothelial cells. Hum Reprod. 2004;19:21-29.

19. Favier J, Plouin PF, Corvol P, Gasc JM. Angiogenesis and vascular architecture in pheochromocytomas: distinctive traits in malignant tumors. Am J Pathol. 2002;161:1235-1246.

20. Thijssen VL, Brandwijk RJ, Dings RP, Griffioen AW. Angiogenesis gene expression profiling in xenograft models to study cellular interactions. Exp Cell Res. 2004;299:286-293.

21. Meex SJ, van der Kallen CJ, van Greevenbroek MM, Eurlings PM, et al. Up-regulation of CD36/FAT in preadipocytes in familial combined hyperlipidemia. Faseb J. 2005;19:2063-2065.

22. Ghazalpour A, Doss S, Yang X, Aten J, et al. Thematic review series: The pathogenesis of atherosclerosis. Toward a biological network for atherosclerosis. J Lipid Res. 2004;45:1793-1805.

23. Sanoudou D, Kang PB, Haslett JN, Han M, et al. Transcriptional profile of postmortem skeletal muscle. Physiol Genomics. 2004;16:222-228.

24. Semenza GL. Targeting HIF-1 for cancer therapy. Nat Rev Cancer. 2003;3:721-732.

25. Baan C, van Gelder T, Peeters A, Mol W, et al. Living kidney donors and hypoxia-inducible factor-1alpha. Transplantation. 2003;75:570-571.

26. Lemos FB, Ijzermans JN, Zondervan PE, Peeters AM, et al. Differential expression of heme oxygenase-1 and vascular endothelial growth factor in cadaveric and living donor kidneys after ischemia-reperfusion. J Am Soc Nephrol. 2003;14:3278-3287.

27. Kuliwaba JS, Fazzalari NL, Findlay DM. Stability of RNA isolated from human trabecular bone at post-mortem and surgery. Biochim Biophys Acta. 2005;1740:1-11.

28. Lee J, Hever A, Willhite D, Zlotnik A, et al. Effects of RNA degradation on gene expression analysis of human postmortem tissues. Faseb J. 2005;19:1356-1358.

29. Zhao D, Zhu BL, Ishikawa T, Quan L, et al. Real-time RT-PCR quantitative assays and postmortem degradation profiles of erythropoietin, vascular endothelial growth factor and hypoxia-inducible factor 1 alpha mRNA transcripts in forensic autopsy materials. Leg Med (Tokyo). 2006;8:132-136.

30. Martinet W, De Meyer GR, Herman AG, Kockx MM. RNA damage in human atherosclerosis: pathophysiological significance and implications for gene expression studies. RNA Biol. 2005;2:4-7. 


\section{Hypoxia, HIF and macrophages in human atherosclerotic plaques are correlated with intraplaque angiogenesis}

J.C. Sluimer, J.M. Gasc, J.L. van Wanroij, N. Kisters, M. Groeneweg, M.D. Sollewijn Gelpke, J.P. Cleutjens, L.H. van den Akker, P. Corvol, B.G. Wouters, M.J.A.P. Daemen, A.P.J.J. Bijnens

J Am Coll Cardiol. 2008; 51(13):1258-65. 
$80 \quad$ Chapter 3

\section{Abstract}

Atherosclerotic plaques develop intraplaque angiogenesis, which is a typical feature of hypoxic tissue and expression of hypoxia-inducible transcription factor (HIF). Therefore, the presence of hypoxia in human carotid atherosclerosis and its association with HIF and intraplaque angiogenesis were studied.

To examine the presence of hypoxia in atherosclerotic plaques, the hypoxia marker pimonidazole was infused prior to carotid endarterectomy in 7 symptomatic patients. Also, the mRNA and protein expression of HIF1 $\alpha$, HIF2 $\alpha$, HIF-responsive genes (VEGF, GLUT1, GLUT3, HK1, and HK2), and microvessel density were determined in larger series of non-diseased and atherosclerotic carotid arteries using microarray, qRT-PCR, in situ hybridization, and immunohistochemistry. Pimonidazole immunohistochemistry demonstrated the presence of hypoxia, especially within the macrophage-rich center of the lesions. Hypoxia correlated with the presence of a thrombus, angiogenesis, and expression of CD68, HIF, and VEGF. The mRNA and protein expression of HIF, its target genes, and microvessel density increased from early to stable lesions, but no changes were observed between stable and ruptured lesions.

This is the first study directly demonstrating hypoxia in advanced human atherosclerosis and its correlation with the presence of macrophages and the expression of HIF and VEGF. Also, the HIF pathway was associated with lesion progression and angiogenesis, suggesting its involvement in the response to hypoxia and the regulation of human intraplaque angiogenesis. 


\section{Introduction}

Human atherosclerotic plaques demonstrate extensive intraplaque angiogenesis which is associated with plaque growth and instability. ${ }^{1-3}$ However the molecular pathways initiating intraplaque angiogenesis in atherosclerotic lesions have not been revealed. As angiogenesis is a major consequence of hypoxic tissue, the mere presence of intraplaque angiogenesis suggests the existence of hypoxia in human atherosclerosis. Evidence of hypoxia in human vascular disease is supported by the in vivo detection of hypoxia in macrophage regions in rabbit atherosclerosis $^{4}$ and the expression of several hypoxia-induced genes in atherogenesis. ${ }^{5}$ Nevertheless, hypoxia per se has not yet been demonstrated in human atherosclerosis.

Two well-known sensors and mediators of the hypoxic response are the hypoxia-inducible transcription factors (HIF) 1 and 2 . The heterodimer protein consists of two subunits: a HIF1 $\beta$ subunit, which is constitutively expressed, and a HIF $1 \alpha$ or $2 \alpha$ subunit, whose protein levels are highly regulated by the oxygen concentration. $^{6}$ HIF $1 \alpha$ and $2 \alpha$ proteins are rapidly degraded by the ubiquitin/proteasome pathway in the presence of oxygen. Upon inhibition of HIF $\alpha$ subunit degradation by hypoxia, the protein translocates to the nucleus, dimerizes with HIF1 $\beta$, and induces transcription of hypoxia-responsive genes involved in angiogenesis and glucose metabolism, vascular endothelial growth factor (VEGF), glucose transporter 1 (GLUT1, GLUT3, hexokinase 1 (HK1), and HK2. ${ }^{6}$

Although it is widely accepted that HIF expression is mainly regulated at the protein level, quantitative and qualitative differences exist between HIF1 $\alpha$ and $2 \alpha$ mRNA expression. ${ }^{7}$ In addition, some studies indicate a transcriptional regulation of HIF., 9

A possible role for HIF in atherosclerosis is supported by the presence of intraplaque angiogenesis, and the implication of several known HIF-responsive genes in atherosclerosis, such as VEGF, ${ }^{5,6}$ endothelin-1, ${ }^{6,10}$ and matrixmetalloproteinase-2. ${ }^{6}{ }^{11}$ However, the association of hypoxia and the HIF pathway with human atherosclerosis has not yet been established. In the present study, we tested the hypotheses that hypoxia is present in human atherosclerosis and associated with the HIF pathway, and that the HIF pathway is associated with progression and angiogenesis of human atherosclerosis. 


\section{Chapter 3}

\section{Material and methods}

\section{Hypoxia detection in human atherosclerosis}

Hypoxia was detected in human atherosclerotic carotid arteries using the hypoxia marker pimonidazole hydrochloride (Hypoxyprobe-1, Natural Pharmacia Inc., Belmont, MA, USA). The investigation was approved by an external ethical committee, and written informed consent was obtained. Pimonidazole $\left(0.5 \mathrm{~g} / \mathrm{m}^{2}\right)$ was injected intravenously two hours prior to carotid endarterectomy of 7 symptomatic patients (Table 3.1). Four tissue samples were consecutively removed: 1) arterial wall after incision of the artery, 2) atherosclerotic plaque, 3) arterial wall after removing the plaque, and 4) skin prior to wound closure.

Table 3.1. Clinical characteristics of patients infused with hypoxia marker

\begin{tabular}{cccccccccc}
\hline ID & Age & Gender & BMI & Symptoms & Stenosis (\%) & Diabetes & Hypertension & Statins & Smoking \\
\hline 1 & 62 & M & 29 & TIA & $80-99$ & Type 2 & - & + & + \\
2 & 47 & M & 31 & A. fugax & $80-99$ & - & + & + & + \\
3 & 77 & M & 24 & TIA & $80-99$ & - & + & + & - \\
4 & 72 & F & 25 & TIA & $80-99$ & - & + & + & + \\
5 & 76 & F & 28 & A. fugax & $80-99$ & - & + & + & - \\
6 & 59 & F & 27 & Minor stroke & $80-99$ & - & + & + & - \\
\hline
\end{tabular}

Abbreviations: BMI, Body mass index; TIA, transient ischemic attack; A. fugax, amourosis fugax

In vivo, pimonidazole is subject to oxidative metabolism, and resulting pimonidazole derivatives form protein adducts. Oxygen and pimonidazole compete for electron addition, explaining the oxygen-dependence of pimonidazole adduct formation. Although pimonidazole itself may react with reactive oxygen species (ROS), the anti-pimonidazole antibody only recognizes hypoxia-derivatives. In vivo formed pimonidazole adducts in hypoxic, but viable cells ( $\mathrm{pO}_{2} \leq 10 \mathrm{mmHg} 1 \% \mathrm{O}_{2}$ ) were detected ex vivo in formalin-fixed, paraffinembedded tissue by immunohistochemistry with an antibody that only detects hypoxia-derivatives of pimonidazole.

\section{THP-1 cell culture and differentiation}

Human THP-1 cells were obtained from the American Type Culture Collection (ATCC 10801, Manassas, VA). Cells were grown in RPMI 1640 medium (Gibco- 
Invitrogen, Grand Island, NY, USA) containing 10\% FetalClone ${ }^{\circledast}$ III (Hyclone, PE-bio, Hogan, UT, USA) (v/v), 1\% GlutaMAX ${ }^{\mathrm{TM}} \mathrm{I}$ (w/v) (Gibco-Invitrogen), 125 $\mathrm{mM}$ Hepes, penicillin (100 units $/ \mathrm{ml})$, and streptomycin $(100 \mu \mathrm{g} / \mathrm{ml})$ (GibcoInvitrogen) at $37^{\circ} \mathrm{C}$ in a humidified incubator with a $5 \% \mathrm{CO}_{2}$ atmosphere using plastic disposables Greiner Bio-One (Alphen a/d Rijn, The Netherlands). THP-1 cells were seeded at a density of $1 \times 10^{6}$ cells $/ \mathrm{ml}$, and incubated for 72 hours with $0.2 \mu \mathrm{M}$ phorbol 12-myristate 13-acetate (PMA, Sigma, Saint Louis, MO, USA) to differentiate into macrophages.

\section{Flow cytometry experiments with pimonidazole}

THP-1 macrophages were exposed to an oxygen gradient $(0,0.2,1,5$, and $21 \%$ $\mathrm{O}_{2}$; MACS VA500 micro-aerophilic workstation, Don Whitley Scientific, Shipley, $\mathrm{UK}$ ), $100 \mu \mathrm{M} \mathrm{H}_{2} \mathrm{O}_{2}$ (Merck, Darmstadt, Germany), or a combination of $0.2 \% \mathrm{O}_{2}$ and $\mathrm{H}_{2} \mathrm{O}_{2}$ for 15 minutes, and 1 and 4 hours, all in triplicate. Cells were incubated with and without pimonidazole $(100 \mu \mathrm{M})$, and stained with fluorescein isothiocyanate-conjugated anti-pimonidazole (1:1000; Chemicon, Temecula, CA). Pimonidazole was quantified in $1 \times 10^{4}$ cells (FACS Calibur) using the excitation geomean at $530 \mathrm{~nm}$ (CellQuest, BD-Science, San Jose, CA, USA).

\section{Expression of HIF pathway in human atherosclerosis}

A total of 10 human caval veins, 15 non-diseased pulmonary or mammary arteries, and 72 atherosclerotic carotid arteries were obtained from patients undergoing vascular surgery (Departments of Surgery, Sittard and Maastricht, the Netherlands) or at autopsy (Department of Pathology, University Hospital Maastricht, Maastricht, the Netherlands) to study the expression pattern of the HIF pathway. Tissue collection was performed in agreement with the "Dutch code of conduct for Observational Research with personal data (2004) and tissue (2001)" (http://www.fmwv.nl). The mean age was 69 \pm 11.5 years, and $51 \%(\mathrm{n}=52)$ were male. Samples were processed and classified as described previously, ${ }^{12,13}$ and subdivided as non-diseased, early (intimal thickening or pathological intimal thickening), stable (thin or thick fibrous cap atheroma) or thrombuscontaining (luminal thrombus or intraplaque hemorrhage) lesions.

\section{Immunohistochemistry}

Sections were stained with primary antibodies against pimonidazole, HIF $1 \alpha$, HIF2 $\alpha$, VEGF, GLUT1, GLUT3, HK1, CD68, Ki-67, CD31, CD34, or activated caspase 3 (Table 3.2), with unrelated IgG1 or without the primary antibody (negative controls). Immunoreactivity in the plaques was scored by one observer 


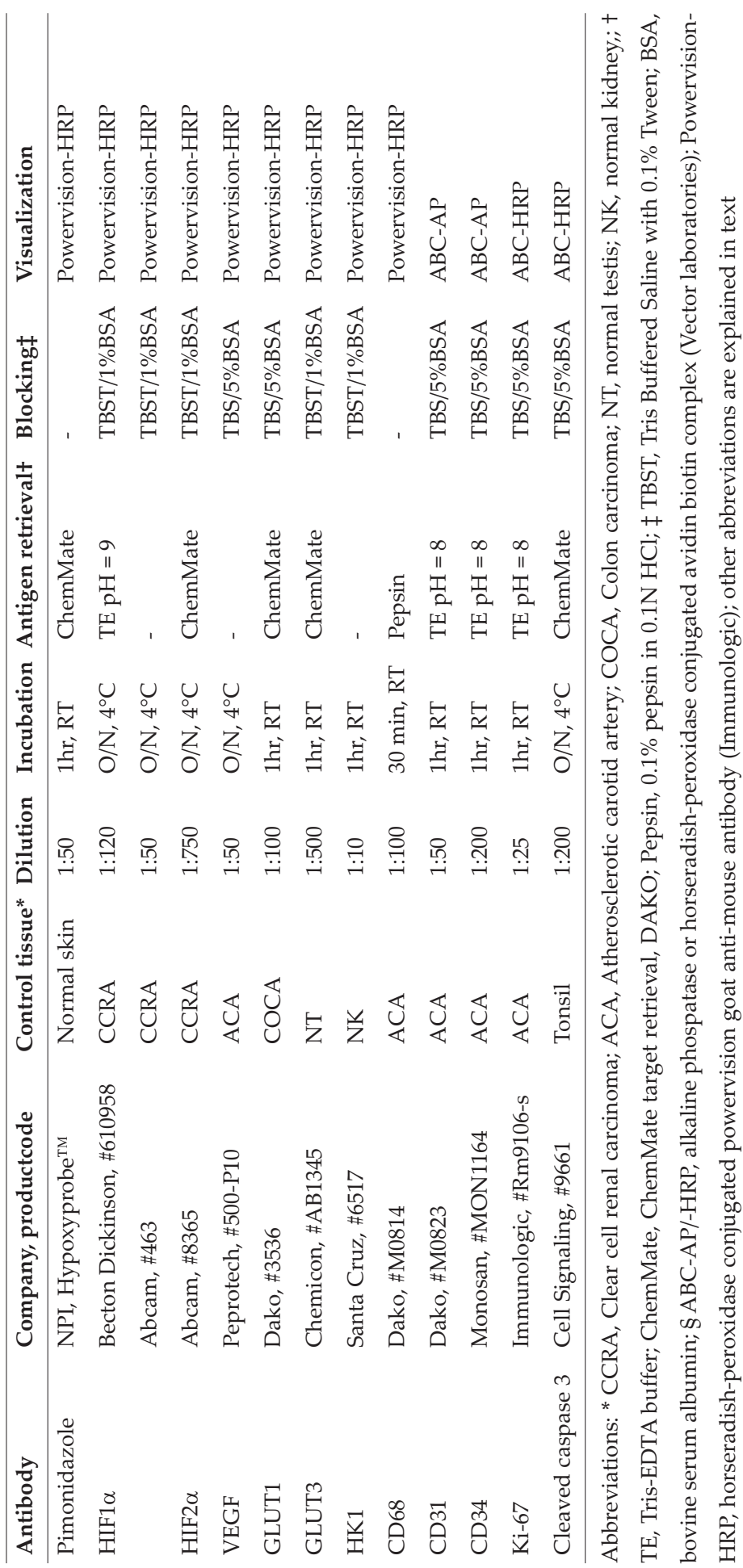


(J.C.S) as follows: ( $0=$ none; $1=$ mild; $2=$ moderate; $3=$ extensive). Hematoxylin and eosin (HE) stained sections were used to score fibrosis, thrombus ( $0=a b s e n t$, $1=$ present), and angiogenesis ( $0=$ none; $1=$ mild; $2=$ moderate; $3=$ extensive).

\section{In situ hybridization}

RNA expression of HIF1 $\alpha$ and HIF2 $\alpha$ was evaluated in $7 \mu$ m sections of 3 carotid arteries with early, stable or thrombus-containing lesions by in situ hybridization as previously described, ${ }^{14,15}$

\section{Microarray}

RNA was isolated from 9 early and 6 advanced, stable carotid lesions collected at autopsy. ${ }^{12}$ RNA was isolated using the guanidine isothiocyanate/CsCl method..$^{16}$ RNA quantity and quality were determined using a nanodrop spectophotometer (Witec AG, Littau, Switzerland) and a 2100 Bioanalyzer (Agilent Technologies, Palo Alto, USA) respectively. All samples included had a RNA integrity number $\geq 5$. Samples were individually hybridized to HGU133 2.0 Plus arrays ( $\mathrm{n}=17$, Affymetrix) according to the manufacturer's instructions. The array represents $>54,000$ probe sets and 47,000 transcripts (including $>38,000$ genes). Double-stranded cDNA was synthesized from 1.6 or $2.0 \mu \mathrm{g}$ total RNA using the One-Cycle Target Labeling Kit (Affymetrix, Santa Clara, USA), and used as a template for the preparation of biotin-labeled cRNA using the GeneChip IVT Labeling Kit (Affymetrix). Biotin-labeled cRNA of 16 samples were hybridized to separate HGU133 2.0 Plus Arrays (Affymetrix). After washing, arrays were stained with biotin-labeled anti-streptavidin antibody (Vector Laboratories, Burlingame, USA), followed by phycoerythrinstreptavidin conjugate (Molecular Probes, Eugene, USA) to amplify the signals. The arrays were laser scanned with the GeneChip Scanner 3000 (Affymetrix) according to the manufacturer's instructions. Data were saved as a raw image file, and quantified using GCOS 1.2 (Affymetrix). Pre-processing and normalization of signal intensities was carried out using the error model of Rosetta Resolver v5.1 (Rosetta Biosoftware, Seattle, WA, USA), which was developed for Affymetrix GeneChips. Technical and biological duplicates were combined to obtain intensities and standard errors per group. Rosetta Resolver and Locuslink (Entrez Gene) were used to combine the expression intensities of multiple probes per gene to obtain the expression intensity per gene. The error model of Rosetta Resolver was used to determine fold changes between early and advanced stable atherosclerotic lesions and were considered significantly different when $p<0.05$. Ingenuity pathway analysis (Ingenuity Systems, Mountain View, CA, USA; https://analysis.ingenuity.com/pa) was performed on genes with a p-value $<0.01$. 


\section{Quantitative RT-PCR (qRT-PCR)}

A comparison of mRNA expression was made between early $(n=5)$ and stable lesions $(n=5)$ from autopsy, and between stable $(n=4)$ and thrombus-containing lesions $(n=5)$ from surgery. QRT-PCR for HIF1 $\alpha$, HIF2 $\alpha$, VEGF, GLUT1, GLUT3, HK1, HK2, GAPDH, and 18S rRNA (Applied biosystems, Foster City) were performed as previously described..$^{12}$

\section{Plaque angiogenesis}

Computerized morphometric analysis (Leica QWin V3, Cambridge, UK) of plaque microvessel density (total count/total plaque area was performed on 6 carotids with intimal thickening, 6 stable and 5 thrombus-containing lesions of post-mortem carotid arteries. A double staining with Ki-67 and a CD31+CD34 cocktail was used to quantify proliferating EC (KiEC).

\section{Statistical analysis}

All data are presented as mean \pm SEM. QRT-PCR, immunoreactivity, and MVD were compared between groups using a Mann-Whitney rank-sum test, and Spearmann's $\rho$ correlation coefficient was calculated for ordinal immunohistochemistry variables (SPSS 12.0 Chicago, IL). Bonferroni's multiple testing correction was performed, and results were considered statistically different when $\mathrm{p}<0.05$.

\section{Results}

\section{Hypoxia present in human carotid atherosclerosis}

The presence of hypoxia in human carotid atherosclerosis was demonstrated by pimonidazole immunoreactivity in all patients injected with pimonidazole (Figure 3.1). Hypoxia was present throughout the plaque ( $n=27 / 31$ segments) of 5 patients containing advanced atheromas with intraplaque hemorrhage or a luminal thrombus. In two patients, hypoxia was present in only one segment per plaque $(n=2 / 12)$. One lesion was a stable fibrocalcified plaque with no or minor inflammation, the other showed almost neglectable intraplaque hemorrhage (data not shown). As pimonidazole was previously shown to detect hypoxia in normal skin, ${ }^{17}$ staining of a skin biopsy confirmed that the pimonidazole injection was successful in all patients (Figure 3.2A-B). Antibody specificity was confirmed by a complete lack of immunoreactivity in 5 patients without pimonidazole administration (Figure 3.2C-D). 

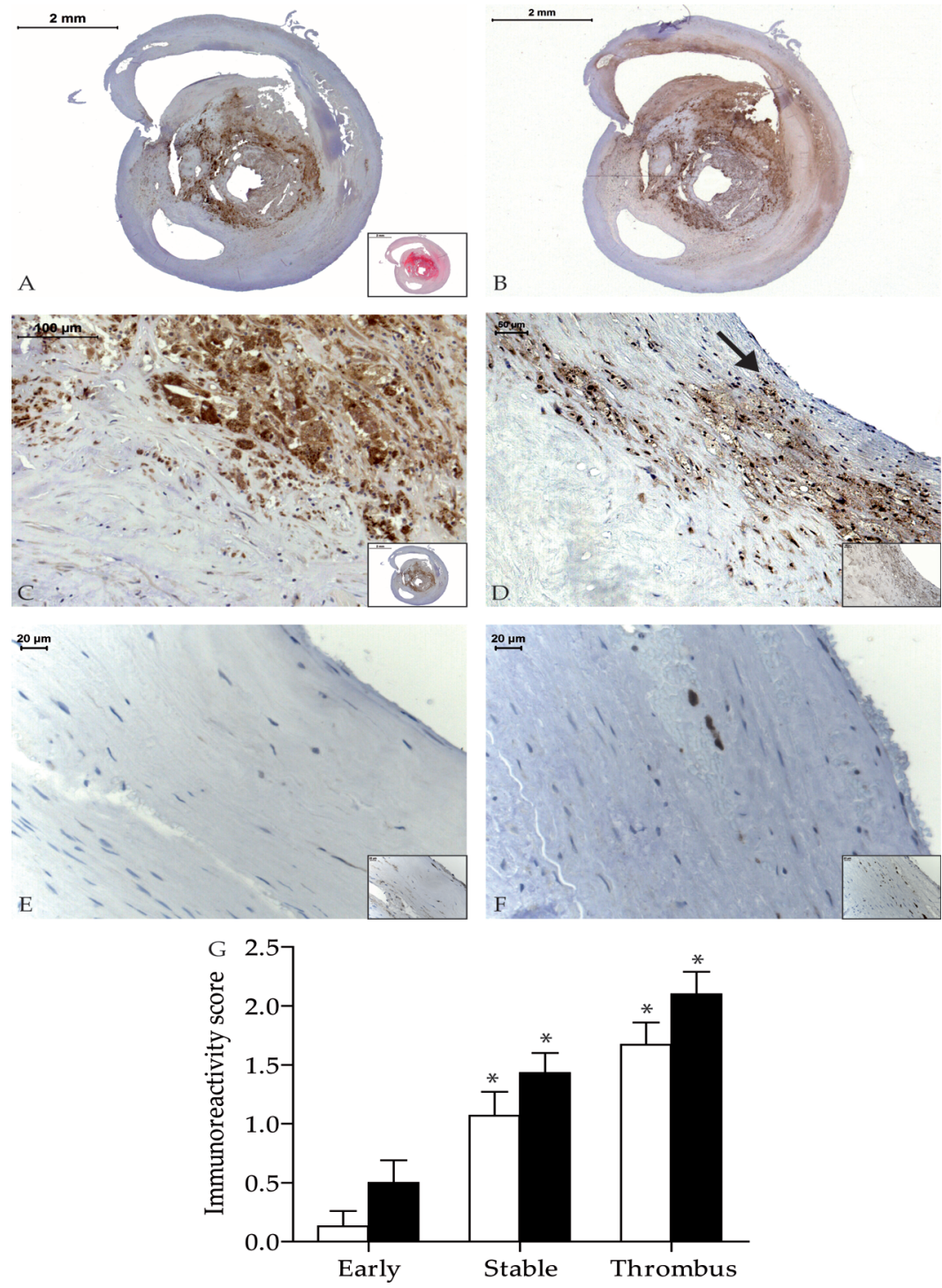

Figure 3.1. Hypoxia detection using pimonidazole in human carotid endarterectomy

A. Hypoxia (pimonidazole immunoreactivity) is present in the center of an advanced human carotid atherosclerotic plaque, but not in the media. Inset shows HE staining. B A serial section of A shows that CD68-positive macrophages co-localize with hypoxia. C. Macrophage regions of lesion A show extensive hypoxia, whereas the cap shows mild or no hypoxia. D. Hypoxia is present in CD68positive macrophages (inset) at 20-30 $\mu \mathrm{m}$ from the lumen. E. Hypoxia is absent in CD68-positive macrophages (inset) of a plaque shoulder segment (pathological intimal thickening). F. Hypoxia is present in an atherosclerotic plaque segment with intimal thickening, more specifically in a few CD68-positive macrophages (inset). L indicates lumen. G. The immunoreactivity score of hypoxia (white bars) and CD68 (black bars) is increased in stable and ruptured atherosclerotic lesions vs. early lesions. ( $p$-value $<0.05$ vs. early, stable vs. ruptured is not significant) 

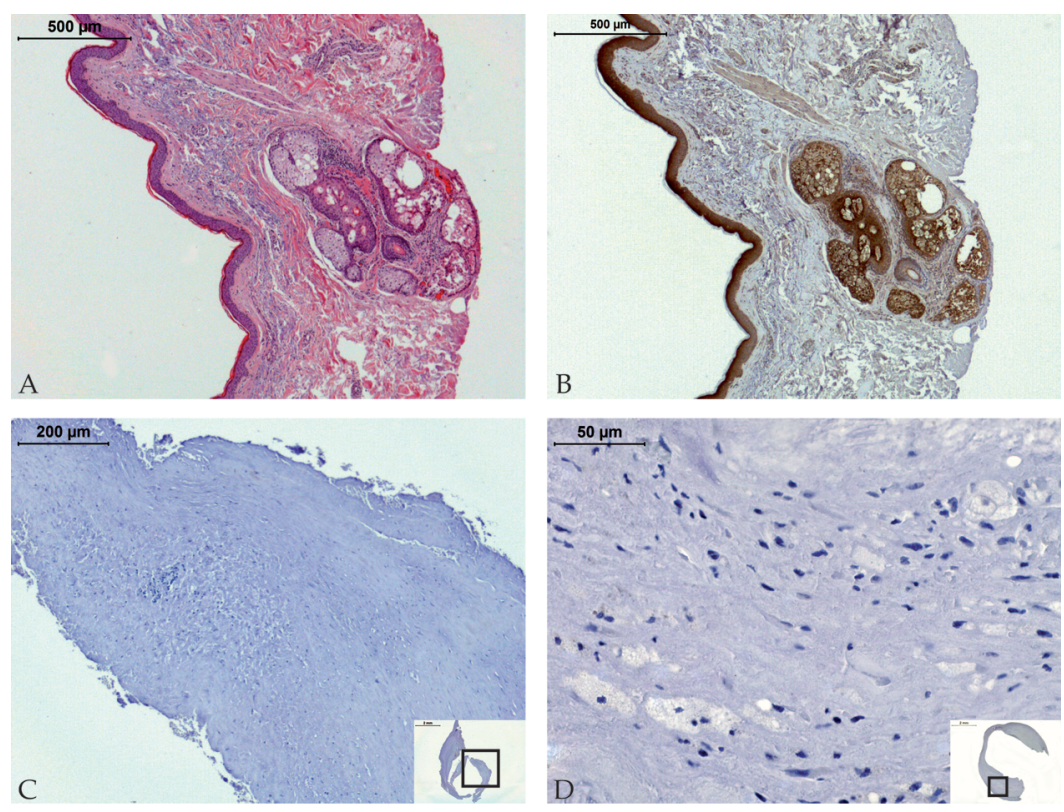

Figure 3.2. No pimonidazole immunoreactivity in control patients

A. Hematoxylin and eosin staining of normal skin at incision site. B. Hypoxia (pimonidazole immunoreactivity) is present in the epithelium, hair follicle and sebaceous gland of normal skin tissue, a positive control for pimonidazole infusion. C. No pimonidazole immunoreactivity was detected in the carotid atherosclerotic plaques of a patient without pre-operative pimonidazole injection. Inset shows origin of magnification. D. No pimonidazole immunoreactivity was detected in the macrophages of carotid atherosclerotic plaques of another patient without pre-operative pimonidazole treatment. Inset shows CD68 staining.

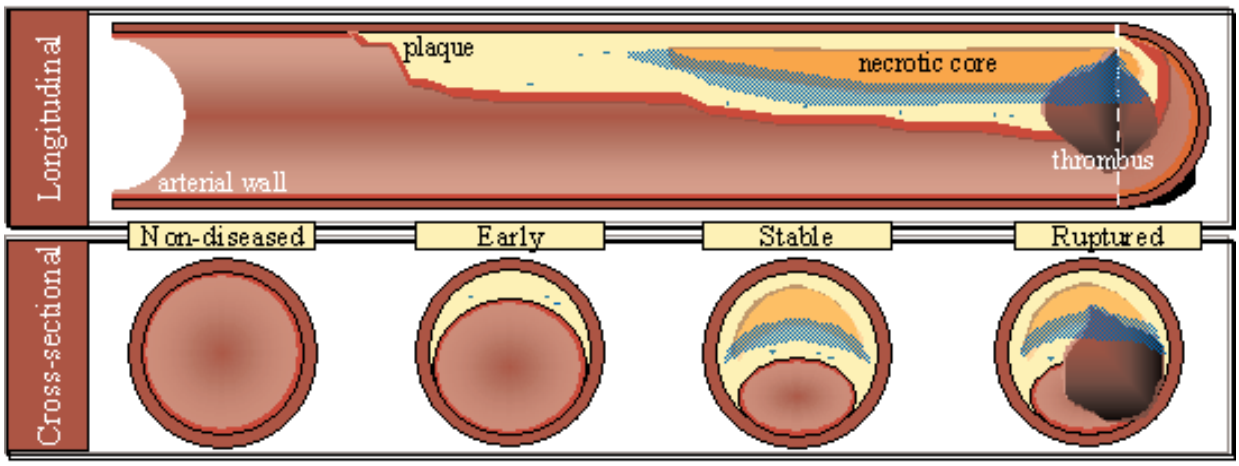

Figure 3.3. Schematic illustration of hypoxia in atherosclerosis

Illustration of the presence of hypoxia (blue areas) in a longitudinal and cross-sectional representation of atherogenesis. a.wall, arterial wall; nc, necrotic core; th, thrombus 
Hypoxia immunoreactivity co-localized with CD68-positive macrophage foam cells, but was also mildly present in smooth muscle cells (Figure 3.1A-D). Pimonidazole is only metabolized in viable cells, explaining the lack of staining in necrotic or acellular areas. Hypoxia strongly correlated with CD68, angiogenesis, and the presence of a thrombus, but not with the presence of fibrosis (Table 3.3) or apoptosis (data not shown). Two hypoxic gradients were observed as illustrated by Figure 3.3. Cross-sectionally, hypoxia was very strong in macrophage clusters surrounding the plaque core, but was absent in a 100-250 $\mu \mathrm{m}$ rim bordering the lumen (Figure 3.1A-B) and in the media (Figure 3.1A, C). However, some isolated macrophages located $20-30 \mu \mathrm{m}$ of the lumen were hypoxic (Figure 3.1D). Longitudinally, hypoxia was most intense in parts of the plaque containing an advanced atheroma with a thrombus and inflammation (Figure 3.1A, B), and mostly absent in shoulder regions with (pathological) intimal thickening despite inflammatory infiltration (Figure 3.1E, G). However, in a minority of shoulder segments with (pathological) intimal thickening hypoxia was present, but only in macrophages (Figure 3.1F). Hypoxia was present in all longitudinal parts of the plaque, predominantly in macrophages, although not all macrophages were hypoxic (Table 3.4, Figure 3.1G).

\section{Hypoxia detection is not influenced by surgery-induced ischemia or ROS}

To exclude that pimonidazole immunoreactivity in the atherosclerotic plaque was the result of surgery-induced ischemia, arterial wall segments were collected at two time-points: directly after incision of the carotid artery and directly following excision of the plaque. Pimonidazole immunoreactivity in

Table 3.3. Spearman correlation coefficients of hypoxia immunoreactivity with characteristics of carotid atherosclerosis

\begin{tabular}{llllllll}
\hline & Thrombus & Fibrosis & Angiogenesis & CD68 & HIF1 $\alpha$ & HIF2 $\alpha$ & VEGF \\
\hline Spearmann's $\rho$ & $0.60^{*}$ & 0.07 & $0.62^{*}$ & $0.70^{*}$ & $0.83^{*}$ & $0.75^{*}$ & $0.49^{*}$ \\
\hline
\end{tabular}

* Bonferroni corrected p-value $<0.05$

Table 3.4. Percentage of segments showing hypoxia or CD68 immunoreactivity

\begin{tabular}{lll}
\hline Lesion type (n) & Hypoxia \% (n) & CD68 \% (n) \\
\hline Early (8) & $13(1)$ & $50(4)$ \\
Stable (14) & $71(10)$ & $93(13)$ \\
Thrombus (21) & $90(19)$ & $95(20)$ \\
\hline
\end{tabular}


these two pieces was not different (Figure 3.4A-B), suggesting that hypoxia and pimonidazole adducts were already present in the plaques before surgery.

Although the anti-pimonidazole antibody only recognizes hypoxiaderivatives, pimonidazole itself may react with ROS. Hypoxia specificity was confirmed in human THP-1 macrophages exposed to hypoxia and/or $\mathrm{H}_{2} \mathrm{O}_{2}$ (Figure 3.4C). Exposure to $\mathrm{H}_{2} \mathrm{O}_{2}$ induced intracellular antioxidant activity without influencing cell viability (data not shown). Only hypoxic exposure up to $1 \% \quad \mathrm{O}_{2}$ showed pimonidazole-immunoreactive cells (data not shown). Immunoreactivity of combined exposure to hypoxia and $\mathrm{H}_{2} \mathrm{O}_{2}$ was similar to single hypoxic exposure, showing that the concentration pimonidazole available for hypoxia detection was not limited by $\mathrm{H}_{2} \mathrm{O}_{2}$-derivatives of pimonidazole (Figure 3.4C).

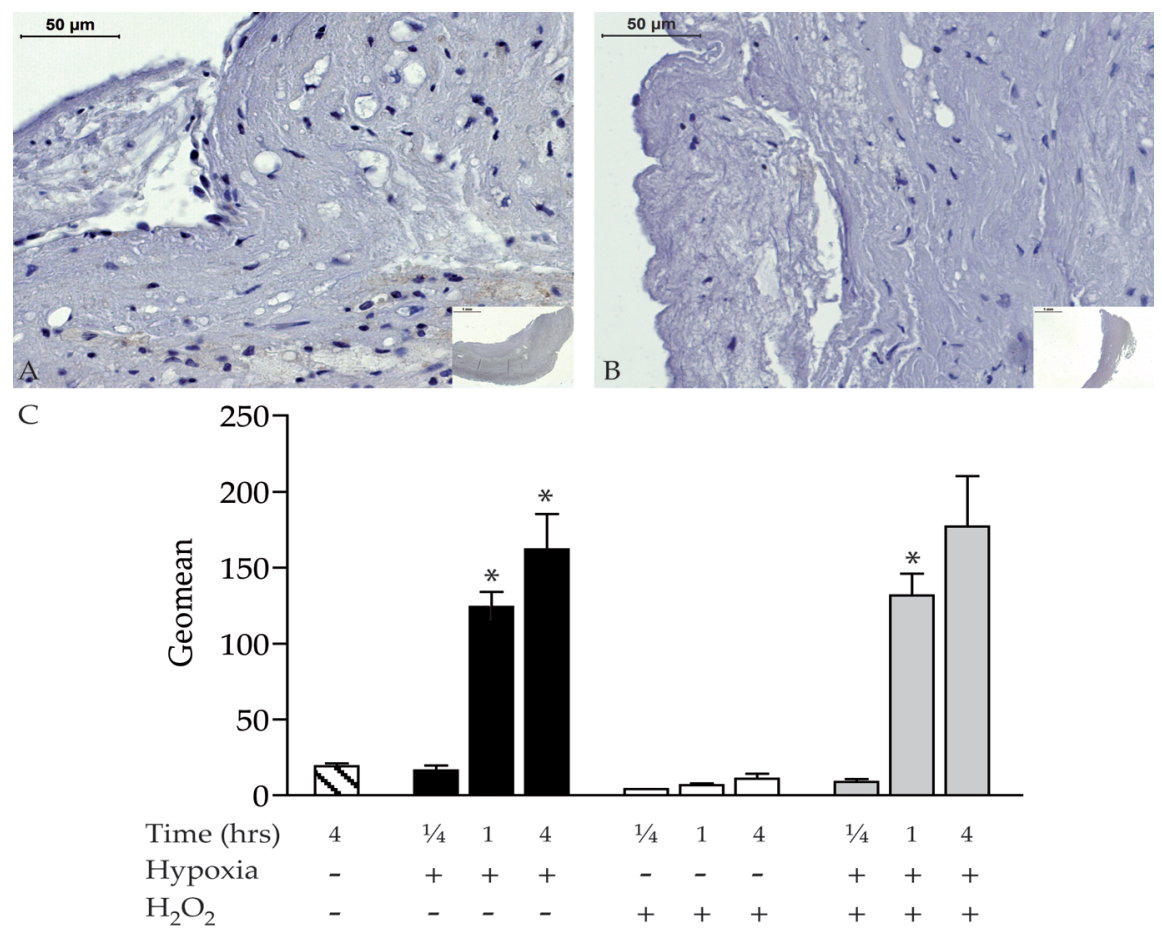

Figure 3.4. Hypoxia detection in arterial wall and human THP-1 macrophages

A. Hypoxia (pimonidazole immunoreactivity) is almost absent in the arterial wall collected right after carotid incision, as well as B. right after excision of the atherosclerotic plaque. Insets show origin of magnification. C. Pimonidazole was detected in human THP- 1 macrophages in $0.2 \% \mathrm{O}_{2}$ (hypoxia) using FACS analysis (black bars), but was undetectable in $21 \% \mathrm{O}_{2}$ (black and white striped bars) or after $\mathrm{H}_{2} \mathrm{O}_{2}$ stimulus (white bars). No significant differences were found between single hypoxia and hypoxia $+\mathrm{H}_{2} \mathrm{O}_{2}$ exposure (grey bars). ${ }^{*}$-v-value $<0.05$ vs. $21 \% \mathrm{O}_{2}$ 


\section{Co localization of hypoxia, HIF and macrophages}

Hypoxia typically stabilizes HIF protein, and the co-localization and correlation of hypoxia (Figure 3.5A) with HIF1 $\alpha$ (Figure 3.5AB), HIF2 $\alpha$ (data not shown), and VEGF (Figure 3.5C) suggests this also occurs in atherosclerosis (Table 3.4). Analogous to hypoxia immunoreactivity, nuclear HIF1 $\alpha$ (Figure 3.6C-D) and 2 (Figure 3.6G-H) immunoreactivity and mRNA (Figure 3.7B-C) were predominantly detected at sites of inflammation. Strong correlations of CD68 immunoreactivity were found with HIF1 $\alpha(\rho=0.70, p=0.007)$ and $\operatorname{HIF} 2 \alpha(\rho=0.63, p=0.02)$.
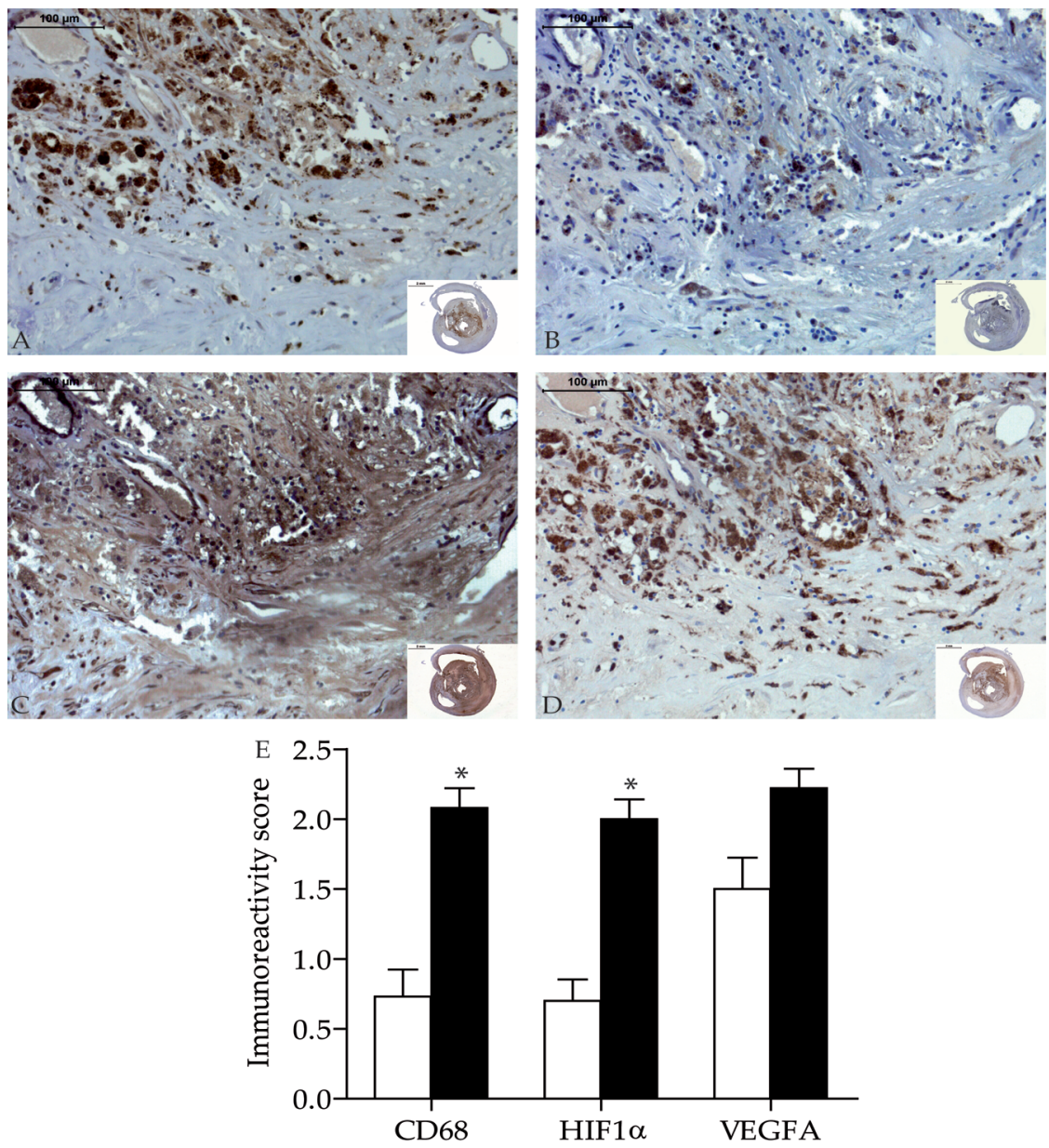

Figure 3.5. Hypoxia co-localizes with CD68, HIF and VEGF

A. Hypoxia detected by pimonidazole immunoreactivity in human carotid atherosclerosis. Serial sections show co-localization with B. HIF1 $\alpha$, C. VEGF and D. CD68-positive macrophages. E. The immunoreactivity score of CD68, HIF1 $\alpha$ and VEGF is increased when hypoxia is present (black bars) vs. absent (open bars) in human carotid atherosclerosis ( $\mathrm{p}$-value $<0.05$ ) 

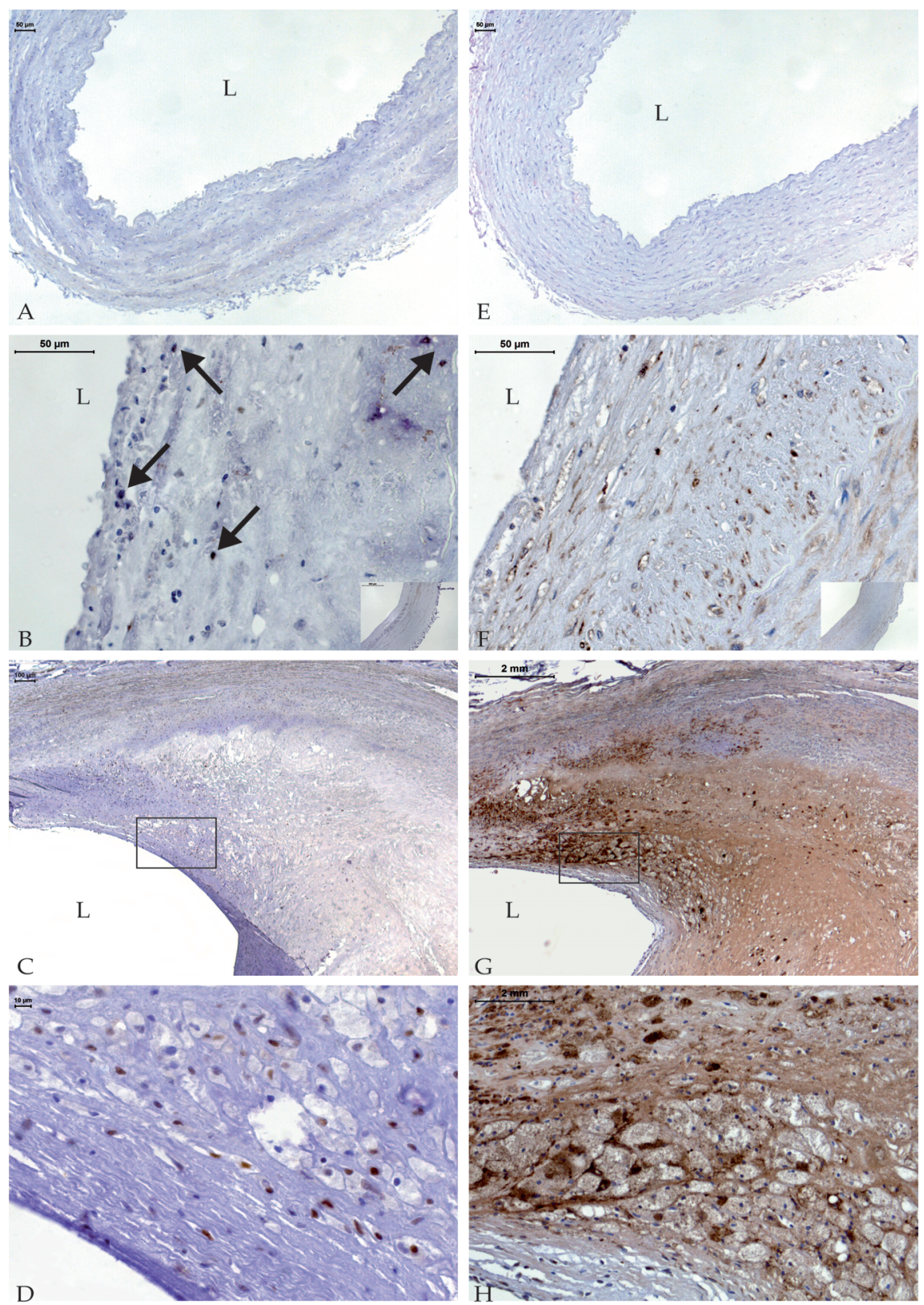

Figure 3.6. Immunolocalization of HIF1 $\alpha$ and $2 \alpha$ and responsive genes in human non-diseased and atherosclerotic vasculature.

Nuclear staining of HIF1 $\alpha$ (A-D) and HIF2 $\alpha$ (E-H) is absent in human mammary artery (A and E resp.,) and increased from early ( $\mathrm{B}$ and $\mathrm{F}$ resp.) to advanced carotid lesions ( $\mathrm{C}$ and $\mathrm{G}$ resp.). Macrophages in advanced lesions demonstrated strong HIF1 $\alpha$ (D) and $2 \alpha(\mathrm{H})$ expression. Nuclear immunoreactivity (functional protein levels) of HIF1 $\alpha$ and $2 \alpha$ are similar. L indicates lumen. 

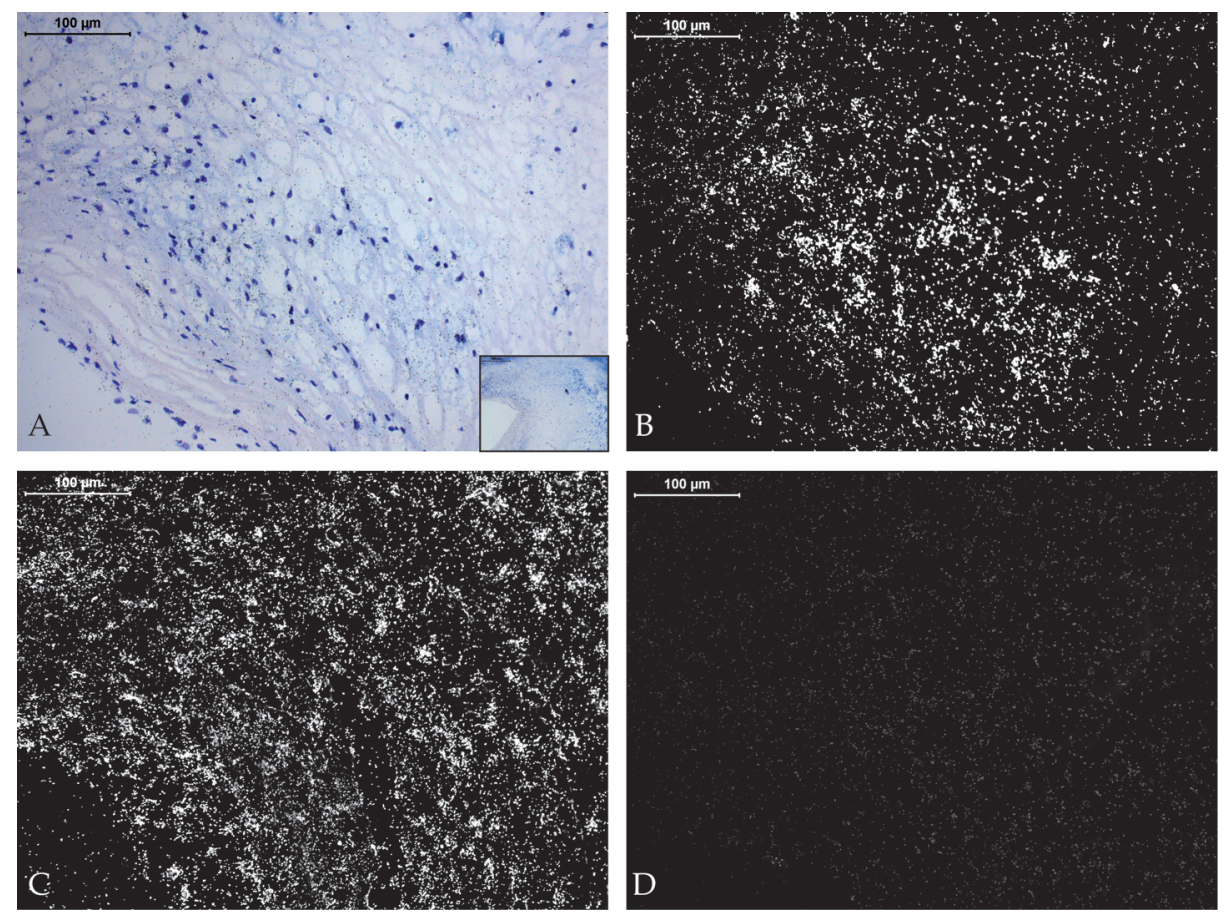

Figure 3.7. Cellular localization of HIF1 and 2 mRNA in advanced carotid lesion

A. Bright field images of human carotid with an advanced atherosclerotic plaque corresponding to dark field images B-C. Expression of HIF1 $\alpha$ (B) and HIF2 $\alpha$ (C) mRNA (white signal) was observed in macrophages surrounding the core and in the shoulder regions of advanced atherosclerosis. D. No signal is observed using sense probes (negative control) for HIF1 $\alpha$. L indicates lumen. 
HIF pathway mRNA and protein are associated with progression from early to advanced atherosclerosis

Microarray, qRT-PCR, and semiquantitative immunohistochemistry showed that mRNA and protein expression of $\operatorname{HIF} 1 \alpha, 2 \alpha$, and their targets increased from early to advanced human atherosclerosis (Figures 3.6, 3.8 and 3.9). Microarray pathway analysis revealed the significant differential expression of canonical pathways "HIF signaling" (7/70 genes, p=0.02) and "VEGF signaling" (15/90 genes, $\mathrm{p}=0.02$ ) between early and advanced human atherosclerosis. At the single gene level, HIF1 $\alpha$, VEGF, GLUT3, and HK2 mRNA were significantly upregulated between early and stable lesions: 1.4, 1.8, 2.0, and 2.3 fold, respectively (Figure 3.8A). Microarray results were validated with qRT-PCR using a different set of patient samples, explaining that only VEGF mRNA was significantly upregulated using qRT-PCR analysis (Figure 3.8B). However, the same trends were shown using microarray and qRT-PCR. Likewise, protein expression levels of HIF and HIF-responsive genes were significantly increased with progression of atherosclerosis from early to advanced plaques, except for HK1 (Figure 3.9A). The lack of corresponding GLUT1 and GLUT3 mRNA and protein levels may be explained by previous observations of increased translation efficiency and protein stability respectively. No significant differences of HIF and HIF-responsive genes were seen between the two advanced lesion types, stable or thrombus-containing lesions, neither on mRNA level nor on protein level (Figure 3.8C, 3.9A).

\section{Angiogenesis in human carotid atherosclerosis paralleled HIF and VEGF expression}

Intraplaque microvessel density increased from early to advanced lesions $(p=0.01)$, but was not different between stable or thrombus-containing lesions (Figure 3.9E). In addition, strong correlations were found between microvessel density and HIF1 $\alpha(\rho=0.80, p=0.001), \operatorname{HIF} 2 \alpha(\rho=0.77, p=0.001)$, and VEGF $(\rho=0.66$, $\mathrm{p}=0.01$ ). Although abundant proliferating macrophages and SMC were seen, hardly any KiEC were detected in plaque microvessels: 3 KiEC in 5 thrombuscontaining lesions. However, microvessel EC were not apoptotic either as indicated by the absence of activated-caspase 3 (data not shown). 

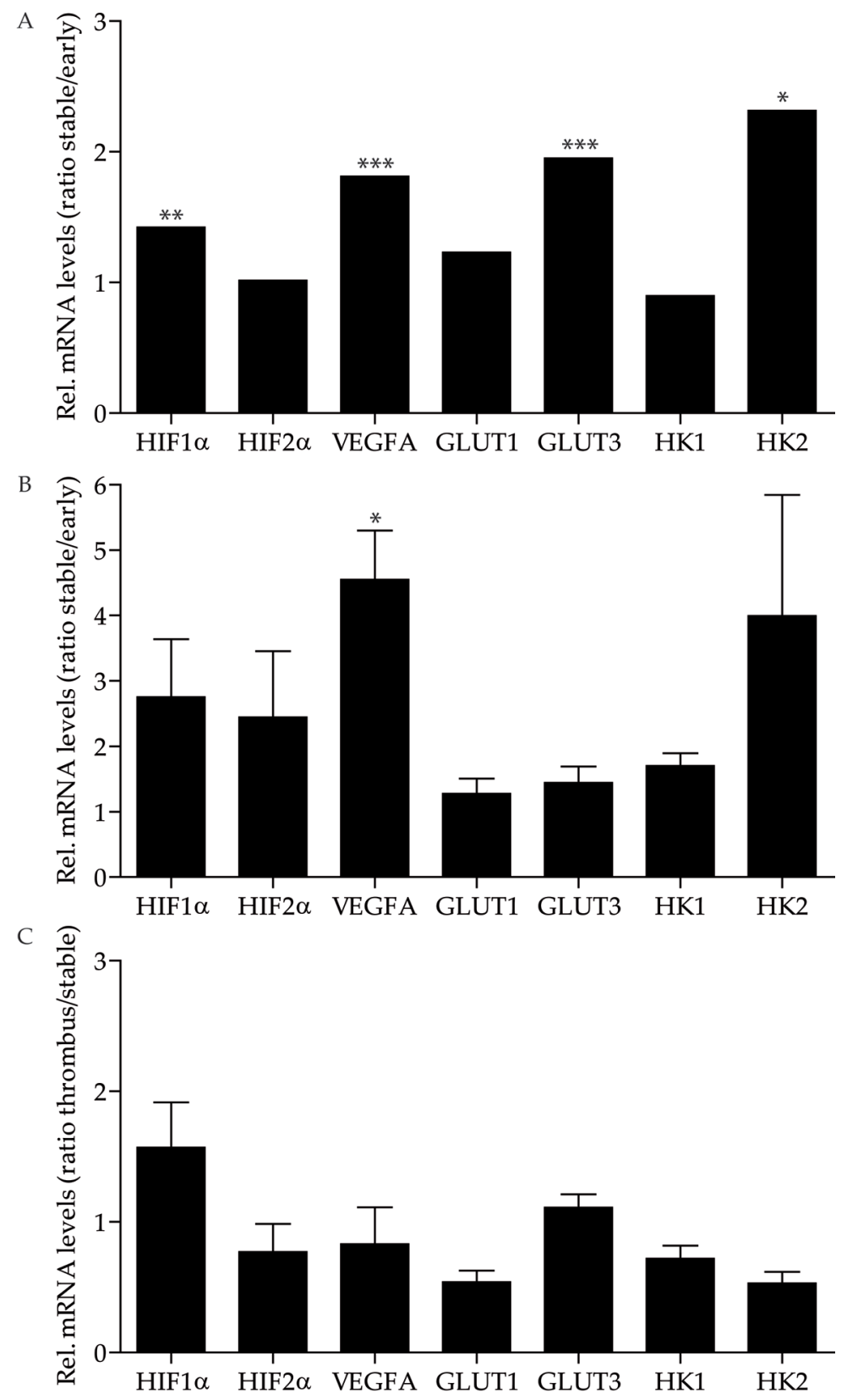

Figure 3.8. Relative expression levels of HIF pathway mRNA

A. The expression ratio determined between 9 early and 6 stable lesions by microarray analysis was significantly different for HIF1 $\alpha$, VEGF, GLUT3 and HK2. ${ }^{*} \mathrm{p}<0.01$; ${ }^{* *} \mathrm{p}<0.001$; ${ }^{* * *} \mathrm{p}<0.00001$ B. QRTPCR compared the expression ratio between 5 early 5 and stable lesions collected at autopsy $\left({ }^{*} \mathrm{p}<0.05\right)$ and $\mathrm{C}$. between 4 stable and 5 thrombus-containing lesions collected at surgery. 


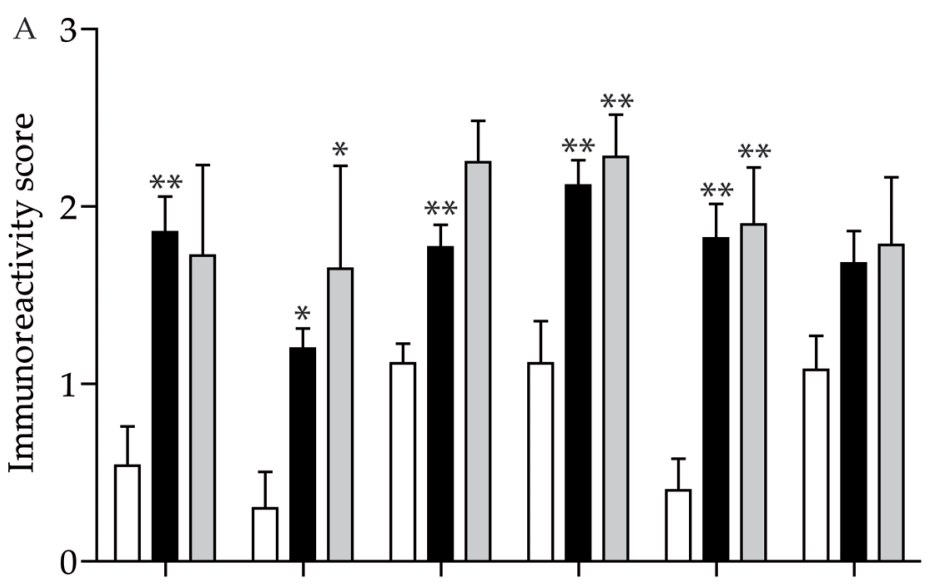

HIF1 $\alpha$ HIF2 $\alpha$ VEGFA GLUT1 GLUT3 HK1
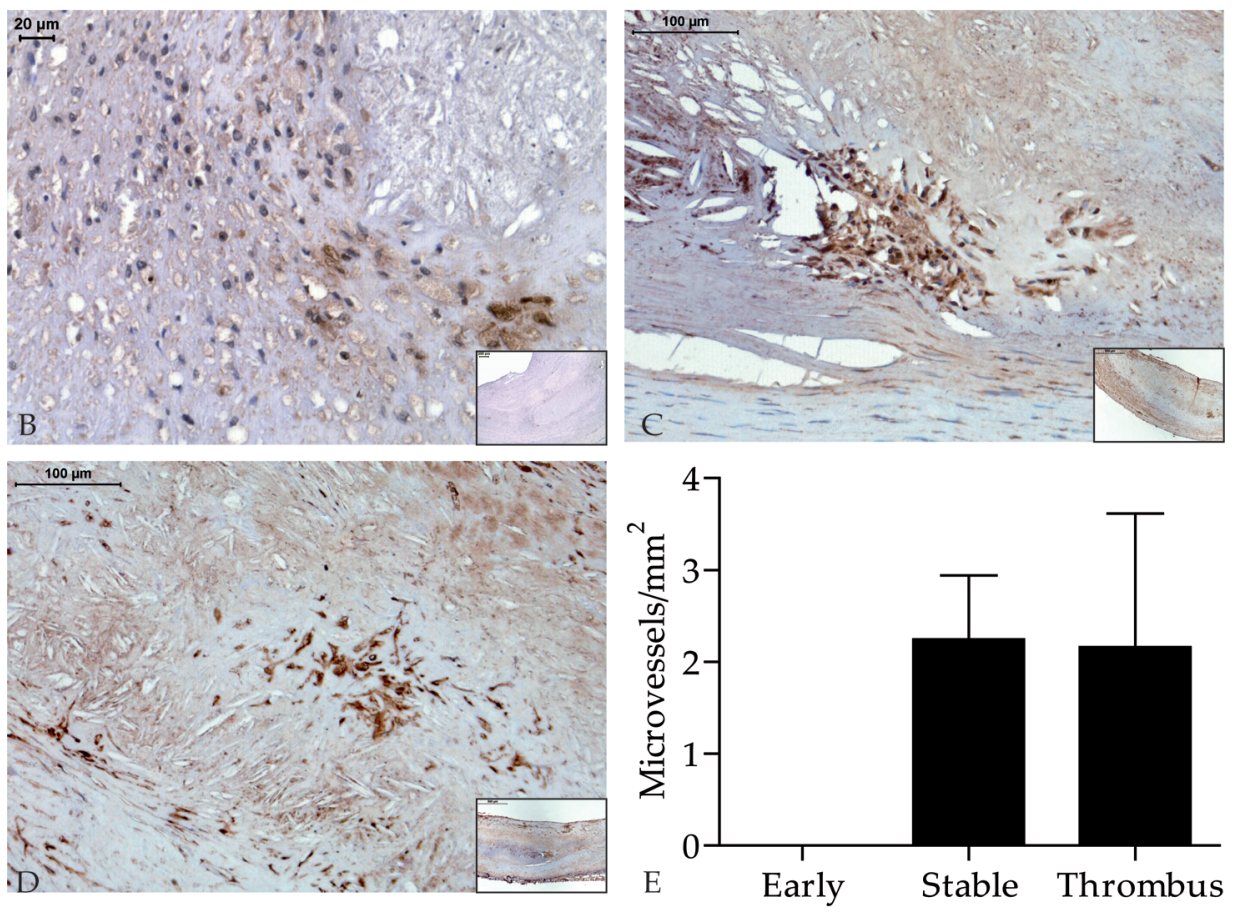

Figure 3.9. Semiquantification HIF pathway immunoreactivity in human carotid atherosclerosis

A. Immunoreactivity of HIF pathway proteins was significantly increased from early (white bars, $\mathrm{n}=5$ ) to stable lesions (black bars, $\mathrm{n}=5$ ) for HIF1 $\alpha$, HIF2 $\alpha$, VEGF, GLUT1 and GLUT3, but similar in stable and thrombus-containing lesions (grey bars, $\mathrm{n}=5$ ). ${ }^{*} \mathrm{p}<0.05$ vs. early; ${ }^{* *}<0.01$ vs. early. B. Macrophages in advanced lesions demonstrated strong immunoreactivity of HIF-responsive genes: VEGF (B), GLUT3 (C) and HK1 (D). L indicates lumen. E. Microvessel density was determined in 6 human carotid arteries with early (intimal thickening), 6 stable or 5 thrombus-containing atherosclerotic lesions. ${ }^{*} \mathrm{p}<0.01$ vs. early 


\section{Discussion}

This study convincingly demonstrates the direct presence of genuine hypoxia in the macrophage-rich center of human carotid atherosclerosis using the hypoxia marker pimonidazole. Hypoxia was strongly correlated with CD68-positive macrophages, similar to previous studies in rabbit atherosclerosis, ${ }^{4}$ but also with the presence of angiogenesis and a thrombus. The latter effect is most likely mediated by macrophages, as these infiltrate into the thrombus resolving the clot.

Hypoxia detection was not due to an artifact of surgery or ROS. First, not all cells nor every part of the plaque was hypoxic. Hypoxia was mild or absent in the media and close to the main artery lumen, even though smooth muscle cells are assumed to be metabolically active. Second, hypoxia detection was similar between vascular specimens collected either immediately after carotid clamping or just prior to clamp release, arguing that hypoxia was present in the plaque prior to clamping. In addition, macrophage in vitro data confirmed the hypoxiaselective detection of pimonidazole by its antibody. As previously shown, ${ }^{18}$ the antibody did not cross-react with ROS-derivatives of pimonidazole, nor was the pimonidazole dose a limiting factor.

Hypoxia occurs when oxygen supply is decreased and/or demand is increased. Hypoxia of the vessel wall could arise when the intimal thickness exceeds the maximal oxygen diffusion distance of $\sim 100-250 \mu \mathrm{m},{ }^{19}$ reducing oxygen supply. In fact, intimal thickness of the advanced, carotid lesions analyzed was significantly greater $(1500 \pm 350 \mu \mathrm{m})$ than the oxygen diffusion distance, and in most lesions a hypoxia-negative rim of 100-250 $\mu \mathrm{m}$ borders the lumen. Hypoxia may also develop from an increased oxygen demand, resulting from the high oxygen demand of metabolically active inflammatory cells. ${ }^{20}$ Hypoxia is indeed typically present in macrophage foam cells, but not all macrophages are hypoxic. However, some subluminal $(20-30 \mu \mathrm{m})$ foam cells were already hypoxic, despite their location well within the oxygen diffusion distance. Thus, the hypoxia threshold seems mostly dependent on the inflammatory micro-environment, although our observations support a (minor) contribution for a decreased oxygen supply.

As hypoxic cells typically activate hypoxia-inducible factors (HIF), we studied whether HIF was present in hypoxic atherosclerosis. Although several non-hypoxic stimuli are known to induce HIF protein, such as lipopolysacharide, ${ }^{21}$ and angiotensin $\mathrm{II}^{8}{ }^{3}$ hypoxia is the most obvious stimulator of HIF-induced angiogenesis to restore oxygen load. Indeed, in human atherosclerosis hypoxia co-localized and correlated with HIF, VEGF, and 
intraplaque angiogenesis. Recent studies showed no association of HIF immunoreactivity with coronary intraplaque angiogenesis, ${ }^{22}$ and an inverse correlation with carotid and femoral intraplaque angiogenesis. ${ }^{23}$ These results are unexpected considering the established positive correlation between HIF and angiogenesis in tumors, ${ }^{6}$ in rabbit atherosclerosis in vivo, and in our study. ${ }^{24}$ Nonetheless, the strong correlation of HIF immunoreactivity with inflammation and VEGF has been confirmed. ${ }^{23}$

We hypothesize that hypoxia in macrophages stimulates HIF and angiogenesis in the progression of human atherosclerosis. In addition to a proangiogenic effect, hypoxia in macrophages has been described to increase cytokine production, ${ }^{20}$ low density lipoprotein (LDL) oxidation, ${ }^{25}$ and lipid loading $^{26}$ in vitro, processes all associated with the development of macrophage foam cells, a lipid and/or necrotic core, and hence with destabilization of a plaque. ${ }^{1}$ Thus, we speculate that hypoxic macrophages contribute to atherosclerotic plaque instability. However, due to the cross-sectional, observational study design it remains unclear at what plaque stage hypoxia first occurs, and whether hypoxia is a cause or consequence of atherogenesis. The HIF expression study precludes establishing an association between hypoxia and atherogenesis, as upstream stimuli other than hypoxia may explain HIF stabilization in atherosclerosis. Other limitations of this study are the lack of clinical characteristics in the HIF expression study and of quantitative protein data (e.g. western blot).

In conclusion, this is the first study to directly demonstrate hypoxia in human advanced atherosclerotic lesions. Hypoxia correlated with the presence of macrophages, angiogenesis, thrombus, and the expression of HIF and VEGF. Also, the HIF pathway and microvessel density were associated with lesion progression and angiogenesis, suggesting the involvement of the HIF pathway in the response to hypoxia and the regulation of human intraplaque angiogenesis.

\section{Acknowledgements}

We gratefully acknowledge Marie-Thérèse Morin, Chantal Pottgens, Petra Aarts, Roselinde van Os, and Roger van de Wetering for excellent technical assistance, and Erik Biessen and Sylvia Heeneman for critically reading the manuscript. The authors participate in the European Vascular Genomics Network (http://www.evgn.org), a Network of Excellence supported by the European Community's Sixth Framework Program for Research Priority 1 (contract LSHM-CT-2003-503254). Research was supported in part by grants from the van 
Walree Fund, Royal Netherlands Academy of Arts and Sciences, the Innovational research Veni program of the Netherlands Organization of Scientific research (grant 916.046.083) and the SenterNovem agency of the Dutch Ministry of Economic Affairs (grant TSGE3088). The authors have no conflicts of interest to declare. 


\section{Chapter 3}

\section{References}

1. Virmani R, Kolodgie FD, Burke AP, et al. Atherosclerotic Plaque Progression and Vulnerability to Rupture Angiogenesis as a Source of Intraplaque Hemorrhage. Arterioscler Thromb Vasc Biol. 2005;25:2054-2061

2. Moreno PR, Purushothaman KR, Sirol M, et al. Neovascularization in human atherosclerosis. Circulation. 2006;113:2245-2252.

3. Herrmann J, Lerman LO, Mukhopadhyay D, et al. Angiogenesis in Atherogenesis. Arterioscler Thromb Vasc Biol. 2006;26:1948-1957.

4. Bjornheden T, Levin M, Evaldsson M, et al. Evidence of hypoxic areas within the arterial wall in vivo. Arterioscler Thromb Vasc Biol. 1999;19:870-876.

5. Celletti FL, Waugh JM, Amabile PG, et al. Vascular endothelial growth factor enhances atherosclerotic plaque progression. Nat Med. 2001;7:425-429.

6. Semenza GL. Targeting HIF-1 for cancer therapy. Nat Rev Cancer. 2003;3:721-732.

7. Talks KL, Turley H, Gatter KC, et al. The expression and distribution of the hypoxia-inducible factors HIF-1alpha and HIF-2alpha in normal human tissues, cancers, and tumor-associated macrophages. Am J Pathol. 2000;157:411-421.

8. Page EL, Robitaille GA, Pouyssegur J, et al. Induction of hypoxia-inducible factor-1alpha by transcriptional and translational mechanisms. J Biol Chem. 2002;277:48403-48409.

9. Zhou J, Schmid T, Brune B. Tumor necrosis factor-alpha causes accumulation of a ubiquitinated form of hypoxia inducible factor-1alpha through a nuclear factor-kappaB-dependent pathway. Mol Biol Cell. 2003;14:2216-2225.

10. Ihling C, Szombathy T, Bohrmann B, et al. Coexpression of endothelin-converting enzyme-1 and endothelin-1 in different stages of human atherosclerosis. Circulation. 2001;104:864-869.

11. Pasterkamp G, Schoneveld AH, Hijnen DJ, et al. Atherosclerotic arterial remodeling and the localization of macrophages and matrix metalloproteases 1,2 and 9 in the human coronary artery. Atherosclerosis. 2000;150:245-253.

12. Sluimer JC, Kisters N, Cleutjens KB, et al. Dead or Alive: Gene expression profiles of advanced atherosclerotic plaques from autopsy and surgery. Physiol Genomics. 2007;30:335-341.

13. Virmani R, Kolodgie FD, Burke AP, et al. Lessons from sudden coronary death: a comprehensive morphological classification scheme for atherosclerotic lesions. Arterioscler Thromb Vasc Biol. 2000;20:1262-1275.

14. Sibony M, Commo F, Callard P, et al. Enhancement of mRNA in situ hybridization signal by microwave heating. Lab Invest. 1995;73:586-591.

15. Favier J, Kempf H, Corvol P, et al. Coexpression of endothelial PAS protein 1 with essential angiogenic factors suggests its involvement in human vascular development. Dev Dyn. 2001;222:377-388.

16. Chomczynski P, Sacchi N. Single-step method of RNA isolation by acid guanidinium thiocyanate-phenol-chloroform extraction. Anal Biochem. 1987;162:156-159. 
17. Haroon ZA, Raleigh JA, Greenberg CS, et al. Early wound healing exhibits cytokine surge without evidence of hypoxia. Ann Surg. 2000;231:137-147.

18. Kleiter MM, Thrall DE, Malarkey DE, et al. A comparison of oral and intravenous pimonidazole in canine tumors using intravenous CCI-103F as a control hypoxia marker. Int J Radiat Oncol Biol Phys. 2006;64:592-602.

19. Torres Filho IP, Leunig M, Yuan F, et al. Noninvasive measurement of microvascular and interstitial oxygen profiles in a human tumor in SCID mice. Proc Natl Acad Sci U S A. 1994;91:2081-2085.

20. Murdoch C, Muthana M, Lewis CE. Hypoxia regulates macrophage functions in inflammation. J Immunol. 2005;175:6257-6263.

21. Blouin CC, Page EL, Soucy GM, et al. Hypoxic gene activation by lipopolysaccharide in macrophages: implication of hypoxia-inducible factor 1alpha. Blood. 2004;103:1124-1130.

22. Chen F, Eriksson P, Kimura T, et al. Apoptosis and angiogenesis are induced in the unstable coronary atherosclerotic plaque. Coron Artery Dis. 2005;16:191-197.

23. Vink A, Schoneveld AH, Lamers D, et al. HIF-1alpha expression is associated with an atheromatous inflammatory plaque phenotype and upregulated in activated macrophages. Atherosclerosis. 2007;195:e69-75.

24. Wilson SH, Herrmann J, Lerman LO, et al. Simvastatin preserves the structure of coronary adventitial vasa vasorum in experimental hypercholesterolemia independent of lipid lowering. Circulation. 2002;105:415-418.

25. Rydberg EK, Krettek A, Ullstrom C, et al. Hypoxia increases LDL oxidation and expression of 15-lipoxygenase-2 in human macrophages. Arterioscler Thromb Vasc Biol. 2004;24:2040-2045.

26. Bostrom P, Magnusson B, Svensson PA, et al. Hypoxia converts human macrophages into triglyceride-loaded foam cells. Arterioscler Thromb Vasc Biol. 2006;26:1871-1876. 
Hypoxia in murine plaque macrophages overrides the effect of LysMcre/HIF1 $\alpha$ and PHD1 deficiency on HIF protein expression and murine atherosclerosis

J.C. Sluimer, L. Beckers, M. Groeneweg, C. Pottgens, J. Pol, V. Herias, D. Lievens, E. Lutgens, M.P.J. de Winther, A.P.J.J. Bijnens, M.J.A.P. Daemen

Submitted for publication 


\section{Abstract}

Recently, we reported that hypoxia and hypoxia-inducible transcription factor $1 \alpha(\mathrm{HIF} 1 \alpha)$ were associated with macrophage content and progression of human atherosclerosis. As the underlying mechanism is unknown, possible mechanisms were addressed in murine atherosclerosis. First, we investigated whether hypoxia was present in murine atherosclerosis using the hypoxia marker pimonidazole, while the effect of hypoxia on atherogenesis was investigated by exposing mice with advanced plaques for four weeks to $10 \% \mathrm{O}_{2}$. The function of macrophage-specific HIF1 $\alpha$ and its regulator prolyl hydroxylase (PHD1) in the development of diet- and/or collar-induced atherosclerosis was studied using LysMcre/HIF1 $\alpha^{-/}$and full $\mathrm{PHD1}^{-/}$bone marrow transplantations into $\mathrm{LDLR}^{-/}$ mice. Atherosclerotic load, intimal (medial) thickness, lipid core-, collagen-, macrophage-, hypoxic-, and HIF1 $\alpha$ plaque content were determined in the aortic root, brachiocephalic artery, and collared carotid artery using quantitative (immuno)histology. HIF1 $\alpha$ protein and gene expression were determined in hypoxic bone marrow-derived macrophages using western blot and qRT-PCR respectively. Hypoxia was present in $70 \%$ of murine plaques, and correlated with macrophage content, but not with intimal thickness, and was absent in nondiseased arteries. Neither hypoxic exposure, nor LysMcre/HIF1 $\alpha^{-/}$and PHD1 ${ }^{-1}$ BMT changed plaque size, -composition, or hypoxic content. HIF1 $\alpha$ protein in WT macrophages was transiently increased in acute hypoxia, but prolonged hypoxic exposure lead to reversal of HIF stabilization. In contrast, hypoxia in LysMcre/HIF1 $\alpha^{-/}$macrophages was able to induce remnant HIF1 $\alpha$ mRNA and protein, as conditional deletion of HIF1 $\alpha$ was incomplete. Also, VEGF mRNA expression was similar in WT and LysMcre/HIF1 $\alpha^{-/}$macrophages after prolonged hypoxic exposure, although lower in LysMcre/HIF1 $\alpha^{-/-}$in normoxia and acute hypoxia. In PHD1 ${ }^{-/}, \mathrm{HIF} 1 \alpha$ protein was marginally increased in normoxia, but similar to WT in acute and prolonged hypoxia. Thus, HIF1 $\alpha$ protein expression in macrophages exposed to prolonged hypoxia was similar in WT, LysMcre/HIF1 $\alpha^{-/}$, and PHD1 ${ }^{-1}$ macrophages in vitro. Nuclear HIF1 $\alpha$ immunoreactivity was also similar in WT, LysMcre/HIF1 $\alpha^{-/}$, and PHD1 ${ }^{-/}$BMT plaques.

In conclusion, hypoxia in murine atherosclerosis correlated with inflammation, but plaque hypoxia and -size were unaffected by exogenous hypoxia. The restoration of HIF1 $\alpha$ and its target gene VEGF in macrophages exposed to prolonged hypoxia may explain the absent effect of LysMcre/HIF1 ${ }^{-/}$ and $\mathrm{PHD}^{-/}$on atherosclerosis in vivo, since plaque macrophages in vivo are also chronically hypoxic. The results identify hypoxia as a strong stimulus of HIF1 $\alpha$ protein expression in plaque macrophages, compensating the effect of LysMcre/HIF1 $\alpha$ and PHD1 deletion. 


\section{Introduction}

Inflammation, lipid accumulation, and angiogenesis are manifest in the development of atherosclerosis, and are related to the presence of macrophages in the atherosclerotic plaque. ${ }^{1}$ Low oxygen tension (hypoxia) significantly augments inflammation, lipid accumulation, and angiogenesis. ${ }^{2-4}$ Recently, we detected hypoxia and its key effector, the hypoxia-inducible transcription factor (HIF) in macrophages of human carotid atherosclerosis. Hypoxia and HIF were associated with progression and angiogenesis of human atherosclerosis, but currently the mechanism underlying this association is unknown. ${ }^{5}$

HIF consists of an $\alpha$ and a $\beta$ subunit, and the HIF $\alpha$ protein is tightly regulated by the oxygen concentration. In normoxia, HIF protein degradation is regulated by three isoforms of an oxygen-dependent prolyl hydroxylase (PHD1, PHD2, and PHD3), whose hydroxylation targets HIF $\alpha$ for immediate ubiquitin/proteasomal degradation. In hypoxia, HIF $\alpha$ subunit degradation is inhibited, and the ensuing heterodimeric HIF protein initiates the transcription of a multitude of genes involved in inflammation, glucose- and lipid metabolism, and angiogenesis, such as interleukin $1 \beta$ (IL1 $\beta$ ), glucose transporter 3 (GLUT3), lipoxidase 1 (LOX1), and vascular endothelial growth factor (VEGF) ${ }^{6.8}$ In prolonged hypoxia, several molecules execute a negative feedback loop on HIF transcription, translation and activity, including OS-9, IPAS, antisense HIF, and PHD enzymes. ${ }^{913}$ PHD2 and PHD3 are upregulated by HIF $\alpha$ protein in long-term hypoxia to prevent excessive accumulation of $\mathrm{HIF} \alpha{ }^{9,}{ }^{13} \mathrm{In}$ addition, the two $\alpha$ subunits, HIF1 $\alpha$ and HIF2 $\alpha$ negatively regulate their reciprocal expression. ${ }^{14}$ Moreover, HIF1 $\alpha$ and HIF $2 \alpha$ are also differentially activated: HIF $1 \alpha$ is preferentially stabilized in acute hypoxia, while HIF2 $\alpha$ is more prevalent in long-term hypoxia. ${ }^{12,}{ }^{15}$ The differential availability of HIF1 $\alpha$ and HIF2 $\alpha$ is paralleled by a differential transcription of their target genes. ${ }^{12,15}$

The function of hypoxia and HIF-driven transcripts suggests that hypoxia and HIF driven transcription in macrophages contribute to atherogenesis in vivo. Atherosclerosis is commonly studied in vivo in mouse models, but hypoxia has not been demonstrated in murine atherosclerosis. Therefore the presence of hypoxia and HIF in murine atherosclerosis, and a possible association with intimal thickness and macrophage content were investigated using the hypoxia marker pimonidazole. Subsequently, the effect of environmental hypoxia on atherosclerotic load was studied in murine atherosclerosis. Also, the effect of macrophage-specific deletion of HIF1 $\alpha$ or its oxygen-dependent regulator PHD1 on murine atherogenesis was studied using bone marrow transplantations into atherosclerosis-prone low-density lipoprotein receptor knockout $\left(\mathrm{LDLR}^{-}\right)$mice. Furthermore, the effect of hypoxia on HIF1 $\alpha$, HIF2 $\alpha$, PHD1, PHD2, PHD3, and VEGF expression was studied in bone marrow-derived macrophages in vitro. 
Hypoxic chamber

\begin{tabular}{|c|c|c|}
\hline 0 & Time-line (weeks) & Plaque morphometry: \\
\hline 111 & & $\begin{array}{l}\text { Size, core, IMT, MAC } \\
\text { hypoxia, HIF1 } \alpha\end{array}$ \\
\hline $\begin{array}{l}\text { Expoxure } \\
21 / 10 \% \text { O2 }\end{array}$ & $\begin{array}{l}\text { Sacrifice: } \\
\text { IP Pimonidazole } \\
\text { Collect aortic arch, -root, carotid }\end{array}$ & \\
\hline
\end{tabular}

\section{HIF1 BMT}

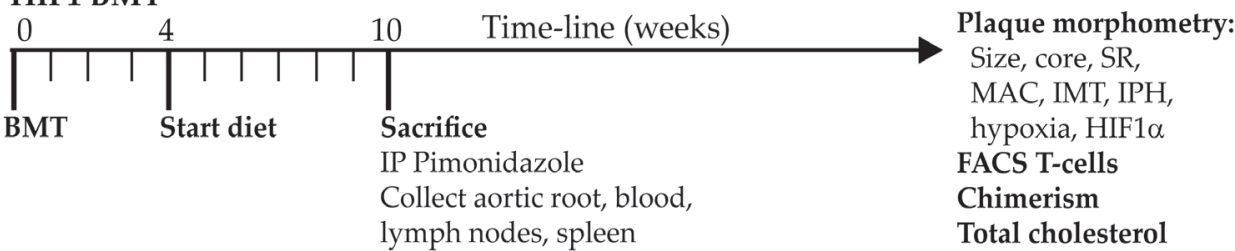

PHD1 BMT

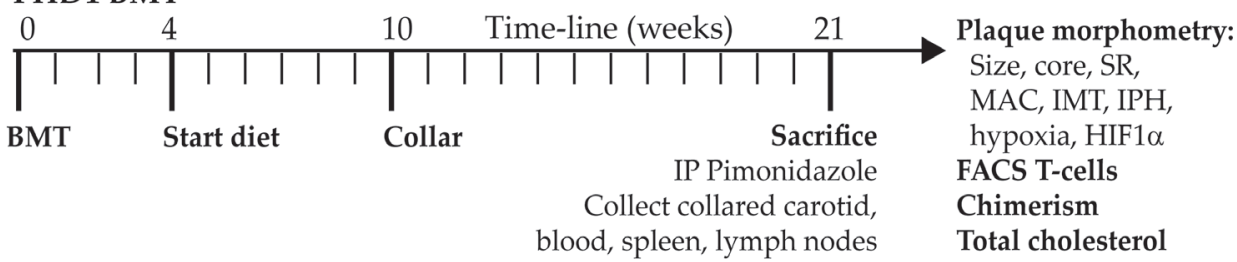

Figure 4.1 Timeline and outcome parameters of mice experiments

Abbreviations: IP, intra-peritoneal; SR, Sirius red; MAC, macrophage; IMT, intima media thickness; $\mathrm{IPH}$, intraplaque hemorrhage, FACS, fluorescence-activated cell sorting.

\section{Material and methods}

Mice

Mouse experiments were approved by the regulatory authority of the University of Maastricht, and were performed in compliance with Dutch government guidelines. Male ApoE ${ }^{--}$mice on a C57/BL6 background were obtained from Iffa credo (Lyon, France), and female LDLR $^{-}$were obtained from Charles River (Wilmington, MA, USA). Myeloid-specific lysMcre/HIF1 $\alpha^{-/}$mice on a pure C57/BL6 background are previously described ${ }^{16}$, and were kindly provided by Randall Johnson. PHD1 ${ }^{-/}$were constructed on a mixed 129SvEv/BL6 background, and were kindly provided by Peter Carmeliet. ${ }^{17}$

\section{Hypoxic chamber pilot study}

Five male $\mathrm{ApoE}^{-/}$mice, 8 months of age, were placed in chronic, normobaric hypoxia $\left(10 \% \mathrm{O}_{2}\right)^{18}$ for four weeks, while five other male $\mathrm{ApoE}^{-/}$mice were kept 
under standard, normoxic conditions (Figure 4.1). Normal chow diet and water were provided ad libitum before and during the experiment. $\mathrm{O}_{2}$ levels were measured daily (AVL 993; AVL LIST GmbH, Graz, Austria) without opening the chamber. The chamber was opened once a week for approximately $10 \mathrm{~min}$ to replenish food and water. Body weight was determined at the start of the experiment and before sacrifice. The complete arterial tree was excised after sacrifice, fixed in $1 \%$ paraformaldehyde, and processed as described. ${ }^{19}$

\section{Bone marrow transplantation (BMT)}

Recipient LDLR ${ }^{-}$mice $(\mathrm{n}=69)$ were given acidified water $(\mathrm{pH}=2)$ containing neomycin (100 mg/L; Gibco, Breda, The Netherlands) and polymyxin B sulphate (6x10 $\mathrm{U} / \mathrm{L} ; \mathrm{Gibco})$ from 1 week before until 4 weeks after BMT. Twelve-week-old female LDLR $^{-}$mice were lethally irradiated (10 Gy) one day before transplantation. Bone marrow was collected from femurs and tibias of male donor lysMcre/HIF1 $\alpha^{-1}$, PHD1 ${ }^{-1}$, and wildtype (WT) mice, and injected intravenously $\left(10^{7}\right.$ cells) into recipient female LDLR ${ }^{-/}$mice (Figure 4.1). All mice were placed on a 1.25\% cholesterol diet (Product cD12108; Research Diets, New Brunswick, NJ) starting four weeks after BMT. Mice in the HIF1 study (n=16 WT and $\mathrm{n}=16$ lysMcre $/ \mathrm{HIF} 1 \alpha^{-1}$ ) were sacrificed after 6 weeks on diet (10 weeks postBMT) when advanced lesions appear in the aortic root. Mice in the PHD study $\left(\mathrm{n}=22 \mathrm{WT}\right.$ and $\left.\mathrm{n}=15 \mathrm{PHD}^{-}{ }^{-}\right)$received a bilateral, perivascular collar around the carotid artery after 4 weeks on diet, and were sacrificed after another 13 weeks on diet (21 weeks post-BMT).$^{20}$ All mice were sacrificed after an $8 \mathrm{~h}$ fast, and blood $( \pm 1 \mathrm{~mL})$ was drawn from the right ventricular apex for analysis of chimerism ${ }^{21}$ and total cholesterol. Aortic roots and collared carotid arteries were excised, fixed in $1 \%$ paraformaldehyde, and processed as previously described. ${ }^{19}$, 20

\section{Hypoxia detection}

Hypoxia was detected in murine kidney (positive control) and atherosclerotic arteries (aortic root, aortic arch, and (collared) carotid artery) using the hypoxia marker pimonidazole hydrochloride (hypoxyprobe 3, Chemicon, Temecula, CA, USA). ${ }^{22,}{ }^{23}$ Pimonidazole (100 $\mu \mathrm{g} / \mathrm{g}$ bodyweight) was injected intra peritoneally one hour prior to sacrifice of mice in the hypoxic chamber study and the HIF1 and PHD1 BMT studies (Figure 4.1). In vivo formed pimonidazole adducts in hypoxic cells $\left(\mathrm{pO}_{2} \leq 10 \mathrm{mmHg} 1 \% \mathrm{O}_{2}\right)$ were detected ex vivo in formalin-fixed, paraffin-embedded tissue by immunohistochemistry with a rabbit polyclonal antibody that only detects hypoxia-derivatives of pimonidazole. ${ }^{24}$ 


\section{Total serum cholesterol}

Plasma was separated by centrifugation, and stored at $-20^{\circ} \mathrm{C}$. Standard enzymatic techniques were used for the assessment of serum cholesterol (product no. 07-3663-5, Roche, Almere, the Netherlands) automated on the Cobas Fara centrifugal analyzer (Roche).

\section{Systemic effects}

Fluorescence-activated cell sorting (FACS) analysis (FACS Calibur, BD Biosciences) was performed on cells isolated from spleen and lymph nodes ( $\mathrm{n}=6$ per BMT group) as described previously. ${ }^{25}$ Cells were labeled with T lymphocytespecific antibodies: CD3FITC, CD4Cy-Chrome, CD8PE, and CD25PE (Pharmingen-BD Biosciences).

In addition, over 20 tissues (heart, lung, liver, spleen, pancreas, stomach, intestines, brain, muscle, adipose tissue, bone, thyroid, skin, etc) were excised from 5 randomly chosen mice per group, and evaluated macroscopically and microscopically (4- $\mu \mathrm{m}$ hematoxylin-eosin (HE) stained sections) for tissue abnormalities.

\section{Immunohistochemistry}

Sections were stained with primary antibodies against pimonidazole, MAC3, and HIF1 $\alpha$ (Table 4.1) or without the primary antibody (negative controls).

Table 4.1 Immunohistochemical procedures

\begin{tabular}{|c|c|c|c|c|c|c|}
\hline Antibody & Company, code & $\begin{array}{l}\text { Antigen } \\
\text { retrieval }\end{array}$ & Blocking & Dilution & Incubation & Detection \\
\hline Pimonidazole & $\begin{array}{l}\text { NPI, } \\
\text { Hypoxyprobe } 3\end{array}$ & ChemMate & TBS/5\%BSA & $1: 10,000$ & $1 \mathrm{hr}, \mathrm{RT}$ & $\begin{array}{l}\text { Powervision } \\
\text {-HRP }\end{array}$ \\
\hline MAC3 & $\begin{array}{l}\text { Pharmingen, } \\
550292\end{array}$ & ChemMate & TBST/1\%NMS & $1: 30$ & $\mathrm{O} / \mathrm{N}, 4^{\circ} \mathrm{C}$ & ABC-AP \\
\hline HIF1 $\alpha$ & Novus, $100-449$ & None & TBS/5\%BSA & $1: 250$ & $1 \mathrm{hr}, \mathrm{RT}$ & $\begin{array}{l}\text { Powervision } \\
\text {-HRP }\end{array}$ \\
\hline
\end{tabular}

Abbreviations: ChemMate, ChemMate target retrieval, DAKO; TBST, Tris-buffered saline with $0.1 \%$ Tween; BSA, bovine serum albumin; NMS, normal mouse serum; O/N, overnight; RT, room temperature; $\mathrm{ABC}-\mathrm{AP}$, alkaline phosphatase-conjugated $\mathrm{ABC}$ reagent (DAKO); Powervision-HRP, horseradish-peroxidase conjugated powervision goat anti-mouse or rabbit antibody (Immunologic); other abbreviations as explained in text. 


\section{Histology and morphometry}

Histological and morphometric analysis of atherosclerosis was performed as described before, ${ }^{19,20}$ and parameters for each study are shown in Figure 4.1. Aortic root, -arch, and carotid artery were serially sectioned, and stained with HE (Sigma) for quantification of the lesion areas using computerized morphometry (Leica QWin V3, Cambridge, UK). Total plaque area (HE or Lawson) and lipid core content were obtained by averaging measurements of four representative sections ( $20 \mu \mathrm{m}$ apart) of the aortic root and aortic arch, or of four carotid sections of collar-induced plaques representing maximal stenosis. In addition, plaque volume in the collared carotid was calculated in 6 sections, $100 \mu \mathrm{m}$ apart (sum plaque area x 600). Maximal intimal thickness (IT) and intima-media thickness (IMT) were measured at the thickest region of the plaque. The average thickness was calculated of three measurements, taken perpendicular from the plaque surface to the internal or external elastic lamina for IT and IMT respectively. The maximal percentage of artery stenosis in the collared carotid artery was calculated in sections representing maximal stenosis as (plaque area/(plaque area+lumen area)*100). Plaques were further characterized for collagen content (Sirius red area/plaque area), macrophage content $\left(\mathrm{MAC}^{+}\right.$cells/total cells and $\mathrm{MAC}^{+}$cells/plaque area), frequency of intraplaque hemorrhage (HE and Perl's iron staining) ${ }^{26}$ hypoxia (pimonidazole ${ }^{+}$ cells/total cells), and HIF1 $\alpha$ (HIF1 $\alpha^{+}$nuclei/total cells). The frequency of plaques with hypoxia was based on the presence of more than $5 \%$ pimonidazole ${ }^{+}$cells.

\section{Cell culture}

Bone marrow (BM)-derived macrophages were acquired as described. ${ }^{21}$ Cells were exposed to $21 \%$ and $0.2 \% \mathrm{O}_{2}$ (MACS VA500 micro-aerophilic workstation, Don Whitley Scientific, Shipley, UK) for 1, 4, and 16 hours. Experiments were performed in triplicate (mRNA), and repeated twice (protein and mRNA). Plastic disposables were obtained from Greiner Bio-One (Alphen a/d Rijn, The Netherlands).

\section{Quantitative RT- PCR (qRT-PCR)}

Total RNA was isolated and transcribed as described. ${ }^{27}$ Primers for murine HIF1 $\alpha$, HIF2 $\alpha$, PHD1, PHD2, PHD3, ${ }^{28}$ VEGF, GLUT3, GAPDH, cyclophilin, and $18 \mathrm{~S}$ ribosomal RNA (rRNA) are shown in Table 4.2. Three housekeeping genes (GAPDH, cyclophilin, 18S rRNA) were used to correct for difference in mRNA levels between samples. 
110 Chapter 4

Table 4.2 Sequences of quantitative RT-PCR primers

\begin{tabular}{lll}
\hline Gene & Forward primer & Reverse primer \\
\hline Cyclophylin & CAAATGCTGGACCAAACACAA & TTCACCTTCCCAAAGACCACAT \\
GAPDH & TCCGCCCCTTCCGCTGATGCC & TAGTGGGCCCTCGGCCGCCTG \\
18S rRNA & GTAACCCGTTGAACCCCATT & CCATCCAATCGGTAGTAGCG \\
GLUT3 & GTGGCATGATTGGCTCTTTT & CCAGGATCAGCATTTCAACA \\
HIF1 $\alpha$ & TGCTCATCAGTTGCCACTTC & CCATCTGTGCCTTCACA \\
HIF2 $\alpha$ & ACCCCGAGGAGCTACTTGGA & GATACCACCTGCCCCTTGGT \\
PHD1 & CATCAATGGGCGCACCA & GATTGTCAACATGCCTCACGTAC \\
PHD2 & TAAACGGCCGAACGAAAG & GGGTTATCAACGTGACGGACA \\
PHD3 & CTATGTCAAGGAGCGGTCCAA & GTCCACATGGCGAACATAACC \\
VEGFA & CAGAAGGAGAGCAGAAGTCC & CTCCAGGGCTTCATCGTTA \\
\hline
\end{tabular}

Western blot

Nuclear protein lysates were extracted from $1 \times 10^{6}$ cells using the NE-PER extraction kit (Pierce, Rockford, IL, USA). Samples $(30 \mu \mathrm{g})$ were separated by SDS-PAGE (7.5\%) followed by transfer onto Protran nitrocellulose (Schleicher\&Schuell, 's-Hertogenbosch, The Netherlands). Equal loading was confirmed by Ponceau S (Serva, Heidelberg, Germany) staining of blots. Blots were blocked overnight at $4^{\circ} \mathrm{C}$ in PBS containing $4 \%$ (w/v) skimmed milk powder, incubated for one hour at RT with primary antibody against murine HIF1 $\alpha$ (1:500, product no. 100-449 Novus biologicals, Littleton, CO, USA), and with horseradish peroxidase conjugated anti-rabbit secondary antibody (1:2000, Cell signaling technology, Danvers, MA, USA). Specific antibody binding was visualized using SuperSignal West PICO substrate (Pierce).

\section{Statistical analysis}

All data are presented as mean \pm SEM. Plaque morphometry and qRT-PCR were compared between groups using a Mann-Whitney rank-sum test and one-way ANOVA respectively (SPSS 12.0 Chicago, IL). Spearmann's $\rho$ correlation coefficient was calculated for ordinal immunohistochemistry variables. The intraplaque hemorrhage (IPH) frequency was compared using Pearson's chisquare test. Results were considered statistically different when $\mathrm{p}<0.05$. 

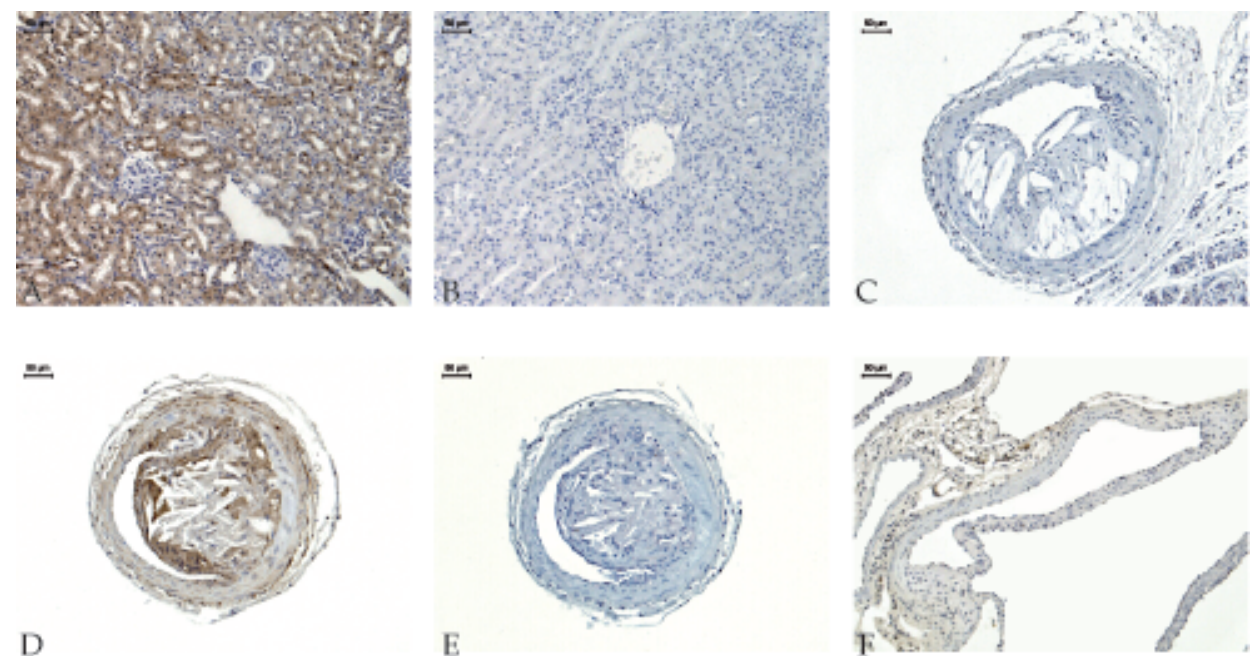

D

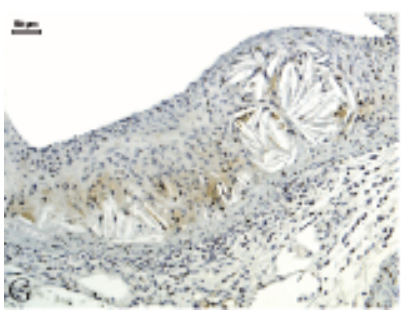

E

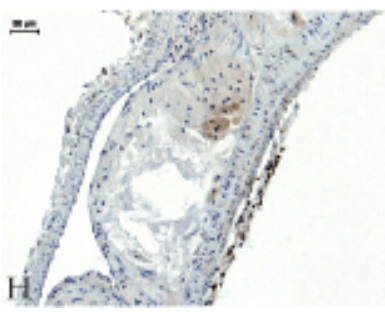

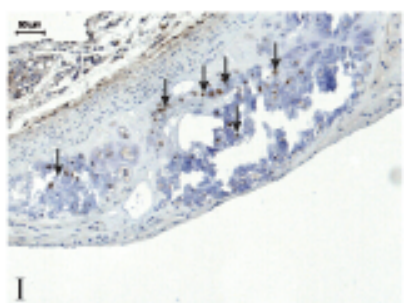

Figure 4.2 Hypoxia in murine kidney and plaques of different arterial sites

A. Hypoxia (anti-pimonidazole immunoreactivity in brown) was detected in the kidney of a pimonidazole-injected mice. B. Pimonidazole was absent in the kidney and C. collar-induced plaques in the carotid artery of mice without pimonidazole injection. D. Hypoxia was present in collarinduced atherosclerosis in the carotid artery of mice with pimonidazole injection, and E. absent in lesions not incubated with primary anti-pimonidazole antibody. F. No hypoxia was present in the non-diseased aortic root of a C57/BL6 mouse. G. Hypoxia was also present in the atherosclerotic aortic root and (H-I) brachiocephalic artery. Arrows indicate chondrocytes.

\section{Results}

Hypoxia is present in murine atherosclerosis

The hypoxia marker pimonidazole was administered to C57/BL6 ( $\mathrm{n}=2), \mathrm{ApoE}^{-1-}$ $(\mathrm{n}=10)$, and LDLR ${ }^{-/}$mice $(\mathrm{n}=39)$ receiving WT $(\mathrm{n}=22)$, lysMcre/HIF1 $\alpha^{-/}(\mathrm{n}=11)$, or $\mathrm{PHD1}^{-1}(\mathrm{n}=6)$ bone marrow. As pimonidazole was previously shown to detect hypoxia in normal mouse kidney, staining of a kidney section confirmed that the pimonidazole injection was successful in all mice (Figure 4.2A). Antibody specificity was confirmed by a complete lack of immunoreactivity in the kidney 
and the carotid collar-induced plaques of 10 mice without pimonidazole administration (Figure 4.2B-C).

Pimonidazole immunoreactivity was investigated in 64 atherosclerotic and 9 normal artery specimens of 51 mice (Table 4.3). Hypoxia (pimonidazole immunoreactivity) was present in $45(70 \%)$ of all 64 murine atherosclerotic plaques (Figure 4.2D). In these plaques, 5-55\% of total plaque area was hypoxic, while hypoxia was absent in non-diseased carotid arteries $(\mathrm{n}=7)$ and aortic arches $(n=2$, Figure $4.2 F)$. Hypoxia was detected in $95 \%$ of collar-induced plaques in the carotid artery (Figure 4.2 and Table 4.3 ), in $50 \%$ of native plaques in the carotid artery (not shown), in 57\% of plaques in the atherosclerotic aortic root (Figure $4.2 \mathrm{G}$ ), and in $67 \%$ of plaques in the brachiocephalic artery (Figure $4.2 \mathrm{H}-\mathrm{I}$ ). Macrophage foam cells deep in the plaque (Figure 4.2G-H), and more superficial foam cells (Figure 4.2D) and chondrocytes (Figure 4.2I) surrounding the core were positive. Also, some medial and intimal smooth muscle cells (Figure 4.2D), and adventitial adipocytes and macrophages were hypoxic (Figure 4.2F, I). The percentage of hypoxic cells correlated significantly with macrophage content, however after stratification for arterial site this effect was lost (Table 4.3). Plaques in the collared carotid artery showed significantly more hypoxic cells $(54.3 \pm 5.5 \%)$ than in the brachiocephalic artery $(6.5 \pm 1.4 \%, \mathrm{p}=0.001)$ and the aortic root (19.3 $\pm 3.9 \%, p=0.001)$. Although the difference between collar and brachiocephalic plaques was likely explained by the increased macrophage content in the collar (39 $\pm 3.4 \%$ and $65 \pm 1.4 \%$ respectively, $\mathrm{p}=0.001)$, macrophage content between plaques in the collar and aortic root were similar. As intimal thickness of collarinduced plaques was significantly smaller than in the aortic root $(207 \pm 24 \mu \mathrm{m}$ vs. $225 \pm 9 \mu \mathrm{m}, \mathrm{p}=0.03)$, intimal thickness did not explain the difference in hypoxic cells. Likewise, the hypoxic cell percentage did not correlate significantly with maximal stenosis and intimal thickness (Table 4.4).

Table 4.3 Frequency of hypoxia in murine atherosclerosis at different sites

\begin{tabular}{lcccccc}
\hline & \multicolumn{2}{c}{ Non-diseased $^{*}$} & \multicolumn{3}{c}{ Atherosclerosis } \\
& AR & Carotid & AR & Brach & Collared carotid & Native carotid \\
& $\%(\mathrm{n})$ & $\%(\mathrm{n})$ & $\%(\mathrm{n})$ & $\%(\mathrm{n})$ & $\%(\mathrm{n})$ & $\%(\mathrm{n})$ \\
\hline Controlt & $0(0)$ & $0(0)$ & $47(7)$ & $86(6)$ & $92(11)$ & $0(0)$ \\
Experimentalf & & & $69(9)$ & $40(2)$ & $100(8)$ & $100(2)$ \\
All & $0(0)$ & $0(0)$ & $57(16)$ & $67(8)$ & $95(19)$ & $50(2)$ \\
\hline
\end{tabular}

$\mathrm{AR}$, aortic root; Brach, brachiocephalic trunk; ${ }^{*} 7$ carotid arteries and 2 aortic roots tested; † Normoxic exposure or WT BMT; $\ddagger$ Hypoxic exposure, LysMcre/HIF $1 \alpha^{-/}$or PHD $1^{-/}$BMT 
Table 4.4 Correlations between hypoxic cell content and plaque characteristics

\begin{tabular}{lcccccc}
\hline & $\begin{array}{c}\text { MAC3 } \\
(\%)\end{array}$ & $\begin{array}{c}\text { IT } \\
(\mu \mathrm{m})\end{array}$ & $\begin{array}{c}\text { Stenosis } \\
(\%)\end{array}$ & $\begin{array}{c}\text { Collagen } \\
(\%)\end{array}$ & $\begin{array}{c}\text { Cellularity } \\
\left(\mathrm{n} / \mu \mathrm{m}^{2}\right)\end{array}$ & $\begin{array}{c}\text { HIF } \\
(\%)\end{array}$ \\
\hline Spearmann's $\rho$ & 0.40 & -0.16 & -0.05 & -0.10 & 0.56 & 0.37 \\
P-value & 0.01 & 0.56 & 0.78 & 0.57 & 0.00 & 0.03 \\
$\mathrm{~N}$ & 43 & 47 & 16 & 37 & 47 & 34 \\
\hline
\end{tabular}

Four weeks exposure of 8-month-old ApoE ${ }^{-1-}$ mice with advanced atherosclerosis to hypoxia did not alter plaque size, lipid core or macrophage content in the brachiocephalic trunk (Figure 4.3A-E). The presence of hypoxia in the atherosclerotic brachiocephalic trunk, aortic root or carotid artery after hypoxic exposure was not different form normoxia (Figure 4.3F). Body weight was significantly lower in mice after hypoxic exposure $(28.5 \pm 1.3 \mathrm{~g})$ compared to normoxia $(34.4 \pm 1.0 \mathrm{~g} ; \mathrm{p}=0.009)$.
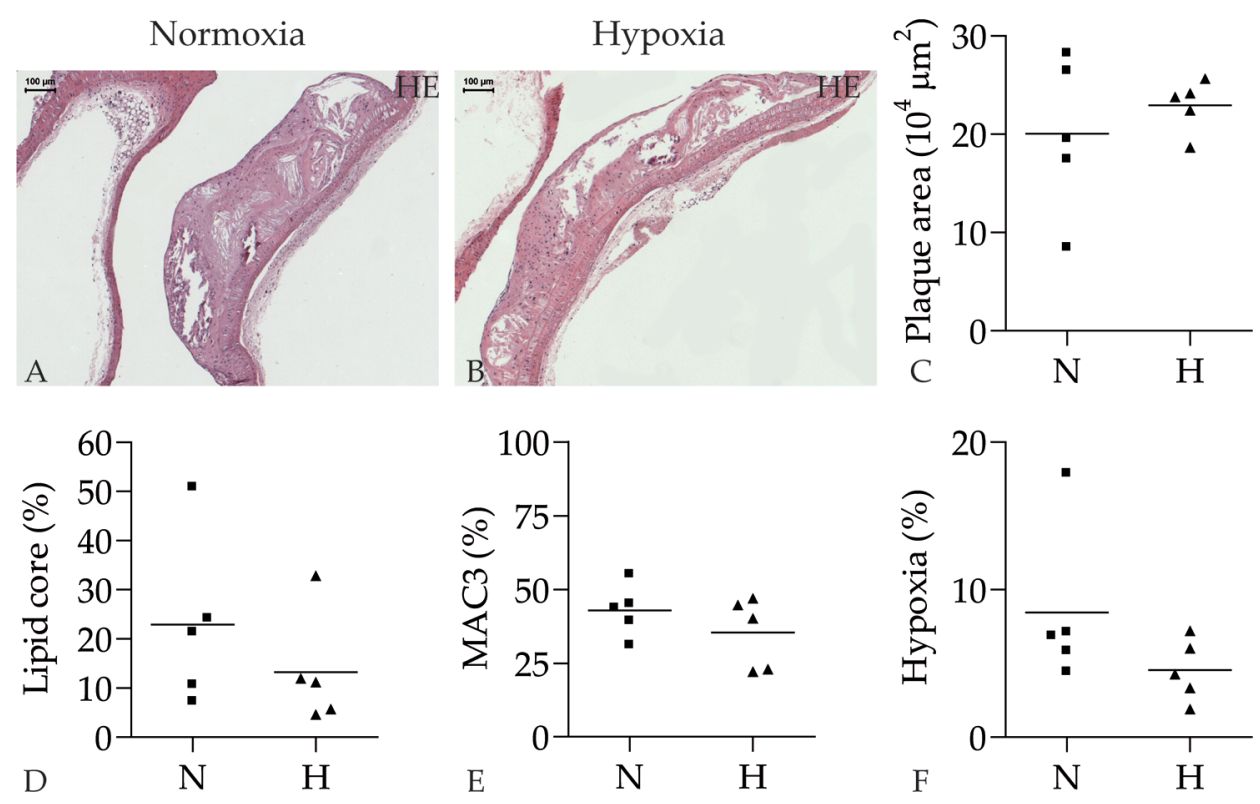

Figure 4.3 Hypoxic exposure of mice does not influence advanced atherosclerosis

A. Chronic exposure of $\mathrm{ApoE}^{-/}$mice with advanced atherosclerosis to regular oxygen $(21 \%, \mathrm{n}=5$ mice $)$ or B. low oxygen levels $(10 \%, \mathrm{n}=5$ mice) showed similar C. brachiocephalic plaque size, D. lipid core content, E. macrophage content, and F. hypoxic cell content. All p-values $>0.05$. 
No effect of lysMcre/HIF1 $\alpha^{-/-}$on murine atherogenesis

As hypoxia was present in murine atherosclerotic plaques, the presence of HIF1 $\alpha$ in murine atherosclerosis was investigated using immunohistochemistry. Atherosclerotic plaques in the aortic root and collared carotid of WT transplanted LDLR $^{-1}$ mice showed immunoreactivity of HIF1 $\alpha$ in nuclei of macrophages, endothelial cells, and chondrocytes (Figure 4.4A-B), and nuclear HIF1 $\alpha$ immunoreactivity correlated with hypoxic cell content (Table 4.4). Notably, plaque HIF1 $\alpha$ content was similar in the atherosclerotic brachiocephalic trunk of mice exposed to normoxia and hypoxia $(13 \pm 3.3 \%$ and $15 \pm 2.9 \%$ respectively, $\mathrm{p}=0.42$ ), in parallel with the similar plaque hypoxia levels (Figure 4.3F).

The effect of macrophage-specific HIF1 $\alpha$ deletion on murine atherogenesis was studied using transplantation of LysMcre/HIF1 $\alpha^{-/}$or WT bone marrow to LDLR $^{-/}$mice. Reconstitution of the hematopoietic system was successful in both groups as shown by qRT-PCR analysis of LDLR chimerism in genomic DNA of white blood cells $\left(93 \pm 0.6 \%\right.$ and $92 \pm 0.6 \%$, LysMcre/HIF $1 \alpha^{-1-}$ and WT respectively). Atherosclerotic plaques in the aortic root studied 6 weeks after BMT were all advanced, and plaque size was similar between LysMcre/HIF1 $\alpha^{-/}$and WT transplanted mice (Figure 4.4C-E). Neither lipid core-, collagen- nor macrophage content were different between the groups (Figure 4.4F-L). Also, lesion cellularity (not shown), maximal IT, IMT, hypoxia, and the frequency of intraplaque hemorrhages (IPH) were similar (Table 4.5). No differences in total cholesterol, or activatation of splenic and lymphoid T-cells were observed between $\mathrm{LDLR}^{-/}$mice receiving LysMcre/HIF1 $\alpha^{-/-}$or WT bone marrow (Table 4.6). Macroscopic and microscopic evaluation of over 20 tissues did not reveal any tissue abnormalities or differences between the groups.

Table 4.5 Plaque characteristics of HIF and PHD BMT

\begin{tabular}{llllll}
\hline & $\begin{array}{l}\text { IT } \\
\mu \mathbf{m}^{*}\end{array}$ & $\begin{array}{l}\text { IMT } \\
\mu \mathbf{m}^{*}\end{array}$ & $\begin{array}{l}\text { Stenosis } \\
\mathbf{\%}^{*}\end{array}$ & $\begin{array}{l}\text { Hypoxia } \\
\mathbf{\%}^{*}\end{array}$ & $\begin{array}{l}\text { IPH } \\
\text { \% (n) }\end{array}$ \\
\hline WT AR & $209(12)$ & $236(13)$ & na & $19(5)$ & $40(8)$ \\
LysMcre/HIF1 $\alpha^{-/}$AR & $229(11)$ & $253(10)$ & na & $23(5)$ & $41(8)$ \\
WT collar & $183(13)$ & $235(13)$ & $84(4)$ & $62(5)$ & $19(4)$ \\
PHD1 collar & $209(24)$ & $260(25)$ & $87(4)$ & $42(10)$ & $20(3)$ \\
\hline
\end{tabular}

* Mean (SEM); AR, aortic root; collar, collared carotid; na, not applicable; no significant p-values WT vs. respective ${ }^{-1}$. Abbreviations explained in text 

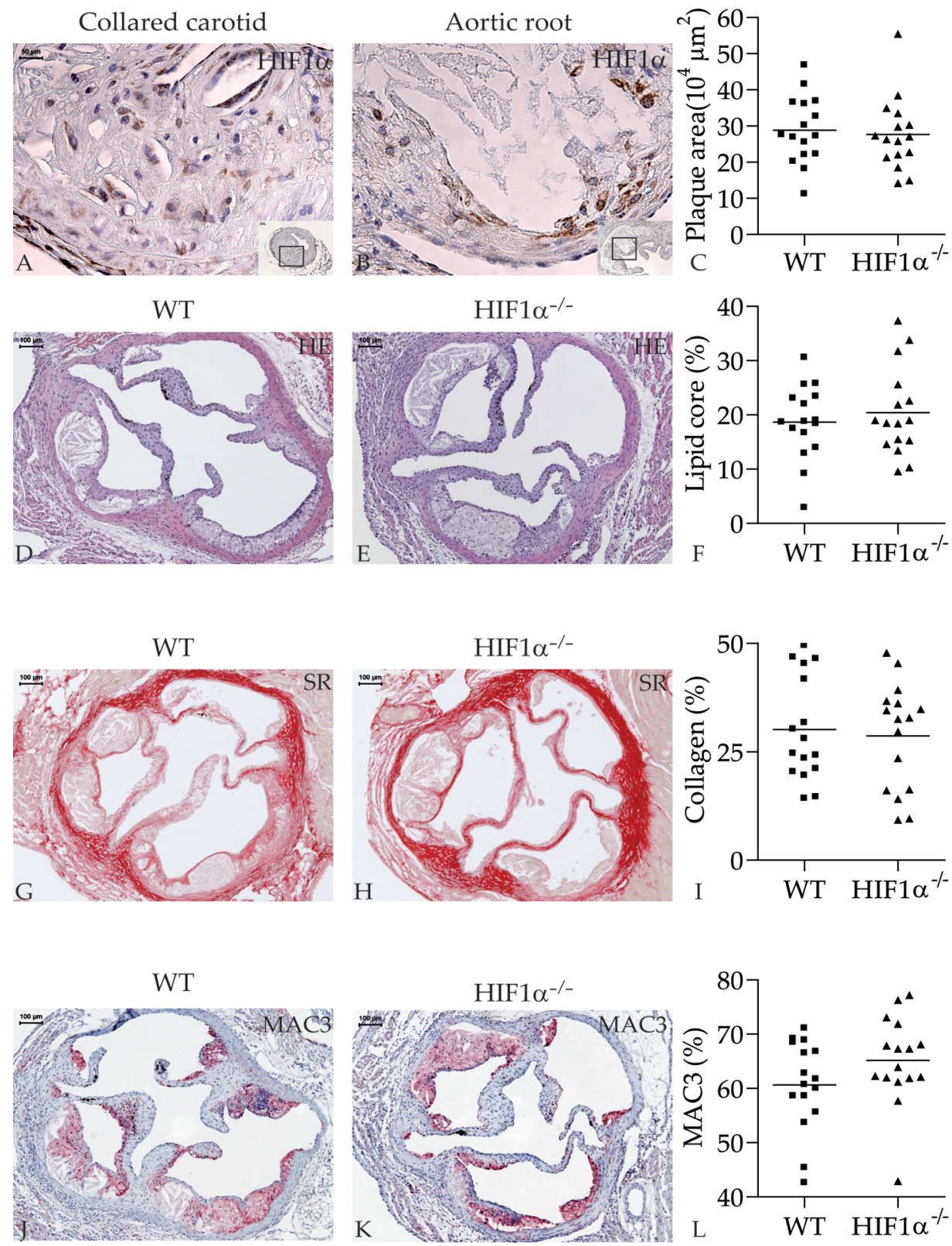

Figure 4.4 LysMcre/HIF1 $\alpha^{-/}$BMT does not change murine atherosclerotic plaque size or composition A. Nuclear HIF1 $\alpha$ immunoreactivity (in brown) is present in macrophages and smooth muscle cells of collar-induced atherosclerosis and B. in the atherosclerotic aortic root. Boxed regions in insets show origin of magnification. C. Plaque size of 16 WT (D, G, J) and 17 LysMcre/HIF1 $\alpha^{-1}$ (E, H, K) recipients were similar, as well as F. lipid core, G-I. collagen content, and J-L. macrophage content (in red). All p-values>0.05; HIF1 $\alpha^{-1}$ indicates lysMcre/HIF $1 \alpha^{-1}$. 


\section{Chapter 4}

Table 4.6 Serum cholesterol and T-cells in HIF and PHD BMT

\begin{tabular}{|c|c|c|c|c|c|c|c|}
\hline \multicolumn{3}{|c|}{ Total cholesterol } & \multicolumn{2}{|l|}{ Lymph } & \multirow[b]{2}{*}{ CD4/CD8 } & \multirow[b]{2}{*}{ CD4CD25 } & \multirow[b]{2}{*}{ CD4CD69 } \\
\hline & $(\mathrm{mg} / \mathrm{dl})$ & $\mathrm{CD} 4 / \mathrm{CD} 8$ & $\mathrm{CD} 4 \mathrm{CD} 25$ & CD4CD69 & & & \\
\hline WT AR & $938(50)$ & $0.62(0.06)$ & $2.72(0.13)$ & $33.16(0.83)$ & $1.00(0.09)$ & $1.44(0.05)$ & $24.72(0.42)$ \\
\hline LysMcre/HIF1 $\alpha^{-1-}$ AR & $896(35)$ & $0.60(0.05)$ & $2.74(0.22)$ & $36.18(0.80)$ & $1.27(0.11)$ & $1.55(0.10)$ & $26.66(1.52)$ \\
\hline WT collar & $1108(49)$ & $1.93(0.07)$ & $5.58(0.54)$ & $46.18(1.63)$ & $3.77(0.36)$ & $3.10(0.30)$ & $30.24(0.63)$ \\
\hline PHD1 $^{-\alpha}$ collar & $1019(43)$ & $2.44(0.24)$ & $4.16(0.23)$ & $41.36(2.68)$ & $4.88(0.30)$ & $2.87(0.08)$ & $29.44(2.21)$ \\
\hline
\end{tabular}

Mean (SEM); AR, aortic root; collar, collared carotid; no significant p-values

No effect of PHD1-I- on murine atherogenesis

As macrophage-specific LysMcre/HIF1 $\alpha$ deletion did not affect murine atherogenesis, the effect of its oxygen-dependent regulator, PHD1, on murine collar-induced atherosclerosis in the carotid artery was studied using PHD1 ${ }^{-1}$ BMT. Analysis of chimerism $\left(96 \pm 0.2 \%\right.$ and $97 \pm 0.1 \%$ for WT and PHD ${ }^{-1}$ respectively) confirmed a successful reconstitution of the hematopoietic system with donor marrow. Atherosclerotic lesions in collared carotids were all advanced. The atherosclerotic plaque area and volume, and lipid core-, collagen-, macrophage-, and cell content were similar between $\mathrm{PHD}^{-}$and WT transplanted mice (Figure 4.5A-I). No difference was observed in maximal IT, IMT, and -stenosis, hypoxia, and intraplaque hemorrhage (Table 4.5) nor in serum cholesterol and T-cell markers (Table 4.6). No tissue abnormalities were seen.

Similar HIF1 $\alpha$ and VEGF expression in WT and LysMcre/HIF1 $\alpha^{--}$macrophages after prolonged hypoxia

The effect of LysMcre/HIF1 $\alpha$ deletion and hypoxia on gene and protein expression of HIF $1 \alpha, \mathrm{HIF} 2 \alpha$, their target genes and regulators (PHD) was studied in further detail in bone marrow-derived macrophages in vitro. Bone marrow-derived LysMcre/HIF1 $\alpha^{-1}$ macrophages showed a $90 \%$ reduction in HIF $1 \alpha$ mRNA compared to WT macrophages (Figure 4.6A). Normoxic protein levels were minimal, but HIF1 $\alpha$ protein levels in normoxic conditions were only $44 \%$ reduced in LysMcre/HIF1 $\alpha^{-1-}$ compared to WT macrophages in vitro (Figure 4.6A-B). As macrophages in murine plaques were hypoxic, we investigated whether in vitro hypoxia would increase HIF1 $\alpha$ protein levels in LysMcre/HIF1 $\alpha^{-1}$ macrophages to levels similar to those in WT macrophages. Indeed, hypoxic exposure increased HIF1 $\alpha$ protein levels in WT, but also in LysMcre/HIF1 $\alpha^{-1}$ 


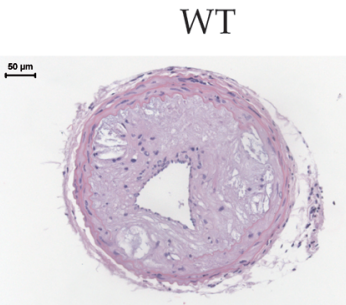

A
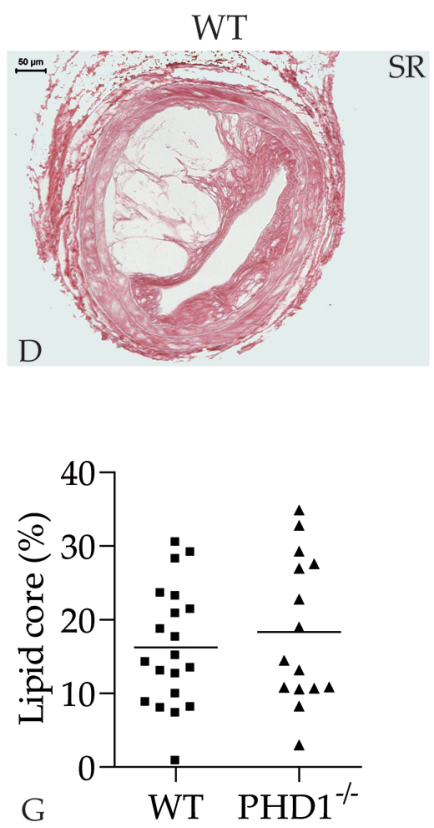

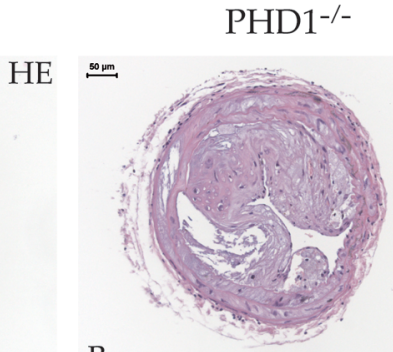

B

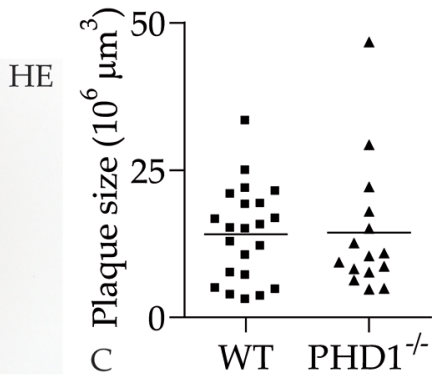

Figure 4.5 PHD1 $^{-/}$BMT does not change murine atherosclerotic plaque size or composition

A. HE staining of representative collar-induced plaques in the carotid artery of WT and B. PHD1 transplanted mice. C. Plaque volume, D. lipid core content, E. macrophage content, and F. cell content of $22 \mathrm{WT}$ and $15 \mathrm{PHD}^{-\kappa}$ recipients were similar. G. Sirius red (SR) staining of WT and H. $\mathrm{PHD}^{-1}$ transplanted mice, showing that I. collagen content was similar. Abbreviations indicated in text. All p-values $>0.05$ 


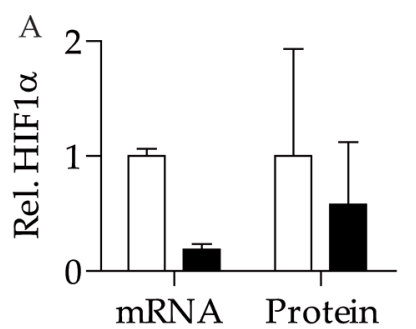

B

HIF1 $\quad+/+\quad-/-\quad+/+\quad-/-\quad+/+\quad-/-\quad+/+\quad-/-$

$\begin{array}{lllllllll}\text { Time (hr) } & 0 & 0 & 1 & 1 & 4 & 4 & 16 & 16\end{array}$

HIF1 $\alpha$

C

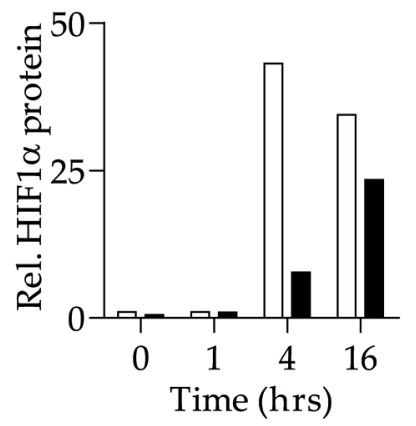

F
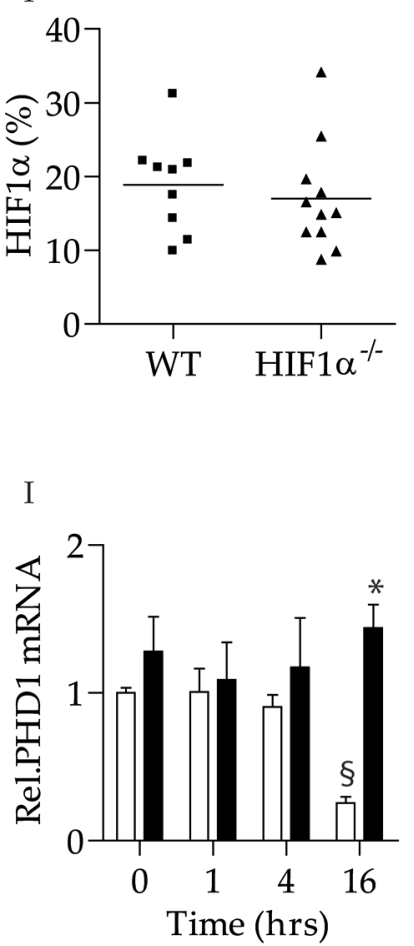

$\mathrm{D}$

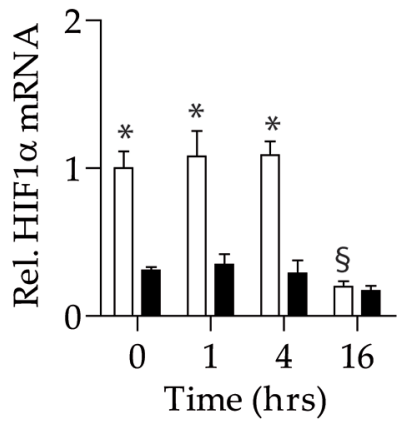

G

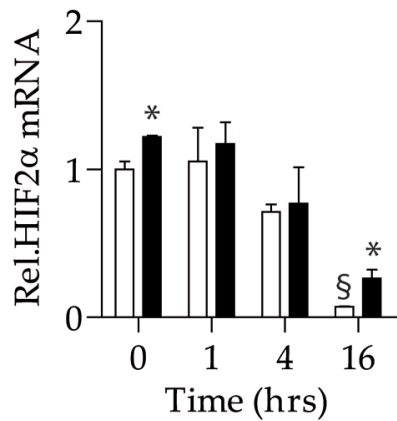

$\mathrm{J}$

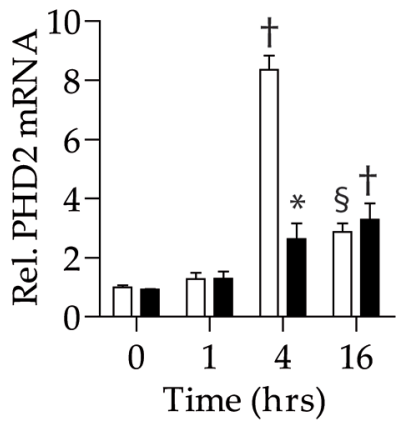

E

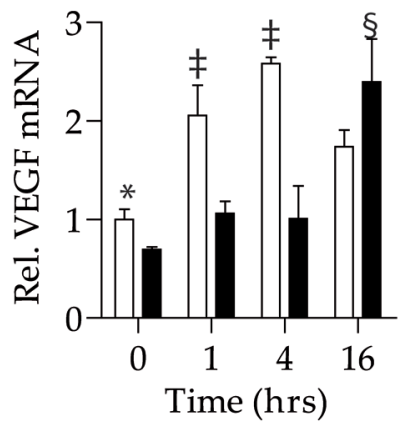

$\mathrm{H}$

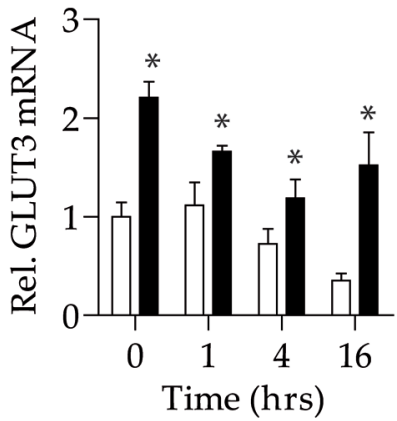

$\mathrm{K}$

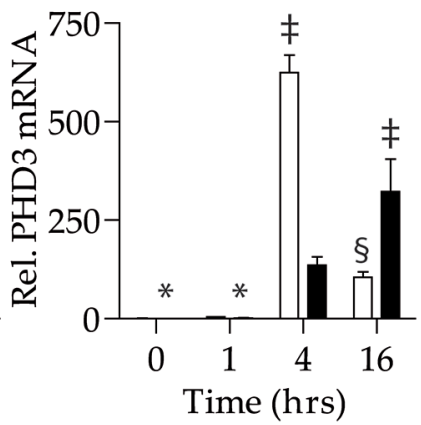


Figure 4.6 HIF and PHD expression in bone marrow-derived and plaque LysMcre/HIF1 $\alpha-/-$ macrophages

A. HIF $1 \alpha$ mRNA and protein expression is decreased $90 \%$ and $44 \%$ respectively in normoxic LysMcre/HIF1 $\alpha^{-/}$(black bars) vs. WT (open bars) macrophages. WT values were arbitrarily set as one. B. Western blot of HIF1 $\alpha$ expression in WT en LysMcre/HIF $1 \alpha^{-/}$macrophages after exposure to $21 \%$ or $0.2 \% \mathrm{O}_{2}$ for 1,4 and 16 hours. C. Quantification of HIF1 $\alpha$ protein expression on western blot in WT (open bars) and LysMcre/HIF1 $\alpha^{-/}$macrophages (black bars) after exposure to $21 \%$ or $0.2 \% \mathrm{O}_{2}$ for 1,4 and 16 hours. WT values in normoxia were arbitrarily set as one. D. HIF1 $\alpha$ and E. VEGF mRNA expression in WT (open bars) and LysMcre/HIF1 $\alpha^{-/}$macrophages (black bars) after exposure to 21\% or $0.2 \% \mathrm{O}_{2}$ for 1,4 and 16 hours. F. Nuclear HIF1 $\alpha$ immunoreactivity (\% of cells) was similar in atherosclerotic aortic roots of 10 WT en 10 LysMcre/HIF1 $\alpha^{-/}$recipients. G. HIF2 $\alpha$, H. GLUT3, I. PHD1, J. PHD2, and K. PHD3 mRNA expression in WT (open bars) and LysMcre/HIF1 $\alpha^{-/}$macrophages (black bars) after exposure to $21 \%$ or $0.2 \% \mathrm{O}_{2}$ for 1,4 and 16 hours. ${ }^{*} \mathrm{p}<0.05$ WT vs. KO; $\dagger$ p<0.05 vs. normoxia; $\ddagger \mathrm{p}<0.05$ vs. normoxia and WT vs. KO $\S \mathrm{p}<0.05$ vs. normoxia and vs. hypoxia 4 hrs. $\mathrm{HIF} 1 \alpha^{-/-}$indicates lysMcre/HIF1 $\alpha^{-/}$.

macrophages. WT macrophages showed a 5.6 fold and 3.2 fold increase in HIF1 $\alpha$ protein (Figure 4.6B-C) and mRNA respectively (Figure 4.6D) compared to LysMcre/HIF $1 \alpha^{-/}$after 4 hours of acute hypoxia. However, 16 hours of (prolonged) hypoxic exposure reduced HIF1 $\alpha$ protein and mRNA in WT macrophages (Figure 4.6B-D) compared to acute hypoxia. In addition, HIF1 $\alpha$ protein and mRNA in LysMcre/HIF1 $\alpha^{-/-}$macrophages further increased between 4 and 16 hours, leading to a minor 33\% reduction in HIF1 $\alpha$ protein compared to WT macrophages (Figure 4.6B-D). Also, exposure to the iron chelator $\mathrm{CoCl}_{2}$, inhibiting all PHD activity, resulted in similar HIF1 $\alpha$ protein levels (data not shown). The findings are schematically depicted in Figure 4.7A-B.

Gene sxpression of the HIF-responsive gene VEGF was also similar in WT and LysMcre/HIF1 $\alpha^{-/}$macrophages in prolonged hypoxia, while mRNA was reduced in LysMcre/HIF1 $\alpha^{-/}$in normoxia and acute hypoxia (Figure 4.6E). Thus, prolonged hypoxia in vitro resulted in similar protein and mRNA expression of HIF1 $\alpha$ and VEGF in WT and LysMcre/HIF1 $\alpha^{-/}$macrophages (Figure 4.6B-D). The same observation was made in vivo, as chronically hypoxic atherosclerotic plaques of LysMcre/HIF1 $\alpha^{-/}$and WT recipients also expressed similar nuclear HIF1 $\alpha$ immunoreactivity (Figure 4.6F). Therefore, a combination of incomplete LysMcre/HIF1 $\alpha$ deletion and negative regulation of HIF1 $\alpha$ and its target gene VEGF in prolonged hypoxia may explain the absent effect of LysMcre/HIF1 $\alpha^{-/}$ and $\mathrm{PHD}^{-/}$on atherosclerosis in vivo, since plaque macrophages in vivo are also chronically hypoxic (Figure 4.7A-B). 


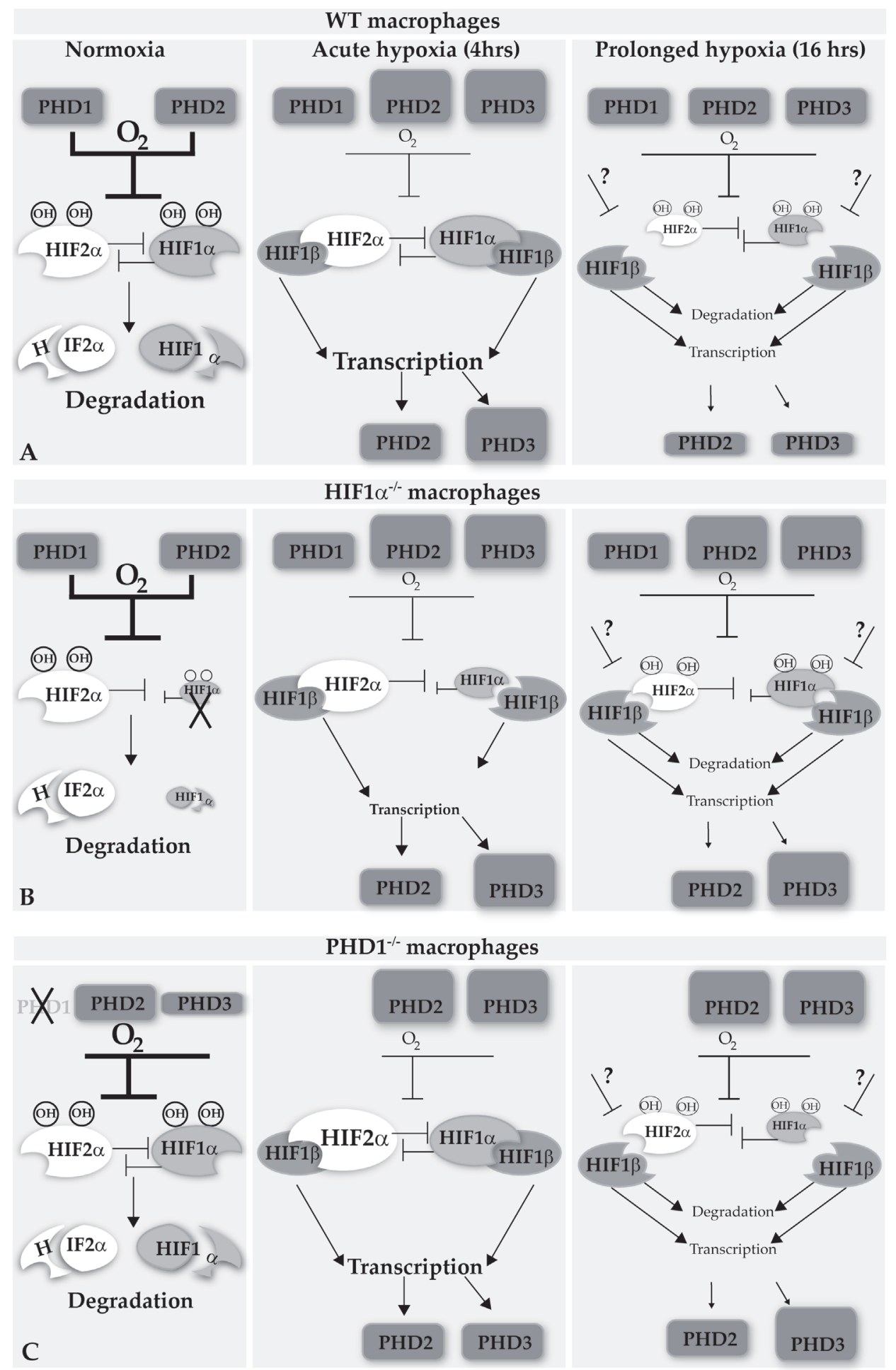


Figure 4.7 Illustration of interactions between hypoxia, HIF and PHD in WT, LysMcre/HIF1 $\alpha^{-/-}$ and $\mathrm{PHD1}^{-/}$macrophages

A. Interactions between HIF and PHD in normoxia (left panel), acute (middle panel) and prolonged hypoxia (right panel) in WT macrophages. In normoxia PHD1 and PHD2 hydroxylate HIF1 $\alpha$ and $\mathrm{HIF} 2 \alpha$, resulting in protein degradation. In acute hypoxia, oxygen availability is reduced and consequently PHD hydroxylation activity is reduced. HIF1 $\alpha$ and HIF2 $\alpha$ proteins can bind HIF1 $\beta$ and induce transcription of several genes, including PHD2 and PHD3. In prolonged hypoxia, HIF1 $\alpha$ and HIF2 $\alpha$ mRNA, protein and activity are reduced by moderate PHD hydroxylation activity and (putatively) by other factors (indicated by "?").

B. Interactions between HIF and PHD in normoxia (left panel), acute (middle panel) and prolonged hypoxia (right panel) in LysMcre/HIF1 $\alpha^{-/}$macrophages. LysMcre conditional deletion of HIF1 $\alpha$ is incomplete, resulting in continuous stabilization of HIF1 $\alpha$ in acute and prolonged hypoxia. The (putative) balance between HIF1 $\alpha$ and HIF2 $\alpha$ is shifted in favor of HIF2 $\alpha$, explaining increased VEGF expression in prolonged hypoxia and GLUT3 expression in normoxia, acute and prolonged hypoxia (not depicted). PHD transcription is unaffected by LysMcre/HIF1 $\alpha$ deletion. HIF $1 \alpha^{-/}$indicates lysMcre/HIF1 $\alpha^{-1}$.

C. Interactions between HIF and PHD in normoxia (left panel), acute (middle panel) and prolonged hypoxia (right panel) in PHD1 ${ }^{-}$macrophages. Deletion of PHD1 only marginally increases HIF1 $\alpha$ in normoxia, but HIF1 $\alpha$ mRNA, protein and activity are similar to WT in acute and prolonged hypoxia. Increased transcription of GLUT3 (not depicted) in normoxia, acute and prolonged hypoxia in PHD1 ${ }^{-1}$ in the presence of similar HIF1 $\alpha$ protein levels, suggests increased HIF $2 \alpha$ protein. It is currently unknown if PHD1 deletion influenced HIF2 $\alpha$ protein levels in macrophages.

\section{HIF2 $\alpha$ mRNA negatively regulated in macrophages by prolonged hypoxia and HIF1 $\alpha$}

HIF $2 \alpha$ provides negative feedback on HIF1 $\alpha$ expression, although HIF1 $\alpha$ also represses HIF2 $\alpha$ expression (Figure 4.7A). ${ }^{9}{ }^{14}$ HIF2 $\alpha$ mRNA expression was investigated to further explore the negative regulation of HIF1 $\alpha$ mRNA and protein in prolonged hypoxia. However, HIF $2 \alpha$ was also downregulated in WT macrophages exposed to prolonged hypoxia similar to HIF1 $\alpha$ expression, while unchanged over time in LysMcre/HIF1 $\alpha^{-/}$macrophages (Figure 4.6G). In contrast, HIF2 $\alpha$ mRNA was significantly increased in LysMcre/HIF1 $\alpha^{-/}$over WT macrophages in normoxia and prolonged hypoxia, but not in acute hypoxia. In addition, mRNA of the HIF target GLUT3 was dramatically increased in LysMcre/HIF1 $\alpha^{-/}$over WT macrophages (Figure $4.6 \mathrm{H}$ ). The parallel increase in GLUT3 and HIF2 $\alpha$ mRNA suggested an increase in active HIF2 $\alpha$ protein together with a modest reduction of HIF1 $\alpha$ protein. These results rather suggest a negative regulation or compensation of HIF $2 \alpha$ by HIF1 $\alpha$ in LysMcre/HIF $1 \alpha^{-/-}$ mice, instead of a HIF1 $\alpha$ downregulation by HIF2 $\alpha$ in prolonged hypoxia. 
PHD mRNA downregulated in macrophages by prolonged hypoxia, while also providing negative feedback on HIF1 $\alpha$ expression

As PHD enzymes also provide negative feedback on HIF1 $\alpha$ expression (Figure 4.7A), PHD expression was further investigated to explain HIF1 $\alpha$ downregulation in prolonged hypoxia. In contrast to PHD1, PHD2 and PHD3 mRNA were transiently upregulated by acute hypoxia in WT macrophages in parallel to HIF1 $\alpha$ mRNA and protein (Figure 4.6I-K). PHD2 and PHD3 possibly provided a negative feedback loop in acute hypoxia leading to decreased HIF1 $\alpha$ at 16 hours. In prolonged hypoxia, all PHD enzymes were downregulated in WT macrophages compared to acute hypoxia, similar to HIF $1 \alpha$ and HIF $2 \alpha$, whereas expression in LysMcre/HIF1 $\alpha^{--}$did not change from 4 to 16 hours. Also, PHD2 and PHD3 mRNA in acute hypoxia was decreased in LysMcre/HIF1 $\alpha^{-/}$compared to WT macrophages, suggesting that HIF1 $\alpha$ positively regulates their expression. Thus, PHD expression may negatively regulate HIF1 $\alpha$ in prolonged hypoxia, but HIF1 $\alpha$ may also provides positive and negative feedback on PHD and HIF $2 \alpha$ mRNA expression respectively.

\section{HIF1 $\alpha$ expression similar in WT and PHD1-- macrophages after prolonged hypoxia}

Bone marrow-derived PHD1 ${ }^{-1}$ macrophages did not express PHD1 mRNA as expected (Figure 4.7A). Disruption of PHD1, responsible for HIF1 $\alpha$ degradation in normoxia, should result in increased HIF1 $\alpha$ protein stabilization, depicted schematically in Figure 4.7C. However, hypoxia in plaque macrophages might increase HIF1 $\alpha$ protein levels in WT macrophages, resulting in similar HIF1 $\alpha$ levels in plaques of PHD1 ${ }^{--}$and WT recipients. Bone marrow-derived PHD1 ${ }^{-1}$ macrophages indeed expressed 10.5 fold more HIF1 $\alpha$ protein compared to WT mice in normoxia (Figure 4.8B-C). However, HIF1 $\alpha$ protein levels in normoxic $\mathrm{PHD}^{-/}$attained only $14 \%$ of maximal HIF protein levels in hypoxia. Hypoxia increased HIF1 $\alpha$ protein levels more profoundly in WT macrophages, resulting in similar HIF1 $\alpha$ protein and mRNA levels in WT and PHD1 ${ }^{-/}$macrophages after 4 hours (Figure 4.8B-D). Correspondingly, HIF1 $\alpha$ nuclear immunoreactivity in WT and $\mathrm{PHD}^{-/}$plaque was similar (Figure 4.8E). Thus, possible effects of PHD1 in macrophages are independent of HIF1 $\alpha$ expression, as hypoxia strongly affected HIF1 $\alpha$ protein levels.

PHD isoforms compensated PHD1 ${ }^{--}$and unchanged PHD1 in hypoxic macrophages

As three PHD isoforms regulate HIF degradation, the expression of PHD2 and PHD3 was also investigated in bone marrow-derived PHD1 ${ }^{-/}$macrophages. PHD2 mRNA was similarly expressed in $\mathrm{PHD}^{-/}$and WT macrophage in 
normoxia and after hypoxic induction (Figure 4.8A, F). PHD3 mRNA was significantly increased in $\mathrm{PHD}^{-}$compared to WT macrophages in normoxia and 1 hour of hypoxia (Figure 4.8G), although expression was probably too low to be relevant (Figure 4.8A). PHD3 mRNA was almost absent in normoxia and 1 hour of hypoxia, wile strongly induced after 4 and 16 hours of hypoxia to a similar extent in $\mathrm{PHD}^{-1}$ and WT macrophages. PHD1 mRNA in WT and $\mathrm{PHD}^{-}$was unresponsive to acute or prolonged hypoxia (Figure 4.8H). Thus, PHD1 deletion resulted in a modest compensatory expression of PHD3 in normoxia, but not of PHD2. The hypoxic induction of PHD2 and PHD3 and the similar HIF1 $\alpha$ levels in hypoxic WT and PHD1 ${ }^{-\nsim}$ macrophages indicate that isoform redundancy could also explain that macrophage-specific PHD1 deletion did not influence HIF1 $\alpha$ expression in murine plaque macrophages.

\section{HIF2 $\alpha$ mRNA unchanged, but VEGF and GLUT3 increased in PHD1}

As PHD1 ${ }^{-}$skeletal muscle showed increased HIF2 $\alpha$ expression, ${ }^{17}$ the response of HIF2 $\alpha$ mRNA to PHD1 deletion was studied in normoxia and hypoxia. Increased HIF $2 \alpha$ may negatively regulate HIF1 $\alpha$, explaining that $\mathrm{PHD}^{-1}$ and WT macrophages show similar HIF1 $\alpha$ protein levels. HIF2 $\alpha$ mRNA was similar in $\mathrm{WT}$ and $\mathrm{PHD}^{-1}$ in normoxia, acute, and prolonged hypoxia (Figure 4.8I). However, the increased expression of the HIF targets VEGF and GLUT3 in $\mathrm{PHD}^{-1}$ compared to WT macrophages (Figure 4.8J-K), indicate that HIF2 $\alpha$ protein expression may be increased.

\section{Differential regulation by acute and prolonged hypoxia irrespective of mouse strain}

Despite a different genetic background between PHD1 WT and LysMcre/HIF1 $\alpha$ WT macrophages (29SvEv/BL6 vs. B16 respectively), mRNA expression of HIF1 $\alpha$, HIF2 $\alpha$, PHD1-3, VEGF and GLUT3 (Figure 4.8D, F-K) was also differentially regulated by acute and prolonged hypoxia in PHD1 WT macrophages, similar to LysMcre/HIF1 $\alpha$ WT macrophages. Together, these results suggest an intricate, reciprocal regulation in macrophages of HIF and PHD, and between their mutual isoforms, all of which are differentially affected by oxygen level and duration of hypoxia (Figure 4.7). 


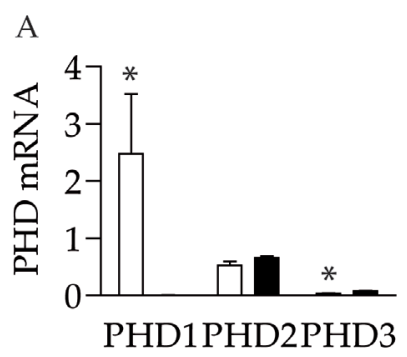

B
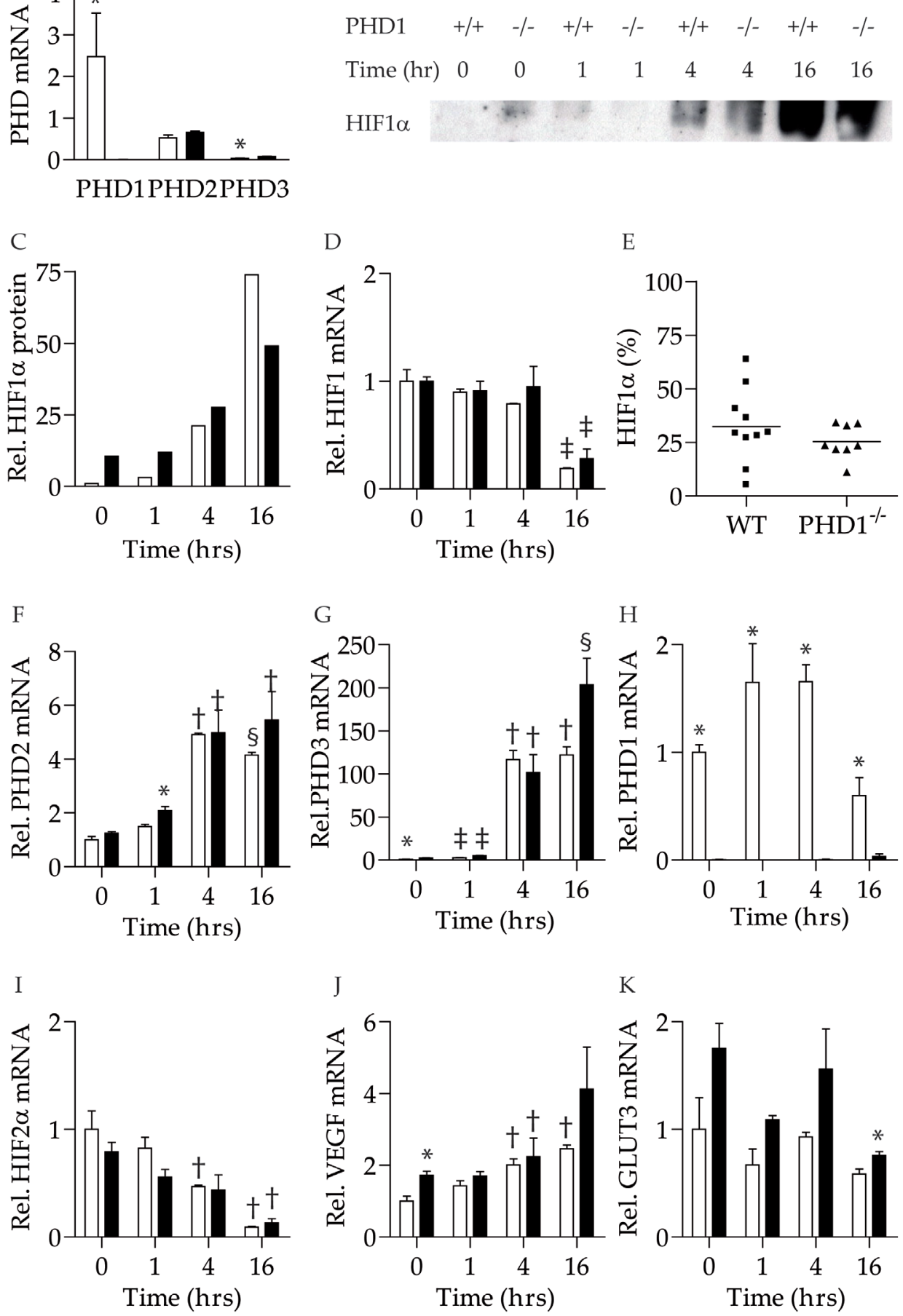
Figure 4.8 HIF and PHD expression in bone marrow-derived and plaque PHD1 ${ }^{-/}$macrophages

A. PHD1, PHD2 and PHD3 mRNA expression on qRT-PCR (normalized to housekeeping genes) in normoxic WT (open bars) and PHD1 ${ }^{-1}$ macrophages (black bars). B. A representative western blot of HIF1 $\alpha$ expression in WT en PHD $1^{-/}$macrophages after exposure to $21 \%$ or $0.2 \% \mathrm{O}_{2}$ for 1,4 and 16 hours. C. Quantification of HIF1 $\alpha$ protein expression on western blot in WT (open bars) and PHD $^{-1}$ macrophages (black bars) after exposure to $21 \%$ or $0.2 \% \mathrm{O}_{2}$ for 1,4 and 16 hours. WT values in normoxia were arbitrarily set as one. D. HIF1 $\alpha$ mRNA expression in WT (open bars) and PHD1 ${ }^{-1}$ macrophages (black bars) after exposure to $21 \%$ or $0.2 \% \mathrm{O}_{2}$ for 1,4 and 16 hours. E. Nuclear HIF1 $\alpha$ immunoreactivity (\% of cells) was similar in atherosclerotic aortic roots of $10 \mathrm{WT}$ en $10 \mathrm{PHD}^{-}$ recipients. F. PHD2, G. PHD3, H. PHD1, I. HIF2 $\alpha$, J. VEGF, and K. GLUT3 mRNA expression in WT (open bars) and $\mathrm{PHD}^{-/}$macrophages (black bars) after exposure to $21 \%$ or $0.2 \% \mathrm{O}_{2}$ for 1,4 and 16 hours. ${ }^{*} \mathrm{p}<0.05$ WT vs. KO; † p $<0.05$ vs. normoxia; $\ddagger \mathrm{p}<0.05$ vs. normoxia and WT vs. KO § $\mathrm{p}<0.05$ vs. normoxia and vs. hypoxia $4 \mathrm{hrs}$. HIF1 $\alpha^{-/}$indicates lysMcre/HIF1 $\alpha^{-/}$.

\section{Discussion}

The presence of hypoxia was demonstrated in murine atherosclerosis using the hypoxia marker pimonidazole. Hypoxia was most severe in collar-induced atherosclerosis and in mouse macrophage (foam) cells deep in the lesion. However, subluminal chondrocytes and macrophage foam cells of smaller lesions were also hypoxic. The hypoxic cell types and their location in the plaque were similar to human ${ }^{5}$ and rabbit atherosclerotic plaques. ${ }^{29}$ The threshold for cellular hypoxia is set by the increased oxygen demand of inflammatory cells and by limited oxygen diffusion beyond 100-250 $\mu \mathrm{m}$ from a blood vessel. ${ }^{30}$ Although murine plaque thickness, representing the distance of oxygen diffusion, was greater than accepted values of the oxygen diffusion distance, plaque thickness was not correlated with hypoxia. In contrast, plaque macrophage content was correlated with the presence of hypoxia in murine as well as in human plaques. ${ }^{5}$ Macrophage foam cells in human atherosclerosis were already hypoxic at 20-30 $\mu \mathrm{m}$ from the lumen. ${ }^{5}$ In addition, hypoxia detection in advanced plaque macrophages was not enhanced by low environmental oxygen, suggesting that the presence of hypoxia is mostly dictated on a cellular level by the inflammatory cell microenvironment instead of by the oxygen diffusion distance.

Mice were subjected to hypoxic exposure to study a functional effect of hypoxia on existing, advanced atherosclerosis and the high metabolic demand of macrophages. However, progression and phenotype of plaques was unchanged, most likely due to similar hypoxia and HIF1 $\alpha$ levels in the plaques. In contrast with our advanced atherosclerosis study, recent initiation studies have shown 
aggravated atherosclerosis by hypoxic exposure in balloon-injured rabbits, ${ }^{31}$ ApoE $^{-/-}$mice $^{32}$, and atherosclerosis-resistant C57/BL6 mice. ${ }^{33}$ Results were similar in all models, despite the variability in duration (3, 6, or 12 weeks) and oxygen exposure (chronic or intermittent; $5 \%$ or $10 \%$ ). As our severe hypoxic regime did not increase plaque hypoxia, effects of exogenous hypoxia are probably mediated by reduced arterial blood oxygen pressure. Also, the pro-atherogenic effects in these initiation studies were mediated via diet-induced reactive oxygen species (ROS) and dyslipidemia. All animals in the initiation studies were subjected to a high fat/cholesterol diet, while mice in our study received normal chow. Therefore, exogenous hypoxia either only enhances the initiation of atherosclerosis, or two stimuli are necessary to alter atherosclerotic progression: reduced blood (not plaque) oxygen levels ánd diet-induced increased lipid and ROS accumulation.

The cellular response to hypoxia is chiefly mediated by HIF-driven transcription. Similar to the observation in human atherosclerosis, hypoxia and HIF1 $\alpha$ immunoreactivity were mostly shown in murine macrophages. Hence, the macrophage-specific effect of LysMcre/HIF1 $\alpha$ disruption on murine atherosclerosis was investigated using bone marrow transplantation. Despite the in vitro enhancement of pro-atherogenic processes (inflammation and lipid accumulation) by macrophage $\mathrm{HIF} 1 \alpha{ }^{8,16}$ no functional effect was found of LysMcre/HIF1 $\alpha^{-1-}$ on murine atherogenesis in vivo. A first explanation of the unexpected lack of effect of LysMcre/HIF1 $\alpha$ deletion on atherogenesis is intrinsic to the cell lineage-specific transgenic model. Although HIF1 $\alpha$ mRNA expression was drastically reduced to $75 \%$ in neutrophils, and even $91 \%$ in peritoneal ${ }^{16}$ and bone marrow macrophages, full deletion in the myeloid lineage was not achieved. Notably, HIF1 $\alpha$ protein levels were only moderately reduced by genetic deletion, explaining the hypoxic increase of HIF1 $\alpha$ protein in LysMcre/HIF1 $\alpha^{-/}$macrophages in vitro and in vivo. Also, we and others ${ }^{16}$ observed residual transcriptional activity in LysMcre/HIF1 $\alpha^{-/}$macrophages in hypoxia. In addition, prolonged hypoxic exposure led to reversal of HIF1 $\alpha$ stabilization in WT macrophages, possibly explained by negative feedback of increased PHD expression as observed in this and other studies (Figure 4.7A). . $^{\text {, } 13}$ Feedback loops involving PHD, OS-9 and IPAS only affect HIF1 $\alpha$ protein or activity in prolonged hypoxia, while HIF1 $\alpha$ mRNA was also altered in this study. As hypoxic induction of an endogenous HIF antisense also lead to decreased HIF1 $\alpha$ mRNA and protein in prolonged compared to acute hypoxia, ${ }^{12}$ antisense HIF may be involved in HIF1 $\alpha$ mRNA degradation. Taken together, incomplete LysMcre/HIF1 $\alpha$ deletion and the decline in HIF1 $\alpha$ protein after prolonged hypoxic exposure resulted in similar protein levels in hypoxic LysMcre/HIF1 $\alpha^{-/-}$ 
and WT plaque macrophages, explaining the lack of effect on atherosclerosis (Figure 4.7A-B). Conversely, the slightest residual HIF1 $\alpha$ protein may suffice to drive transcription in atherosclerosis.

Nevertheless, incomplete LysMcre/HIF1 $\alpha$ deletion impressively affected inflammation in several in vivo models. ${ }^{16,34}$ It cannot, therefore, be excluded that other HIF1 $\alpha$-expressing cell types in atherosclerosis, such as smooth muscle cells (SMC) and T-cells, may have balanced the HIF1 $\alpha$ deletion in plaque macrophages. Indeed, we showed that plaque SMC were slightly hypoxic. Also, local HIF1 $\alpha$ siRNA-treatment reduced HIF1 $\alpha$ expression in SMC, SMC content and neointimal area after wire injury in $\mathrm{ApoE}^{-/}$mice. ${ }^{35} \mathrm{In}$ contrast, T-cell specific HIF $1 \alpha^{-/}$aggravated cytokine production and neointima formation after femoral cuff placement, ${ }^{36}$ suggesting that the effect of HIF1 $\alpha$ may also be cell type dependent.

As HIF1 $\alpha$ and HIF $2 \alpha$ have reciprocal suppressive effects, ${ }^{14,15}$ functional compensation of HIF2 $\alpha$ in plaque macrophages might also have occurred in the absence of HIF1 $\alpha$ (Figure 4.7A-B). Indeed, genetic deletion of HIF1 $\alpha$ was compensated by increased HIF2 $\alpha$ mRNA expression in macrophages in vitro. Although HIF2 $\alpha$ protein levels should be determined, increased mRNA of the HIF target GLUT3 in LysMcre/HIF1 $\alpha^{-/}$macrophages corroborated functional HIF2 $\alpha$ transcription. These results suggest that target gene transcription is differentially regulated by HIF $1 \alpha$ or HIF $2 \alpha$ depending on their dominant availability, which has been shown previously. ${ }^{12,15}$ The relative importance of HIF $1 \alpha$ and HIF2 $\alpha$ in macrophages remains unclear, as conflicting results are reported. ${ }^{34,37,38}$ We speculate that HIF2 $\alpha$ protein compensated reduced HIF1 $\alpha$ protein in LysMcre/HIF1 $\alpha^{-1}$ macrophages. If this were true, this would indicate that HIF transcription is compensated by HIF $2 \alpha$ or that macrophage HIF2 $\alpha$ is not functionally involved in murine atherogenesis.

As hypoxia and HIF1 $\alpha$ disruption did not influence murine atherogenesis, the effect of PHD1 deletion, responsible for normoxic HIF degradation, on murine atherogenesis was investigated. Atherosclerotic load and plaque phenotype were unchanged in PHD1 ${ }^{-}$bone marrow recipients compared to WT recipients. Also, hypoxic WT and $\mathrm{PHD}^{-}$macrophages showed similar HIF1 $\alpha$ protein expression in vitro and in vivo, indicating that the unchanged plaque size was independent of HIF1 $\alpha$ overexpression.

In addition, HIF protein degradation is regulated by three isoforms, PHD1, PHD2, and PHD3, which were all shown to be expressed in bone marrowderived macrophages. PHD1 deletion resulted in compensatory expression of PHD3 in normoxia. In hypoxia, the relative importance of PHD1 for HIF1 $\alpha$ degradation diminished due to induction of PHD2 and PHD3, but not PHD1. 
Others have also created PHD knockouts, and found major functional importance of PHD2 compared to PHD1 and PHD3., 28, 39 In addition, PHD2 deletion was embryonically lethal, not PHD1 or PHD3 deletion. ${ }^{28}$ Moreover, the recently described conditional $\mathrm{PHD}^{-/}$demonstrated enhanced HIF1 $\alpha$ expression and angiogenesis in adult vasculature, whereas the full PHD1 and PHD3 knock-outs did not. ${ }^{28,39}$ The hypoxic induction of PHD2 and PHD3 and the similar HIF1 $\alpha$ levels in hypoxic WT and PHD1 ${ }^{-/}$macrophages suggest that PHD1 is not the most important PHD for HIF1 $\alpha$ degradation.

Unlike its irrelevance for HIF1 $\alpha$ degradation, PHD1 contributed significantly to HIF $2 \alpha$ repression in normoxic and hypoxic skeletal muscle. ${ }^{17}$ In contrast, HIF $2 \alpha$ mRNA was similar in WT and PHD1 ${ }^{-/}$macrophages, although macrophage HIF2 $\alpha$ protein has not been determined. Nonetheless, increased VEGF and GLUT3 mRNA in the presence of similar HIF1 $\alpha$ protein indicate that HIF2 $\alpha$ protein may be upregulated in $\mathrm{PHD}^{-}$macrophages, as observed in $\mathrm{PHD}^{-/}$skeletal muscle. ${ }^{17}$ Indeed, differential target gene specificity of HIF1 $\alpha$ and HIF2 $\alpha$ was previously shown and depended on their availability. ${ }^{12,}{ }^{14,15}$ Nevertheless, the hypothetical increase of $\mathrm{HIF} 2 \alpha$ protein in $\mathrm{PHD}^{-/}$plaque macrophages, did not affect murine atherogenesis.

Although hypoxia and HIF1 $\alpha$ were expected to be pro-atherogenic based on their enhancement of inflammation, lipid accumulation, and angiogenesis, ${ }^{2,4,7,8}$ the current study is unable to demonstrate such effect. However, the clear presence of hypoxia in plaque macrophages may have obscured a possible effect of genetic manipulation of HIF1 $\alpha$. Plaque hypoxia precluded a definite conclusion on the functional effect of macrophage HIF1 $\alpha$ on murine atherogenesis, since it may have overridden the effects of LysMcre/HIF1 $\alpha$ and PHD1 deletion. Thus, a model is warranted wherein HIF1 $\alpha$ up- or downregulation sustains in hypoxic conditions, and even then prevails over the hypoxic control. No genetic model will be able to study the effect of HIF1 $\alpha$ downregulation on atherogenesis, as residual expression is inherent to any conditional or cell lineage-specific transgene, and full HIF $1 \alpha^{-/}$is lethal. ${ }^{40}$ In addition, most siRNA treatments are not fully effective, and their effect will thus not be maintained in hypoxia either. Genetic models upregulating HIF1 $\alpha$, such as von Hippel-Lindau (VHL) and PHD2 knock-out mice, may also be used to study the effect of HIF1 $\alpha$ on atherogenesis. However, the effect of VHL or PHD2 deletion in hypoxia on HIF1 $\alpha$ protein expression has not been determined, and results of HIF transcriptional activity are mixed. ${ }^{16,28,39}$ Although several options exist for pharmacological inhibition or induction of HIF, effects are rarely HIF-specific, the working mechanisms are mostly unknown, and it is currently unclear whether their effect sustains in hypoxia. ${ }^{41,42}$ Therefore, it will prove 
difficult to determine a possible function for HIF1 $\alpha$ in atherogenesis.

In this study, the role of HIF1 $\alpha$ in murine plaque angiogenesis was not addressed as reliable and specific immunohistochemical detection of microvessel endothelial cells in mice are currently unavailable. Although some have shown $13 \%$ microvessel-positive murine plaques using immunohistochemistry, ${ }^{43,44}$ many others have failed to reproduce this. In cryo sections unambiguous morphological identification of plaque microvessels is challenging. While in our hands, the few markers suitable for paraffin sections fail to stain all (adventitial) microvessels, including the ones morphologically distinguishable using histology. Novel murine endothelial imaging markers may shed light on the presence and/or frequency of murine plaque angiogenesis. Micro-computed tomography indeed showed murine microvessels extending from the adventitia into the arterial wall, however the plaque was not delineated by a plaque marker excluding the identification of genuine plaque microvessels. ${ }^{45}$ Therefore, their existence remains under debate and murine plaque microvessels are scarce ate the very least.

In conclusion, hypoxia is present in murine atherosclerotic plaques, and dictated by the high metabolism in an inflammatory cellular milieu. Prolonged hypoxia in plaque macrophages resulted in similar HIF1 $\alpha$ protein levels in LysMcre/HIF1 $\alpha^{-1-}$ and WT plaques, explaining that LysMcre/HIF1 $\alpha^{-1-}$ BMT did not affect murine atherogenesis. Macrophage-specific PHD1 deletion only marginally increased HIF1 $\alpha$ expression, and did not affect murine atherosclerosis, possibly explained by isoform redundancy and the stimulatory effect of the hypoxic milieu on HIF1 $\alpha$ protein expression.

\section{Acknowledgements}

We gratefully acknowledge Rik Tinnemans for excellent technical assistance. The authors (EL, MPJdW, MJAPD) participate in the European Vascular Genomics Network (http://www.evgn.org), a Network of Excellence supported by the European Community's Sixth Framework Program for Research Priority 1 (contract LSHM-CT-2003-503254). The authors have no conflicts of interest to declare. 


\section{Chapter 4}

\section{References}

1. Virmani R, Kolodgie FD, Burke AP, et al. Atherosclerotic Plaque Progression and Vulnerability to Rupture Angiogenesis as a Source of Intraplaque Hemorrhage. Arterioscler Thromb Vasc Biol. 2005;25:2054-2061

2. Murdoch C, Muthana M, Lewis CE. Hypoxia regulates macrophage functions in inflammation. J Immunol. 2005;175:6257-6263.

3. Rydberg EK, Krettek A, Ullstrom C, et al. Hypoxia increases LDL oxidation and expression of 15-lipoxygenase-2 in human macrophages. Arterioscler Thromb Vasc Biol. 2004;24:2040-2045.

4. Bostrom P, Magnusson B, Svensson PA, et al. Hypoxia converts human macrophages into triglyceride-loaded foam cells. Arterioscler Thromb Vasc Biol. 2006;26:1871-1876.

5. Sluimer JC, Gasc JM, van Wanroij JL, et al. Hypoxia in human atherosclerotic plaques is correlated with the expression of CD68, HIF, VEGF and the presence of a thrombus and angiogenesis. J Am Coll Cardiol. 2008;In press.

6. Pouyssegur J, Dayan F, Mazure NM. Hypoxia signalling in cancer and approaches to enforce tumour regression. Nature. 2006;441:437-443.

7. Semenza GL. Targeting HIF-1 for cancer therapy. Nat Rev Cancer. 2003;3:721-732.

8. Jiang G, Li T, Qiu Y, et al. RNA interference for HIF-1alpha inhibits foam cells formation in vitro. Eur J Pharmacol. 2007;562:183-190.

9. Appelhoff RJ, Tian YM, Raval RR, et al. Differential function of the prolyl hydroxylases PHD1, PHD2, and PHD3 in the regulation of hypoxia-inducible factor. J Biol Chem. 2004;279:3845838465.

10. Makino Y, Kanopka A, Wilson WJ, et al. Inhibitory PAS domain protein (IPAS) is a hypoxiainducible splicing variant of the hypoxia-inducible factor-3alpha locus. J Biol Chem. 2002;277:32405-32408.

11. Baek JH, Mahon PC, Oh J, et al. OS-9 interacts with hypoxia-inducible factor 1alpha and prolyl hydroxylases to promote oxygen-dependent degradation of HIF-1alpha. Mol Cell. 2005;17:503512.

12. Uchida T, Rossignol F, Matthay MA, et al. Prolonged hypoxia differentially regulates hypoxiainducible factor (HIF)-1alpha and HIF-2alpha expression in lung epithelial cells: implication of natural antisense HIF-1alpha. J Biol Chem. 2004;279:14871-14878.

13. Aprelikova O, Chandramouli GV, Wood M, et al. Regulation of HIF prolyl hydroxylases by hypoxia-inducible factors. J Cell Biochem. 2004;92:491-501.

14. Raval RR, Lau KW, Tran MG, et al. Contrasting properties of hypoxia-inducible factor 1 (HIF-1) and HIF-2 in von Hippel-Lindau-associated renal cell carcinoma. Mol Cell Biol. 2005;25:56755686 .

15. Holmquist-Mengelbier L, Fredlund E, Lofstedt T, et al. Recruitment of HIF-1alpha and HIF2alpha to common target genes is differentially regulated in neuroblastoma: HIF-2alpha promotes an aggressive phenotype. Cancer Cell. 2006;10:413-423. 
16. Cramer T, Yamanishi Y, Clausen BE, et al. HIF-1alpha is essential for myeloid cell-mediated inflammation. Cell. 2003;112:645-657.

17. Aragones J, Schneider M, Van Geyte K, et al. Deficiency or inhibition of oxygen sensor Phd1 induces hypoxia tolerance by reprogramming basal metabolism. Nat Genet. 2008.

18. van Suylen RJ, Smits JF, Daemen MJ. Pulmonary artery remodeling differs in hypoxia- and monocrotaline-induced pulmonary hypertension. Am J Respir Crit Care Med. 1998;157:14231428.

19. Lutgens E, Gorelik L, Daemen MJ, et al. Requirement for CD154 in the progression of atherosclerosis. Nat Med. 1999;5:1313-1316.

20. von der Thusen JH, van Berkel TJ, Biessen EA. Induction of rapid atherogenesis by perivascular carotid collar placement in apolipoprotein E-deficient and low-density lipoprotein receptordeficient mice. Circulation. 2001;103:1164-1170.

21. Kanters E, Pasparakis M, Gijbels MJ, et al. Inhibition of NF-kappaB activation in macrophages increases atherosclerosis in LDL receptor-deficient mice. J Clin Invest. 2003;112:1176-1185.

22. Cobb LM, Nolan J, Butler SA. Distribution of pimonidazole and RSU 1069 in tumour and normal tissues. Br J Cancer. 1990;62:915-918.

23. Varia MA, Calkins-Adams DP, Rinker LH, et al. Pimonidazole: a novel hypoxia marker for complementary study of tumor hypoxia and cell proliferation in cervical carcinoma. Gynecol Oncol. 1998;71:270-277.

24. Kleiter MM, Thrall DE, Malarkey DE, et al. A comparison of oral and intravenous pimonidazole in canine tumors using intravenous CCI-103F as a control hypoxia marker. Int J Radiat Oncol Biol Phys. 2006;64:592-602.

25. Donners MM, Bot I, De Windt LJ, et al. Low-dose FK506 blocks collar-induced atherosclerotic plaque development and stabilizes plaques in ApoE-/- mice. Am J Transplant. 2005;5:1204-1215.

26. Bot I, de Jager SC, Zernecke A, et al. Perivascular mast cells promote atherogenesis and induce plaque destabilization in apolipoprotein E-deficient mice. Circulation. 2007;115:2516-2525.

27. Sluimer JC, Kisters N, Cleutjens KB, et al. Dead or Alive: Gene expression profiles of advanced atherosclerotic plaques from autopsy and surgery. Physiol Genomics. 2007;30:335-341.

28. Takeda K, Ho VC, Takeda H, et al. Placental but not heart defects are associated with elevated hypoxia-inducible factor alpha levels in mice lacking prolyl hydroxylase domain protein 2. Mol Cell Biol. 2006;26:8336-8346.

29. Bjornheden T, Levin M, Evaldsson M, et al. Evidence of hypoxic areas within the arterial wall in vivo. Arterioscler Thromb Vasc Biol. 1999;19:870-876.

30. Torres Filho IP, Leunig M, Yuan F, et al. Noninvasive measurement of microvascular and interstitial oxygen profiles in a human tumor in SCID mice. Proc Natl Acad Sci U S A. 1994;91:2081-2085.

31. Lau AK, Chaufour X, McLachlan C, et al. Intimal thickening after arterial balloon injury is increased by intermittent repetitive hypoxia, but intermittent repetitive hyperoxia is not protective. Atherosclerosis. 2005. 


\section{Chapter 4}

32. Nakano D, Hayashi T, Tazawa N, et al. Chronic hypoxia accelerates the progression of atherosclerosis in apolipoprotein E-knockout mice. Hypertens Res. 2005;28:837-845.

33. Savransky V, Nanayakkara A, Li J, et al. Chronic intermittent hypoxia induces atherosclerosis. Am J Respir Crit Care Med. 2007;175:1290-1297.

34. Peyssonnaux C, Datta V, Cramer T, et al. HIF-1alpha expression regulates the bactericidal capacity of phagocytes. J Clin Invest. 2005;115:1806-1815.

35. Karshovska E, Zernecke A, Sevilmis G, et al. Expression of HIF-1alpha in injured arteries controls SDF-1alpha mediated neointima formation in apolipoprotein $\mathrm{E}$ deficient mice. Arterioscler Thromb Vasc Biol. 2007;27:2540-2547.

36. Kurobe H, Urata M, Izawa $\mathrm{Y}$, et al. Hif-1 in T Cells pathway plays a crucial role in the progression of arteriosclerosis and artery intimal thickening. Abstract AHA 2007. Circulation. 2007;116:_246.

37. Burke B, Tang N, Corke KP, et al. Expression of HIF-1alpha by human macrophages: implications for the use of macrophages in hypoxia-regulated cancer gene therapy. J Pathol. 2002;196:204-212.

38. Talks KL, Turley H, Gatter KC, et al. The expression and distribution of the hypoxia-inducible factors HIF-1alpha and HIF-2alpha in normal human tissues, cancers, and tumor-associated macrophages. Am J Pathol. 2000;157:411-421.

39. Takeda K, Cowan A, Fong GH. Essential Role for Prolyl Hydroxylase Domain Protein 2 in Oxygen Homeostasis of the Adult Vascular System. Circulation. 2007.

40. Iyer NV, Kotch LE, Agani F, et al. Cellular and developmental control of O2 homeostasis by hypoxia-inducible factor 1 alpha. Genes Dev. 1998;12:149-162.

41. Melillo G. Inhibiting hypoxia-inducible factor 1 for cancer therapy. Mol Cancer Res. 2006;4:601605.

42. Patiar S, Harris AL. Role of hypoxia-inducible factor-1alpha as a cancer therapy target. Endocr Relat Cancer. 2006;13 Suppl 1:S61-75.

43. Moulton KS, Heller E, Konerding MA, et al. Angiogenesis inhibitors endostatin or TNP-470 reduce intimal neovascularization and plaque growth in apolipoprotein E-deficient mice. Circulation. 1999;99:1726-1732.

44. Moulton KS, Olsen BR, Sonn S, et al. Loss of collagen XVIII enhances neovascularization and vascular permeability in atherosclerosis. Circulation. 2004;110:1330-1336.

45. Langheinrich AC, Michniewicz A, Sedding DG, et al. Correlation of vasa vasorum neovascularization and plaque progression in aortas of apolipoprotein $\mathrm{E}(-/-) /$ low-density lipoprotein(-/-) double knockout mice. Arterioscler Thromb Vasc Biol. 2006;26:347-352. 


\section{Infrequent mural cell coverage and structural abnormalities of microvessels in human coronary atherosclerotic plaques}

J.C. Sluimer, F.D. Kolodgie, A.P.J.J. Bijnens, K. Maxfield,

E. Pacheco, H. Duimel, P.M. Frederik, V.W.M. van Hinsbergh, A.P. Burke, R. Virmani, M.J.A.P. Daemen

Submitted for publication 


\section{Chapter 5}

\section{Abstract}

Microvessels in atherosclerotic plaques are an entry point for inflammatory and red blood cells, presumably due to microvascular leakage. Yet there is limited data on the (ultra)structural integrity of microvessels in human atherosclerosis. Therefore, microvessel density (MVD) and (ultra)structural morphology were determined in the adventitia, intima-media border, and atherosclerotic plaque of 30 coronary arteries using immunohistochemistry markers of endothelial cells (Ulex europeus lectin-1 CD31/CD34), basement membrane (laminin, collagen IV), and mural cells (desmin, alpha-smooth muscle actin (aSMA)), and using electron microscopy (EM).

MVD was increased in advanced plaques compared to early plaques, and correlated with plaque morphology. Adventitial MVD was higher than intraplaque MVD in normal arteries and early lesions, but MVD was similar in all regions of advanced lesions. Basement membrane was intact, but mural cell coverage was infrequent in normal and atherosclerotic coronary arteries, and similar in all plaque types and vessel wall regions. EM showed an abnormal morphology of intraplaque microvascular EC, with membrane blebs, intracytoplasmic vacuoles, open EC-EC junctions, and basement membrane detachment. Leucocyte infiltration was frequently observed by EM, and was confirmed by CD45 and CD68 immunohistochemistry.

In conclusion, microvessel density was associated with coronary plaque progression and morphology. Microvessel mural cell coverage was incomplete in normal and atherosclerotic arteries, and is thus unlikely to account for microvascular leakage. The compromised structural integrity of microvascular endothelium may explain microvascular leakage in human coronary atheroslerosis. 


\section{Introduction}

Atherosclerotic plaque rupture and symptomatic disease are near inseparable from the presence of intraplaque and adventitial neovascularization..$^{1-3}$ Intraplaque microvessels are typically surrounded by lipid pools, leukocytes, and red blood cells, ${ }^{4}$ which have been shown to cause free cholesterol- and iron deposition, lipid peroxidation, and macrophage foam cell formation. ${ }^{5,6}$ All these processes are known to stimulate subsequent intraplaque hemorrhage and/or plaque rupture. $^{7}$

Intraplaque microvessels are thought to serve as the entry point for detrimental plasma components, presumably because they are leaky. ${ }^{8}$ The angiogenic process starts with increased microvessel permeability and matrix degradation, and is followed by EC migration and/or proliferation. The resulting immature sprouts show increased permeability, but are subsequently matured by basement membrane formation and mural cell recruitment (pericyte/smooth muscle cell) at least in physiological angiogenesis. Insight from angiogenesis research in tumor biology has established features of microvascular leakage. ${ }^{9}$ Pathological angiogenesis in tumor tissue often shows immature, fragile structures, which are prone to collapse with concomitant leakage. ${ }^{10}$ Thus, immature microvessels are endothelial-lined tubes without (full) coverage by a basement membrane and mural cells." "11 The possible fragile nature of atherosclerotic angiogenesis corroborates their suggested propensity to collapse and hemorhage, explaining the surrounding lipid pools and red blood cell spillage.

Microvascular leakage is also characterized by a disruption of endothelial integrity, normally maintained by inter-cellular junctions, such as tight, gap, and adherens junction. ${ }^{12}$ Microvessels with aberrant or missing endothelial junctions demonstrate microvascular leakage. ${ }^{10}$ Based on the findings in physiological and pathological angiogenesis, we hypothesize that the maturation and structural integrity of plaque microvessels in human atherosclerosis is incomplete, possibly explaining the inflammatory infiltration and red blood cell extravasation.

Therefore, microvessel density and maturation was studied in human atherosclerotic plaques and in normal coronary arteries using quantitative (immuno) histochemistry of plaque phenotype, endothelial cells, mural cells, and basement membrane. Also, the ultra structural endothelial integrity and morphology were investigated using transmission electron microscopy. 


\section{Chapter 5}

Table 5.1 Demographics and clinical characteristics

\begin{tabular}{ll}
\hline & Frequency $\%(\mathbf{n})^{*}$ \\
\hline Age (years) ${ }^{*}$ & $55.5(2.8)$ \\
Male & $89(25)$ \\
Ethnicity $\quad$ Caucasian & $71(21)$ \\
& $25(7)$ \\
Hypertension & $26(6)$ \\
Hypercholesterolemia & $9(2)$ \\
Smoking & $30(7)$ \\
Alcohol use & $22(5)$ \\
Statin therapy & $0(0)$ \\
Diabetes mellitus 2 & $9(2)$ \\
History of cardiovascular disease & $17(4)$ \\
\hline
\end{tabular}

* unless stated otherwise, + mean (SEM).

\section{Materials and methods}

\section{Tissue collection}

A total of 30 atherosclerotic coronary arteries were obtained at autopsy from 28 sudden death donors, and processed as described. ${ }^{13}$ Collection, storage, and use of tissue and patient data were performed in agreement with institutional ethical guidelines. Demographics and clinical characteristics are presented in Table 5.1. Samples were processed, and classified based on plaque morphology as intimal thickening (IT, normal), pathological intimal thickening (PIT), a thick fibrous cap atheroma with an early (E-FA) or late necrotic core (L-FA), a thin fibrous cap atheroma (TCFA) or a ruptured plaque as described previously. ${ }^{14}$ Samples were randomly included in the study without any pre-selection based on plaque morphology or angiogenesis.

\section{Immunohistochemistry}

Immunohistochemistry was performed on paraffin-embedded sections with IT $(n=5)$, PIT $(n=5)$, E-FA $(n=5)$, L-FA $(n=5)$, TCFA $(n=5)$ or ruptured plaques $(n=5)$. Serial sections were stained with primary antibodies against macrophages (CD68), endothelial cells (Ulex europeus lectin-1, a CD31/CD34 cocktail), mural cells (desmin, alpha-smooth muscle actin ( $\alpha \mathrm{SMA})$ ), basement membrane 


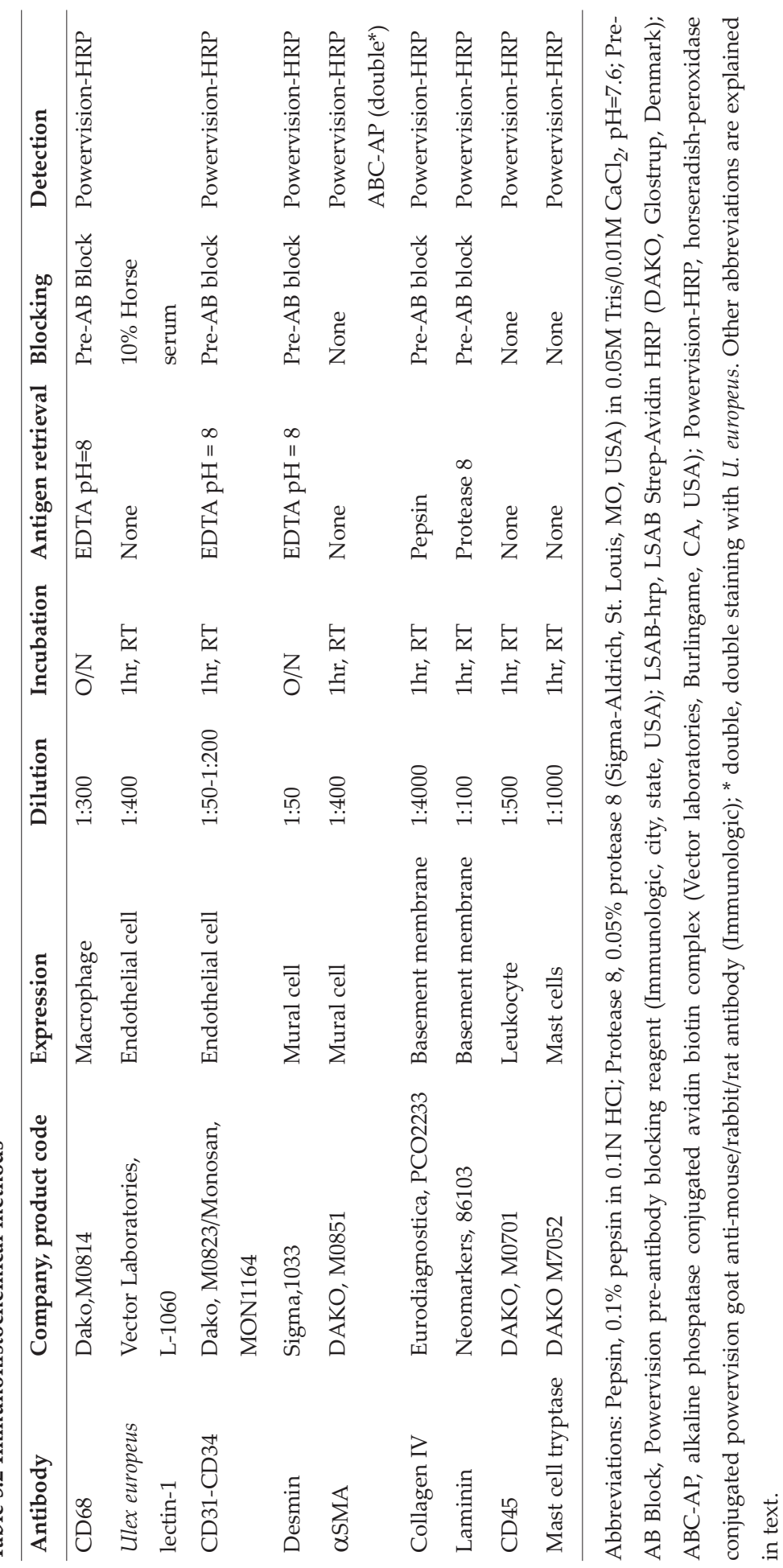


(laminin, collagen IV), leucocytes (CD45), and mast cells (MCT) as described in Table 5.2. Sections were then incubated with appropriate secondary antibodies, and staining was visualized as a brown precipitate using 3, 3'-diaminobenzidine tetrachloride (DAKO, Glostrup, Denmark) tinted with 0.04\% nickel chloride (Sigma-Aldrich, St. Louis, MO, USA). Sections were counterstained in Gill's hematoxylin (Sigma-Aldrich) or methyl green (Vector laboratories, Burlingame, CA, USA) in case of double immunohistochemistry. Evaluation of the staining pattern in control tissue, in which marker expression had previously been described, and omission of a primary antibody served as specificity controls.

\section{Quantitative morphometry}

Histological and morphometric analysis of atherosclerosis was performed as described. ${ }^{13}$ Hematoxylin and eosin (HE) and modified MOVAT stained sections were used for quantification of total plaque area, lipid core ( $\%$ of plaque area), and calcification (\% of plaque area) using computerized morphometry (IVision, Scanalytics, Rockville, MD, USA). Macrophage content (\% of plaque area) was determined using CD68 stained sections. Intimal thickness was measured in the three thickest plaque regions, perpendicular from the plaque surface to the internal elastic lamina (IEL), and the maximal (max.) distance represented the max. intimal thickness. The maximal percentage of artery stenosis was calculated as ((IEL perimeter - lumen perimeter)/(IEL perimeter))x100.

Microvessels were defined as a lumen surrounded by endothelial cells (EC), and quantified in three regions of interest: the adventitia, intima-media (IM) border, and pericore using image-processing software (IVision). Adventitial microvessels were quantified using $\mathrm{ULEX}^{+}$microvessels, whereas microvessels in the IM border and pericore regions were $\mathrm{CD} 31^{+} \mathrm{CD} 34^{+}$. Microvessels were counted using 200x magnified fields in up to 3 hotspots ( $\geq 3$ microvessels) in the IM border and pericore, and in four hotspots (one per quadrant) in the adventitia. The adventitial area was limited to twice the width of the media. Necrotic core and lumen area were excluded from the IM border and pericore area measurements, as well as adventitia and media respectively. Microvessel lumen was included in the area measurements. Microvessel density (MVD) was computed as total count/total area, and mural cell coverage as $\alpha \mathrm{SMA}^{+}$ microvessel/total microvessel. When present, mural cell layers were differentiated as one or multiple layers. The average across hotspots was computed per region of interest (adventitia, IM border, pericore). 


\section{Electron microscopy}

Six coronary artery sections with FA $(n=2)$ or ruptured plaques $(n=4)$ were obtained from 6 donors (age $63 \pm 6$ years, $n=6$ male, $n=5$ African-American). Sections were divided in fragments of $\sim 1 \mathrm{~mm}^{3}$, and fixed overnight in $2.5 \%$ glutaraldehyde (Ted Pella, Redding, CA, USA) in 0.1M phosphate buffer $(\mathrm{pH}=7.6)$. After several washes, tissue fragments were post fixed in $1 \%$ osmium tetroxide solution, and routinely dehydrated through $100 \%$ ethanol, cleared with propylene oxide, and embedded in epoxy resin. Semi-thin $(1 \mu \mathrm{m})$ serial sections were stained with toluidine blue to identify the presence of plaque microvessels. Subsequently, ultra-thin sections $(70-90 \mathrm{~nm})$ with microvessel positive regions were cut on an ultra-microtome, mounted on Formvar (1595 E, Merck)-coated 75 mesh copper grids, and counterstained with uranyl acetate and lead citrate before analysis on a Philips CM100 transmission electron microscope.

\section{Statistical analysis}

All data are presented as mean \pm SEM. The overall difference between plaques types in plaque phenotype, MVD, and mural cell coverage was tested using a non-parametric Kruskall-Wallis test (SPSS 12.0 Chicago, IL, USA). If significantly different, a non-parametric Mann-Whitney test was used to determine which plaque types were different. A Chi-square test was used to test the frequency distribution of concentric and eccentric morphology between plaque types. Spearmann's non-parametric correlation coefficient was calculated for plaque phenotype, MVD, and mural cell coverage. Results were considered statistically different when $\mathrm{p}<0.05$.

\section{Results}

Plaque phenotype changed with plaque type

The phenotype of normal and atherosclerotic coronary arteries was determined using computer-assisted morphometry (Figure 5.1). Plaque area, max. intimal thickness, stenosis, necrotic core, and macrophage content were all significantly increased with progression of atherosclerosis (Figure 5.1A-E). The macrophage content in TCFA was not significantly different from early and late FA or ruptured plaques. Plaque calcification content was similar between different plaque types (Figure 5.1F). Ruptured plaques were more often concentric than eccentric as compared to PIT, late, and early FA (Table 5.3). The relation between plaque phenotype and plaque type were as reported in literature, indicating that a representative selection of coronary plaques was collected. 

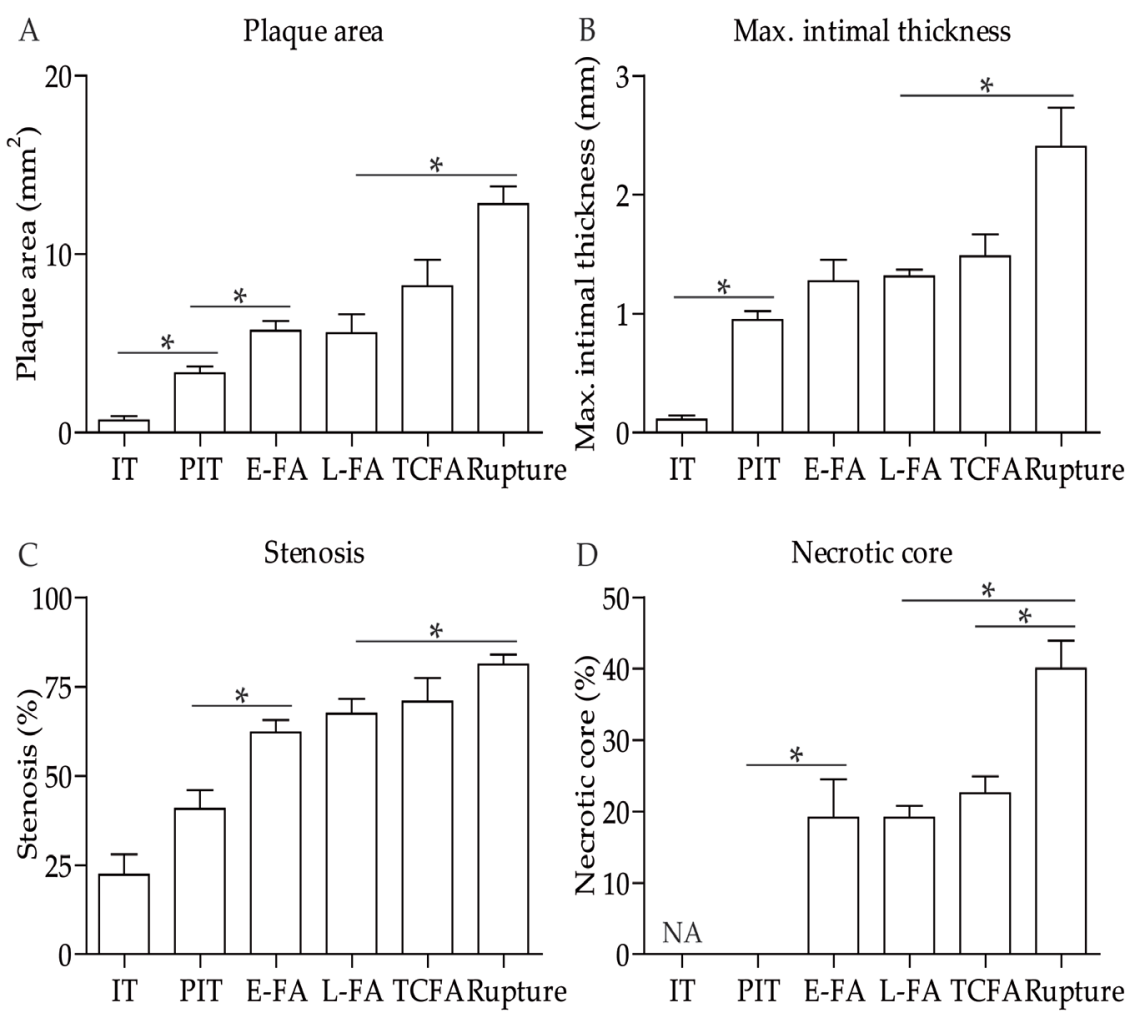

D Necrotic core
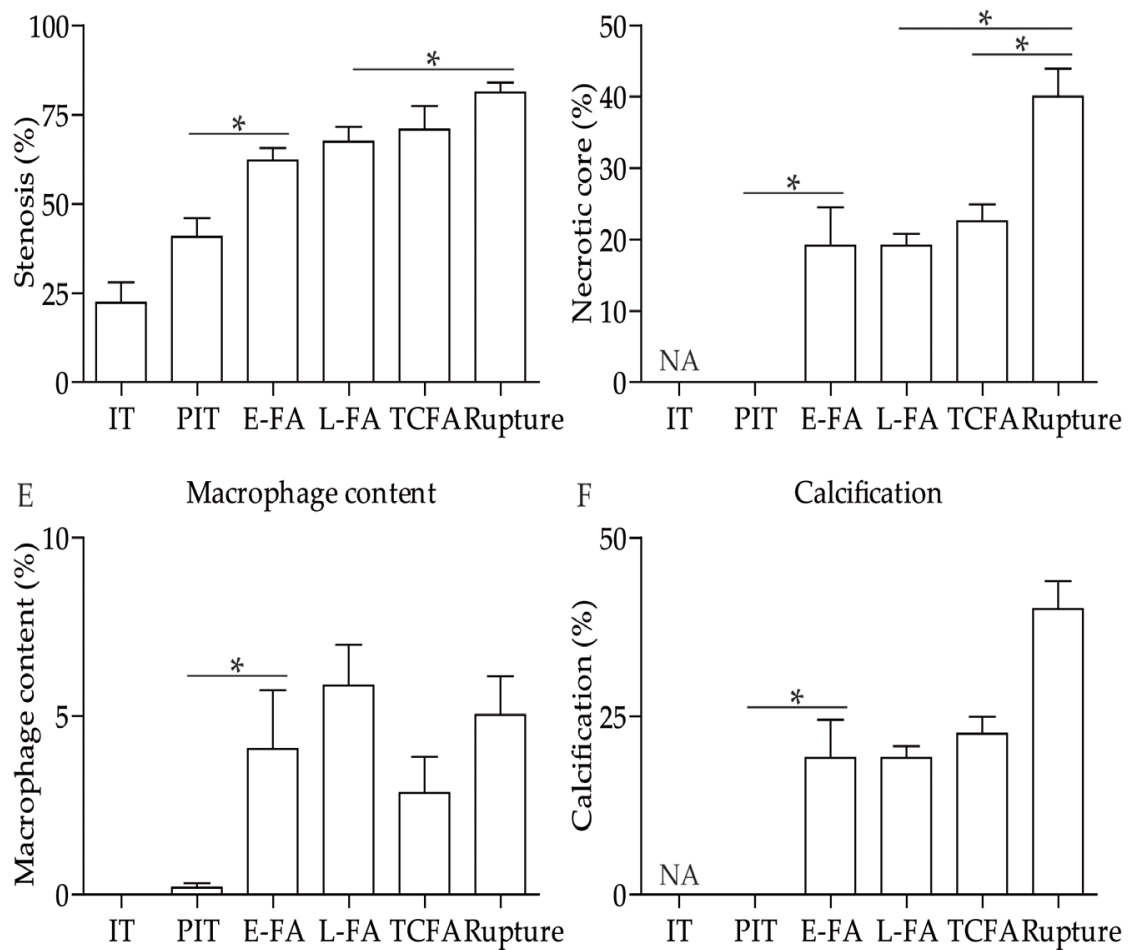

F

Calcification

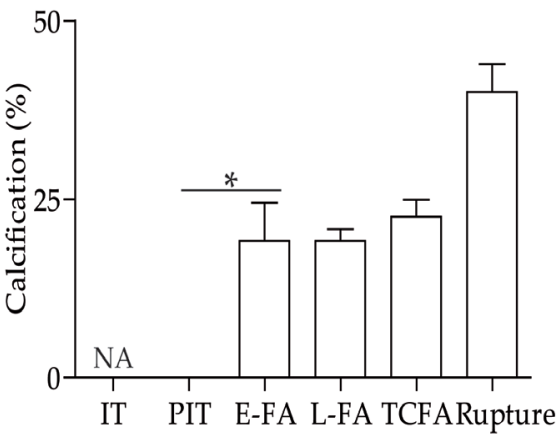

Figure 5.1. Atherosclerotic plaque phenotype in normal and atherosclerotic coronary arteries

A. Plaque area, B. max. intimal thickness, C. stenosis, D. necrotic core content, E. macrophage content, and F. calcification content in normal coronary artery and different coronary plaque types. * indicates p-value $<0.05$. Abbreviations: PIT, pathological intimal thickening; FA, thick fibrous cap atheroma with an early or (E-FA) late necrotic core (L-FA); TCFA, thin fibrous cap atheroma; Rupture; ruptured plaque 
Table 5.3 Frequencies of concentric vessel morphology in different plaque types

\begin{tabular}{ll}
\hline Plaque type & Concentric \% (n) \\
\hline PIT $^{*}$ & $20(1)$ \\
E-FA* $^{*}$ & $40(2)$ \\
L-FA* & $40(2)$ \\
TCFA & $80(4)$ \\
Rupture & $100(5)$ \\
\hline
\end{tabular}

* indicates p-value $<0.05$ vs. rupture. Abbreviations: PIT, pathological intimal thickening; FA, thick fibrous cap atheroma with an early or (E-FA) late necrotic core (L-FA); TCFA, thin fibrous cap atheroma; Rupture; ruptured plaque

\section{Microvessel density increased with plaque progression and plaque morphology}

Angiogenesis in atherosclerotic plaques is present in three regions, the adventitia, IM border, and surrounding the core (pericore) (Figure 5.2 A-D). Microvessel density was significantly increased with atherosclerotic progression in the adventitia $(\mathrm{p}=0.02)$, IM border $(\mathrm{p}=0.01)$, and pericore $(\mathrm{p}=0.025)$ (Figure 5.2E-G). A significant difference in MVD was observed between normal (IT) or PIT and advanced lesions (FA and ruptured) in all arterial wall regions, while MVD in fibroatheromas did not differ from ruptured plaques (Figure 5.2E-G). MVD was significantly higher in concentric plaques, presumably as advanced lesions were more often concentric and showed a higher MVD (Figure 5.2H).

Although the magnitude of MVD in the adventitia, IM border, and pericore in advanced lesions was not significantly different, microvessel density in the adventitia was higher in normal $(\mathrm{p}=0.008)$, PIT $(\mathrm{p}=0.008)$, and early FA $(\mathrm{p}=0.008)$ compared to IM border (Figure 5.2E-F). Also, adventitial MVD in PIT was higher $(\mathrm{p}=0.008$ ) compared to pericore MVD (Figure 5.2E, G). As pericore MVD was naturally absent in normal arteries, no comparison could be made with adventitia or IM border. In addition, adventitial MVD did not correlate with pericore and IM border MVD ( $\rho=0.30, p=0.140$ and $\rho=0.35, p=0.056$ resp.). MVD was not different between IM border and pericore, and the trends between MVD pericore or in the IM border with plaque stage showed a moderate correlation $(\rho=0.44, p=0.028)$. Also, microvessels were observed running from the adventitia, through the media into the plaque, indicating that the adventitia was the origin of microvessel sprouting (Figure 5.3A-B). Together these results suggest that the onset of adventitial microvessels in atherogenesis preceded those in the IM border and pericore. 

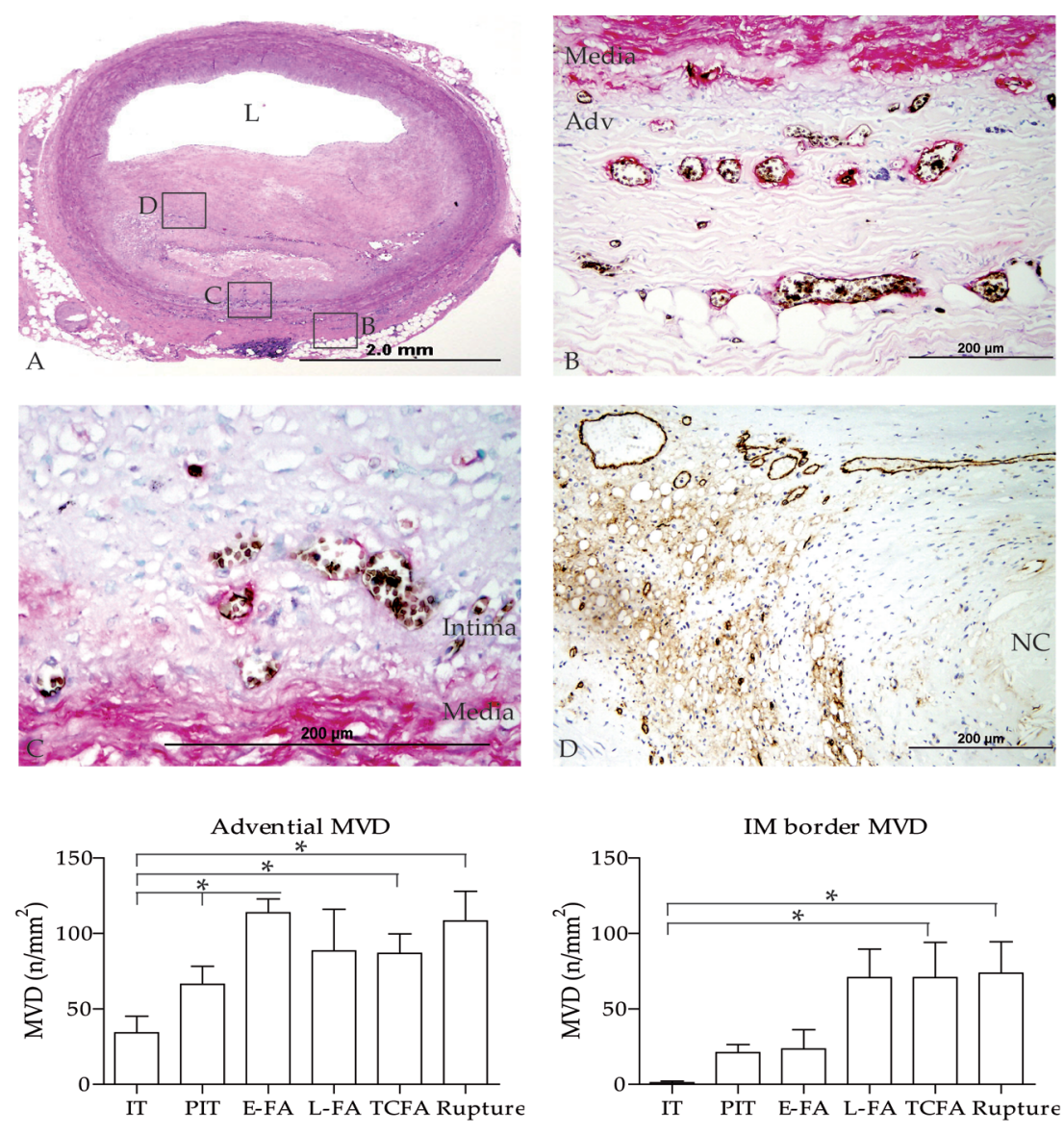

E

F
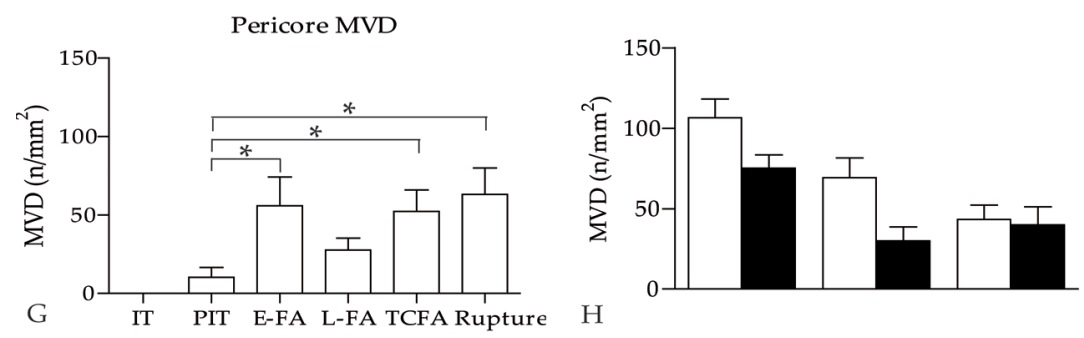

Figure 5.2. Microvessel density increases with atherosclerotic progression

A. Hematoxylin and eosin stained coronary artery with thick cap fiboratheroma (L indicates lumen). Boxed regions B-D are shown in more detail in corresponding photographs. B. Adjacent section of fibroatheroma in A double-stained with Ulex lectin-1 (black) and SMA (red) showing a minority of microvessels with mural cell coverage in the adventitia and C. in the IM border. D. Adjacent section of fibroatheroma in A stained with CD31/CD34 cocktail (brown) showing microvessels pericore (NC indicates necrotic core). E. Mean microvessel density was quantified in adventitia, F. in the IM border, and G. pericore, and increased with progression. H. Microvessel density is higher in concentric (open bars) than in eccentric (black bars) plaques. * indicates p-value $<0.05$ 
Microvessel density correlated significantly with plaque morphology, such as plaque area, max. intimal thickness, stenosis, necrotic core, and macrophage content, in all three regions (Table 5.4). However, after stratification for plaque stage this effect was no longer observed. No association was observed between microvessel density and plaque calcification (Table 5.4).

Table 5.4 Spearmann's $\rho$ correlation coefficients of microvessel density and plaque phenotype

\begin{tabular}{llll}
\hline & & \multicolumn{2}{c}{ Microvessel density } \\
& Adventitia & IM border & Pericore \\
\hline Plaque area & $0.54^{\dagger}$ & $0.79^{+}$ & $0.60^{\dagger}$ \\
Max. intimal thickness & $0.54^{+}$ & $0.70^{+}$ & $0.60^{+}$ \\
Stenosis & $0.60^{+}$ & $0.66^{+}$ & $0.44^{*}$ \\
Necrotic core content & $0.60^{\dagger}$ & $0.48^{*}$ & $0.43^{\dagger}$ \\
Macrophage content & $0.52^{+}$ & $0.52^{\dagger}$ & $0.53^{+}$ \\
Calcification content & 0.34 & $0.66^{\dagger}$ & 0.33 \\
\hline
\end{tabular}

Abbreviations indicated in text. ${ }^{*}$ p-values $<0.05,+<0.01$

Basement membrane is intact, but mural cell coverage is low in normal and atherosclerotic coronary arteries

Immunohistochemistry of basement membrane (laminin, collagen IV) and mural cells ( $\alpha \mathrm{SMA}$, desmin) was performed to establish the maturation status of microvessels in normal coronary arteries and in coronary atherosclerosis. Microvessels in all regions were generally surrounded by laminin, and some also by collagen IV (Figure 5.3C-D), indicating that the microvessel basement membrane was intact. In contrast, aSMA and desmin were only rarely bordering microvessels in all regions, and both mural cell markers showed similar patterns (Figure 5.3E-F). Unexpectedly, mural cell coverage was not different between normal and atherosclerotic arteries, or between the different plaque types (Figure 5.4A-C). If present, mural cell layers (one or multiple) did not differ between plaque types either (Figure 5.4D-F). Also, no difference in mural cell coverage was observed between different vessel wall regions, nor was mural cell coverage correlated with plaque morphology. 

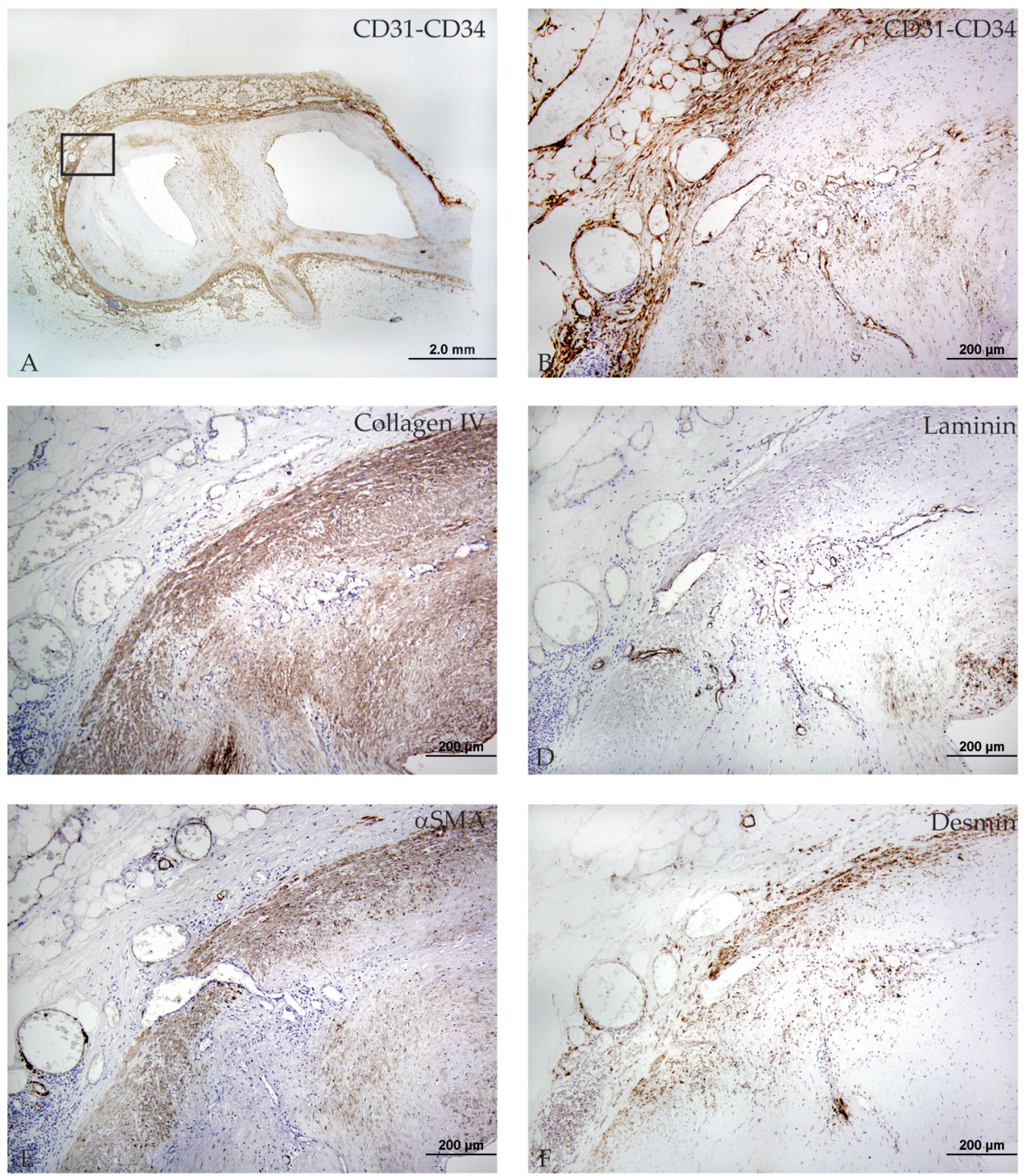

Figure 5.3. Basement membrane is intact, but mural cell coverage is low in normal and atherosclerotic coronary arteries

A. Coronary artery with fibroatheroma stained with CD31/CD34 cocktail. Boxed region shows origin of magnification of $\mathrm{B}$. showing $\mathrm{CD} 31^{+} \mathrm{CD} 34^{+}$microvessels running from the adventitia through the media into the plaque. C. Adjacent section stained with laminin showing intact laminin ${ }^{+}$microvessel basement membrane in the adventitia, IM border and plaque. D. Adjacent section stained with collagen IV showing intact collagen $\mathrm{IV}^{+}$microvessel basement membrane in adventitia, IM border, and plaque. E. Adjacent section stained with $\alpha$ SMA showing mostly $\alpha$ SMA- microvessel in the adventitia, IM border and plaque. F. Adjacent section stained with desmin showing some desmin ${ }^{+}$ microvessel in the adventitia, IM border and plaque. 

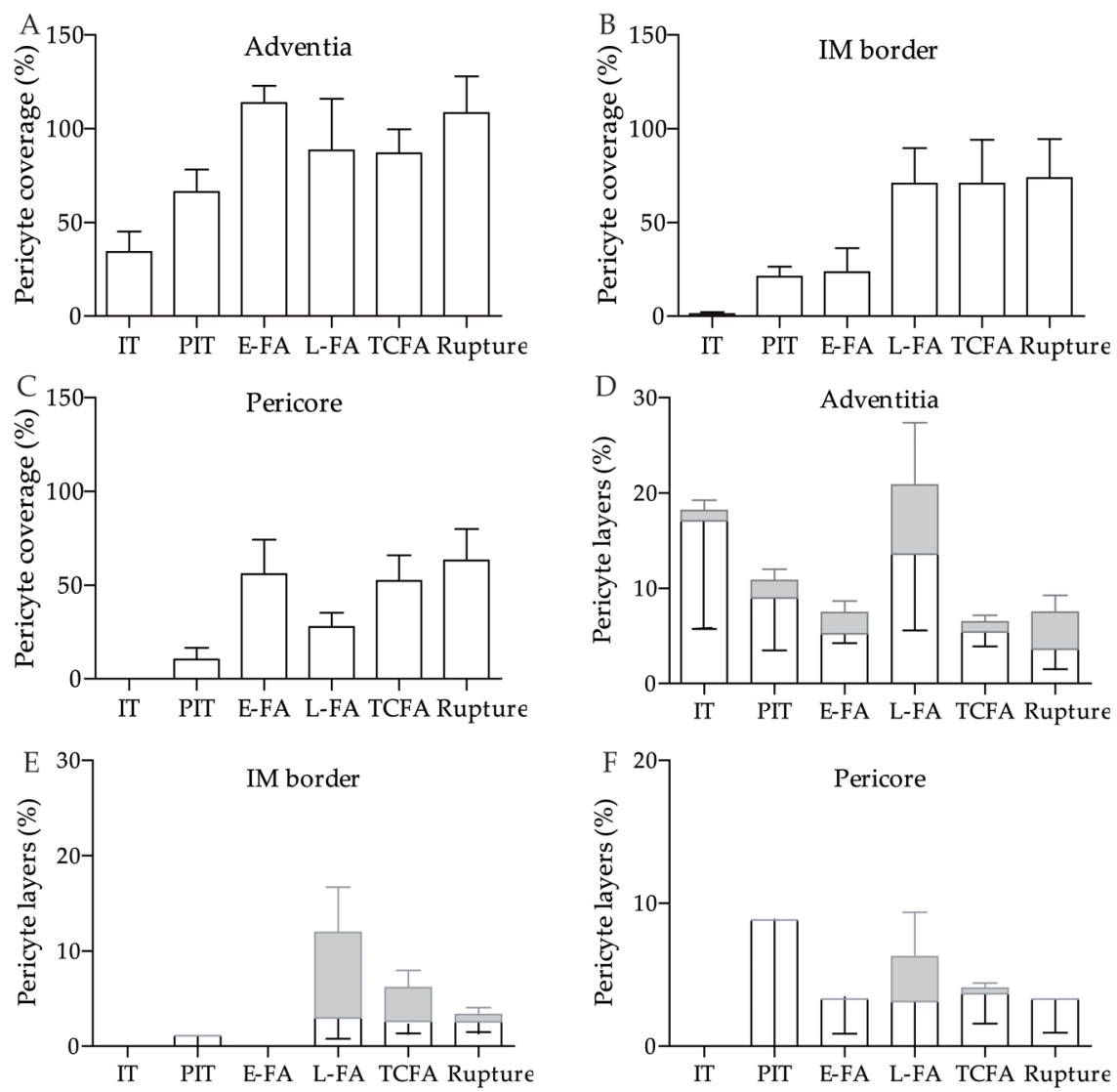

Figure 5.4. Quantification of mural cell coverage in different plaque types

A. Mural cell coverage was low in the adventitia, B. IM border, and C. pericore of both normal and atherosclerotic coronary arteries. D. The percentage of microvessels with one (open bars, black error bars) and multiple (grey (error) bars) mural cell layers in the adventitia, E. IM border, and F. pericore. All p-values $>0.05$.

Plaque microvessels show abnormal EC morphology, aberrant EC junctions and leukocyte adherence

As microvascular leakage is also characterized by a disruption of endothelial integrity, intraplaque (pericore) microvessels and inter-endothelial junctions were studied in atherosclerotic coronary arteries with advanced fibroatheromas and ruptured plaques using electron microscopy. A total of 27 microvessels and 58 junctions in 6 patients were analyzed. Inter-endothelial junctions were only completely intact in $24 \%(n=8)$ of intraplaque microvessels (Figure 5.5A-B). Although an intact basement membrane surrounding intraplaque microvessels 
148 Chapter 5
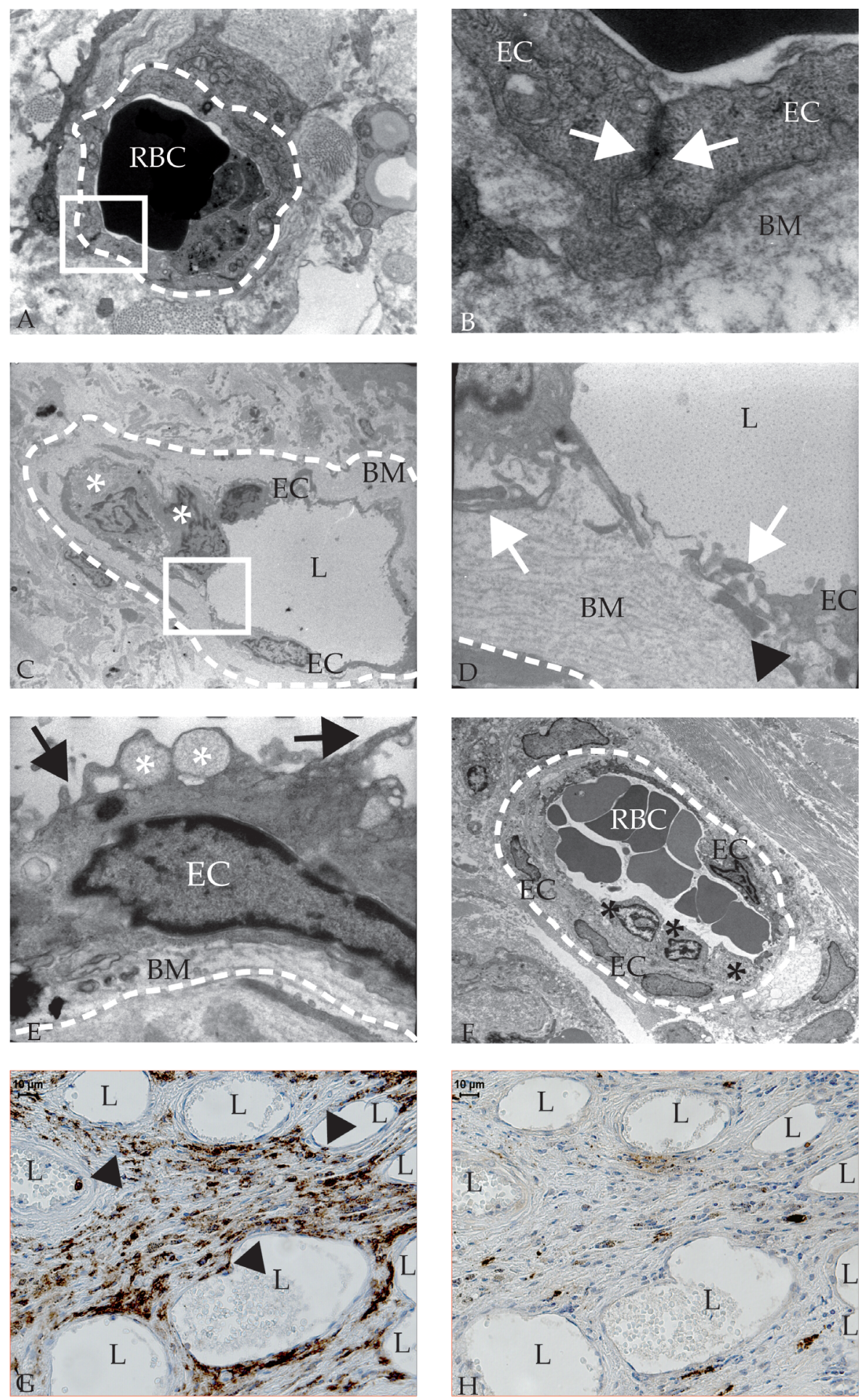
Figure 5.5. Intraplaque microvessels show abnormal EC morphology, aberrant EC junctions, and leukocyte infiltration as demonstrated by electron microscopy

A. Ultra structure of a microvessel (circumference indicated by white dashed line) with luminal red blood cell (RBC) obtained with electron microscopy (magnification 2650x) B. Magnification of the boxed region in $\mathrm{A}$ of microvessel with intact basement membrane (BM) and inter-endothelial junction indicated by closed contact (white arrows) between endothelial cells (EC) (magnification 15500x) C. Ultra structure of an intraplaque microvessel with leucocytes (white asterisks) (magnification 650x) D. Magnification of the boxed region in C of intraplaque microvessel lacking junction, shown by absent inter-EC contact (white arrows). EC show basement membrane detachment (black arrowhead) (magnification 4600x) E. Ultra structure of an EC in an intraplaque microvessel (magnification 6300x) showing features of dysfunction: membrane blebs (black arrow), and intracytoplasmic vacuoles (white asterisk) F. Leukocytes (arrowhead) adhering to intraplaque microvessel endothelium (magnification 460x) G. Immunohistochemistry shows CD45 ${ }^{+}$cells in and near microvessels. H. Immunohistochemistry does not show mast cells $\left(\mathrm{MCT}^{+}\right)$in microvessel, but only at larger distance from microvessels. L indicates lumen.

was generally observed (Figure 5.5C-F), inter-endothelial contact was incomplete or fully absent in $76 \%(n=19)$ of microvessels (Figure 5.5D). Thus, 59\% ( $n=34)$ of all analyzed endothelial junctions were aberrant or missing, indicating that endothelial integrity was severely compromised. In addition, endothelial cell morphology frequently represented an activated, dysfunctional status, characterized by blebbing and spike-like protrusions of the cell membrane. Also, numerous intracytoplasmic vacuoles were observed, a sign of increased secretory capacity (Figure 5.5E). Moreover, membrane detachment of EC was observed in $42 \%(n=11)$ of microvessels (Figure 5.5E). Another interesting observation were cells adhering to the microvessel lumen and infiltrating into the plaque in $50 \%(n=13)$ of microvessels (Figure 5.5C,F). These were identified as leukocytes based on nuclear morphology, and CD45 (Figure 5.5G) and CD68 (not shown) immunoreactivity. Although mast cells (mast cell tryptase immunoreactivity) were frequently present in the proximity of microvessels, they were not observed adhering to the microvessel endothelium (Figure 5.5H). Thus, abnormal EC morphology and junctions were associated with leukocyte infiltration and microvascular leakage. 


\section{Discussion}

The association of microvessel density and microvessel (ultra) structural morphology with coronary atherosclerosis plaque type morphology was determined using parameters related to microvascular leakage: basement membrane- and mural cell coverage, and endothelial junction integrity. Microvessel density was increased in fibroatheromas and ruptured plaques compared to (pathological) thickening similar to carotid atherosclerosis,$^{15}$ and was associated with plaque morphology, i.e. plaque area and thickness, stenosis, lipid core- and macrophage content. Microvessels were observed meandering from the adventitia through the media into the atherosclerotic plaque. The onset of adventitial angiogenesis preceded intraplaque angiogenesis, in agreement with previous studies assigning the adventitia as primary point of origin., ${ }^{36}$ The temporal pattern of adventitial angiogenesis and atherosclerosis was corroborated by one available report on human atherosclerosis, ${ }^{17}$ and an elegant study has described a similar association in murine atherosclerosis. ${ }^{1}$

Thus, angiogenesis and atherogenesis develop in close conjunction, and microvessel density in atherogenesis may represent a physiological reaction to a pathophysiological state of the vessel wall. Although the amount of microvessels may also be causative instead of reactive, our results suggest it is more likely that the morphology of microvessels is the causative factor in the development of atherosclerosis.

Mural cells surrounding microvessels may present as pericytes or smooth muscle cells, a distinction mostly based on a shared or separate basement membrane from EC respectively. However, this morphology and marker expression (desmin/aSMA) may vary between tissue and/or pathology type, hindering the unambiguous identification of pericytes or smooth muscle cells. ${ }^{18-}$ ${ }^{20}$ Therefore, in this study we did not quantitatively distinguish pericytes from smooth muscle cells, but rather the phrase "mural cells" was used. Qualitatively, the multi-layered mural cells most likely represented a more mature, welldifferentiated smooth muscle cell type, while EM also showed (single-layered) pericytes sharing the basement membrane with EC. Thus, both mural cell types were encountered surrounding microvessels of the arterial wall, although rather infrequently.

Microvessels in human coronary atherosclerosis commonly showed incomplete mural cell coverage, and a compromised structural integrity accompanied by extensive leucocyte adherence and infiltration. In striking contrast to our expectations, mural cell coverage was infrequent even in normal coronary arteries, and was similar in all plaque types and vessel wall regions. Therefore, incomplete mural cell coverage cannot explain microvascular- and 
subsequent intraplaque leakage. Recent reports also described intraplaque angiogenesis lacking mural cell coverage in atherosclerotic femoral ${ }^{21}$ and carotid

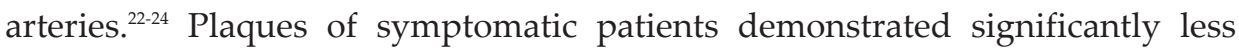
(often) microvessels covered with smooth muscle cells than asymptomatic patients ${ }^{22}$ in contrast to our study of sudden death victims. Unfortunately, in these studies mural cell coverage was not studied in normal carotid or femoral arteries, hindering the extrapolation of our results. Nonetheless, the phenomenon of absent mural cell coverage does not seem to be restricted to atherosclerotic coronary arteries.

The infrequent mural cell coverage may be explained by ongoing angiogenesis in atherosclerotic plaques: microvessels may not have reached the maturation stage characterized by mural cell coverage. However, this seems unlikely as pericytes were recruited within 2 weeks in a corneal angiogenesis model ${ }_{1}^{25}$ whereas angiogenesis associated with atherosclerotic progression is likely a matter of decades. In addition, EC in microvessels are not (longer) proliferating ${ }^{15,26}$ nor apoptotic. ${ }^{15,27}$ Secondly, microvessel maturation may be inhibited either by the lack of available pericyte (progenitor) cells ${ }^{18}$ or by inadequate pericyte recruitment signals, such as platelet derived growth factor (PDGF) B, angiopoietin 1, N-cadherin, placental growth factor, and AKT1. ${ }^{28}$ Although pericytes ${ }^{21,29}$ and several of its recruitment signal ${ }^{30-33}$ have previously been demonstrated in human and/or mouse atherosclerosis, mural cell recruitment to intraplaque angiogenesis has not yet been investigated in vivo.

Nevertheless, these observations do not elucidate the infrequent mural cell coverage of angiogenesis in the adventitia of a normal artery. As the normal adventitia represents a physiological artery wall, it is unclear why the morphology of arterial wall angiogenesis differs from the accepted morphology of physiological angiogenesis. Morphology is generally adapted to local tissue demand, suggesting that mural cells are often dispensable in arterial wall angiogenesis. Smooth muscle cell coverage provides vessel stabilization, likely preventing microvessel compression in high tissue pressure. A recent review described the mathematical theory of arterial wall- and microvessel stress in relation to angiogenic perfusion and compression. ${ }^{34}$ The arterial wall stress, determined by arterial lumen pressure, and the relatively low microvessel lumen pressure probably lead to the transient (cardiac cycle-dependent) compression of microvessels surrounded by loose structures. Arterial wall stress drops sharply close to the adventitia according to Lamé's law. ${ }^{34}$ This relatively low adventitial stress might reduce compression, suggesting that smooth muscle cell presence in the arterial adventitia is dispensable. Still, this does not explain their absence in intraplaque angiogenesis. A higher wall stress in the plaque would necessitate 
smooth muscle cell-mediated rigidity to withstand compression, unless microvascular rigidity is undesirable to sustain successive transient compression in the cardiac cycle. Therefore, a local demand for microvascular flexibility may be the most likely explanation of the apparent physiological lack of microvascular mural cells.

Unlike mural cell coverage, the compromised EC morphology and integrity as demonstrated by electron microscopy may be the origin of microvascular leakage. Strikingly, similar deviant EC morphology is observed for large artery endothelium at the initiation of atherosclerosis. ${ }^{35}, 36$ Dysfunctional EC in early stages of atherosclerosis also showed cell membrane protrusions, intracytoplasmic vacuoles, and membrane detachment, associated with lipoprotein and leucocyte infiltration. ${ }^{35,36}$ In contrast to microvascular endothelium, inter-endothelial junctions appeared intact in the coronary artery and aorta of hyperlipidemic-hyperglycemic hamsters. ${ }^{36}$

An important factor determining microvascular permeability is vascular endothelial growth factor (VEGF), as its alternate name "vascular permeability factor" clearly suggests. ${ }^{37}$ As VEGF disrupts endothelial junctions, ${ }^{38}$ and its expression is present throughout atherogenesis, ${ }^{15}$ a chronic VEGF stimulus might be involved in the aberrant integrity of microvascular EC and subsequent microvascular leakage. EC in microvessels require mural cells to exert an adequate barrier function. The abnormal EC morphology and missing EC junctions may also be caused by the absence of pericytes, as shown in the $\mathrm{PDGFB}^{-/}$and PDGF-receptor $\beta^{-/}$mouse with failed pericyte recruitment and EC blebbing. ${ }^{39}$ Actually, these mice also showed increased vascular endothelial growth factor expression, and decreased capillary perfusion as a result of EC protruding into and possibly blocking the lumen. ${ }^{40}$ This suggests compromised microvessel blood flow and even hypoxia, which we recently demonstrated in human atherosclerosis. ${ }^{15}$

In addition, inflammation and reactive oxygen species, produced by macrophages in atherosclerotic plaques, ${ }^{41,42}$ are associated with enlarged gaps between EC and with EC blebbing. ${ }^{43,44}$ Both previous data ${ }^{2,45}$ as well as our own clearly demonstrated both macrophage infiltration from the microvessel, and their accumulation in the proximity of intraplaque microvessels. Infiltration is triggered by increased expression of adhesion molecules on microvascular endothelium $^{46}$ and increased microvascular permeability. Therefore, macrophages may not only originate from intraplaque microvessels, but after extravasation may further aggravate microvascular leakage.

In conclusion, microvessel density is associated with plaque progression and morphology. Microvessel mural cell coverage is incomplete in normal and 
atherosclerotic arteries, and is thus unlikely to account for microvascular leakage. However, microvascular leakage may be explained by the compromised structural integrity of intraplaque angiogenesis accompanied by extensive leucocyte infiltration, and this leaky morphology may explain intraplaque hemorrhage and instability.

\section{Acknowledgments}

We gratefully acknowledge Lila Adams, Michael Cooper, Bob Kutys, and Russell Jones for excellent technical assistance. Research was partly supported by a travel grant from the Netherlands Organization of Scientific research (J.C.S). M.J.A.P.D and V.W.M.v.H. participate in the European Vascular Genomics Network (http://www.evgn.org), a Network of Excellence supported by the European Community's Sixth Framework Program for Research Priority 1 (contract LSHM-CT-2003-503254). 


\section{Chapter 5}

\section{References}

1. Langheinrich AC, Michniewicz A, Sedding DG, Walker G, et al. Correlation of vasa vasorum neovascularization and plaque progression in aortas of apolipoprotein E(-/-)/low-density lipoprotein(-/-) double knockout mice. Arterioscler Thromb Vasc Biol. 2006;26:347-352.

2. Moreno PR, Purushothaman KR, Fuster V, Echeverri D, et al. Plaque neovascularization is increased in ruptured atherosclerotic lesions of human aorta: implications for plaque vulnerability. Circulation. 2004;110:2032-2038.

3. Virmani R, Kolodgie FD, Burke AP, Finn AV, et al. Atherosclerotic Plaque Progression and Vulnerability to Rupture Angiogenesis as a Source of Intraplaque Hemorrhage. Arterioscler Thromb Vasc Biol. 2005;25:2054-2061.

4. Jeziorska M, Woolley DE. Neovascularization in early atherosclerotic lesions of human carotid arteries: its potential contribution to plaque development. Hum Pathol. 1999;30:919-925.

5. Kockx MM, Cromheeke KM, Knaapen MW, Bosmans JM, et al. Phagocytosis and macrophage activation associated with hemorrhagic microvessels in human atherosclerosis. Arterioscler Thromb Vasc Biol. 2003;23:440-446.

6. Kolodgie FD, Gold HK, Burke AP, Fowler DR, et al. Intraplaque hemorrhage and progression of coronary atheroma. N Engl J Med. 2003;349:2316-2325.

7. Lusis AJ. Atherosclerosis. Nature. 2000;407:233-241.

8. Virmani R, Narula J, Farb A. When neoangiogenesis ricochets. Am Heart J. 1998;136:937-939.

9. Carmeliet P, Jain RK. Angiogenesis in cancer and other diseases. Nature. 2000;407:249-257.

10. Hashizume H, Baluk P, Morikawa S, McLean JW, et al. Openings between defective endothelial cells explain tumor vessel leakiness. Am J Pathol. 2000;156:1363-1380.

11. Jain RK. Molecular regulation of vessel maturation. Nat Med. 2003;9:685-693.

12. Dejana E. Endothelial cell-cell junctions: happy together. Nat Rev Mol Cell Biol. 2004;5:261-270.

13. Kolodgie FD, Burke AP, Skorija KS, Ladich E, et al. Lipoprotein-associated phospholipase A2 protein expression in the natural progression of human coronary atherosclerosis. Arterioscler Thromb Vasc Biol. 2006;26:2523-2529.

14. Virmani R, Kolodgie FD, Burke AP, Farb A, et al. Lessons from sudden coronary death: a comprehensive morphological classification scheme for atherosclerotic lesions. Arterioscler Thromb Vasc Biol. 2000;20:1262-1275.

15. Sluimer JC, Gasc JM, van Wanroij JL, Kisters N, et al. Hypoxia in human atherosclerotic plaques is correlated with the expression of CD68, HIF, VEGF and the presence of a thrombus and angiogenesis. J Am Coll Cardiol. 2008;In press.

16. Kumamoto M, Nakashima Y, Sueishi K. Intimal neovascularization in human coronary atherosclerosis: its origin and pathophysiological significance. Hum Pathol. 1995;26:450-456.

17. Lappalainen H, Laine P, Pentikainen MO, Sajantila A, et al. Mast cells in neovascularized human coronary plaques store and secrete basic fibroblast growth factor, a potent angiogenic mediator. Arterioscler Thromb Vasc Biol. 2004;24:1880-1885. 
18. Abramsson A, Berlin O, Papayan H, Paulin D, et al. Analysis of mural cell recruitment to tumor vessels. Circulation. 2002;105:112-117.

19. Ko YS, Coppen SR, Dupont E, Rothery S, et al. Regional differentiation of desmin, connexin43, and connexin 45 expression patterns in rat aortic smooth muscle. Arterioscler Thromb Vasc Biol. 2001;21:355-364.

20. Shardonofsky FR, Capetanaki Y, Boriek AM. Desmin modulates lung elastic recoil and airway responsiveness. Am J Physiol Lung Cell Mol Physiol. 2006;290:L890-896.

21. Liu Y, Wilkinson FL, Kirton JP, Jeziorska M, et al. Hepatocyte growth factor and c-Met expression in pericytes: implications for atherosclerotic plaque development. J Pathol. 2007;212:12-19.

22. Dunmore BJ, McCarthy MJ, Naylor AR, Brindle NP. Carotid plaque instability and ischemic symptoms are linked to immaturity of microvessels within plaques. J Vasc Surg. 2007;45:155-159.

23. Mazzone A, Epistolato MC, Gianetti J, Castagnini M, et al. Biological features (inflammation and neoangiogenesis) and atherosclerotic risk factors in carotid plaques and calcified aortic valve stenosis: two different sites of the same disease? Am J Clin Pathol. 2006;126:494-502.

24. Fryer JA, Myers PC, Appleberg M. Carotid intraplaque hemorrhage: the significance of neovascularity. J Vasc Surg. 1987;6:341-349.

25. Cursiefen C, Hofmann-Rummelt C, Kuchle M, Schlotzer-Schrehardt U. Pericyte recruitment in human corneal angiogenesis: an ultrastructural study with clinicopathological correlation. Br J Ophthalmol. 2003;87:101-106.

26. O'Brien ER, Garvin MR, Dev R, Stewart DK, et al. Angiogenesis in human coronary atherosclerotic plaques. Am J Pathol. 1994;145:883-894.

27. Tricot O, Mallat Z, Heymes C, Belmin J, et al. Relation between endothelial cell apoptosis and blood flow direction in human atherosclerotic plaques. Circulation. 2000;101:2450-2453.

28. Armulik A, Abramsson A, Betsholtz C. Endothelial/pericyte interactions. Circ Res. 2005;97:512-523.

29. Alexander MY, Wilkinson FL, Kirton JP, Rock CF, et al. Identification and characterization of vascular calcification-associated factor, a novel gene upregulated during vascular calcification in vitro and in vivo. Arterioscler Thromb Vasc Biol. 2005;25:1851-1857.

30. Chen F, Eriksson P, Kimura T, Herzfeld I, et al. Apoptosis and angiogenesis are induced in the unstable coronary atherosclerotic plaque. Coron Artery Dis. 2005;16:191-197.

31. Irvine CD, George SJ, Sheffield E, Johnson JL, et al. The association of platelet-derived growth factor receptor expression, plaque morphology and histological features with symptoms in carotid atherosclerosis. Cardiovasc Surg. 2000;8:121-129.

32. Pilarczyk K, Sattler KJ, Galili O, Versari D, et al. Placenta growth factor expression in human atherosclerotic carotid plaques is related to plaque destabilization. Atherosclerosis. 2006.

33. Khurana R, Moons L, Shafi S, Luttun A, et al. Placental growth factor promotes atherosclerotic intimal thickening and macrophage accumulation. Circulation. 2005;111:2828-2836.

34. Ritman EL, Lerman A. The dynamic vasa vasorum. Cardiovasc Res. 2007.

35. Simionescu M. Implications of early structural-functional changes in the endothelium for 


\section{Chapter 5}

vascular disease. Arterioscler Thromb Vasc Biol. 2007;27:266-274.

36. Simionescu M, Popov D, Sima A, Hasu M, et al. Pathobiochemistry of combined diabetes and atherosclerosis studied on a novel animal model. The hyperlipemic-hyperglycemic hamster. Am J Pathol. 1996;148:997-1014.

37. van Hinsbergh VW, van Nieuw Amerongen GP. Intracellular signalling involved in modulating human endothelial barrier function. J Anat. 2002;200:549-560.

38. Suarez S, Ballmer-Hofer K. VEGF transiently disrupts gap junctional communication in endothelial cells. J Cell Sci. 2001;114:1229-1235.

39. Hellstrom M, Gerhardt H, Kalen M, Li X, et al. Lack of pericytes leads to endothelial hyperplasia and abnormal vascular morphogenesis. J Cell Biol. 2001;153:543-553.

40. Gerhardt H, Betsholtz C. Endothelial-pericyte interactions in angiogenesis. Cell Tissue Res. 2003;314:15-23.

41. Hazell LJ, Arnold L, Flowers D, Waeg G, et al. Presence of hypochlorite-modified proteins in human atherosclerotic lesions. J Clin Invest. 1996;97:1535-1544.

42. Rajagopalan S, Meng XP, Ramasamy S, Harrison DG, et al. Reactive oxygen species produced by macrophage-derived foam cells regulate the activity of vascular matrix metalloproteinases in vitro. Implications for atherosclerotic plaque stability. J Clin Invest. 1996;98:2572-2579.

43. McDonald DM, Thurston G, Baluk P. Endothelial gaps as sites for plasma leakage in inflammation. Microcirculation. 1999;6:7-22.

44. Hastie LE, Patton WF, Hechtman HB, Shepro D. Filamin redistribution in an endothelial cell reoxygenation injury model. Free Radic Biol Med. 1997;22:955-966.

45. Balakrishnan KR, Kuruvilla S. Images in cardiovascular medicine. Role of inflammation in atherosclerosis: immunohistochemical and electron microscopic images of a coronary endarterectomy specimen. Circulation. 2006;113:e41-43.

46. O'Brien KD, McDonald TO, Chait A, Allen MD, et al. Neovascular expression of E-selectin, intercellular adhesion molecule-1, and vascular cell adhesion molecule-1 in human atherosclerosis and their relation to intimal leukocyte content. Circulation. 1996;93:672-682. 


\section{General discussion}


160 Chapter 6 


\section{General discussion}

Angiogenesis is a key morphological feature of atherosclerotic lesions and is associated with plaque growth- and instability. ${ }^{1-3}$ The mechanisms governing the formation of intraplaque microvessels in atherosclerotic disease are largely unknown, as well as information on the (ultra) structural microvessel morphology that may explain microvascular leakage.

Angiogenesis is a typical feature of tissue hypoxia and HIF expression. Therefore, we hypothesized that hypoxia-induced, HIF-driven transcription stimulates atherosclerotic progression and angiogenic infestation in atherosclerotic plaques. Hypoxia was detected by pre-operative infusion of the hypoxia marker pimonidazole to symptomatic patients undergoing carotid endarterectomy (chapter 3). A functional effect of hypoxia, HIF1 $\alpha$ and its regulator PHD1 on atherogenesis were investigated by placing mice 4 weeks at $10 \%(n=5)$ or $21 \% \mathrm{O}_{2}(\mathrm{n}=5)$, and by $\mathrm{HIF}^{-1 /}$ and $\mathrm{PHD}^{-1}$ bone marrow transplantations into $\mathrm{LDLR}^{-/}$mice (chapter 4). The main conclusions of our studies were 1) that hypoxia and HIF were present in human ánd murine atherosclerosis, and 2) that hypoxia and HIF were associated with atherosclerotic progression, macrophages and angiogenesis, but not with intimal thickness. Nonetheless, we were not able to show a functional involvement of hypoxic exposure, HIF1 $\alpha$ or PHD1 deletion in murine atherogenesis, as hypoxia in plaque macrophages seemed to override the effect of incomplete genetic deletion of macrophage HIF1 $\alpha$ and the marginal stimulus of PHD1 deletion on HIF1 $\alpha$ protein.

In addition, we hypothesized that the (ultra) structural morphology of intraplaque microvessels is abnormal and associated with plaque progression. The ultra structural morphology was investigated in normal and atherosclerotic human coronary arteries using quantitative immunohistochemistry and electron microscopy (chapter 5). We showed that microvessel mural cell (pericytes/smooth muscle cells) coverage is incomplete in both normal and atherosclerotic arteries, and mural cell coverage is thus unlikely to account for microvascular leakage. However, the compromised structural integrity of microvascular endothelium may explain microvascular leakage in human coronary atherosclerosis. 


\section{Hypoxia and HIF in atherosclerosis}

\section{Hypoxia-inducible expression in autopsy and surgery specimens}

Before investigating the association of hypoxia- and HIF driven gene expression in different stages of atherosclerosis, the gene expression profiles of advanced atherosclerotic plaques from autopsy and surgery were evaluated. Hypoxiainducible expression profiles of plaques from different sources (autopsy and surgery) were compared, to asses whether autopsy and surgery samples were interchangeable (chapter 2). Although gene expression in autopsy- and surgeryderived plaques were largely similar, some basal cell metabolism and hypoxiadriven genes were differentially expressed. These changes were not reflected at the protein level, possibly because protein turnover is a time-consuming process. A comparison of the gene expression profiles of skeletal muscle from autopsy and surgery confirmed the differential expression of only a minority of genes, which were also involved in basal cell metabolism. ${ }^{4}$ It seems likely that these processes represent a cellular survival response triggered by the complex environmental changes associated with death, as death at the cellular level may not occur in chorus. Therefore, although differences between autopsy and surgery were relatively small, human expression profiling studies using a combination of both sources should be analyzed with caution.

\section{Hypoxia and HIF in atherosclerosis}

As angiogenesis is a major consequence of hypoxia, the mere presence of intraplaque angiogenesis suggests the existence of hypoxia and its transcriptional activator, HIF, in human atherosclerosis. Indeed, hypoxia was demonstrated in most, but not all, macrophages, and in smooth muscle cells and osteoclasts in human plaques (chapter 3). If the threshold for hypoxia would depend solely on oxygen diffusion distance, which is governed by plaque thickness, then its presence in mouse plaques would not be evident. Murine plaque thickness was generally smaller than the depth $(100-250 \mu \mathrm{m})$ at which severe hypoxia was encountered in rabbit and human atherosclerosis, ${ }^{5,6}$ as can be appreciated from table 1.3 (chapter 1). Surprisingly, hypoxia was detected in murine plaques, specifically in similar cell types as in human plaques (chapter 4). Analyses of human and mice plaques showed that the presence and extent of plaque hypoxia is mostly determined by inflammatory cell content, and not by the distance to the lumen. A direct comparison between human and murine carotid plaques reflected the same conclusion (Table 6.1). Despite a 4-40 fold smaller intimal thickness in murine plaques, the hypoxic surface area is 2-300 
Table 6.1 Comparison of carotid atherosclerosis in human symptomatic patients and LDLR mice with a perivascular collar

\begin{tabular}{lll}
\hline & $\begin{array}{l}\text { Human } \\
(\mathrm{n}=7)\end{array}$ & $\begin{array}{l}\text { Mouse } \\
(\mathrm{n}=10)\end{array}$ \\
\hline Hypoxia (\% of plaque area) & $0.4-23.5$ & $4.4-55.2$ \\
Max. IT (mm) & $1.7-4.6$ & $0.11-0.30$ \\
Plaque area (mm2) & $11-146$ & $0.02-0.12$ \\
Macrophages (\% of cells) & $11-44^{*}$ & $47-73$ \\
Cells (n/mm2) & $743-1313^{*}$ & $1833-5317$ \\
\hline
\end{tabular}

The range of minimal and maximal values is presented of measurements of the complete plaque in the max. stenotic section. *, Average of 5 random 100x fields per plaque

fold greater in murine plaques in parallel with the greater macrophage content (2-7 fold) in murine plaques. In addition, isolated subluminal $(20-30 \mu \mathrm{m})$ macrophage foam cells in human atherosclerosis were also hypoxic. ${ }^{6}$ Therefore, plaque hypoxia is independent of species, and subsequent plaque size, but depends on the high metabolic demand of the inflammatory microenvironment.

Hypoxia was detected in plaques of different arterial sites in mice, and it would be interesting to extend these observations to plaques in different human arteries. Especially since hypoxia in plaques of the coronary artery, pivotal for development of myocardial infarction, remains unexplored. Oxygen consumption of porcine coronary artery smooth muscle in vitro $(40-60 \mu \mathrm{mol} / \mathrm{ml} / \mathrm{g})^{7}$ was about 100 fold higher than of carotid smooth muscle (0.5$0.6 \mu \mathrm{mol} / \mathrm{ml} / \mathrm{g}$ ), ${ }^{8}$ while blood oxygen saturation in both coronary and carotid artery was almost maximal. Thus, coronary plaque hypoxia is highly anticipated. In mice, the extent of hypoxia differed between arterial sites in parallel with their macrophage content. Based on the higher macrophage content of coronary plaques, ${ }^{9}$ it is speculated that coronary plaque hypoxia is more severe than carotid plaque hypoxia. Hypothetical, varying levels of hypoxia in human plaques at different arterial sites may also be related to variations in gene expression profiles between sites, which are currently being investigated by our group.

The presence of hypoxia may not only vary between plaques at different sites, but may also change with progression. In our cross-sectional study we observed that hypoxia was less prominent in the longitudinal shoulder regions without a core. However, these regions were still part of a lesion with a thrombus, and these results cannot be extrapolated to early atherosclerosis. As the inflammatory content seems to predict the extent of hypoxia, we speculate 
that hypoxia will also be present in macrophages of early lesions. Furthermore, early and stable lesions contain less macrophages and more smooth muscle cells compared to ruptured lesions and might thus show less hypoxia than ruptured lesions. This hypothesis may be tested in vivo using mice with normal arteries, initial and advanced plaques. Of course, ruptured lesions are questionable in mice, ${ }^{10}$ but hypoxia in advanced plaques of apoE ${ }^{-/}$mice may be compared to plaques with a pronounced stable phenotype, such as plaques of $\mathrm{CD}^{-\sigma^{-}} / \mathrm{apoE}^{-/}$ double knock-out (dKO) mice. These plaques showed a high smooth muscleand collagen content and low macrophage content. ${ }^{11}$ Equally interesting would be a comparison with the cathepsin $\mathrm{K}^{-1} / \mathrm{apoE}^{-/-} \mathrm{dKO}$ mice. Plaques from these mice showed more smooth muscle cells and collagen, but macrophages with increased size and lipid accumulation. ${ }^{12}$ As hypoxia and HIF are involved in foam cell formation, cathepsin $\mathrm{K}^{-1} / \mathrm{apoE}^{-/} \mathrm{dKO}$ plaques may show increased hypoxia and HIF expression compared to stable plaques.

In conclusion, hypoxia is present in human and murine atherosclerosis and is associated with macrophages, not plaque thickness (Figure 6.1).

\section{Hypoxia and HIF: causative or reactive?}

HIF1 $\alpha$ protein in human and mouse atherosclerosis co-localized with hypoxia and macrophages (chapters 3 and 4). It is widely accepted that HIF $\alpha$ expression is mainly regulated by hypoxia at the protein level, and our gene and protein expression data implied that hypoxia stabilized HIF1 $\alpha$ in atherosclerosis. Nonetheless, our cross-sectional human expression study does not provide definite prove of hypoxia-driven HIF, since numerous normoxic HIF stimuli are also present in plaques and plaque macrophages, such as reactive oxygen species, ${ }^{13}$ vasoactive ${ }^{14}$ and thrombotic factors. ${ }^{15}$ However, HIF1 $\alpha$ protein was undetectable after in vitro exposure of human THP-1 macrophages to a concentration range of $\mathrm{H}_{2} \mathrm{O}_{2}$, while $\mathrm{HIF} 1 \alpha$ protein was abundant after exposure to $0.2 \%$ hypoxia (preliminary data). These results imply that hypoxia is an important stimulus of HIF1 $\alpha$ protein in macrophages.

The aim of the hypoxic exposure of atherosclerotic mice in chapter 4 was to increase plaque hypoxia and determine a functional effect of hypoxia on HIF expression and atherogenesis. However, neither plaque hypoxia, nor HIF expression was affected by hypoxic exposure, precluding a definite conclusion on a causal contribution of plaque hypoxia to HIF stabilization and atherosclerotic plaques. Nonetheless, the in vitro and in vivo effects of hypoxia on lipid metabolism, inflammation and angiogenesis all point towards a causative pro-atherogenic effect of hypoxia. An effective intervention of plaque hypoxia, perhaps exposure to hyperoxia, is necessary to elucidate whether the presence of 


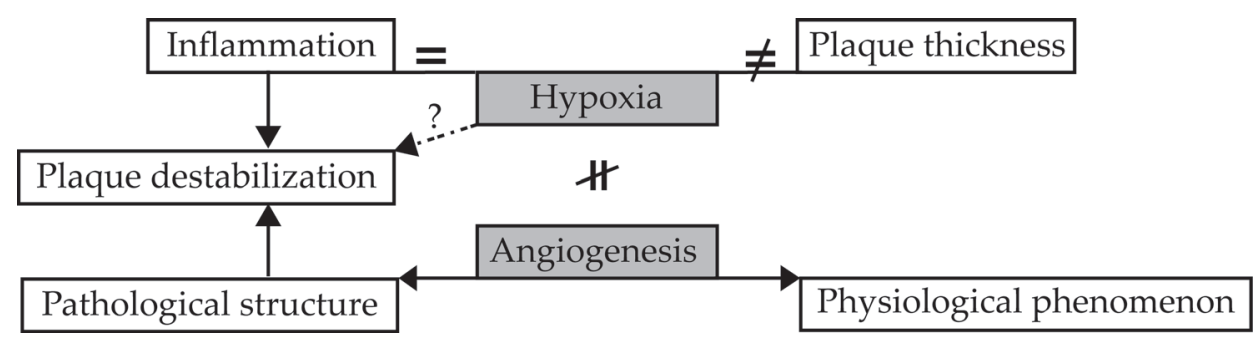

Figure 6.1 Summary of associations between inflammation, hypoxia, and angiogenesis

Dashed arrow indicates unproven association; =, equal to; =, not equal to.

hypoxia is simply the resultant of macrophage oxygen demand, or that it actually fulfills a causal role in plaque progression.

Despite our meticulous study of HIF1 $\alpha$ mRNA and protein in human atherosclerosis (chapter 3) and our experimental studies using bone marrow transplantations of myeloid-specific HIF1 $\alpha$ and full PHD1 knockout mice into $\mathrm{LDLR}^{-}$mice (chapter 4), the final proof of a functional effect of HIF1 $\alpha$ on atherosclerosis is still lacking. As conditional deletion of HIF1 $\alpha$ was incomplete, hypoxia in plaque macrophages was able to induce remnant HIF1 $\alpha$ mRNA and protein expression. In addition, chronic hypoxic exposure lead to reversal of HIF1 $\alpha$ stabilization in WT macrophages, resulting in similar HIF1 $\alpha$ protein levels in WT and HIF1 $\alpha^{-1}$ macrophages. The results in chapter 4 exemplify that hypoxia is a strong stimulus of HIF1 $\alpha$ in plaque macrophages. Data from atherosclerosis intervention studies using HIF1 $\alpha$ disruption in other cell types, ${ }^{16,}$ ${ }^{17}$ as well as in vitro studies ${ }^{18}$ strongly argue in favor of a causative effect of HIF1 $\alpha$ in atherogenesis.

As HIF1 $\alpha$ disruption was not preserved in murine plaques, an approach to study HIF1 $\alpha$ overexpression was initiated. The effect of macrophage-specific deletion of HIF's negative regulator, PHD1, on HIF1 $\alpha$ expression and atherogenesis was investigated. Macrophage-specific PHD1 deletion, accomplished by bone marrow transplantations in atherosclerosis-prone mice, did not change plaque size or phenotype. Unfortunately, the marginal stimulus of PHD1 deletion on HIF protein levels was also overruled by hypoxia and $\mathrm{PHD}^{-1}$ in macrophages did not result in HIF1 $\alpha$ overexpression in plaques. As two other PHD isofoms exist, i.e. PHD2 and PHD3, isoform redundancy may explain the lack of effect on HIF stabilization. Nevertheless, PHD1 also has effects independent of HIF1 $\alpha$ and its PHD isoforms. ${ }^{19,20}$ PHD $^{-\kappa}$ skeletal muscle was more efficient in generating energy and preventing ROS formation in hypoxia. ${ }^{19}$ Although PHD1 in macrophages was clearly not causally involved in plaque development, the involvement of PHD1 in muscle metabolism suggests 
that $\mathrm{PHD}^{-\kappa}$ in smooth muscle cells might be anti-atherogenic based on ROS prevention. Therefore, the effects of $\mathrm{PHD}^{-}$on wire-induced, SMC-rich neointima formation, as well as the effect of the $\mathrm{PHD}^{-\kappa} / \mathrm{apoE}^{-/} \mathrm{dKO}$ on atherogenesis are worth investigating.

\section{Cell type specificity}

Similar to the cell type-dependent effect of PHD1, the net effect of hypoxia and HIF on atherosclerosis may depend on the relative contribution of several cell types. HIF1 $\alpha$ in smooth muscle cells (SMC) mediated wire-induced neointima formation and SMC recruitment, ${ }^{17}$ but the effect of SMC HIF1 $\alpha$ on (de)stabilization of atherosclerotic plaques is yet unknown. Hypoxia and HIF1 $\alpha$ in myeloid cells were generally pro-inflammatory, ${ }^{21,22}$ whereas T cell HIF1 $\alpha$ was anti-inflammatory ${ }^{23}$ and anti-atherogenic. ${ }^{16}$ It is also interesting to speculate that hypoxia affects a phenotypic switch in macrophage subsets from antiinflammatory M2, towards pro-inflammatory M1 macrophages. Currently, such data are unavailable and not addressed in this thesis either, but hypoxic macrophages have been reported to produce M1-specific cytokines and enzymes, i.e. IL1, IL6, TNF $\alpha$, IFN $\gamma$ and iNOS, but also M2-specific IL10, arginase, CXCL1 and fibronectin. 22, 24, 25 These expression data are not conclusive on macrophage M1 or M2 polarization by hypoxia. Adipose tissue in obese mice was generally hypoxic ${ }^{26}$ and M2-M1 phenotype switching of adipose tissue macrophages has been observed both in mice as well as in humans. ${ }^{27,28}$ On the other hand, pro-angiogenic tumor-associated macrophages polarized towards M2, ${ }^{29}$ suggesting that M2 macrophages were responsible for hypoxia-driven angiogenesis in tumors. Aside from hypoxia hypothetically stimulating a phenotypic switch, M1 and M2 macrophages might show a differential oxygen demand. The potentially different threshold for hypoxia could then explain that a subset of plaque macrophages was not hypoxic. The association of hypoxia and M1-M2 subsets thus warrants further investigation.

\section{Angiogenesis in atherosclerosis}

\section{Hypoxia and angiogenesis}

In this thesis, plaque hypoxia and its transcriptional effector HIF were demonstrated in close association with macrophages and angiogenesis (chapters 3 and 4). As angiogenesis is the primary reaction of hypoxic tissue to restore oxygen levels, we hypothesized that angiogenesis in atherosclerosis is regulated by hypoxia and HIF. Since plaque hypoxia and angiogenesis were present 
simultaneously, the questions arises why plaque hypoxia persisted in the presence of oxygen-supplying microvessels. One possibility is that the oxygen demand of plaque macrophages may not be sufficiently met as a consequence of an imbalance between macrophage and microvessel content of the plaque. As microvessels not only deliver oxygen to the plaque, but also inflammatory cells, a vicious cycle of inflammation, hypoxia and angiogenesis, could perpetuate the hypoxic state of the atherosclerotic plaque. Another possibility is that microvessel flow may be insufficient or compromised. Blood flow into the vessel wall has been shown to increase with atherosclerotic progression in primates. ${ }^{30}$ However, the cardiac cycle supposedly transiently compresses the plaque and its microvessels, ${ }^{31}$ causing at the very least intermittent flow. Flow may also be hampered as a result of the abnormal EC morphology associated with protrusions that block the microvessel lumen. Similar aberrant EC morphology in pericyte-deficient vasculature was indeed associated with compromised capillary perfusion. ${ }^{32}$ Finally, even if flow is not hampered, blood may not transport enough oxygen into the plaque. Oxygen transport capacity is reduced with age, smoking, and in males, ${ }^{33-35}$ which may also clarify the co-existence of plaque hypoxia and angiogenesis. Intriguingly, atherosclerotic plaques in premenopausal women demonstrated less microvessels. ${ }^{1}$ Although hormonal regulation of angiogenesis is probably the basis of differential angiogenesis in men and women, a higher oxygen saturation in women compared to men may be involved to some extent. In conclusion, the persistence of plaque hypoxia despite angiogenesis may depend on a combination of an ever-increasing oxygen demand, compromised blood flow or reduced oxygen transport.

\section{Cause of angiogenesis}

The initiation of angiogenesis is stimulated by metabolic stress, such as hypoxia, or on inflammatory infiltration. ${ }^{36}$ Virtually all diseases and conditions characterized by tissue inflammation, such as wound healing, ${ }^{37}$ rheumatoid- and osteoarthritis, $^{38}$ solid tumors, ${ }^{39,}{ }^{40}$ obesity, ${ }^{41}$ bacterial infection ${ }^{42}$ and sepsis, ${ }^{43}$ showed signs of hypoxia. The results presented in this thesis extend this observation to plaque hypoxia and inflammation in human and murine atherosclerosis. Therefore, it may be stated that inflammation simply equals hypoxia (Figure 6.1). Nevertheless, not all macrophages were hypoxic and a causal role of hypoxic inflammatory cells in atherosclerosis has not yet been proven. Of course, many pro-angiogenic stimuli - hypoxia- and/or HIF independent - are present in the atherosclerotic plaque and in plaque macrophages, which could also contribute to angiogenesis in atherosclerosis. In vivo atherosclerosis studies with immunosuppressants or hyperoxia may 
elucidate the role of hypoxic macrophages in angiogenesis of the atherosclerotic plaque. Although the effect of immunosuppressive dugs, such as FK506, ${ }^{44}$ on atherosclerosis has been investigated, angiogenesis was not studied. Unfortunately, angiogenesis intervention studies will be difficult as available animal models of atherosclerosis (mouse, rabbit, and pig) either lack intraplaque angiogenesis or reliable detection thereof.

\section{Angiogenesis in mouse and man}

Research on angiogenesis in atherosclerosis is seriously hindered by the apparent lack or scarcity of intraplaque microvessels in the primary experimental models of atherosclerosis, the mouse, rabbit and pig, as can be appreciated from table 1.3 (chapter 1). Reliable and specific immunohistochemical detection of microvessel EC in murine plaques is unavailable. Micro-CT provided convincing proof of microvessels extending from the adventitia into the vessel wall. ${ }^{45}$ However, a marker delineating the plaque was not used, making it impossible to determine whether microvessels simply extended into the media or also into the plaque.

Clearly murine intraplaque microvessels are a rare event at the very least, while abundant in human plaques. It is therefore quite puzzling that plaque hypoxia was more extensive in mice than in man, while microvessel frequency was low in mice. One explanation of this apparent discrepancy is that the angiogenic switch remains anti-angiogenic in murine atherosclerosis. The initiation of angiogenesis depends on a balance between pro- and antiangiogenic factors, the "angiogenic switch". The angiogenic switch is tipped in favor of angiogenesis by an increase in pro-angiogenic factors, such as in tissue hypoxia. Thus, either plaque hypoxia alone is not sufficient to induce plaque angiogenesis (Figure 6.1), or murine plaques exhibit more angiogenic inhibition than human plaques. Possibly, human individual differences in the angiogenic switch may even explain why angiogenesis is a common, but not inevitable component of early human atherosclerotic plaques. However, a full pro- and anti-angiogenic expression profile of murine and human plaques is currently unavailable. Some endogenous angiostatic factors, ${ }^{36}$ such as endostatin and angiostatin, cleavage fragments of collagen XVIII and plasminogen respectively, platelet factor 4 (PF4), and thrombospondin, have been investigated in murine atherosclerosis. Genetic loss of murine collagen XVIII and subsequent endogenous endostatin, increased the controversial detection of microvesselpositive murine plaques from 13 to $53 \%{ }^{46}$ In addition, plaque size and macrophage content were increased. In contrast, disruption of anti-angiogenic PF4 alleviated murine atherosclerosis, ${ }^{47}$ as PF4 also has major pro-atherogenic 
properties. ${ }^{48}$ The extent of plaque angiogenesis in $\mathrm{PF} 4{ }^{-1} / \mathrm{apoE}^{-1-}$ was not described. Thus, endogenous angiostatic factors also have angiogenesis-independent effects, illustrating that an angiogenic expression profile of whole-mount plaques may be too simple to conclude the net effect of the angiogenic switch on intraplaque angiogenesis. A functional angiogenic profile would thus be more useful. The angiogenic potential of protein lysates of whole-mount plaques may be tested in angiogenesis assays in vitro and in vivo, as has been done previously for human plaque lysates. ${ }^{49}$

\section{Angiogenesis causative or reactive?}

The conclusion drawn from the scarcity of intraplaque angiogenesis in mice, may be that their abundant presence is not absolutely required for the initiation and development of atherosclerosis. Other animal models of atherosclerosis lacking (the convincing detection of) intraplaque microvessels, such as the hypercholesterolemic rabbit and pig models, confirm this (Table 1.3, chapter 1). Although intraplaque angiogenesis may not be essential for plaque growth in animal models, these plaques differ significantly from humans with respect to the occurrence of plaque rupture. It is therefore tempting to speculate that the absence of plaque rupture in animal models is at least partially explained by the scarcity of intraplaque microvessels.

Essential or not, all available human (Table 1.2, chapter 1$)^{1,50-79}$ and animal ${ }^{80-82}$ studies confirmed that adventitial and/or intraplaque microvessel content increased with atherosclerotic plaque growth. In human atherosclerosis, there were some contrasting results on the intraplaque location of microvessels that was associated to plaque hemorrhage and/or rupture: the intima-media border, the cap/shoulders or all locations. In atherosclerosis of the aorta, microvessel density in the intima-media border was specifically associated with plaque hemorrhage and/or rupture..$^{79}$ Conversely, in our study coronary microvessel density was similar between stable fibroatheromas and ruptured lesions in all arterial wall locations; i.e. adventitia, intima-media border, and pericore (chapter 5). In addition, total carotid microvessel density was also similar between stable and ruptured lesions, as described in chapter 3. These differences between carotid or coronary arteries versus the aorta may represent site-specific adaptations to different arterial wall morphology, i.e. an increased number of fibromuscular lamellae in the aorta may necessitate more microvessels in the intima-media border.

Despite the overwhelming evidence supporting a correlation between microvessel content and atherosclerotic progression, a causal association is not conclusively proven by experimental studies. Although angiogenic intervention 
invariably resulted in altered atherosclerosis, ${ }^{83-90}$ this was angiogenesisindependent in the majority of studies. ${ }^{8488}$ The abundance of adventitial and intraplaque microvessels may thus simply be a physiological reaction to the pathophysiological, hypoxic state of the arterial wall (Figure 6.1).

Regardless if microvessel density is merely a reaction to plaque growth, the (ultra) structural microvessel morphology may cause atherosclerotic plaque destabilization (Figure 6.1). In chapter 5 we described the compromised structural integrity of microvascular endothelium in human coronary atherosclerosis, characterized by open EC junctions, membrane blebs, intracytoplasmic vacuoles, and basement membrane detachment of EC. An intriguing parallel was observed between the aberrant morphology of intraplaque microvessel EC and arterial EC. Arterial endothelial cells were thickened at the initiation of atherosclerosis, showing membrane protrusions and cytoplasmic lipid vesicles. ${ }^{91}$ Despite a continuous endothelium with intact junctions, this morphology was associated with barrier dysfunction and enhanced influx of lipoproteins and monocytes. The severe barrier dysfunction of intraplaque microvascular EC, characterized by open junctions, may be caused by the aggravated hypoxic, inflammatory and ROS-rich milieu of microvascular EC compared to arterial EC.

Microvascular leakage is though to be the origin of leukocyte and red blood cell extravasation into the plaque. Although leucocytes and red blood cells are causally associated with plaque growth and destabilization, ${ }^{60,92}$ their actual leakage from intraplaque microvessels has not explicitly been shown. Nevertheless, the abnormal EC morphology and missing microvessel junctions described in this thesis argue that the accumulation of leucocytes and red blood cells in the microvessel surroundings is caused by microvascular leakage. A large-scale electron microscopy study is warranted to study the association of microvessel morphology in different human atherosclerotic plaque types and normal arteries, as well as the frequency of aberrant microvessels relative to all microvessels. In addition, in vivo imaging or quantification of labeled leucocytes or red blood cells should demonstrate if microvessels are indeed functionally leaky.

This type of study can only be performed in primates and humans, as intraplaque hemorrhage has only been convincingly shown in these species. As this raises serious ethical concerns, the lack of a suitable, small animal model showing intraplaque angiogenesis, hemorrhage and rupture represents a major problem in experimental research on intraplaque angiogenesis. Presently, it is thus impossible to conclude whether microvessel abundance and/or morphology in atherosclerosis are causative or simply reactive. 


\section{Future perspectives}

\section{Lymphatic, arterial and venous differentiation of intraplaque microvessels}

The specialization of endothelial cells to a lymphatic, arterial or venous fate is associated with a distinct gene expression signature. It should therefore be possible to discriminate lymphatics from arterial or venous microvessels in the atherosclerotic plaque. The presence of lymphatic microvessels in the atherosclerotic plaque was a rare event ( $0.3 \%$ of intraplaque microvessels) based on lymphatic marker expression of LYVE-1, 13 but expression of this marker was not exclusive to lymphatics. ${ }^{94}$ Two reports using VEGFR3 immunohistochemistry and electron microscopy failed to identify any intraplaque lymphatics.95, 96 Podoplanin and prox-1 are also specific lymph markers, and we have identified podoplanin + microvessels in plaques and adventitia of human coronary and carotid atherosclerosis (Figure 6.2). Podoplanin ${ }^{+}$microvessels were thin-walled, scarcely present and among the smallest microvessels $\left(6 \times 10-17 \times 30 \mu \mathrm{m} ; 70-420 \mu \mathrm{m}^{2}\right)$.

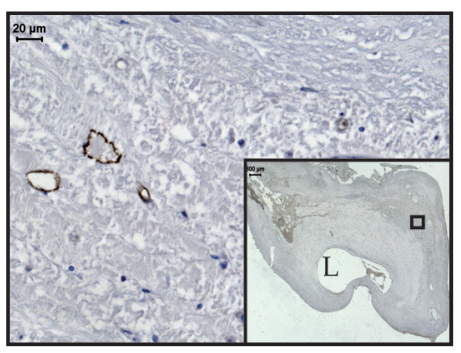

Figure 6.2 Intraplaque lymphatics in human carotid artery Podoplanin immunoreactivity (D2-40 antibody) shows intraplaque lymphatics in human carotid artery. Boxed region in inset shows origin of magnification. L, lumen

Currently, a quantitative study using specific lymph markers in normal and atherosclerotic human arteries is lacking, but results so far suggest that plaque lymphatics are scarce. Inadequate lymphangiogenesis may not only be unable to drain the extravasated red blood cells and leukocytes thereby sustaining inflammation, lymph vessels, at least in tumors, have also been shown to collapse. ${ }^{97}$ Possible inadequate or collapsing lymphatics in atherosclerosis could thus enhance microvascular leakage in atherosclerosis.

The presence of lymphangiogenesis elicits the question whether the microvessels in atherosclerosis have a specific arterial or venous differentiation. This is plausible if adventitial capillaries and venules form the origin of adventitial and intraplaque microvessels. However, when the angiogenic network would form as a plexus, the microvessels might not even have a specific differentiation. As of yet, the differentiation of atherosclerotic microvessels has not been determined. Regardless of their differentiation, at least some type of microvessel, be it of lymphatic or venous origin, should be responsible for transport of solutes and/or cells away from the plaque. 


\section{Chapter 6}

\section{HIF1 $\alpha$ intervention in atherosclerosis}

The studies described in this thesis did not achieve the intended manipulation of macrophage HIF1 $\alpha$ expression in murine atherogenesis. As explained before, hypoxia in plaque macrophages seems to override the effects of HIF1 $\alpha$ and PHD1 deletion (chapter 4). The model needed to determine if HIF1 $\alpha$ has a functional effect on atherosclerosis, should thus maintain HIF1 $\alpha$ manipulation in hypoxia. Constitutional, conditional or siRNA-mediated downregulation of HIF1 $\alpha$ in atherogenesis are unsuitable, as the full HIF $1 \alpha^{-/-}$is lethal ${ }^{98}$ and residual expression is inherent to conditional transgenes and siRNA treatment. Their effect will thus not be maintained in hypoxia. Genetic models up regulating HIF1 $\alpha$, such as VHL and PHD2 knock-outs, may be more useful to study the effect of macrophage HIF1 $\alpha$ in atherogenesis using a bone marrow transplantation model. The effect of VHL or PHD2 deletion on HIF1 $\alpha$ protein expression in hypoxic macrophages should be determined before an in vivo study is carried out, as the effects of $\mathrm{VHL}^{-/}$and $\mathrm{PHD}^{-/-}$on HIF1 $\alpha$ transcriptional activity in hypoxia were mixed. ${ }^{21,99,100}$ While it will be challenging to determine a possible function for macrophage HIF1 $\alpha$ in atherogenesis, genetic models upregulating HIF1 $\alpha$ appear the most promising approach.

\section{Anti-angiogenic therapy}

Despite the unanswered question of angiogenic causality in atherogenesis, therapy aimed at reduction and/or functional improvement of angiogenesis may be beneficial in the treatment of atherosclerosis. Animal studies have shown favorable effects of anti-angiogenic therapy on plaque size and phenotype, ${ }^{89,90,101}$ albeit that the effects may be angiogenesis-independent. Some important issues regarding therapy timing, -aim, -target, and side effects and patient selection should be addressed before angiogenesis inhibition is applied to human atherosclerosis. First, no available anti-atherosclerotic therapy has ever completely prevented disease and any therapy addressing atherosclerosis should thus be able to affect existing lesions. Recent data from our group has failed to show an effect of the angiogenesis inhibitors anginex and endostatin on regression of existing plaques, despite a beneficial effect on early plaque growth. ${ }^{101}$ Other inhibitors also had a positive effect on initial murine lesions, $,{ }^{89}, 90$ but our data clearly indicate the need for in vivo evaluation of their effect on existing lesions before commencing any clinical trial.

Anti-angiogenic therapy may be aimed at diminishing microvessel frequency by preventing or eradicating angiogenesis, or at normalizing aberrant microvessel morphology. As eradicating angiogenesis may enhance plaque 
hypoxia and its detrimental angiogenic-independent effects on plaque stability, normalization of morphology and/or function may be more effective and safe. Normalization may be achieved via the recruitment of mural cells and restoration of the endothelial barrier function. While promising target molecules such as PIGF, ${ }^{102}$ and PDGR $^{103}$ are able to enhance pericyte coverage, it is uncertain whether this will improve microvascular leakage in atherosclerotic plaques. As described in chapter 5 of this thesis, the lack of mural cells appeared physiological in microvessels of the arterial wall. Adventitial microvessels of non-diseased coronary arteries, representing physiological angiogenesis, also showed minimal mural cells and coverage was similar in advanced stable and ruptured coronary plaques. Therefore, mural cell coverage is probably not involved in plaque destabilization. Nevertheless, enhanced mural cell coverage will probably enhance the the EC barrier function preventing microvascular leakage associated with open EC junctions, as mural cell interaction with EC is associated with diminished permeability. ${ }^{103}$

Based on our data (chapter 5), stabilization of EC activation and restoration of EC junctions appears the most attractive therapy to normalize plaque angiogenesis. The appropriate intervention depends on the primary cause of microvascular leakage, but the mechanism responsible for compromised microvessel morphology in atherosclerosis is yet unknown. VEGF is likely involved, as VEGF disrupts endothelial junctions ${ }^{104}$ and its expression is present throughout atherogenesis (chapter 3). Chronic VEGF expression, stimulated in the hypoxic and ROS-rich plaque, might thus be involved in the aberrant integrity of microvascular EC and subsequent microvascular leakage. Therefore, VEGFA inhibition, achievable by blocking its main receptor VEGFR2, could be a smart strategy as it could reduce microvessel number ánd restore EC junctions. PIGF also stimulated vascular permeability in VEGF-rich tissue, despite enhancing pericyte coverage. Blocking VEGFR1, the receptor of both VEGFA and PlGF, appears another attractive approach. In addition, EC integrity can be recovered by blocking signal transduction molecules PKC, Rho or Src kinases involved in junction disruption, while leukocyte infiltration can be reduced by blocking endothelial adhesion molecule receptors. ${ }^{105}$ Future research should dissect the mechanism leading to disruption of endothelial integrity in atherosclerosis, permitting the choice of appropriate and effective therapy.

Anti-angiogenic therapy may consist of drugs targeting a specific (combination of) molecule(s), or drugs with pleiotropic effects, such as statins. In a retrospective study, plaque angiogenesis was diminished in patients treated with statins compared to untreated patients. ${ }^{106}$ However, statins were also reported as pro-angiogenic depending on the dose, ${ }^{107,108}$ and may thus not be a 
suitable therapy. The choice of the target molecule(s) is dependent on the therapy aim, excluding for instance anti-HIF therapy to achieve normalization. HIF inhibition would ofcourse reduce angiogenesis, while HIF overexpression has been shown to stimulate mural cell coverage and lessen vascular leakage, compared to VEGF overexpression. ${ }^{109}$ HIF inhibition may thus be detrimental for microvascular leakage. In addition, prolonged HIF inhibition is impossible as it would result in suppression of innate immunity, ${ }^{21}$ while potentially increasing adaptive immunity. ${ }^{23}$ A combination strategy aimed at pruning, not eradicating, the angiogenic network ánd normalization may increase therapy effectiveness. Such therapy may involve drugs aimed at enhancing PDGR and inhibiting VEGF.

Despite promising effects of VEGF therapy on tumor angiogenesis, serious adverse effects on cardiovascular events (angina pectoris, arterial thrombosis, cerebral- or myocardial ischemia and -infarction) have been shown for the VEGFA inhibitor bevacizumab in a recent meta-review. ${ }^{110}$ This is of particular relevance for its potential use as therapy for atherosclerosis, as a history of atherosclerosis greatly enhanced the risk of cardiovascular events. The so-called "Janus" face of VEGF is explained by its positive effect on maintenance and regeneration of arterial endothelium, as opposed to its destabilizing effect on microvascular endothelium. Similar concerns on increased risk of stroke have been described for the intraocular use of the VEGFA inhibitor ranibizumab, ${ }^{111}$ suggesting that VEGF inhibition in general should be used with caution.

Another threat of angiogenesis inhibition to the overall patient benefit is posed by growth-retardation or elimination of myocardial collaterals, which could be detrimental for patient survival. These side effects illustrate the importance of careful selection of the patient group benefiting instead of suffering from angiogenesis inhibition. This challenging task will be simplified once imaging techniques can non-invasively verify the individual incidence of intraplaque angiogenesis.

\section{Imaging hypoxia and angiogenesis}

Recent development of molecular imaging techniques suitable for magnetic resonance imaging (MRI), positron emission tomography (PET) or near-infrared fluorescence (NIRF) imaging may provide tailored risk assessments based on in vivo delineation of plaque morphology. Several molecular imaging agents specifically targeted angiogenesis, addressed at VCAM-1, ${ }^{112,}{ }^{113} \alpha v \beta 3$-integrin (using RGD peptides) ${ }^{114,115}$ or at CD13 (using cNGR peptides). ${ }^{116}$ These agents were all capable of imaging angiogenesis in animal models of atherosclerosis or MI. Excitingly, angiogenesis probes may even be useful as vehicle for specific 
targeting of drug therapy. ${ }^{114}$ As of yet, clinical trials have not been initiated, but are expected to start soon. These RGD and cNGR peptides specifically home to proliferating EC of early angiogenesis, while intraplaque microvessels in human plaques were quiescent as we showed in chapter 3 . Therefore, the promising in vivo results may not necessarily extend to human plaque angiogenesis.

Contrast-enhanced ultrasound provides another image modality, applicable for cost-effective imaging of plaque angiogenesis. Two recent human validation studies distinguished angiogenesis in carotid atherosclerosis using micro sphere enhancement of echo-contrast. ${ }^{117,118}$ Initial validation of images with EC immunohistochemistry appeared promising, ${ }^{118}$ but the association between $e x$ vivo histology and in vivo imaging of angiogenesis was moderate (spearmann's $\rho=0.68) .{ }^{118}$ The level of agreement seemed to be low, although no intra-class correlation was shown. ${ }^{118}$ Notably, microvessels were not detected in hemorrhagic areas, a striking discrepancy with accepted intraplaque locations of angiogenesis using (immuno)histology. ${ }^{117}$ Although, in vivo imaging of angiogenesis using probes or ultra-sound are pushed forward as specific imaging tools, their validation of angiogenesis in human athersclerosis and/or number of human subjects should be extended further.

Clinical applications successfully dissecting molecular imaging of plaque morphology include magnetic nanoparticle-enhanced MRI ${ }^{119,}{ }^{120}$ and ${ }^{18}$ FDG PET imaging. ${ }^{121,122}$ These agents visualize plaque macrophages and intraplaque hemorrhage, and plaque macrophage metabolism respectively. The results described in chapter 3 of this thesis identified hypoxia as a novel interesting imaging target to non-invasively assess plaque morphology. Hypoxia probes could be used to target macrophages, assess plaque metabolism and may be associated with plaque instability. Although not demonstrated yet, we speculate that hypoxia is more severe in ruptured plaques. Hypoxia detects macrophages and ruptured plaques showed more macrophages per plaque area than stable plaques. ${ }^{1}$ Several imaging modalities and agents are available for non-invasive in vivo imaging of tissue hypoxia. ${ }^{123}$ Some have already been applied to evaluate human tissue or tumor hypoxia in vivo, ${ }^{124-126}$ but none have been used in human cardiovascular disease. Judged by spatial resolution, penetration, and oxygen specificity, sensitivity and detection range, ${ }^{19} \mathrm{~F}$ MRI and PET-computed tomography (PET-CT) appear most suitable for clinical detection of hypoxia in atherosclerosis. Perfluorcarbons and several 2-nitroimidazoles, including misonidazole and EF5, are pre-clinically available as ${ }^{19} \mathrm{~F}$ or ${ }^{18} \mathrm{~F}$-labelled probes. Perfluorcarbons have a wider range of oxygen detection $(0-760 \mathrm{mmHg})$ and sensitivity $(0-3 \mathrm{mmHg})$ than 2-nitroimidazoles $(0-10 \mathrm{mmHg},<10 \mathrm{mmHg}$ respectively), but may face toxicity and distribution issues. A phase II trial using 
${ }^{18} \mathrm{~F}$ misonidazole in rectal cancer has started in December 2007, while results of a phase 1 clinical trial using ${ }^{18} \mathrm{~F}$ EF5 in brain tumors are expected soon (http://clinicaltrials.gov). Pimonidazole appeared more specific for severe hypoxia than EF5 and misonidazole ${ }^{123}$ and pimonidazole has already convincingly detected ex vivo hypoxia in human carotid plaques. ${ }^{6}$ However, ${ }^{19} \mathrm{~F}$ or ${ }^{18} \mathrm{~F}$-labeled pimonidazole are currently not FDA-approved, suggesting that FDA-approved ${ }^{18} \mathrm{~F}$-misonidazole or ${ }^{18} \mathrm{~F}$ EF5 are currently the best probes for the in vivo evaluation of cardiovascular hypoxia.

Once imaging of plaque angiogenesis and hypoxia are sufficiently validated to represent plaque morphology concurring with histology, prospective clinical trials could ascertain the exact importance of intraplaque angiogenesis and hypoxia in the prediction of plaque growth and rupture. In the future, angiogenic or hypoxic imaging may provide tailored risk assessments and be useful to evaluate therapy efficacy.

\section{Concluding remarks}

Hypoxia, HIF and angiogenesis are highly correlated with atherosclerotic progression, but so far evidence to distinguish their reactive or causative role in atherogenesis is unavailable. As of yet, hypoxia, HIF and angiogenesis remain innocent until proven guilty. 


\section{References}

1. Virmani R, Kolodgie FD, Burke AP, Finn AV, et al. Atherosclerotic Plaque Progression and Vulnerability to Rupture Angiogenesis as a Source of Intraplaque Hemorrhage. Arterioscler Thromb Vasc Biol. 2005;25:2054-2061.

2. Moreno PR, Purushothaman KR, Sirol M, Levy AP, et al. Neovascularization in human atherosclerosis. Circulation. 2006;113:2245-2252.

3. Herrmann J, Lerman LO, Mukhopadhyay D, Napoli C, et al. Angiogenesis in Atherogenesis. Arterioscler Thromb Vasc Biol. 2006;26:1948-1957.

4. Sanoudou D, Kang PB, Haslett JN, Han M, et al. Transcriptional profile of postmortem skeletal muscle. Physiol Genomics. 2004;16:222-228.

5. Bjornheden T, Levin M, Evaldsson M, Wiklund O. Evidence of hypoxic areas within the arterial wall in vivo. Arterioscler Thromb Vasc Biol. 1999;19:870-876.

6. Sluimer JC, Gasc JM, van Wanroij JL, Kisters N, et al. Hypoxia in human atherosclerotic plaques is correlated with the expression of CD68, HIF, VEGF and the presence of a thrombus and angiogenesis. J Am Coll Cardiol. 2008;In press.

7. Paul RJ. The effects of isoproterenol and ouabain on oxygen consumption, lactate production, and the activation of phosphorylase in coronary artery smooth muscle. Circ Res. 1983;52:683-690.

8. Barron JT, Kopp SJ, Tow J, Parrillo JE. Substrate-dependent alteration in O2 consumption and energy metabolism in vascular smooth muscle. Am J Physiol. 1996;270:H1869-1877.

9. Virmani R, Ladich ER, Burke AP, Kolodgie FD. Histopathology of carotid atherosclerotic disease. Neurosurgery. 2006;59:S219-227; discussion S213-213.

10. Schwartz SM, Galis ZS, Rosenfeld ME, Falk E. Plaque rupture in humans and mice. Arterioscler Thromb Vasc Biol. 2007;27:705-713.

11. Lutgens E, Cleutjens KB, Heeneman S, Koteliansky VE, et al. Both early and delayed antiCD40L antibody treatment induces a stable plaque phenotype. Proc Natl Acad Sci U S A. 2000;97:7464-7469.

12. Lutgens E, Lutgens SP, Faber BC, Heeneman S, et al. Disruption of the cathepsin K gene reduces atherosclerosis progression and induces plaque fibrosis but accelerates macrophage foam cell formation. Circulation. 2006;113:98-107.

13. Gerald D, Berra E, Frapart YM, Chan DA, et al. JunD reduces tumor angiogenesis by protecting cells from oxidative stress. Cell. 2004;118:781-794.

14. Page EL, Robitaille GA, Pouyssegur J, Richard DE. Induction of hypoxia-inducible factor1alpha by transcriptional and translational mechanisms. J Biol Chem. 2002;277:48403-48409.

15. Gorlach A, Diebold I, Schini-Kerth VB, Berchner-Pfannschmidt U, et al. Thrombin activates the hypoxia-inducible factor-1 signaling pathway in vascular smooth muscle cells: Role of the p22(phox)-containing NADPH oxidase. Circ Res. 2001;89:47-54.

16. Kurobe H, Urata M, Izawa Y, Fukuhara Y, et al. Hif-1a in T Cells pathway plays a crucial role 


\section{Chapter 6}

in the progression of arteriosclerosis and artery intimal thickening. Abstract AHA 2007. Circulation. 2007;116:_246.

17. Karshovska E, Zernecke A, Sevilmis G, Millet A, et al. Expression of HIF-1alpha in injured arteries controls SDF-1alpha mediated neointima formation in apolipoprotein E deficient mice. Arterioscler Thromb Vasc Biol. 2007;27:2540-2547.

18. Jiang G, Li T, Qiu Y, Rui $Y$, et al. RNA interference for HIF-1alpha inhibits foam cells formation in vitro. Eur J Pharmacol. 2007;562:183-190.

19. Aragones J, Schneider M, Van Geyte K, Fraisl P, et al. Deficiency or inhibition of oxygen sensor Phd1 induces hypoxia tolerance by reprogramming basal metabolism. Nat Genet. 2008.

20. Cummins EP, Berra E, Comerford KM, Ginouves A, et al. Prolyl hydroxylase-1 negatively regulates IkappaB kinase-beta, giving insight into hypoxia-induced NFkappaB activity. Proc Natl Acad Sci U S A. 2006;103:18154-18159.

21. Cramer T, Yamanishi Y, Clausen BE, Forster I, et al. HIF-1alpha is essential for myeloid cellmediated inflammation. Cell. 2003;112:645-657.

22. Murdoch $C$, Muthana $M$, Lewis CE. Hypoxia regulates macrophage functions in inflammation. J Immunol. 2005;175:6257-6263.

23. Thiel M, Caldwell CC, Kreth S, Kuboki S, et al. Targeted deletion of HIF-1alpha gene in T cells prevents their inhibition in hypoxic inflamed tissues and improves septic mice survival. PLoS ONE. 2007;2:e853.

24. Lewis JS, Lee JA, Underwood JC, Harris AL, et al. Macrophage responses to hypoxia: relevance to disease mechanisms. J Leukoc Biol. 1999;66:889-900.

25. Murata Y, Ohteki T, Koyasu S, Hamuro J. IFN-gamma and pro-inflammatory cytokine production by antigen-presenting cells is dictated by intracellular thiol redox status regulated by oxygen tension. Eur J Immunol. 2002;32:2866-2873.

26. Hosogai N, Fukuhara A, Oshima K, Miyata Y, et al. Adipose tissue hypoxia in obesity and its impact on adipocytokine dysregulation. Diabetes. 2007;56:901-911.

27. Lumeng $\mathrm{CN}$, Bodzin JL, Saltiel AR. Obesity induces a phenotypic switch in adipose tissue macrophage polarization. J Clin Invest. 2007;117:175-184.

28. Martinez FO, Sica A, Mantovani A, Locati M. Macrophage activation and polarization. Front Biosci. 2008;13:453-461.

29. Heistad DD, Armstrong ML, Marcus ML. Hyperemia of the aortic wall in atherosclerotic monkeys. Circ Res. 1981;48:669-675.

30. Ritman EL, Lerman A. The dynamic vasa vasorum. Cardiovasc Res. 2007.

31. Gerhardt H, Betsholtz C. Endothelial-pericyte interactions in angiogenesis. Cell Tissue Res. 2003;314:15-23.

32. Blom $\mathrm{H}$, Mulder M, Verweij W. Arterial oxygen tension and saturation in hospital patients: effect of age and activity. Bmj. 1988;297:720-721.

33. Malmberg $\mathrm{P}$, Hedenstrom $\mathrm{H}$, Fridriksson HV. Reference values for gas exchange during 
exercise in healthy nonsmoking and smoking men. Bull Eur Physiopathol Respir. 1987;23:131-138.

34. Rodrigues LM, Pinto PC, Leal A. Transcutaneous flow related variables measured in vivo: the effects of gender. BMC Dermatol. 2001;1:4.

35. Carmeliet P, Jain RK. Angiogenesis in cancer and other diseases. Nature. 2000;407:249-257.

36. Haroon ZA, Raleigh JA, Greenberg CS, Dewhirst MW. Early wound healing exhibits cytokine surge without evidence of hypoxia. Ann Surg. 2000;231:137-147.

37. Lee YA, Kim JY, Hong SJ, Lee SH, et al. Synovial proliferation differentially affects hypoxia in the joint cavities of rheumatoid arthritis and osteoarthritis patients. Clin Rheumatol. 2007;26:2023-2029.

38. Kennedy AS, Raleigh JA, Perez GM, Calkins DP, et al. Proliferation and hypoxia in human squamous cell carcinoma of the cervix: first report of combined immunohistochemical assays. Int J Radiat Oncol Biol Phys. 1997;37:897-905.

39. Kaanders JH, Wijffels KI, Marres HA, Ljungkvist AS, et al. Pimonidazole binding and tumor vascularity predict for treatment outcome in head and neck cancer. Cancer Res. 2002;62:7066-7074.

40. Rausch ME, Weisberg S, Vardhana P, Tortoriello DV. Obesity in C57BL/6J mice is characterized by adipose tissue hypoxia and cytotoxic T-cell infiltration. Int J Obes (Lond). 2007.

41. Aly S, Laskay T, Mages J, Malzan A, et al. Interferon-gamma-dependent mechanisms of mycobacteria-induced pulmonary immunopathology: the role of angiostasis and CXCR3targeted chemokines for granuloma necrosis. J Pathol. 2007;212:295-305.

42. James PE, Madhani M, Ross C, Klei L, et al. Tissue hypoxia during bacterial sepsis is attenuated by PR-39, an antibacterial peptide. Adv Exp Med Biol. 2003;530:645-652.

43. Donners MM, Bot I, De Windt LJ, van Berkel TJ, et al. Low-dose FK506 blocks collar-induced atherosclerotic plaque development and stabilizes plaques in ApoE-/- mice. Am J Transplant. 2005;5:1204-1215.

44. Langheinrich AC, Michniewicz A, Sedding DG, Walker G, et al. Correlation of vasa vasorum neovascularization and plaque progression in aortas of apolipoprotein $\mathrm{E}(-/-) /$ low-density lipoprotein(-/-) double knockout mice. Arterioscler Thromb Vasc Biol. 2006;26:347-352.

45. Moulton KS, Olsen BR, Sonn S, Fukai N, et al. Loss of collagen XVIII enhances neovascularization and vascular permeability in atherosclerosis. Circulation. 2004;110:13301336.

46. Sachais BS, Turrentine T, Dawicki McKenna JM, Rux AH, et al. Elimination of platelet factor 4 (PF4) from platelets reduces atherosclerosis in C57Bl/6 and apoE-/- mice. Thromb Haemost. 2007;98:1108-1113.

47. von Hundelshausen P, Petersen F, Brandt E. Platelet-derived chemokines in vascular biology. Thromb Haemost. 2007;97:704-713.

48. Schmeisser A, Marquetant R, Illmer T, Graffy C, et al. The expression of macrophage 
migration inhibitory factor 1alpha (MIF 1alpha) in human atherosclerotic plaques is induced by different proatherogenic stimuli and associated with plaque instability. Atherosclerosis. 2005;178:83-94.

49. McCarthy MJ, Loftus IM, Thompson MM, Jones L, et al. Angiogenesis and the atherosclerotic carotid plaque: an association between symptomatology and plaque morphology. J Vasc Surg. 1999;30:261-268.

50. Milei J, Parodi JC, Alonso GF, Barone A, et al. Carotid rupture and intraplaque hemorrhage: immunophenotype and role of cells involved. Am Heart J. 1998;136:1096-1105.

51. Milei J, Parodi JC, Ferreira M, Barrone A, et al. Atherosclerotic plaque rupture and intraplaque hemorrhage do not correlate with symptoms in carotid artery stenosis. J Vasc Surg. 2003;38:1241-1247.

52. Mofidi R, Crotty TB, McCarthy P, Sheehan SJ, et al. Association between plaque instability, angiogenesis and symptomatic carotid occlusive disease. Br J Surg. 2001;88:945-950.

53. Fleiner M, Kummer M, Mirlacher M, Sauter G, et al. Arterial neovascularization and inflammation in vulnerable patients: early and late signs of symptomatic atherosclerosis. Circulation. 2004;110:2843-2850.

54. de Boer OJ, van der Wal AC, Teeling P, Becker AE. Leucocyte recruitment in rupture prone regions of lipid-rich plaques: a prominent role for neovascularization? Cardiovasc Res. 1999;41:443-449.

55. Jeziorska M, Woolley DE. Neovascularization in early atherosclerotic lesions of human carotid arteries: its potential contribution to plaque development. Hum Pathol. 1999;30:919925.

56. Brandl R, Richter T, Haug K, Wilhelm MG, et al. Topographic analysis of proliferative activity in carotid endarterectomy specimens by immunocytochemical detection of the cell cycle-related antigen Ki-67. Circulation. 1997;96:3360-3368.

57. Yilmaz A, Lipfert B, Cicha I, Schubert K, et al. Accumulation of immune cells and high expression of chemokines/chemokine receptors in the upstream shoulder of atherosclerotic carotid plaques. Exp Mol Pathol. 2007;82:245-255.

58. Kockx MM, Cromheeke KM, Knaapen MW, Bosmans JM, et al. Phagocytosis and macrophage activation associated with hemorrhagic microvessels in human atherosclerosis. Arterioscler Thromb Vasc Biol. 2003;23:440-446.

59. Fryer JA, Myers PC, Appleberg M. Carotid intraplaque hemorrhage: the significance of neovascularity. J Vasc Surg. 1987;6:341-349.

60. Dunmore BJ, McCarthy MJ, Naylor AR, Brindle NP. Carotid plaque instability and ischemic symptoms are linked to immaturity of microvessels within plaques. J Vasc Surg. 2007;45:155-159.

61. Mazzone A, Epistolato MC, Gianetti J, Castagnini M, et al. Biological features (inflammation and neoangiogenesis) and atherosclerotic risk factors in carotid plaques and calcified aortic valve stenosis: two different sites of the same disease? Am J Clin Pathol. 2006;126:494-502. 
62. Chen F, Eriksson P, Kimura T, Herzfeld I, et al. Apoptosis and angiogenesis are induced in the unstable coronary atherosclerotic plaque. Coron Artery Dis. 2005;16:191-197.

63. Nakano D, Hayashi T, Tazawa N, Yamashita C, et al. Chronic hypoxia accelerates the progression of atherosclerosis in apolipoprotein E-knockout mice. Hypertens Res. 2005;28:837-845.

64. Couffinhal T, Kearney M, Witzenbichler B, Chen D, et al. Vascular endothelial growth factor/vascular permeability factor (VEGF/VPF) in normal and atherosclerotic human arteries. Am J Pathol. 1997;150:1673-1685.

65. Kamat BR, Galli SJ, Barger AC, Lainey LL, et al. Neovascularization and coronary atherosclerotic plaque: cinematographic localization and quantitative histologic analysis. Hum Pathol. 1987;18:1036-1042.

66. Baba H, Yonemitsu Y, Nakano T, Onimaru M, et al. Cytoplasmic expression and extracellular deposition of an antiangiogenic factor, pigment epithelium-derived factor, in human atherosclerotic plaques. Arterioscler Thromb Vasc Biol. 2005;25:1938-1944.

67. Kaartinen M, Penttila A, Kovanen PT. Mast cells accompany microvessels in human coronary atheromas: implications for intimal neovascularization and hemorrhage. Atherosclerosis. 1996;123:123-131.

68. Ignatescu MC, Gharehbaghi-Schnell E, Hassan A, Rezaie-Majd S, et al. Expression of the angiogenic protein, platelet-derived endothelial cell growth factor, in coronary atherosclerotic plaques: In vivo correlation of lesional microvessel density and constrictive vascular remodeling. Arterioscler Thromb Vasc Biol. 1999;19:2340-2347.

69. Lappalainen H, Laine P, Pentikainen MO, Sajantila A, et al. Mast cells in neovascularized human coronary plaques store and secrete basic fibroblast growth factor, a potent angiogenic mediator. Arterioscler Thromb Vasc Biol. 2004;24:1880-1885.

70. Kumamoto M, Nakashima Y, Sueishi K. Intimal neovascularization in human coronary atherosclerosis: its origin and pathophysiological significance. Hum Pathol. 1995;26:450-456.

71. Chen YX, Nakashima Y, Tanaka K, Shiraishi S, et al. Immunohistochemical expression of vascular endothelial growth factor/vascular permeability factor in atherosclerotic intimas of human coronary arteries. Arterioscler Thromb Vasc Biol. 1999;19:131-139.

72. Boyle JJ, Wilson B, Bicknell R, Harrower S, et al. Expression of angiogenic factor thymidine phosphorylase and angiogenesis in human atherosclerosis. J Pathol. 2000;192:234-242.

73. Inoue $\mathrm{M}$, Itoh $\mathrm{H}$, Ueda $\mathrm{M}$, Naruko $\mathrm{T}$, et al. Vascular endothelial growth factor (VEGF) expression in human coronary atherosclerotic lesions: possible pathophysiological significance of VEGF in progression of atherosclerosis. Circulation. 1998;98:2108-2116.

74. Zhang Y, Cliff WJ, Schoefl GI, Higgins G. Immunohistochemical study of intimal microvessels in coronary atherosclerosis. Am J Pathol. 1993;143:164-172.

75. Depre C, Havaux X, Wijns W. Neovascularization in human coronary atherosclerotic lesions. Cathet Cardiovasc Diagn. 1996;39:215-220.

76. Tenaglia AN, Peters KG, Sketch MH, Jr., Annex BH. Neovascularization in atherectomy 


\section{Chapter 6}

specimens from patients with unstable angina: implications for pathogenesis of unstable angina. Am Heart J. 1998;135:10-14.

77. Moreno PR, Purushothaman KR, Fuster V, Echeverri D, et al. Plaque neovascularization is increased in ruptured atherosclerotic lesions of human aorta: implications for plaque vulnerability. Circulation. 2004;110:2032-2038.

78. Herrmann J, Lerman LO, Rodriguez-Porcel M, Holmes DR, Jr., et al. Coronary vasa vasorum neovascularization precedes epicardial endothelial dysfunction in experimental hypercholesterolemia. Cardiovasc Res. 2001;51:762-766.

79. Khurana R, Zhuang Z, Bhardwaj S, Murakami M, et al. Angiogenesis-dependent and independent phases of intimal hyperplasia. Circulation. 2004;110:2436-2443.

80. Wilson SH, Herrmann J, Lerman LO, Holmes DR, Jr., et al. Simvastatin preserves the structure of coronary adventitial vasa vasorum in experimental hypercholesterolemia independent of lipid lowering. Circulation. 2002;105:415-418.

81. Celletti FL, Waugh JM, Amabile PG, Brendolan A, et al. Vascular endothelial growth factor enhances atherosclerotic plaque progression. Nat Med. 2001;7:425-429.

82. Leppanen P, Koota S, Kholova I, Koponen J, et al. Gene transfers of vascular endothelial growth factor-A, vascular endothelial growth factor-B, vascular endothelial growth factor$C$, and vascular endothelial growth factor-D have no effects on atherosclerosis in hypercholesterolemic low-density lipoprotein-receptor/apolipoprotein B48-deficient mice. Circulation. 2005;112:1347-1352.

83. Lucerna M, Zernecke A, de Nooijer R, de Jager SC, et al. Vascular endothelial growth factorA induces plaque expansion in ApoE knock-out mice by promoting de novo leukocyte recruitment. Blood. 2007;109:122-129.

84. Luttun A, Tjwa M, Carmeliet P. Placental growth factor (PIGF) and its receptor Flt-1 (VEGFR-1): novel therapeutic targets for angiogenic disorders. Ann N Y Acad Sci. 2002;979:80-93.

85. Petrovan RJ, Kaplan CD, Reisfeld RA, Curtiss LK. DNA vaccination against VEGF receptor 2 reduces atherosclerosis in LDL receptor-deficient mice. Arterioscler Thromb Vasc Biol. 2007;27:1095-1100.

86. Hauer AD, van Puijvelde GH, Peterse N, de Vos P, et al. Vaccination against VEGFR2 attenuates initiation and progression of atherosclerosis. Arterioscler Thromb Vasc Biol. 2007;27:2050-2057.

87. Moulton KS, Heller E, Konerding MA, Flynn E, et al. Angiogenesis inhibitors endostatin or TNP-470 reduce intimal neovascularization and plaque growth in apolipoprotein Edeficient mice. Circulation. 1999;99:1726-1732.

88. Moulton KS, Vakili K, Zurakowski D, Soliman M, et al. Inhibition of plaque neovascularization reduces macrophage accumulation and progression of advanced atherosclerosis. Proc Natl Acad Sci U S A. 2003;100:4736-4741.

89. Simionescu M, Popov D, Sima A, Hasu M, et al. Pathobiochemistry of combined diabetes 
and atherosclerosis studied on a novel animal model. The hyperlipemic-hyperglycemic hamster. Am J Pathol. 1996;148:997-1014.

90. Kolodgie FD, Gold HK, Burke AP, Fowler DR, et al. Intraplaque hemorrhage and progression of coronary atheroma. N Engl J Med. 2003;349:2316-2325.

91. Nakano T, Nakashima Y, Yonemitsu Y, Sumiyoshi S, et al. Angiogenesis and lymphangiogenesis and expression of lymphangiogenic factors in the atherosclerotic intima of human coronary arteries. Hum Pathol. 2005;36:330-340.

92. Schledzewski K, Falkowski M, Moldenhauer G, Metharom P, et al. Lymphatic endotheliumspecific hyaluronan receptor LYVE-1 is expressed by stabilin-1+, F4/80+, CD11b+ macrophages in malignant tumours and wound healing tissue in vivo and in bone marrow cultures in vitro: implications for the assessment of lymphangiogenesis. J Pathol. 2006;209:67-77.

93. Rutanen J, Leppanen P, Tuomisto TT, Rissanen TT, et al. Vascular endothelial growth factor-D expression in human atherosclerotic lesions. Cardiovasc Res. 2003;59:971-979.

94. Eliska O, Eliskova M, Miller AJ. The absence of lymphatics in normal and atherosclerotic coronary arteries in man: a morphologic study. Lymphology. 2006;39:76-83.

95. Padera TP, Stoll BR, Tooredman JB, Capen D, et al. Pathology: cancer cells compress intratumour vessels. Nature. 2004;427:695.

96. Iyer NV, Kotch LE, Agani F, Leung SW, et al. Cellular and developmental control of O2 homeostasis by hypoxia-inducible factor 1 alpha. Genes Dev. 1998;12:149-162.

97. Takeda K, Cowan A, Fong GH. Essential Role for Prolyl Hydroxylase Domain Protein 2 in Oxygen Homeostasis of the Adult Vascular System. Circulation. 2007.

98. Takeda K, Ho VC, Takeda H, Duan LJ, et al. Placental but not heart defects are associated with elevated hypoxia-inducible factor alpha levels in mice lacking prolyl hydroxylase domain protein 2. Mol Cell Biol. 2006;26:8336-8346.

99. Schapira KB, Heeneman S, Donners MMPC, van der Schaft DWJ, et al. Anti-angiogenesis treatment with anginex or endostatn inhibits early lesion development in collar-induced atherosclerotic lesions of apoE-/- mice.

100. Luttun A, Tjwa M, Moons L, Wu Y, et al. Revascularization of ischemic tissues by PlGF treatment, and inhibition of tumor angiogenesis, arthritis and atherosclerosis by anti-Flt1. Nat Med. 2002;8:831-840.

101. Magnusson PU, Looman C, Ahgren A, Wu Y, et al. Platelet-derived growth factor receptorbeta constitutive activity promotes angiogenesis in vivo and in vitro. Arterioscler Thromb Vasc Biol. 2007;27:2142-2149.

102. Suarez S, Ballmer-Hofer K. VEGF transiently disrupts gap junctional communication in endothelial cells. J Cell Sci. 2001;114:1229-1235.

103. van Nieuw Amerongen GP, van Hinsbergh VW. Targets for pharmacological intervention of endothelial hyperpermeability and barrier function. Vascul Pharmacol. 2002;39:257-272.

104. Koutouzis M, Nomikos A, Nikolidakis S, Tzavara V, et al. Statin treated patients have 
reduced intraplaque angiogenesis in carotid endarterectomy specimens. Atherosclerosis. 2007;192:457-463.

105. Urbich C, Dernbach E, Zeiher AM, Dimmeler S. Double-edged role of statins in angiogenesis signaling. Circ Res. 2002;90:737-744.

106. Weis M, Heeschen C, Glassford AJ, Cooke JP. Statins have biphasic effects on angiogenesis. Circulation. 2002;105:739-745.

107. Pajusola K, Kunnapuu J, Vuorikoski S, Soronen J, et al. Stabilized HIF-1alpha is superior to VEGF for angiogenesis in skeletal muscle via adeno-associated virus gene transfer. Faseb J. 2005;19:1365-1367.

108. Scappaticci FA, Skillings JR, Holden SN, Gerber HP, et al. Arterial thromboembolic events in patients with metastatic carcinoma treated with chemotherapy and bevacizumab. J Natl Cancer Inst. 2007;99:1232-1239.

109. Dafer RM, Schneck M, Friberg TR, Jay WM. Intravitreal ranibizumab and bevacizumab: a review of risk. Semin Ophthalmol. 2007;22:201-204.

110. Hamilton AJ, Huang SL, Warnick D, Rabbat M, et al. Intravascular ultrasound molecular imaging of atheroma components in vivo. J Am Coll Cardiol. 2004;43:453-460.

111. Kelly KA, Allport JR, Tsourkas A, Shinde-Patil VR, et al. Detection of vascular adhesion molecule-1 expression using a novel multimodal nanoparticle. Circ Res. 2005;96:327-336.

112. Winter PM, Neubauer AM, Caruthers SD, Harris TD, et al. Endothelial alpha(v)beta3 integrin-targeted fumagillin nanoparticles inhibit angiogenesis in atherosclerosis. Arterioscler Thromb Vasc Biol. 2006;26:2103-2109.

113. Winter PM, Morawski AM, Caruthers SD, Fuhrhop RW, et al. Molecular imaging of angiogenesis in early-stage atherosclerosis with alpha(v)beta3-integrin-targeted nanoparticles. Circulation. 2003;108:2270-2274.

114. Buehler A, van Zandvoort MA, Stelt BJ, Hackeng TM, et al. cNGR: a novel homing sequence for CD13/APN targeted molecular imaging of murine cardiac angiogenesis in vivo. Arterioscler Thromb Vasc Biol. 2006;26:2681-2687.

115. Vicenzini E, Giannoni MF, Puccinelli F, Ricciardi MC, et al. Detection of carotid adventitial vasa vasorum and plaque vascularization with ultrasound cadence contrast pulse sequencing technique and echo-contrast agent. Stroke. 2007;38:2841-2843.

116. Shah F, Balan P, Weinberg M, Reddy V, et al. Contrast-enhanced ultrasound imaging of atherosclerotic carotid plaque neovascularization: a new surrogate marker of atherosclerosis? Vasc Med. 2007;12:291-297.

117. Cappendijk VC, Cleutjens KB, Heeneman S, Schurink GW, et al. In vivo detection of hemorrhage in human atherosclerotic plaques with magnetic resonance imaging. J Magn Reson Imaging. 2004;20:105-110.

118. Kooi ME, Cappendijk VC, Cleutjens KB, Kessels AG, et al. Accumulation of ultrasmall superparamagnetic particles of iron oxide in human atherosclerotic plaques can be detected by in vivo magnetic resonance imaging. Circulation. 2003;107:2453-2458.

119. Rudd JH, Warburton EA, Fryer TD, Jones HA, et al. Imaging atherosclerotic plaque 
inflammation with [18F]-fluorodeoxyglucose positron emission tomography. Circulation. 2002;105:2708-2711.

120. Tawakol A, Migrino RQ, Bashian GG, Bedri S, et al. In vivo 18F-fluorodeoxyglucose positron emission tomography imaging provides a noninvasive measure of carotid plaque inflammation in patients. J Am Coll Cardiol. 2006;48:1818-1824.

121. Vikram DS, Zweier JL, Kuppusamy P. Methods for noninvasive imaging of tissue hypoxia. Antioxid Redox Signal. 2007;9:1745-1756.

122. Eschmann SM, Paulsen F, Reimold M, Dittmann H, et al. Prognostic impact of hypoxia imaging with 18F-misonidazole PET in non-small cell lung cancer and head and neck cancer before radiotherapy. J Nucl Med. 2005;46:253-260.

123. Srinivasan S, Pogue BW, Carpenter C, Jiang S, et al. Developments in quantitative oxygensaturation imaging of breast tissue in vivo using multispectral near-infrared tomography. Antioxid Redox Signal. 2007;9:1143-1156.

124. Hoskin PJ, Carnell DM, Taylor NJ, Smith RE, et al. Hypoxia in prostate cancer: correlation of BOLD-MRI with pimonidazole immunohistochemistry-initial observations. Int J Radiat Oncol Biol Phys. 2007;68:1065-1071. 


\section{Summary}

Angiogenesis is a key morphological feature of atherosclerotic lesions. The presumed microvascular leakage of lipid, leucocytes and red blood cells enhances lipid accumulation, oxidative stress, inflammation and apoptosis, proatherogenic processes associated with plaque growth- and instability. However, insight into the mechanisms governing the formation of intraplaque microvessels in atherosclerotic disease is lacking, as well as knowledge of the (ultra) structural microvessel morphology possibly explaining microvascular leakage. As angiogenesis is a major consequence of hypoxic tissue, the mere presence of intraplaque angiogenesis suggests the existence of hypoxia and its transcriptional activator, HIF, in human atherosclerosis. Hypoxia and HIF significantly augment inflammation and lipid accumulation as well as angiogenesis, suggesting that hypoxia and HF are pro-atherogenic factors. Therefore, the main hypothesis of this thesis was that hypoxia-induced, HIFdriven transcription stimulates the progression and angiogenic infestation of atherosclerosis.

Gene expression is commonly studied in human tissue obtained from living (surgery) and deceased (autopsy) donors, however the oxygen levels and subsequent gene expression may be different between plaques derived from autopsy and surgery. Therefore in chapter 2, the gene expression profiles of advanced atherosclerotic plaques from autopsy and surgery were compared to assess if expression profiles of plaques from different sources (autopsy and surgery) were comparable. Although gene expression of autopsy and surgery was largely similar, some basal cell metabolism and hypoxia genes were differentially expressed at the mRNA, but not the protein level. Therefore, expression of hypoxia-driven genes in different stages of atherosclerosis was only compared between plaques obtained from the same source.

In chapters 3 and 4 , the presence of hypoxia and HIF in the human ánd murine atherosclerotic plaque was positively established using the hypoxia marker pimonidazole. The presence of hypoxia correlated with atherosclerotic progression, macrophages and angiogenesis, but was independent of intimal thickness. Gene and protein expression of HIF and HIF responsive genes, investigated by micorarray, qRT-PCR and immunohistochemistry, were increased with human atherosclerotic progression, inflammation and angiogenesis.

In chapter 4 the functional involvement of hypoxia and HIF in atherogenesis was investigated by exposing mice with advanced plaques four weeks to $10 \% \mathrm{O}_{2}$, while the effect of macrophage-specific HIF1 $\alpha$ and its regulator PHD1 was 
studied using wildtype, LysMcre-HIF1 $\alpha^{-/}$en PHD1 ${ }^{-/}$bone marrow transplantations into $\mathrm{LDLR}^{-/}$mice. Neither hypoxic exposure, nor HIF1 $\alpha$ and PHD1 deletion changed murine atherosclerotic burden or plaque stability. Chronic exposure to hypoxia resulted in similar HIF1 $\alpha$ protein levels in wildtype, LysMcre-HIF1 $\alpha^{-/}$and PHD1 ${ }^{-/}$macrophages in vitro and in vivo, as 1. chronic hypoxia reversed HIF1 $\alpha$ protein and VEGF expression in wildtype macrophages, 2 . chronic hypoxia induced HIF1 $\alpha$ protein and VEGF in LysMcreHIF $1 \alpha^{-/}$due to incomplete genetic deletion, and 3. HIF1 $\alpha$ protein were unchanged in hypoxic PHD $1^{-/}$macrophages. Thus, similar HIF1 $\alpha$ protein levels in wildtype, LysMcre-HIF1 $\alpha^{-/-}$and PHD1 ${ }^{-/}$macrophages after chronic hypoxia as encountered in plaque macrophages - may explain the lack of effect of LysMcre-HIF1 $\alpha^{-/}$and PHD1 ${ }^{-/}$bone marrow transplantations on atherosclerosis. The data identify hypoxia as a strong stimulus of HIF1 $\alpha$ protein expression in plaque macrophages, compensating the effect of their genetic HIF1 $\alpha$ and PHD1.

In addition, we hypothesized that the (ultra) structural abnormal morphology of intraplaque microvessels may explain microvascular leakage and was associated with plaque progression. Microvascular leakage is common in immature microvessels, with incomplete or absent basement membrane and pericyte coverage, and depends on the structural integrity of the endothelium formed by intact inter-endothelial junctions. Therefore, in chapter 5 microvessel density and (ultra)structural morphology were determined in the adventitia, intimamedia border and atherosclerotic plaques of coronary arteries using immunohistochemistry of endothelial cells, basement membrane and pericytes and electron microscopy. Microvessel density was associated with coronary plaque progression and morphology, but was not different between stable and ruptured plaques. Microvessel pericyte coverage was incomplete in normal and atherosclerotic arteries, and is thus unlikely to account for microvascular leakage. However, electron microscopy showed an abnormal morphology of microvascular endothelium, with membrane blebs, intracytoplasmic vacuoles, open inter-endothelial junctions and basement membrane detachment. Thus, the compromised structural integrity of microvascular endothelium may explain microvascular leakage in human coronary atherosclerosis.

In chapter 6 the findings of the experimental studies in chapters 2 through 5 and their implications were discussed. These studies suggest the involvement of hypoxia and HIF in progression and angiogenesis of atherosclerosis. Despite a strong association and their known in vivo function, we were not able to show the functional involvement of hypoxic exposure, HIF1 $\alpha$ or PHD1 deletion in murine atherogenesis. The studies described in this thesis did not achieve the intended manipulation of macrophage HIF1 $\alpha$ expression in murine 
atherogenesis and future studies are warranted using models with sustained HIF1 $\alpha$ manipulation in chronic hypoxia were able to conclude that plaque hypoxia is independent of species, and subsequent plaque size, but depends on the high metabolic demand of the inflammatory microenvironment. Also, we discuss the potential of plaque angiogenesis and hypoxia as promising plaque imaging tools providing tailored risk assessments and to evaluate therapy efficacy after their sufficient validation.

We also observed that the compromised structural integrity of microvascular endothelium most likely explained microvascular leakage in human coronary atherosclerosis, instead of microvessel frequency. Thus, we speculated that antiangiogenic therapy may be best aimed at normalizing aberrant microvessel morphology, instead of preventing or eradicating angiogenesis. Although a causative effect of plaque angiogenesis, hypoxia nor HIF is currently unproven, these studies significantly advance our understanding of the formation and phenotype of plaque microvessels and provide a solid base for future research and therapy of atherosclerotic plaque growth and rupture. 


\section{Samenvatting}

Atherosclerose is een aandoening van de bloedvaten waarbij het aangedane bloedvat langzaam maar zeker afgesloten wordt. Dit wordt veroorzaakt door afzetting van vet, bindweefsel, cellen en weefsel debris (necrotische kern) in de vaatwand, wat samen een atherosclerotische plaque vormt. Als de plaque veel ontstekingscellen en een grote necrotische kern bevat en de bedekkende laag bindweefsel van een plaque erg dun is, is de kans groot dat de plaque openscheurt (plaque ruptuur). Hierbij ontstaat een bloedstolsel (thrombus), dat het bloedvat acuut kan afsluiten met mogelijk een hersen- of hartinfarct tot gevolg.

Ruptuur van een atherosclerotische plaque is dus de belangrijkste onderliggende oorzaak van acute hart- en vaataandoeningen. Behalve veel ontsteking, een grote necrotische kern en een dunne bindweefsellaag, is ook de aanwezigheid van heel kleine bloedvaatjes (microvaten) in de plaque bepalend voor plaque groei en ruptuur. In dit proefschrift zijn de mechanismen bestudeerd die de groei van microvaten in de plaque kunnen veroorzaken en daarnaast is de ultrastructurele morfologie van de microvaten onderzocht.

De meest voor de hand liggende verklaring voor de groei van microvaten is het gebrek aan zuurstof (hypoxie) in de plaque, omdat de belangrijkste functie van microvaten de aanvoer van zuurstof en voedingsstoffen betreft. Hypoxie stabiliseert een hypoxie-induceerbare transcriptiefactor (HIF). Deze transcriptiefactor zorgt voor de overleving van de cel in hypoxie door de stimulatie van HIF-afhankelijke genen die zuurstofonafhankelijk (anaëroob) metabolisme versterken en vorming van microvaten (angiogenese) stimuleren om aan de energie- en zuurstofbehoefte te voldoen. Genexpressie wordt doorgaans bestudeerd in atherosclerotische plaques verwijderd bij levende (operatie) of overleden donoren (autopsie), maar de zuurstofstatus en dus genexpressie kunnen verschillend zijn tussen plaques afkomstig van operatie of autopsie. Resultaten van microarray analyse, kwantitatieve PCR en immuunhistochemie in hoofdstuk 2 lieten zien dat de genexpressie in plaques afkomstig van autopsie and operatie grotendeels vergelijkbaar was, hoewel genexpressie gerelateerd aan hypoxie-induceerbare en basale cel processen verschillend was. Bij vervolgstudies werd de genexpressie in verschillende stadia van atherosclerose dus enkel vergeleken tussen plaques afkomstig van dezelfde bron.

De aanwezigheid van hypoxie werd vastgesteld in plaques van mens en muis met behulp van de hypoxie-specifieke merkstof pimonidazol (hoofdstuk 3 en 4). De aanwezigheid van hypoxie hing sterk samen met de expressie van HIF 
en HIF-afhankelijke genen, de aanwezigheid van microvaten en ontstekingscellen (macrofagen), maar niet met plaque dikte. Ook was er een positief verband tussen gen en eiwit expressie van HIF en HIF-afhankelijke genen, bestudeerd met microarray analyse, kwantitatieve real-time PCR en immuunhistochemie, en de mate van progressie, macrofaag infiltratie en angiogenese van humane atherosclerotische plaques (hoofdstuk 3).

In hoofdstuk 4 werd een functionele rol voor hypoxie en HIF in de ontwikkeling van atherosclerose bestudeerd door $\mathrm{apoE}^{-/}$muizen met gevorderde atherosclerose gedurende vier weken bloot te stellen aan $10 \%$ of $21 \%$ zuurstof. Daarnaast werd een macrofaag-specifiek effect van HIF en zijn regulator prolyl hydroxylase 1 (PHD1) bestudeerd met behulp van transplantaties van wildtype, LysMcre-HIF $1 \alpha^{-1-}$ en PHD1 ${ }^{-/}$beenmerg naar atherosclerose-gevoelige LDLR ${ }^{-}$muizen. Noch omgevingshypoxie, noch het ontbreken van HIF1 $\alpha$ en PHD1 in plaque macrofagen had een effect op plaque hypoxie, grootte en samenstelling in muizen. Na langdurige blootstelling aan hypoxie vertoonden wildtype, LysMcre-HIF $1 \alpha^{-/}$en PHD $1^{-/}$macrofagen in vitro vergelijkbare HIF1 $\alpha$ en HIF-afhankelijke gen expressie, vanwege verminderde HIF1 $\alpha$ expressie na langdurige hypoxie in wildtype macrofagen, herstel van HIF $1 \alpha$ expressie door incomplete HIF1 $\alpha$ deletie in LysMcre-HIF1 $\alpha^{-/}$macrofagen, en vanwege ontbreken van een effect van PHD1 op HIF1 $\alpha$ expressie. Daarbij was ook de HIF1 $\alpha$ expressie vergelijkbaar in plaques van muizen getransplanteerd met wildtype, LysMcre-HIF $1 \alpha^{-/}$en PHD $1^{-}$beenmerg. Dus vergelijkbare expressie van HIF1 $\alpha$ en HIF-afhankelijke genen in macrofagen na langdurige blootstelling aan hypoxie - zoals in plaque macrofagen - kan verklaren dat LysMcre-HIF1 $\alpha^{-/}$en PHD1 $^{-\leftarrow}$ beenmerg transplantaties geen effect hadden op de ontwikkeling van atherosclerose in de muis.

Naast de mechanismen die de groei van microvaten in de plaque kunnen veroorzaken, werd ook de ultrastructurele morfologie van de microvaten onderzocht. Niet de aanwezigheid van plaque microvaten per se, maar lekkage uit microvaten in atherosclerotische plaque is de vermeende bron van ontstekingscellen en cholesterolrijke rode bloedcellen. Dit verhoogt vervolgens vetstapeling, ontsteking, oxidatieve stress en celdood en deze processen dragen bij aan plaque groei en -ruptuur. In hoofdstuk 5 werd onderzocht of de ultrastructurele morfologie van de microvaten afwijkend was en de microvasculaire lekkage zou kunnen verklaren. Het ontbreken van microvaat versteviging door pericyten en een basaal membraan, en een gebrekkig of ontbrekend contact (junctions) tussen endotheelcellen, kan een verhoogde doordringbaarheid van microvaten voor ontstekingscellen en rode bloedcellen veroorzaken (microvasculaire lekkage). Dus werd in hoofdstuk 5 de 
microvaatdichtheid en ultrastructurele morfologie bestudeerd in de normale vaatwand en in de atherosclerotische plaque van coronair arteriën met behulp van immuunohistochemie en electronen microscopie. De microvaatdichtheid vertoonde een verband met progressie en samenstelling van plaques in de coronair arteriën, zoals eerder beschreven. De bekleding van microvaten door pericyten was incompleet in atherosclerotische, maar ook in normale coronair arteriën, en kan dus niet verantwoordelijk zijn voor microvaatlekkage in de atherosclerotische plaque. Daarentegen, vertoonden microvaten met electronen microscopie een abnormale morfologie, gekenmerkt door endotheelcellen met een zeer onregelmatig celmembraan oppervlak, ophoping van celblaasjes (vacuoles) in het cytoplasma, en gebrekkig/ontbrekend contact tussen endotheelcellen onderling en met het onderliggend basaal membraan. Dus de onvolledige structurele integriteit van het microvasculair endotheel kan de microvaatlekkage in humane atherosclerose in coronair arteriën verklaren.

In hoofdstuk 6 werden de resultaten uit de vier experimentele hoofdstukken besproken en in een breder theoretisch kader geplaatst. Deze studies toonden zowel hypoxie als HIF aan in atherosclerose als mogelijke oorzaak voor plaque angiogenese. Ondanks sterke aanwijzingen voor een functionele rol van hypoxie of HIF in progressie en angiogenese van de plaque, weten we nog steeds niet het exacte verband tussen deze factoren. Desondanks kan plaque hypoxie wel gebruikt worden voor non-invasieve beeldvorming van de plaque met verschillende reeds FDA-goedgekeurde hypoxie markers. Hypoxie detectie zal dus mogelijk een grote rol spelen bij de vroegtijdige opsporing van patiënten met een verhoogd risico op plaqueruptuur.

Deze resultaten vormen ook een belangrijke basis voor verder onderzoek naar de mechanismen van plaque angiogenese, zodat specifieke angiogenese therapie toegepast kan worden om plaque groei en ruptuur te verhinderen.

Naast kennis essentieel voor het ontwerpen van angiogenese therapie voor de reductie van plaque angiogenese, is specifiek de kennis over de gebrekkige structurele integriteit noodzakelijk voor therapie gericht op het verminderen van de microvasculaire lekkage. Uit deze resultaten bleek dat niet het aantal microvaten of hun bekleding met pericyten maar wel hun structuur een belangrijke verklaring is voor het verband tussen plaque angiogenese en plaque ruptuur. De resultaten van dit onderzoek vormen dus een belangrijk aangrijpingspunt voor het doel van angiogenese therapie, die mogelijkerwijs de groei en ruptuur van plaques zal verhinderen. 


\section{Full color figures}
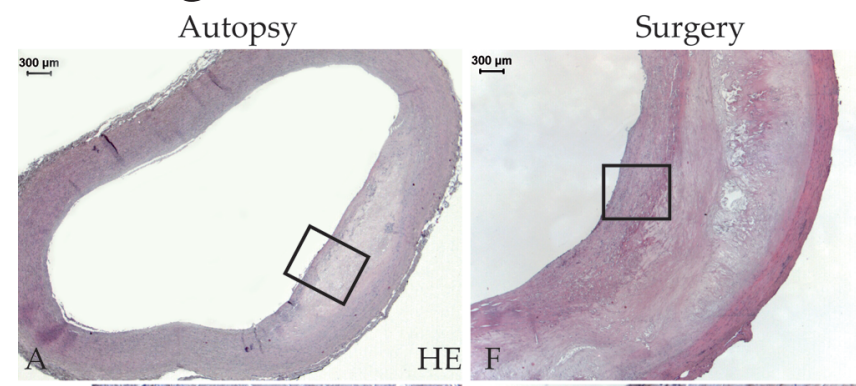

HE
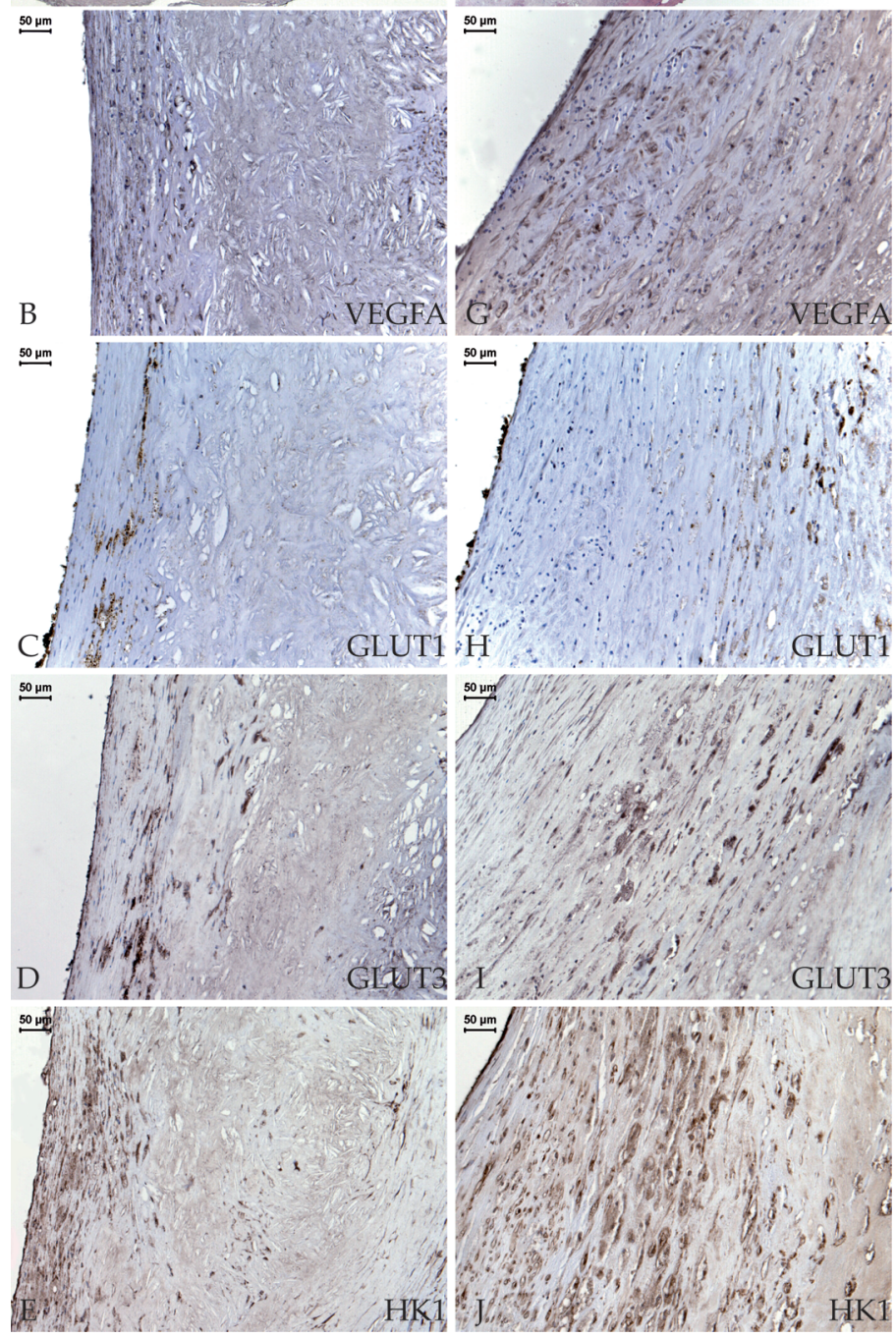

Figure 2.2 Immunohistochemical staining of proteins involved in hypoxia-driven pathways

Advanced lesions from autopsy (A-E) and surgery (F-J) were immunohistochemically stained and quantitative analysis showed similar immunoreactivity of VEGFA (B-G), GLUT1 (C-H), GLUT3 (DI), and HK1 (E, J) between autopsy and surgery. 

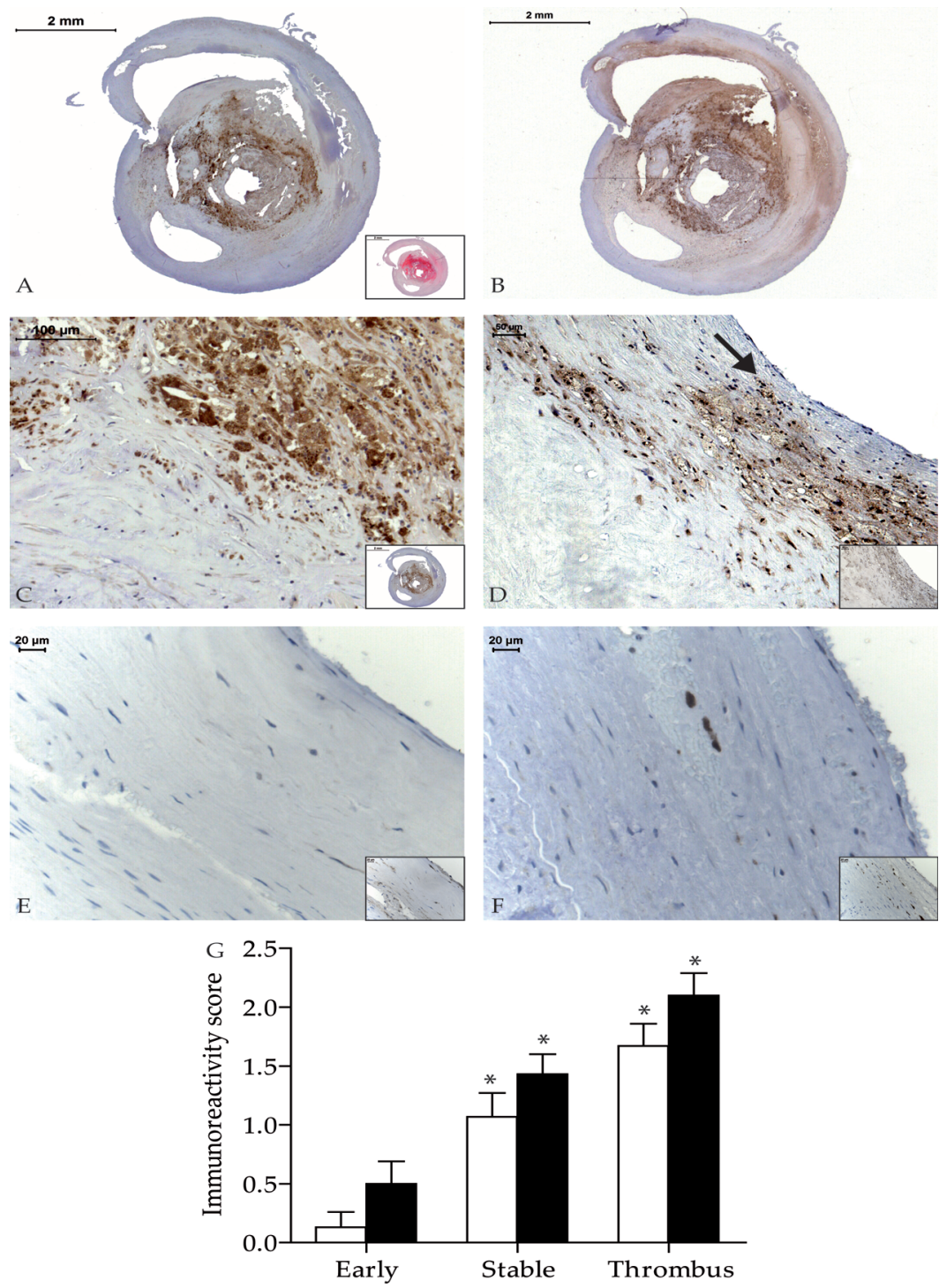

Figure 3.1. Hypoxia detection using pimonidazole in human carotid endarterectomy

A. Hypoxia (pimonidazole immunoreactivity) is present in the center of an advanced human carotid atherosclerotic plaque, but not in the media. Inset shows HE staining. B A serial section of A shows that CD68-positive macrophages co-localize with hypoxia. C. Macrophage regions of lesion A show extensive hypoxia, whereas the cap shows mild or no hypoxia. D. Hypoxia is present in CD68positive macrophages (inset) at 20-30 $\mu \mathrm{m}$ from the lumen. E. Hypoxia is absent in CD68-positive macrophages (inset) of a plaque shoulder segment (pathological intimal thickening). F. Hypoxia is present in an atherosclerotic plaque segment with intimal thickening, more specifically in a few CD68-positive macrophages (inset). L indicates lumen. G. The immunoreactivity score of hypoxia (white bars) and CD68 (black bars) is increased in stable and ruptured atherosclerotic lesions vs. early lesions. (p-value $<0.05$ vs. early, stable vs. ruptured is not significant) 

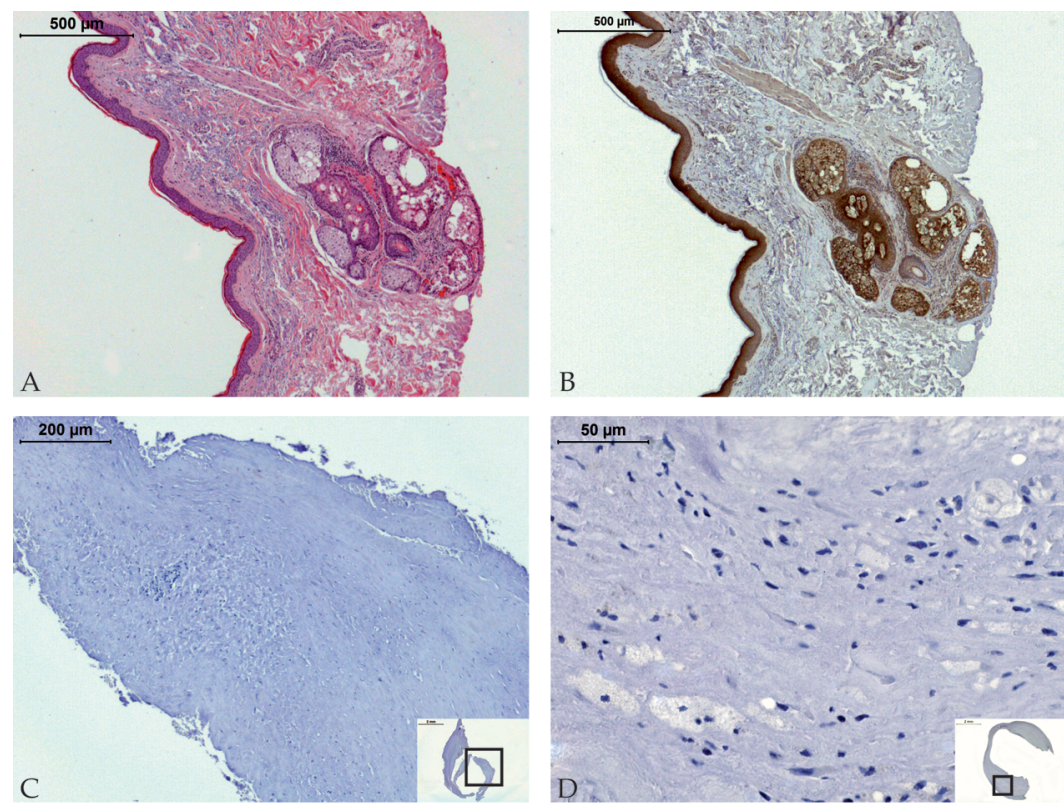

Figure 3.2. No pimonidazole immunoreactivity in control patients

A. Hematoxylin and eosin staining of normal skin at incision site. B. Hypoxia (pimonidazole immunoreactivity) is present in the epithelium, hair follicle and sebaceous gland of normal skin tissue, a positive control for pimonidazole infusion. C. No pimonidazole immunoreactivity was detected in the carotid atherosclerotic plaques of a patient without pre-operative pimonidazole injection. Inset shows origin of magnification. D. No pimonidazole immunoreactivity was detected in the macrophages of carotid atherosclerotic plaques of another patient without pre-operative pimonidazole treatment. Inset shows CD68 staining.

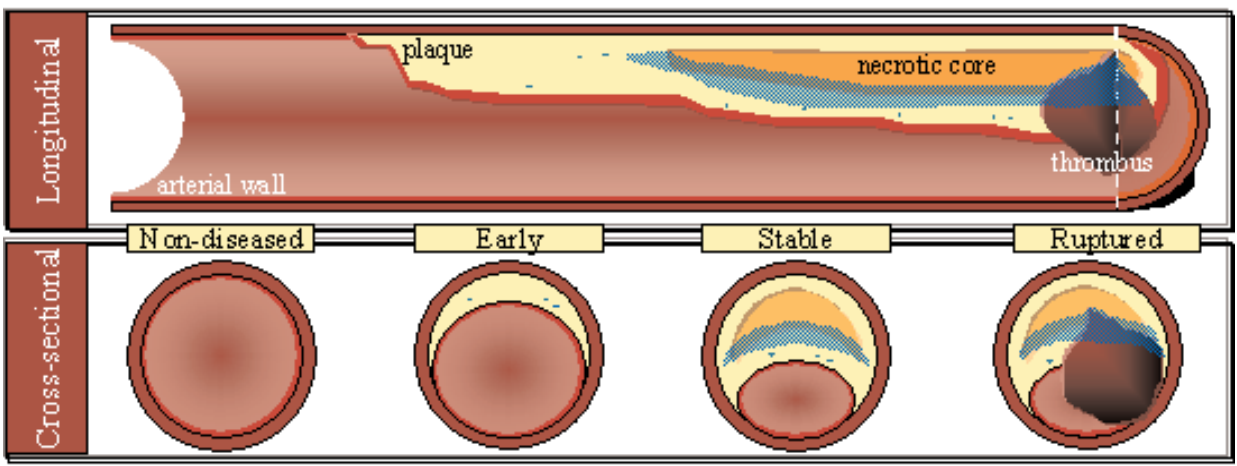

Figure 3.3. Schematic illustration of hypoxia in atherosclerosis

Illustration of the presence of hypoxia (blue areas) in a longitudinal and cross-sectional representation of atherogenesis. a.wall, arterial wall; nc, necrotic core; th, thrombus 


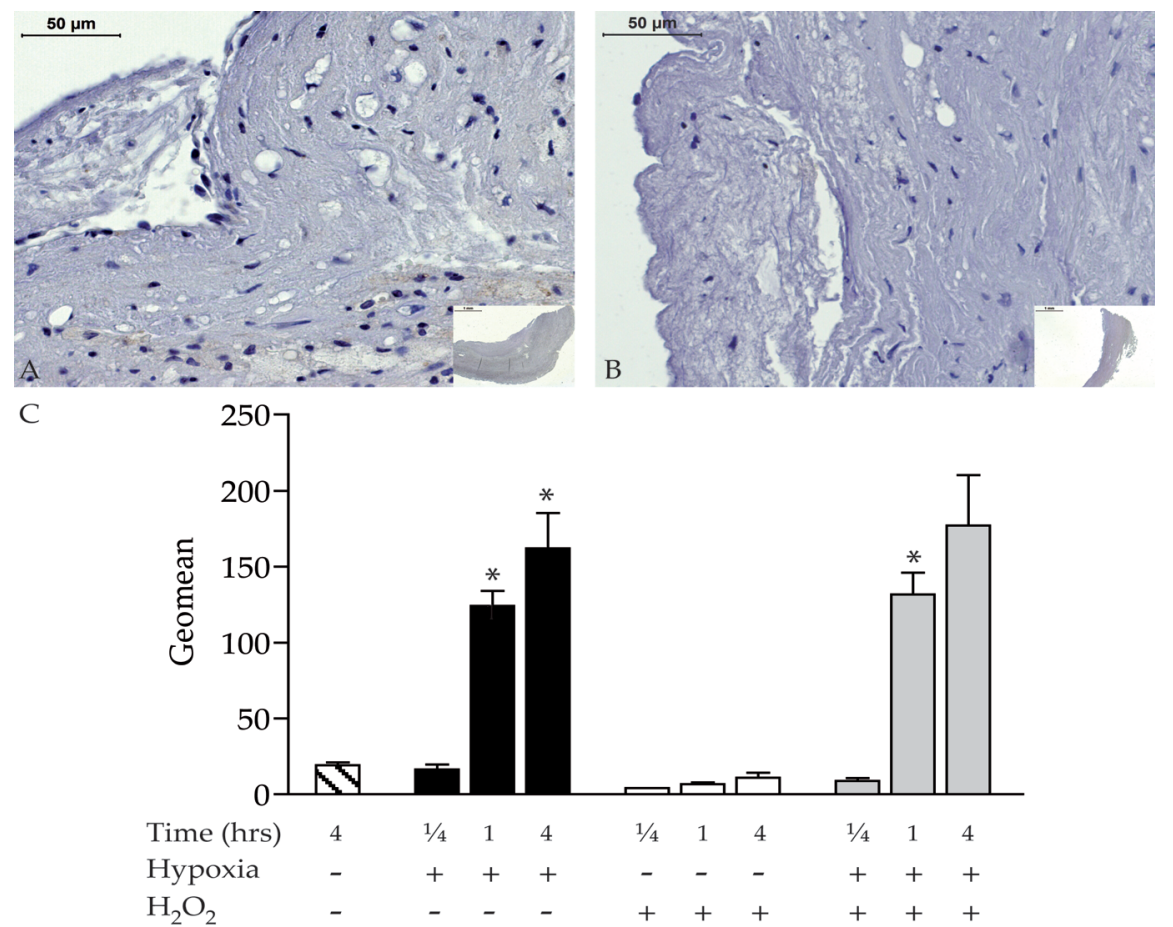

Figure 3.4. Hypoxia detection in arterial wall and human THP-1 macrophages

A. Hypoxia (pimonidazole immunoreactivity) is almost absent in the arterial wall collected right after carotid incision, as well as B. right after excision of the atherosclerotic plaque. Insets show origin of magnification. C. Pimonidazole was detected in human THP-1 macrophages in $0.2 \% \mathrm{O}_{2}$ (hypoxia) using FACS analysis (black bars), but was undetectable in $21 \% \mathrm{O}_{2}$ (black and white striped bars) or after $\mathrm{H}_{2} \mathrm{O}_{2}$ stimulus (white bars). No significant differences were found between single hypoxia and hypoxia $+\mathrm{H}_{2} \mathrm{O}_{2}$ exposure (grey bars). ${ }^{*}$-value $<0.05$ vs. $21 \% \mathrm{O}_{2}$ 

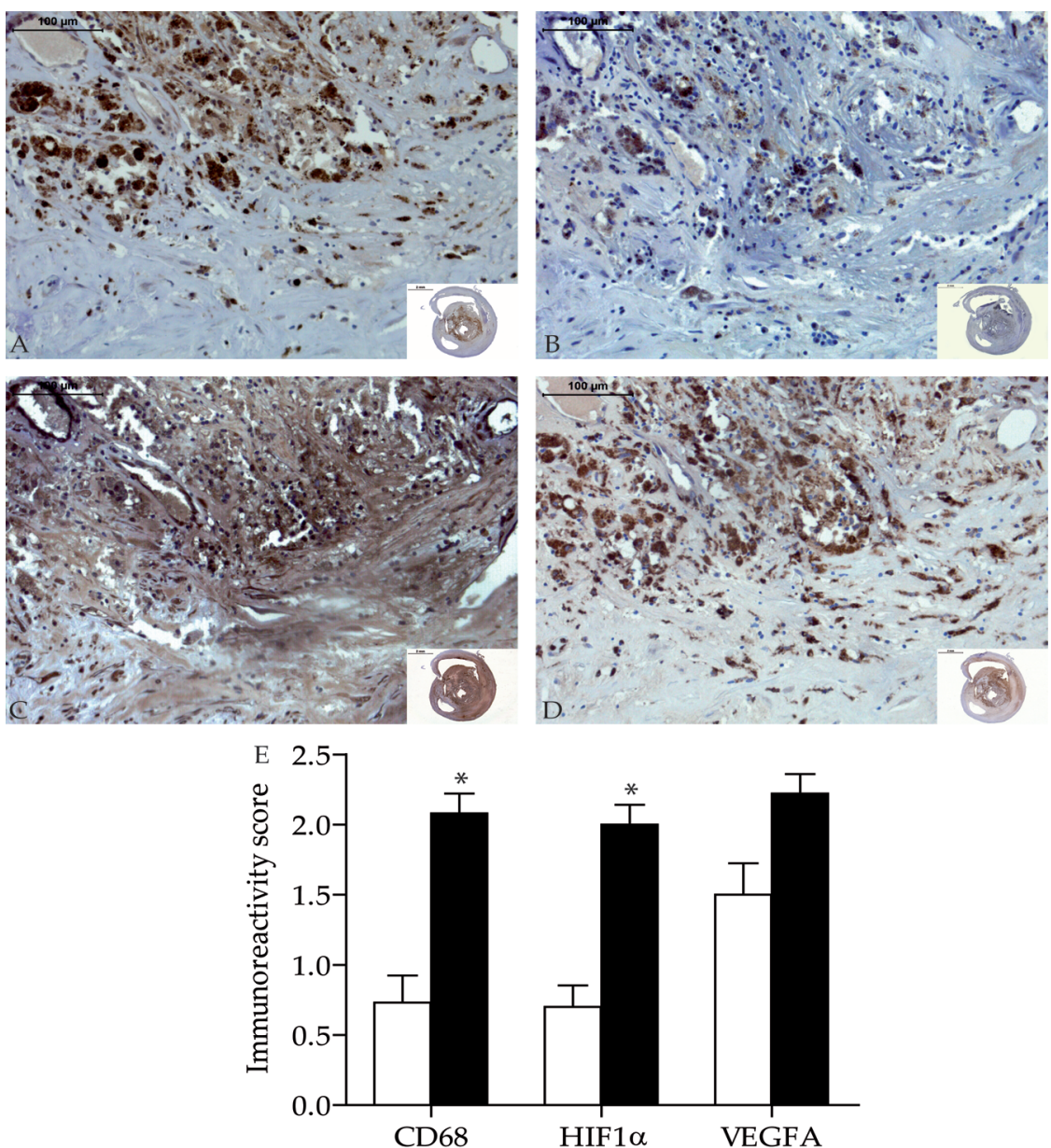

Figure 3.5. Hypoxia co-localizes with CD68, HIF and VEGF

A. Hypoxia detected by pimonidazole immunoreactivity in human carotid atherosclerosis. Serial sections show co-localization with B. HIF1 $\alpha$, C. VEGF and D. CD68-positive macrophages. E. The immunoreactivity score of CD68, HIF1 $\alpha$ and VEGF is increased when hypoxia is present (black bars) vs. absent (open bars) in human carotid atherosclerosis ( $\mathrm{p}$-value $<0.05$ ) 

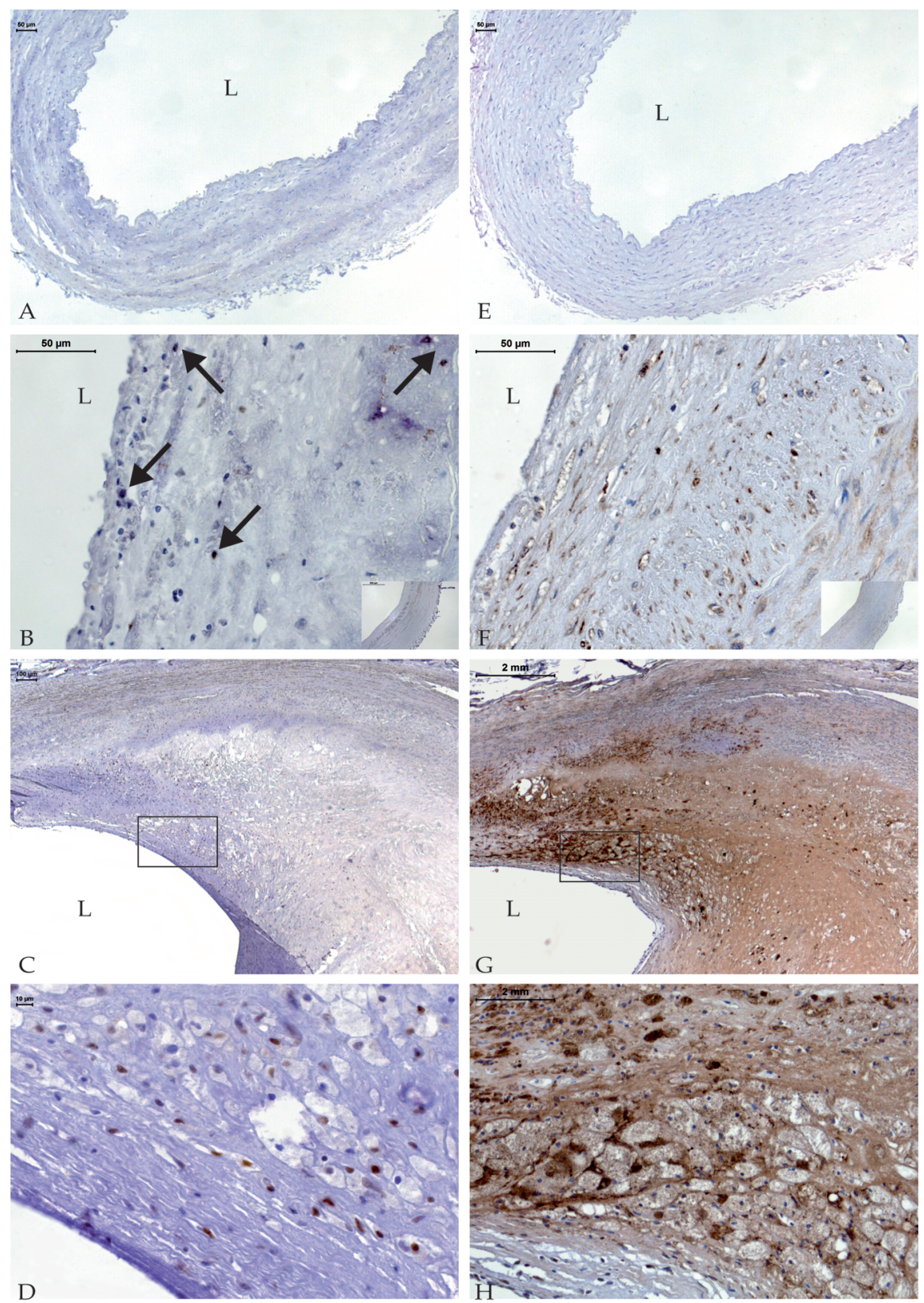

Figure 3.6. Immunolocalization of HIF1 $\alpha$ and $2 \alpha$ and responsive genes in human non-diseased and atherosclerotic vasculature.

Nuclear staining of HIF1 $\alpha$ (A-D) and HIF2 $\alpha$ (E-H) is absent in human mammary artery (A and E resp.,) and increased from early ( $\mathrm{B}$ and $\mathrm{F}$ resp.) to advanced carotid lesions ( $\mathrm{C}$ and $\mathrm{G}$ resp.). Macrophages in advanced lesions demonstrated strong HIF1 $\alpha$ (D) and $2 \alpha(\mathrm{H})$ expression. Nuclear immunoreactivity (functional protein levels) of HIF1 $\alpha$ and $2 \alpha$ are similar. L indicates lumen. 

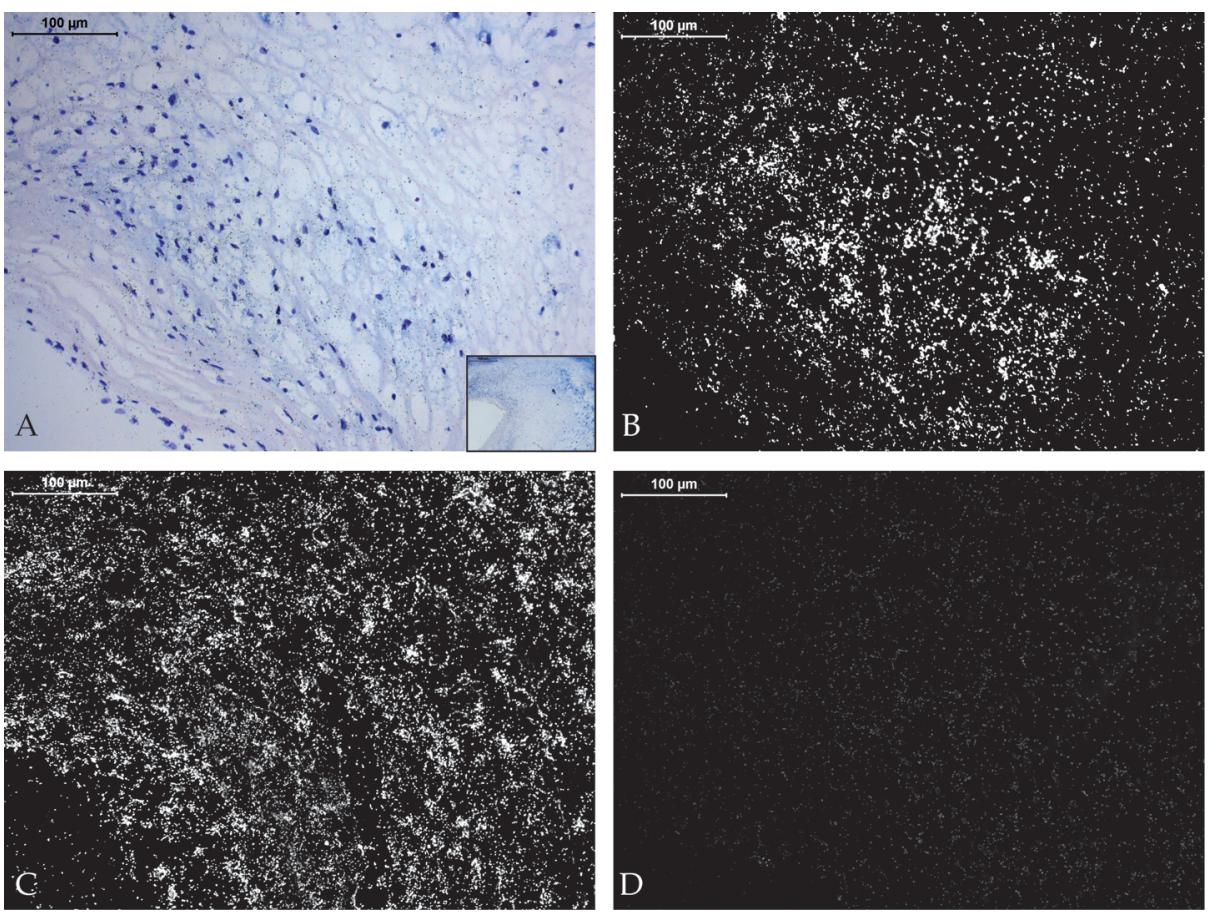

Figure 3.7. Cellular localization of HIF1 and 2 mRNA in advanced carotid lesion

A. Bright field images of human carotid with an advanced atherosclerotic plaque corresponding to dark field images B-C. Expression of HIF1 $\alpha$ (B) and HIF2 $\alpha$ (C) mRNA (white signal) was observed in macrophages surrounding the core and in the shoulder regions of advanced atherosclerosis. D. No signal is observed using sense probes (negative control) for HIF1 $\alpha$. L indicates lumen. 
Full color figures

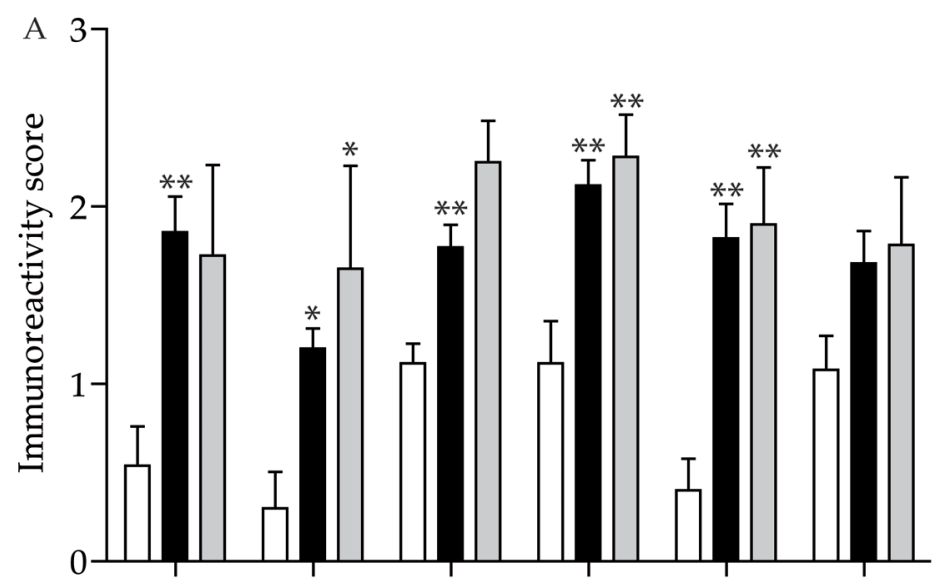

HIF1 $\alpha$ HIF2 $\alpha$ VEGFA GLUT1 GLUT3 HK1
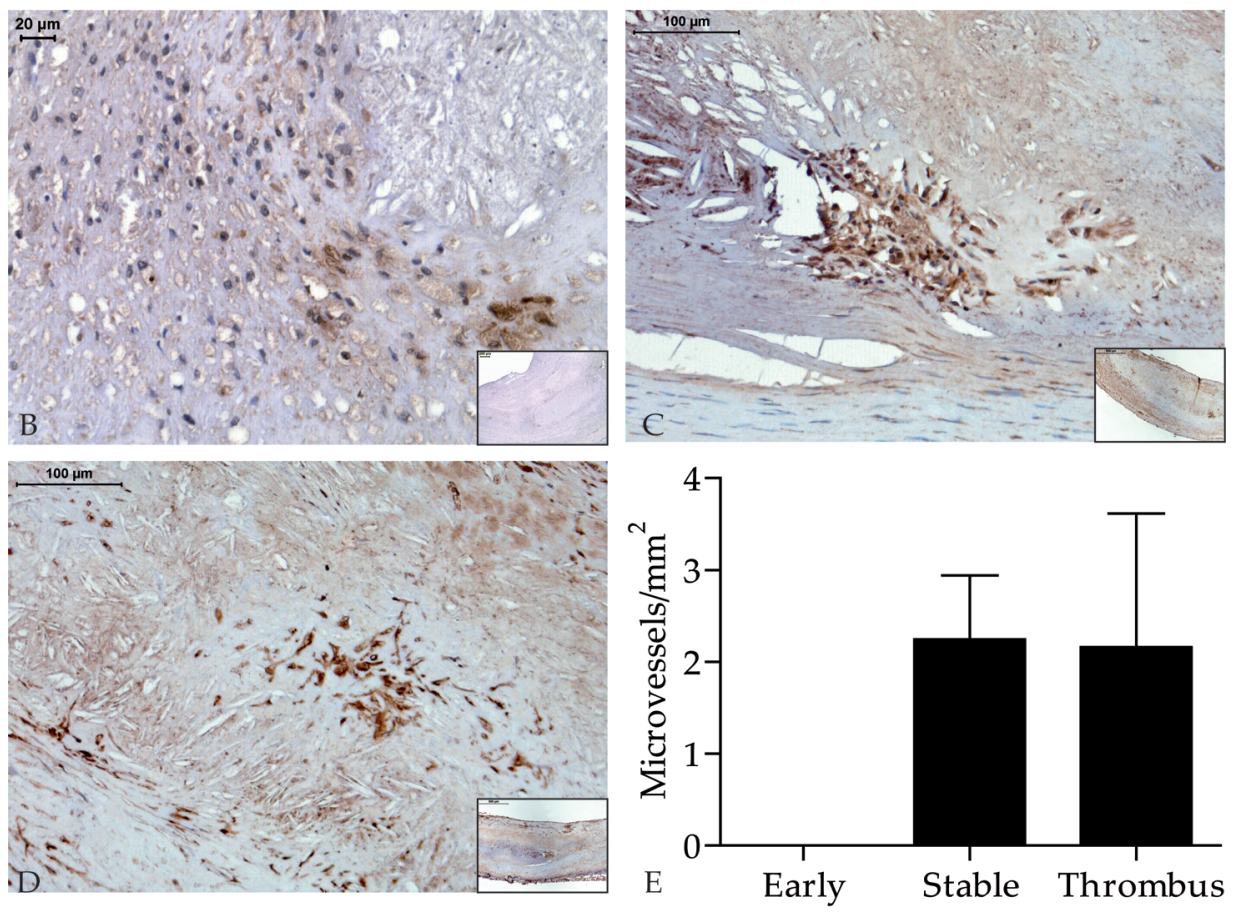

Figure 3.9. Semiquantification HIF pathway immunoreactivity in human carotid atherosclerosis

A. Immunoreactivity of HIF pathway proteins was significantly increased from early (white bars, $\mathrm{n}=5$ ) to stable lesions (black bars, $\mathrm{n}=5$ ) for HIF1 $\alpha$, HIF2 $\alpha$, VEGF, GLUT1 and GLUT3, but similar in stable and thrombus-containing lesions (grey bars, $\mathrm{n}=5$ ). ${ }^{*} \mathrm{p}<0.05$ vs. early; ${ }^{* *}<0.01$ vs. early. B. Macrophages in advanced lesions demonstrated strong immunoreactivity of HIF-responsive genes: VEGF (B), GLUT3 (C) and HK1 (D). L indicates lumen. E. Microvessel density was determined in 6 human carotid arteries with early (intimal thickening), 6 stable or 5 thrombus-containing atherosclerotic lesions. ${ }^{*} \mathrm{p}<0.01$ vs. early 

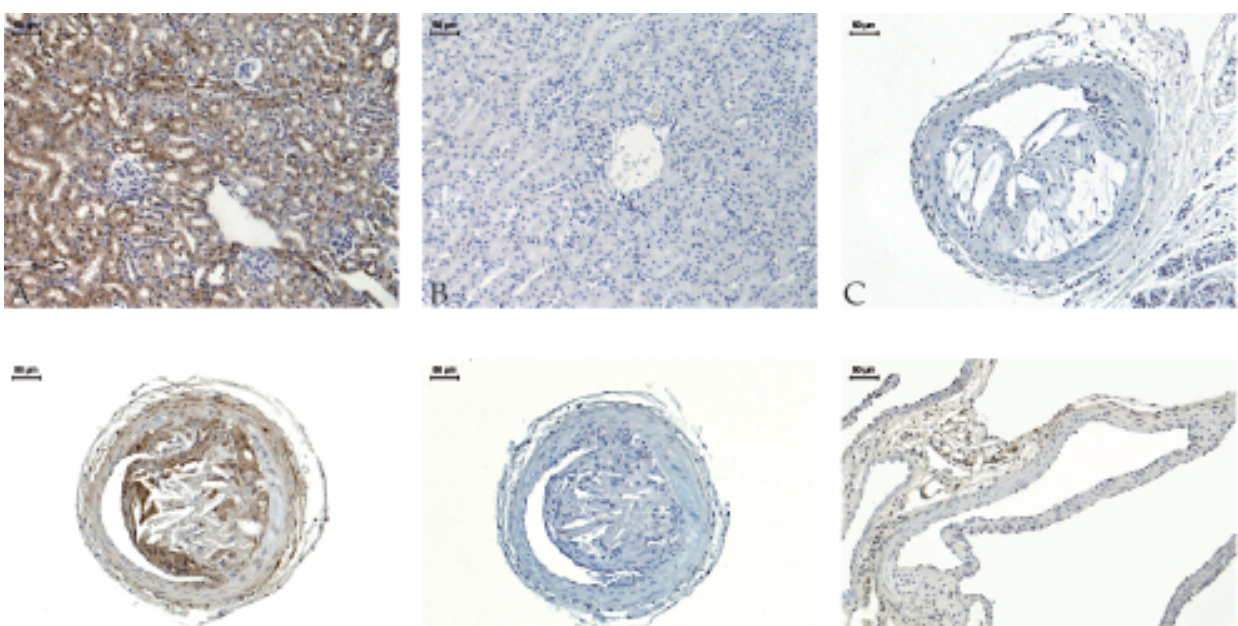

D

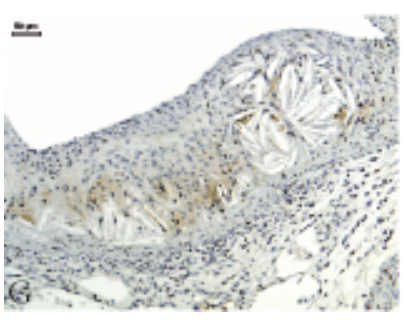

$=$

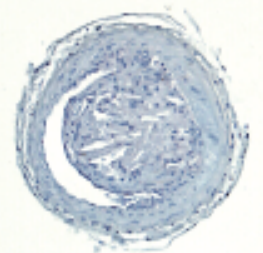

E

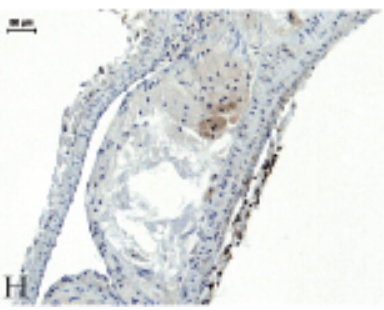

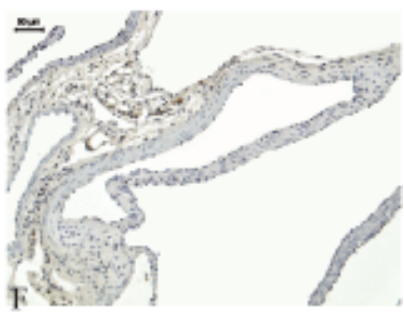

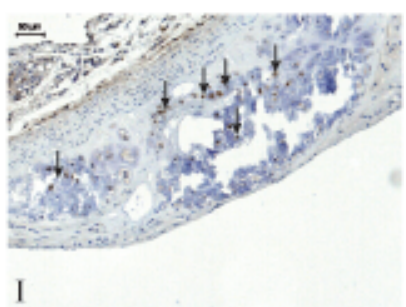

Figure 4.2 Hypoxia in murine kidney and plaques of different arterial sites

A. Hypoxia (anti-pimonidazole immunoreactivity in brown) was detected in the kidney of a pimonidazole-injected mice. B. Pimonidazole was absent in the kidney and C. collar-induced plaques in the carotid artery of mice without pimonidazole injection. D. Hypoxia was present in collarinduced atherosclerosis in the carotid artery of mice with pimonidazole injection, and E. absent in lesions not incubated with primary anti-pimonidazole antibody. F. No hypoxia was present in the non-diseased aortic root of a C57/BL6 mouse. G. Hypoxia was also present in the atherosclerotic aortic root and (H-I) brachiocephalic artery. Arrows indicate chondrocytes. 

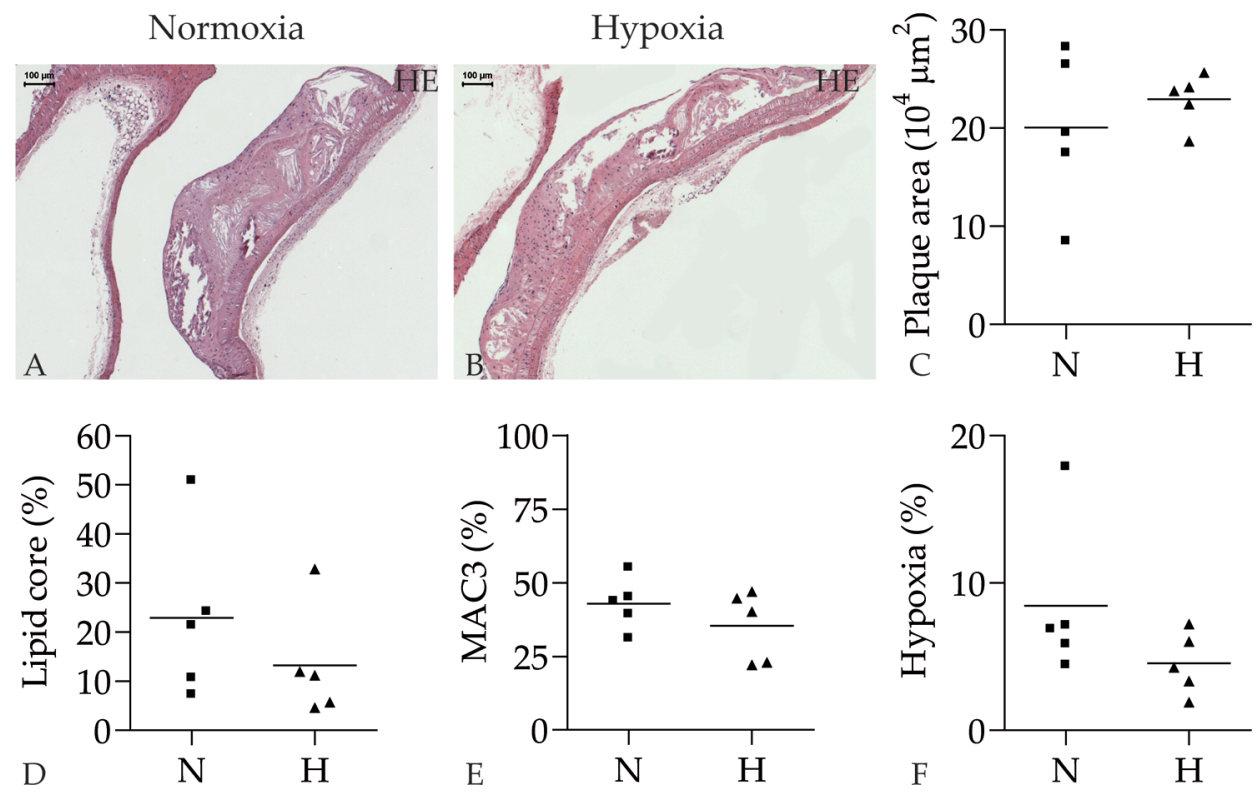

Figure 4.3 Hypoxic exposure of mice does not influence advanced atherosclerosis

A. Chronic exposure of $\mathrm{ApoE}^{-/}$mice with advanced atherosclerosis to regular oxygen $(21 \%, \mathrm{n}=5 \mathrm{mice})$ or B. low oxygen levels ( $10 \%, n=5$ mice) showed similar C. brachiocephalic plaque size, D. lipid core content, E. macrophage content, and F. hypoxic cell content. All p-values $>0.05$. 

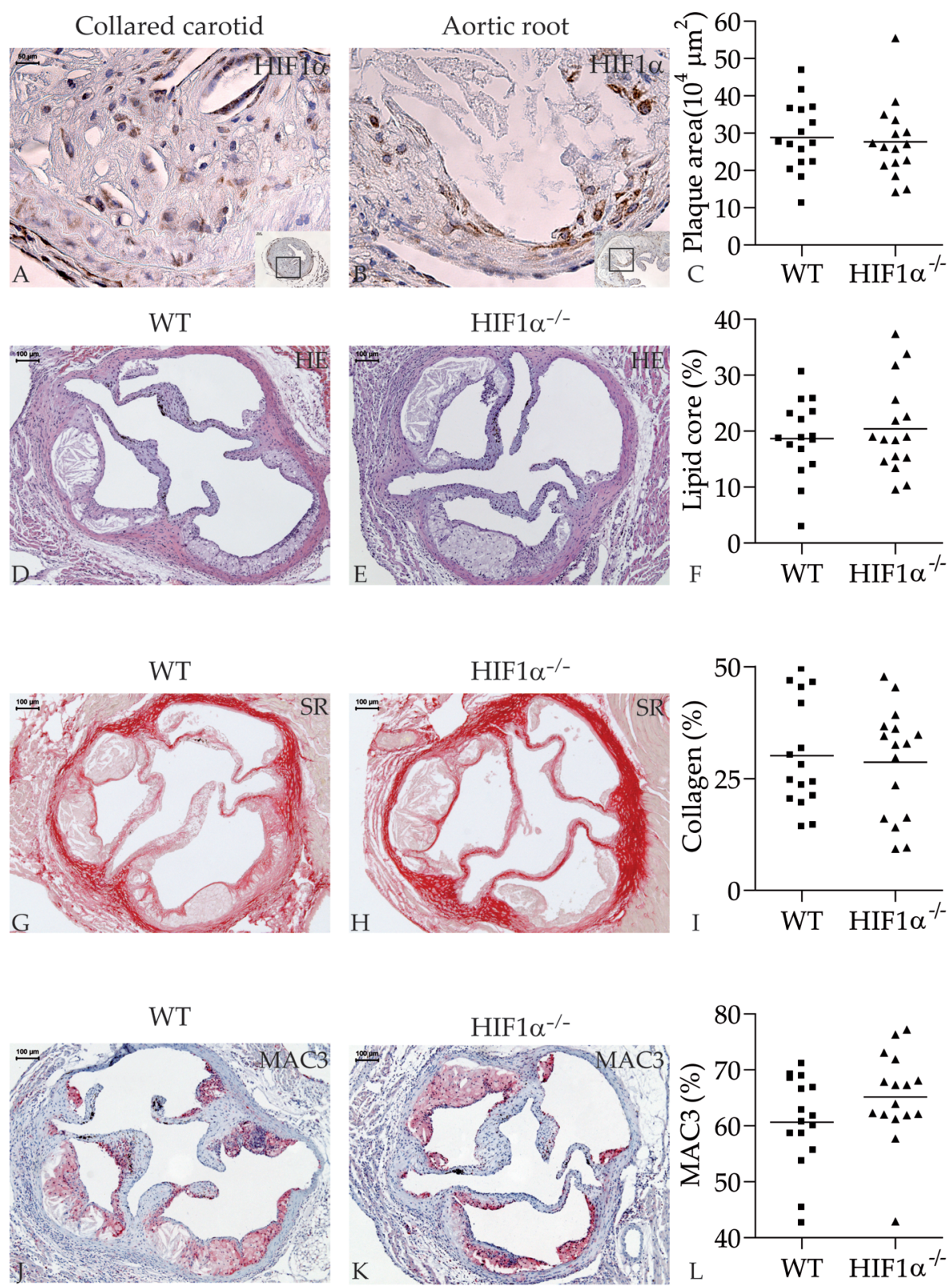

Figure 4.4 LysMcre/HIF1 $\alpha^{-1}$ BMT does not change murine atherosclerotic plaque size or composition A. Nuclear HIF1 $\alpha$ immunoreactivity (in brown) is present in macrophages and smooth muscle cells of collar-induced atherosclerosis and $\mathrm{B}$. in the atherosclerotic aortic root. Boxed regions in insets show origin of magnification. C. Plaque size of 16 WT (D, G, J) and 17 LysMcre/HIF1 $\alpha^{-1-}$ (E, H, K) recipients were similar, as well as F. lipid core, G-I. collagen content, and J-L. macrophage content (in red). All p-values $>0.05 ; \mathrm{HIF} 1 \alpha^{-1 /}$ indicates lysMcre/HIF $1 \alpha^{-1}$. 


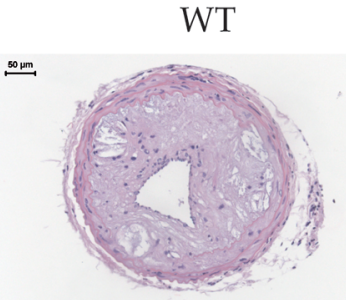

A
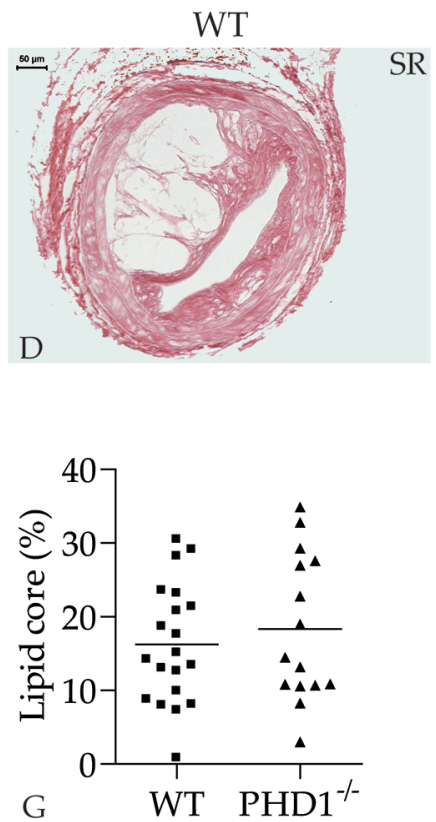

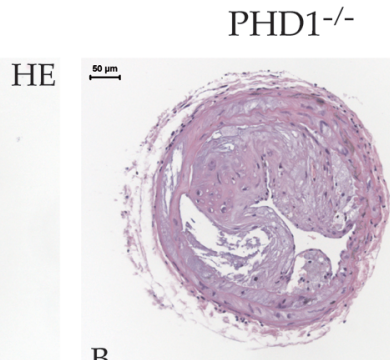

B
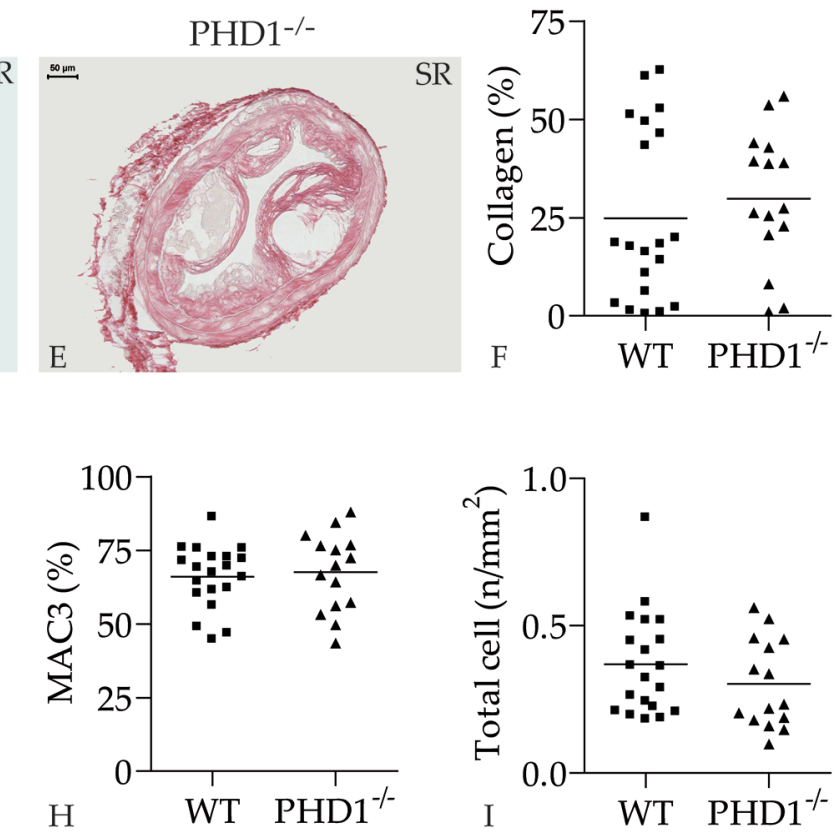

Figure 4.5 PHD1 $^{-/}$BMT does not change murine atherosclerotic plaque size or composition

A. HE staining of representative collar-induced plaques in the carotid artery of WT and B. PHD1 ${ }^{-1}$ transplanted mice. C. Plaque volume, D. lipid core content, E. macrophage content, and F. cell content of $22 \mathrm{WT}$ and $15 \mathrm{PHD}^{-}$recipients were similar. G. Sirius red (SR) staining of WT and H. $\mathrm{PHD}^{-}$transplanted mice, showing that I. collagen content was similar. Abbreviations indicated in text. All p-values $>0.05$ 

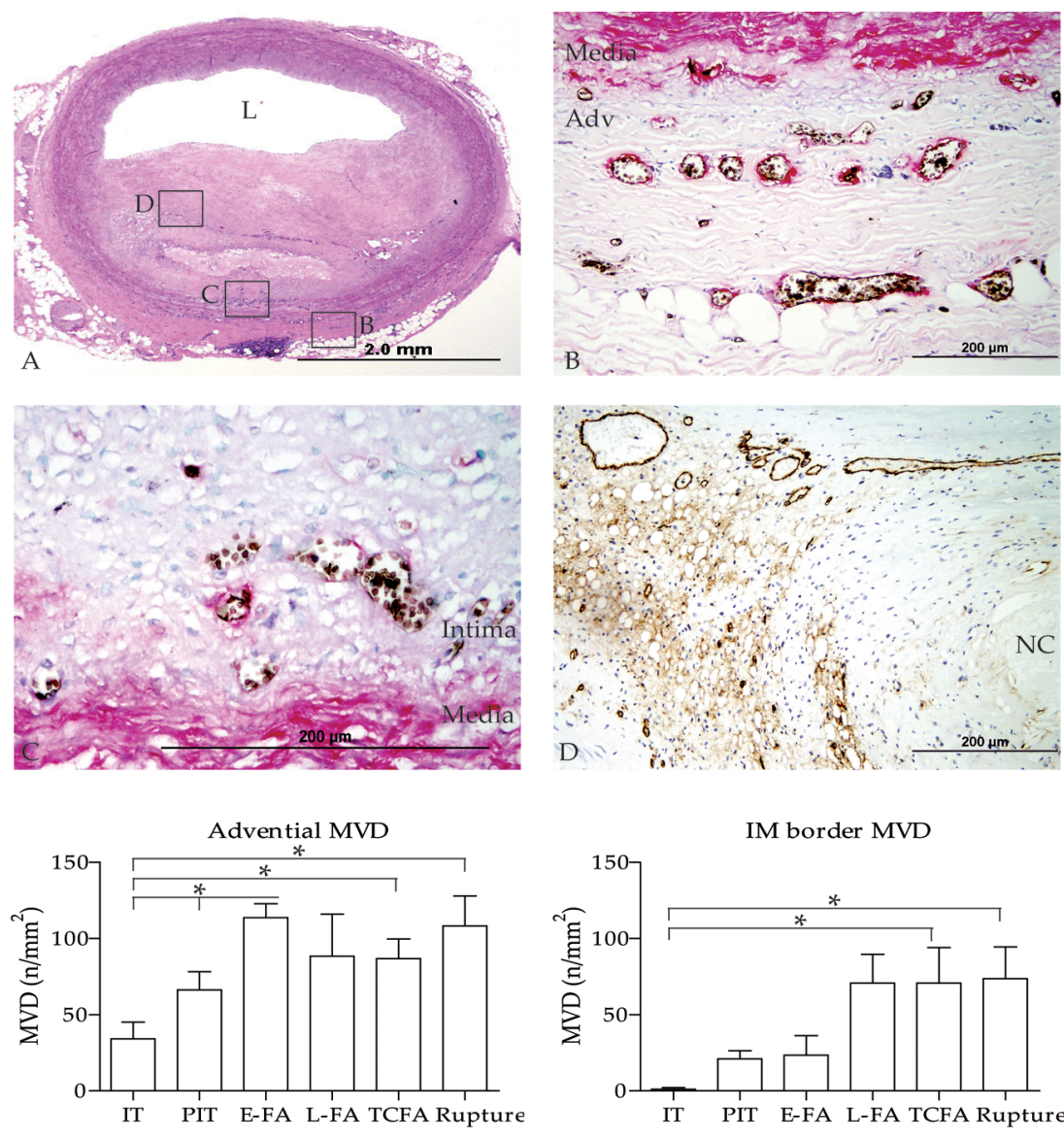

$\mathrm{E}$

F
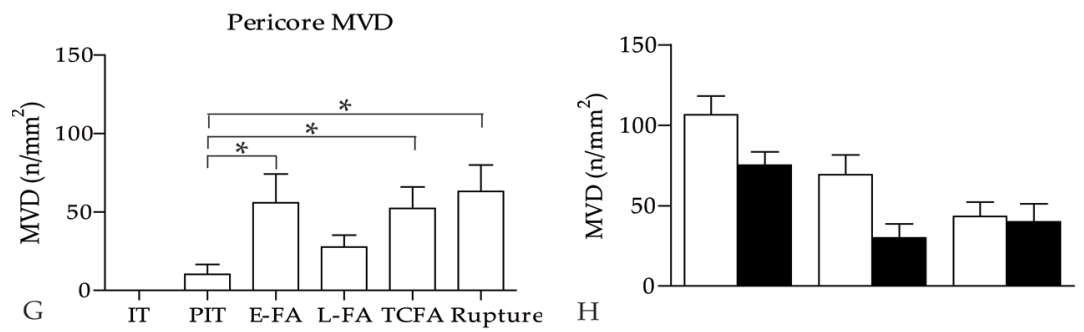

Figure 5.2. Microvessel density increases with atherosclerotic progression

A. Hematoxylin and eosin stained coronary artery with thick cap fiboratheroma (L indicates lumen). Boxed regions B-D are shown in more detail in corresponding photographs. B. Adjacent section of fibroatheroma in A double-stained with Ulex lectin-1 (black) and SMA (red) showing a minority of microvessels with mural cell coverage in the adventitia and C. in the IM border. D. Adjacent section of fibroatheroma in A stained with CD31/CD34 cocktail (brown) showing microvessels pericore (NC indicates necrotic core). E. Mean microvessel density was quantified in adventitia, F. in the IM border, and G. pericore, and increased with progression. H. Microvessel density is higher in concentric (open bars) than in eccentric (black bars) plaques. * indicates p-value $<0.05$ 

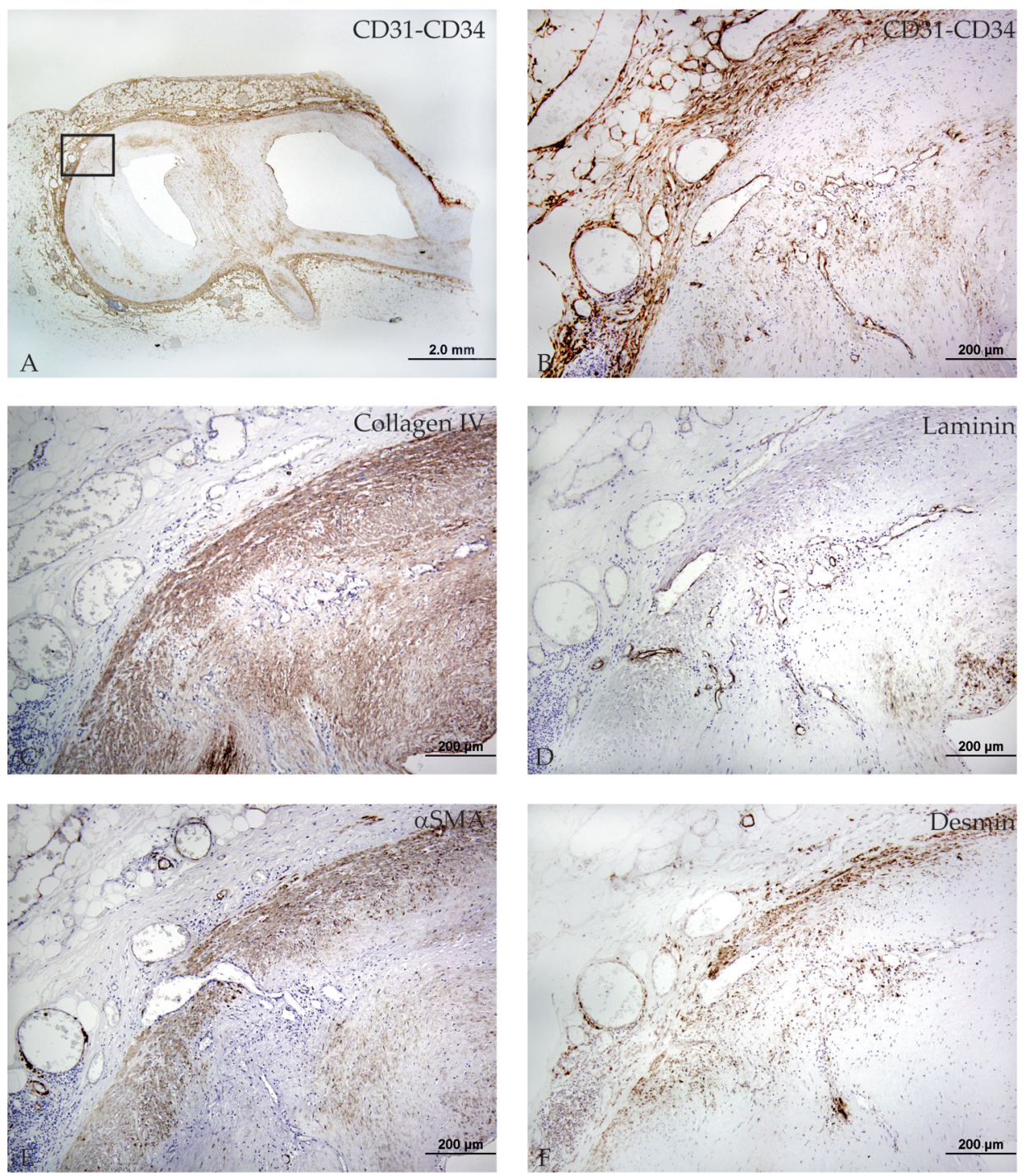

Figure 5.3. Basement membrane is intact, but mural cell coverage is low in normal and atherosclerotic coronary arteries

A. Coronary artery with fibroatheroma stained with CD31/CD34 cocktail. Boxed region shows origin of magnification of $\mathrm{B}$. showing $\mathrm{CD} 31^{+} \mathrm{CD} 34^{+}$microvessels running from the adventitia through the media into the plaque. C. Adjacent section stained with laminin showing intact laminin ${ }^{+}$microvessel $^{-}$ basement membrane in the adventitia, IM border and plaque. D. Adjacent section stained with collagen IV showing intact collagen $\mathrm{IV}^{+}$microvessel basement membrane in adventitia, IM border, and plaque. E. Adjacent section stained with $\alpha$ SMA showing mostly $\alpha$ SMA- microvessel in the adventitia, IM border and plaque. F. Adjacent section stained with desmin showing some desmin ${ }^{+}$ microvessel in the adventitia, IM border and plaque. 

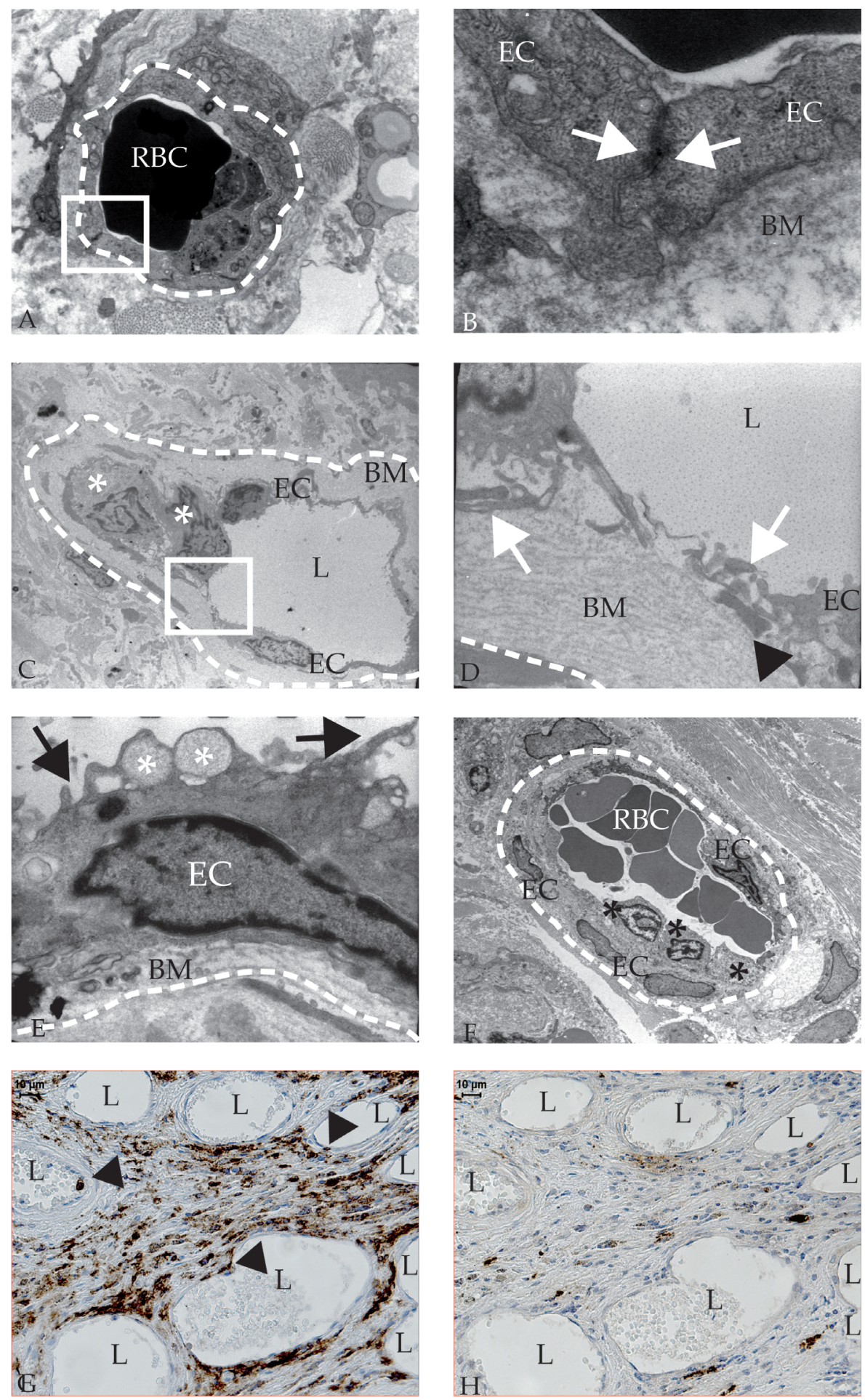
Figure 5.5. Intraplaque microvessels show abnormal EC morphology, aberrant EC junctions, and leukocyte infiltration as demonstrated by electron microscopy

A. Ultra structure of a microvessel (circumference indicated by white dashed line) with luminal red blood cell (RBC) obtained with electron microscopy (magnification 2650x) B. Magnification of the boxed region in A of microvessel with intact basement membrane (BM) and inter-endothelial junction indicated by closed contact (white arrows) between endothelial cells (EC) (magnification 15500x) C. Ultra structure of an intraplaque microvessel with leucocytes (white asterisks) (magnification 650x) D. Magnification of the boxed region in C of intraplaque microvessel lacking junction, shown by absent inter-EC contact (white arrows). EC show basement membrane detachment (black arrowhead) (magnification 4600x) E. Ultra structure of an EC in an intraplaque microvessel (magnification 6300x) showing features of dysfunction: membrane blebs (black arrow), and intracytoplasmic vacuoles (white asterisk) F. Leukocytes (arrowhead) adhering to intraplaque microvessel endothelium (magnification 460x) G. Immunohistochemistry shows CD45 ${ }^{+}$cells in and near microvessels. H. Immunohistochemistry does not show mast cells $\left(\mathrm{MCT}^{+}\right)$in microvessel, but only at larger distance from microvessels. L indicates lumen.

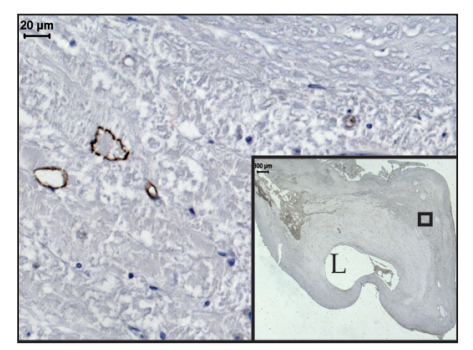

Figure 6.2 Intraplaque lymphatics in human carotid artery

Podoplanin immunoreactivity (D2-40 antibody) shows intraplaque lymphatics in human carotid artery. Boxed region in inset shows origin of magnification. L, lumen 
Full color figures 209 


\section{Bedankt!}

Promotor prof. Mat Daemen, beste Mat, een betere promotor had ik me niet kunnen wensen! Je was altijd zeer betrokken, opmerkzaam, humoristisch en stimulerend (of kalmerend waar nodig), maar ook een fantastische strateeg. ' $t$ waren enerverende jaren met vooral hoogte- en dieptepunten en weinig kalm vaarwater, geheel in lijn met mijn karakter volgens jouw analyse. Mat, een goede mentor onderscheidt zich juist in turbulente tijden. Dus, zoals afgesproken tijdens een mistige autorit naar Groningen, is 't niet "zomaar" een boekje geworden, maar een mooi boekje! De laatste jaren hebben we het helaas zonder AP's hulp moeten stellen, maar ondanks je drukke agenda was je altijd per mail of real-life beschikbaar. Je hebt me ontzettend veel geleerd over wetenschap en mezelf, en me vele (inter)nationale kansen gegeven. Dankzij jou heb ik nu de beste bagage om een wetenschappelijke carrière te beginnen. Dank!!

Co-promotor Dr. Ann Pascale Bijnens, beste AP, bedankt voor je enthousiasme, inzet en alle steun. Ik heb veel van je geleerd bij het gezamenlijk bedenken, schrijven en opzetten van dit project in de zomer van 2004. Veel succes met je nieuwe carrière aan de Universiteit Hassselt, waar IP iets heel anders betekent dan "immunoprecipitation".

Dr. Sylvia Heeneman, beste Syl, je begeleiding in de eerste periode van mijn promotie-traject was erg prettig. Ook de laatste jaren kon ik altijd bij je terecht voor raad, een praatje en het kritisch lezen van manuscripten en projecten. Uiteindelijk hebben we zelfs gedeelde papers, ook al gaan ze niet over phage display.

Het hele stel cardio-chicks is al in menig dankwoord verschenen en ook hier kunnen ze niet ontbreken. Marjo, jouw brede kennis, kritische vragen en interesse in ieders project waren een goed voorbeeld. Proficiat met de Dekker beurs en je a.s. huwelijk. Linda, bedankt voor de geweldige hoeveelheid hulp! Jij hebt je echt onmisbaar gemaakt bij de pathologie en bent de drijvende kracht achter veel feestjes. Natasja, verteller van de long-version, kei in het lab en recordhouder van 's werelds keurigste bench. Veel succes in de toekomst. Suzanne, multi-talent en multi-tasker ten top. Gelukkig heb je na jaren multitasken weer een project erbij: de organisatie van jullie bruiloft. Kitty, je was de sympathieke, stabiele factor in het kippenhok, en stimmung-verhogend op veel feestjes. Succes bij Medtronic. 
De "nieuwe" AIO's, Lili, Dirk, Wouter, Isabelle, Indira en David: thanks for still allowing the last old AIO chick in the AIO-room and good luck with all your PhD projects! Mathijs, Chantal en Jeffrey: zonder jullie hulp was hoofdstuk 4 een stuk kleiner, bedankt!! Jack, Esther, Kitty C., Carine, Mat Rousch, Anique, Erik, Veronica, Ine en Erwin fijn dat ik bij jullie terecht kon voor alle "tips and tricks". Birgit, jij was m'n voorbeeld van "de aanhouder wint", en samen met Ruben en Christine, toffe mede-phage displayers. Barry, je stond altijd klaar bij alle lab/computer problemen. Alle overige ex-cardio's, Anouk, Cherida, Petra A, Wanwissa, en Coby, waren erg prettige collega's. Ook kamergenoot Femke en alle andere angio+colon (ex)AIO's bedankt voor jullie gezelligheid en interesse. Robert-Jan, Benoit en Ruud: leuk die (on)gein in de gang! (RJ de opties uit 1999 zijn nu echt verlopen.) Ton de Goeij, mijn 1ste patho-mentor, ik keek altijd uit naar ons jaarlijks kerst-borrel gesprek. Cor, Elly en alle dames van het secretariaat: bedankt voor alle hulp!

Ook binnen en buiten de UM/AZM ben ik veel mensen dankbaar voor hun betrokkenheid. Job van Wanroij: onze morgenstond had pimonidazole in de mond. Ik heb je enthousiaste hulp bij de opzet en uitvoer van het project en je betrokkenheid bij het manuscript erg gewaardeerd. Brad Wouters, I really appreciated your great ideas and contributions to the manuscript! Menno de Winther, bedankt voor je expertise bij de beenmerg-transplantaties. Luuk van den Akker, medewerkers van de OK, verpleegafdeling en de KNF: bedankt voor jullie begrip en behulpzaamheid. Ook de patiënten wil ik bedanken voor hun medewerking aan het hypoxie onderzoek. Peter Frederik, Hans Duimel en Victor van Hinsbergh, ik stel jullie aandeel in de (interpretatie van de) EM-plaatjes en de kritische noot bij het manuscript op prijs. Hans, óók je hulp bij het boekje was erg goed! Maarten Sollewijn-Gelpke bedankt voor de analyse van de microarrays en medewerkers van het CPV: Rik, Richard, Paulien, Anouk, Mandy, Huub, Sytske, Allard en Nadine voor het verzorgen, fokken, en opereren van de proefdieren.

Ton en Margo, bedankt voor het begrip, luisterend oor en het aanreiken van betere tools voor de toekomst.

The following international collaborators gave me the opportunity to spend time in their labs and countries. At the collège de France in Paris I'd like to thank dr. Jean-Marie Gasc and Prof. Pierre Corvol for an instructive, pleasant, and fruitful stay. JM, your curiosity started this entire project and proposition 7 is for you! Marcu(úúú)s, Marie-Thérèse, François, Annie, Raph, Said and Ferdi you were responsible for the great time in Paris and/or New York. My gratitude extends to 
dr.'s Renu Virmani and Frank Kolodgie at CVPath, USA, for the great opportunity to participate in your efficient organization, for "Virmani classification 1.01" and collecting some fantastic data. Lila, Michael, Heddie, Carol, Kristi, Kim, Erica, Bob and Russ thanks for all the help and the warm welcome in the lab.

Gelukkig was er ook ontspanning naast het harde werken! Paranimfen Veerle en Mirjam, ik ben hartstikke trots om mijn nieuwste en oudste vriendin aan mijn zij te hebben. Veerle, je hebt alle highs en lows in de afgelopen jaren van zo dichtbij meegemaakt: het kon niet anders dan dat jij mijn paranimf was. Ik bof met jou als vriendin! Heel veel succes met afronden van jouw promotie, maar met deze topdata moet dat makkelijk lukken. Mir, je bent 'n lieve, chaotische, en trouwe vriendin. Ik geniet altijd enorm van je telefoontjes (of lange voicemails) en onze logeerpartijen. Je herkent in het lekenpraatje hopelijk meer dan "..plaque.." zoals bij m'n presentatie in A'dam.

"De meiden", Céline, Marret, Audrey en Penny: kletsen, lachen, gieren, brullen, alles kan. Waar vind je dat nog? Jullie (en de rode draad-wijsheden) maken alle meidenweekendjes tot een feest, dus plannen we er snel weer één?! Cé, jij staat altijd voor me klaar: een fijn gesprek (mét capuccino) of een bed en-route, wat een vriendin! Tijdens de afgelopen jaren waren de vele lunch, sport-, dans-, en eet-dates met Mirian, Linda Bekebrede en Liselotte ook heel belangrijk voor me. Mir, onze salsa-reis is een mooie herinnering.

Steven ${ }^{1}$-Dennis ${ }^{2}$-en-Martijn ${ }^{3}$, lange tijd als één woord en synoniem voor de perfecte man, maar ieder afzonderlijk zijn jullie geweldige mannen. Jullie stonden garant voor legendarische tijden op cursus ${ }^{123}$, in de $\operatorname{kroeg}^{123}$ of in de ... 3 , IL FAUT DANSER. Twan, de vierde kookclub chef, bedankt voor alles!! Heel veel succes voor jou en Chantal in Toronto.

Pap en mam, jullie onvoorwaardelijke liefde en steun zijn onmisbaar. Bedankt ook voor alle hulp als ik (alwéér) verhuisde! Mam, jouw levensmotto over het hart is het mijne geworden. Lieve zus en a.s. schoon "bro", wat een eer, dat ik letterlijk van jullie liefde mag getuigen. Es, je hebt alweer een baco-tje verdiend!! Martine, Jean and Ruth, fijn om als "schone" zó welkom te zijn.

Lieve Steven, mijn stoere prince charming op een stalen ros, je bent grappig, oneindig loyaal, de beste sport-coach én lekker duidelijk. Kortom: dat past precies! 
Date and place of birth: 22-03-1977, Rotterdam

Education and professional appointments

$\begin{array}{ll}1989-1995 & \text { Christelijk Lyceum, Gouda, The Netherlands } \\ & \text { Gymnasium } \\ & \text { Maastricht University, Maastricht, The Netherlands } \\ & \text { Faculty of Health Sciences, Biological Health } \\ & \text { Sciences, MSc } \\ & \text { University Hospital Maastricht } \\ & \text { Dept. of Orthopaedics, Maastricht, The Netherlands } \\ & \text { Clinical Research Manager } \\ & \text { Maastricht University } \\ & \text { Dept. of Pathology, Maastricht, The Netherlands } \\ & \text { PhD student } \\ & \text { Columbia University } \\ & \text { Dept. of Medicine, New York, USA } \\ & \text { Post-doc }\end{array}$




\section{Scientific output}

1. Sluimer JC, Kisters N, Cleutjens KB, Volger OL, Horrevoets AJ, van den Akker LH, Bijnens AP, Daemen MJ. Dead or alive: gene expression profiles of advanced atherosclerotic plaques from autopsy and surgery. Physiol Genomics, 2007. 30(3): 335-41.

2. Sluimer JC, Gasc JM, Wanroij JL, Kisters N, Groeneweg M, Sollewijn Gelpke MD, Cleutjens JP, Van den Akker LH, Corvol P, Wouters BG, Daemen MJ, Bijnens AP. Hypoxia in human atherosclerotic plaques is correlated with the expression of CD68, HIF and VEGF and the presence of a thrombus and angiogenesis. J Am Coll Cardiol, 2008 51(13):1258-65.

3. Heeneman S, Sluimer JC, Daemen MJ. Angiotensin-converting enzyme and vascular remodeling. Circ Res, 2007. 101(5): 441-54.

4. Sluimer JC, Gasc JM, Hamming I, Van Goor H, Michaud A, Van den Akker LH, Barry Jütten, Bijnens AP, Corvol P, Daemen MJ, Heeneman S. Angiotensin converting enzyme 2 (ACE2) expression and activity in human carotid atherosclerotic lesions. J Path (provisionally accepted)

5. Sluimer JC, Kolodgie F, Bijnens AP, Pacheco E, Duimel H, Frederik PM, Van Hinsbergh VWM, Virmani R, Daemen MJ. Infrequent pericyte coverage and clear structural abnormalities in intraplaque microvessels in human coronary atherosclerotic plaques. (submitted)

6. Sluimer JC, Beckers LB, Groeneweg M, Bijnens AP, Herias V, Lievens D, Lutgens E, De Winther M, Wouters, Daemen MJ. Hypoxia in murine plaque macrophages overrides the effect of HIF1 $\alpha$ and PHD1 deficiency on HIF protein expression and murine atherosclerosis. (submitted)

7. Sluimer JC, Daemen MJ. Hypoxia, HIF and angiogenesis in atherosclerosis. (in preparation)

8. Sluimer JC, Hoefnagels NH, Emans PJ, Kuijer R, Geesink RG. Comparison of two hydroxyapatite-coated femoral stems: clinical, functional, and bone densitometry evaluation of patients randomized to a regular or modified hydroxyapatite-coated stem aimed at proximal fixation. J Arthroplasty, 2006. 21(3): 344-52.

9. Gosens T, Sluimer JC, Kester AD, van Langelaan EJ. Femoral Fit Predicts Radiologic Changes, But Not Clinical Results, in Mallory-Head Total Hip Arthroplasties. Clin Orthop, 2005(432): 138-147.

10. Brunenberg DE, van Steyn MJ, Sluimer JC, Bekebrede LL, Bulstra SK, Joore MA. Joint Recovery Programme Versus Usual Care: An Economic Evaluation of a Clinical Pathway for Joint Replacement Surgery. Med Care, 2005. 43(10): 1018-1026. 
11. Jaumot M, Yan J, Clyde-Smith J, Sluimer JC, Hancock JF. The linker domain of the Ha-Ras hypervariable region regulates interactions with exchange factors, Raf-1 and phosphoinositide 3-kinase. J Biol Chem, 2002. 277(1): 272-8.

12. Prior IA, Harding A, Yan J, Sluimer JC, Parton RG, Hancock JF. GTP-dependent segregation of $\mathrm{H}$-ras from lipid rafts is required for biological activity. Nat Cell Biol, 2001. 3(4): 368-75.

13. Jonkers D, Sluimer JC, Stobberingh E. Effect of garlic on vancomycinresistant enterococci. Antimicrob Agents Chemother, 1999. 43(12): 3045.

\section{Grants and awards}

2008

2007

2006

2006

2005

2004

1999
Rubicon (24 months)

Netherlands Organization of Scientific research (NWO)

Prof. dr. I. Tabas, Columbia University, New York, USA

Young investigator award

Masterclass "Plaque instability" colloquium, Royal Netherlands

Academy of Arts and Sciences (KNAW)

Merit award for young investigators

American Heart Association (AHA) council on ATVB

PhD student travel grant (6 weeks)

NWO

Dr. R. Virmani, CVPath, Gaithersburg, USA

PhD student conference travel grant

Foundation Scientific Research Limburg (SWOL)

ATVB 2005, Washington, USA

PhD student travel grant (3 months)

Van Walree Fund, Royal Netherlands Academy of Arts and

Sciences (KNAW)

Dr. JM Gasc and Prof P. Corvol, Collège de France/INSERM U36,

Paris, France

Student travel grant (6 months)

University of Maastricht and the Dutch Cancer Foundation (KWF)

Prof J. Hancock, University of Queensland, Dept. of Pathology,

Brisbane, Australia 
